MAURO DE TOLEDO ANDRAUS

\title{
ANÁLISE DO SISTEMA HIDRÁULICO DE UMA SOPRADORA \\ PARA REDUÇÃO DO TEMPO DE POSICIONAMENTO
}

Dissertação apresentada à Escola

Politécnica da Universidade de São

Paulo para a obtenção do título de

Mestre em Engenharia.

SÃO PAULO

2007 


\section{ANÁLISE DO SISTEMA HIDRÁULICO DE UMA SOPRADORA PARA REDUÇÃO DO TEMPO DE POSICIONAMENTO}

Dissertação apresentada à Escola Politécnica da Universidade de São Paulo para a obtenção do título de Mestre em Engenharia.

Área de Concentração:

Engenharia Mecatrônica e de Sistemas Mecânicos.

Orientador:

Prof. Dr. Gilberto Francisco Martha de Souza, LD 
A minha esposa Regina e filhos Danilo e Gabriel, pelo apoio e compreensão. 


\section{AGRADECIMENTOS}

A meu orientador Prof. Dr.Gilberto Francisco Martha de Souza por acreditar em meu trabalho, incentivo e consideração durante a elaboração desta dissertação.

Ao amigo Prof. Dr. Rodolfo Molinari por todos os ensinamentos tanto técnicos como pessoais ao longo deste desafio.

Aos amigos da Multipack Plas pela pronta disposição em sempre ajudar além da confiança na realização do projeto da máquina objeto deste estudo.

À Moog do Brasil, na figura do Eng. Marcelo Soares pela ajuda na realização dos ensaios necessários a este trabalho.

Enfim, agradeço a todos que direta ou indiretamente participaram deste trabalho. 


\section{RESUMO}

ANDRAUS, M. T. (2007). Análise do sistema hidráulico de uma sopradora para redução do tempo de posicionamento. São Paulo, 2007. Dissertação (Mestrado) - Escola Politécnica da Universidade de São Paulo.

Para algumas categorias de produtos, insumos como embalagem podem ter um peso significativo na composição do custo do produto final. No caso de vários produtos embalados em frascos plásticos este é um cenário comum que tem como conseqüência uma exigência de aumento de desempenho das máquinas sopradoras que produzem tais frascos. Com o objetivo de cumprir tal exigência, este trabalho realiza uma análise do sistema hidráulico de uma sopradora para redução do tempo de posicionamento nos principais movimentos executados por alguns dispositivos vitais, os quais possuem comandos eletrohidráulicos de controle de posição e velocidade constituídos de válvulas hidráulicas de controle de vazão, válvulas direcionais proporcionais e atuadores lineares. A forma desta análise é conduzida inicialmente através da modelagem dos componentes hidráulicos envolvidos nos movimentos destes dispositivos e, posteriormente, de um ensaio através do registro das grandezas físicas de interesse como pressões e velocidades de posicionamento utilizando como bancada de testes uma sopradora existente. $\mathrm{O}$ desempenho atual do equipamento em questão, registrado através do ensaio, pode ser então comparado com os resultados obtidos na modelagem para uma análise final com o objetivo de tornar a sopradora mais rápida e produtiva além de validar o modelo estabelecido para a realização de projetos futuros.

Palavras Chave: sistemas hidráulicos, válvulas hidráulicas. 


\begin{abstract}
ANDRAUS, M. T. (2007). Analysis of blow mold machine hydraulic system to reduce positioning time.. São Paulo, 2007. Dissertação (Mestrado) - Escola Politécnica da Universidade de São Paulo, USP.

Many times, for some products classes, inputs as packaging may have an expressive weight in the final product cost structure. In the case of products packaged into plastic containers, this is an usual scenario that has as result, the increase of performance requirements of the blow mold machines that produce such containers. A point to be studied in the blow mold machines to fulfill such requirement is an analysis of its hydraulic system in a way to reduce the positioning time in the most significant movements performed by its main devices. Such devices have electro-hydraulic position and speed controls composed by flow control and proportional valves and linear actuators. So, it is presented in this work the description of blow mold machine, modeling of hydraulic components involved with the main equipment's movements and an experience to record physical values as pressures and positioning speeds using an existent blow mold machine as testing bench. The tested registers can be confronted against the results obtained in the modeling analysis as a target to make the blow mold machine more productive besides of validate the model to the future projects.
\end{abstract}

Key words: hydraulic systems, hydraulic valves. 


\section{SUMÁRIO}

CAPÍTULO 1 - INTRODUÇÃO...........................................................................................1

CAPÍTULO 2 - TÉCNICAS DE CONTROLE DE MOVIMENTO .................................4

CAPÍTULO 3 - CARACTERIZAÇÃO DA MÁQUINA DE SOPRO ................................26

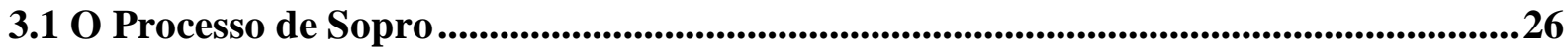

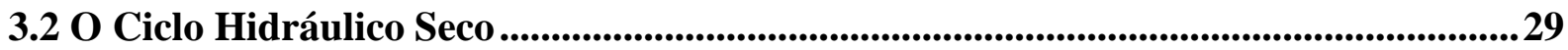

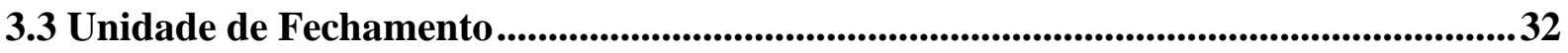

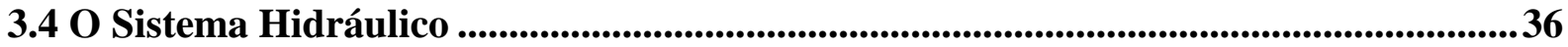

3.4.1 Comando Hidráulico do Movimento de Transporte..................................................36

3.4.2 Comando Hidráulico do Movimento de Abertura e Fechamento do Molde .................38

CAPÍTULO 4 - MODELAGEM DOS COMPONENTES HIDRÁULICOS ...................... 40

4.1 Movimento de Transporte ..............................................................................................40

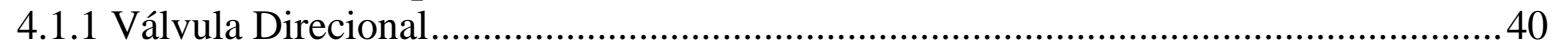

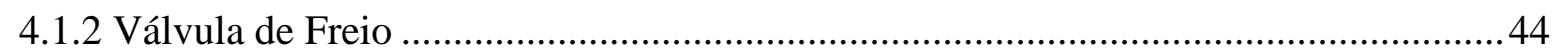

4.2 Movimento de Abertura/Fechamento do Molde.....................................................................68

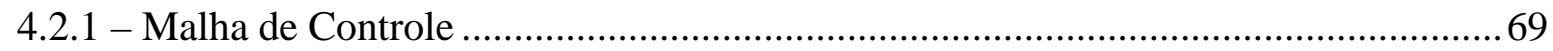

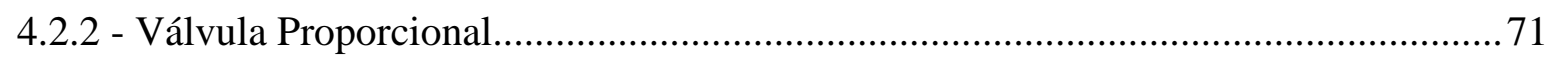

4.2.3 - Dinâmica do Movimento de Abertura/Fechamento do Molde.................................85

CAPÍTULO 5 - METODOLOGIA DE ENSAIO...............................................................94

5.1 - Configuração de Instrumentação ....................................................................................94

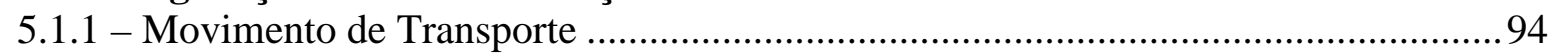

5.1.2 - Movimento de Abertura/Fechamento do Molde ................................................. 95

5.2 - Descrição da Instrumentação Utilizada.............................................................96

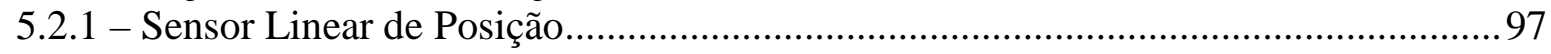

5.2.2 - Sensor de Pressão ....................................................................................... 99

5.2 .3 - Equipamento de Aquisição de Dados .............................................................. 100

5.3 - Metodologia de Obtenção e Utilização dos Dados ...................................................101

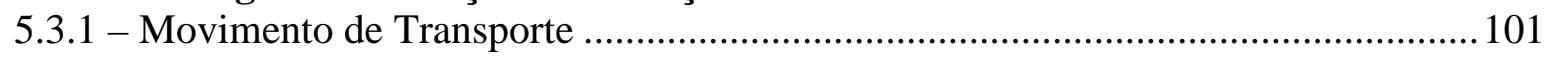

5.3.2 - Movimento de Abertura e Fechamento do Molde .................................................... 103 
6.1- Movimento de Transporte do Carro.........................................................................105

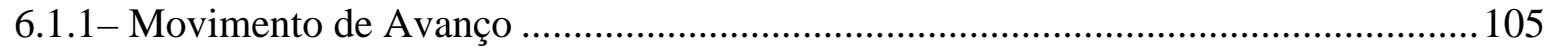

6.1.2 - Movimento de Recuo (Configuração Inicial)......................................................... 109

6.1.3 - Movimento de Recuo (Pressão de Alimentação = 13 [MPa] ) .................................114

6.1.4 - Movimento de Recuo (Bloco de Passagem Residual e Válvula Pilotada)...............117

6.1.5 - Comparativo dos Movimentos de Recuo......................................................... 120

6.2 - Movimento de Abertura / Fechamento do Molde ..................................................121

6.2.1 - Movimento de Fechamento do Molde.................................................................. 121

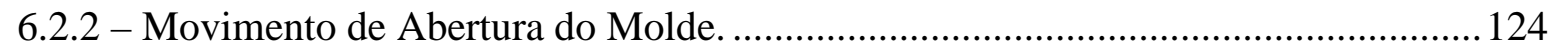

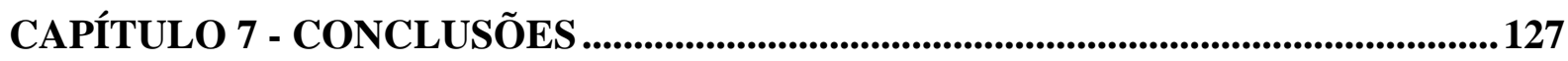

7.1 - Movimento de Transporte ................................................................................................127

7.2 - Movimento de Abertura / Fechamento do Molde ....................................................129

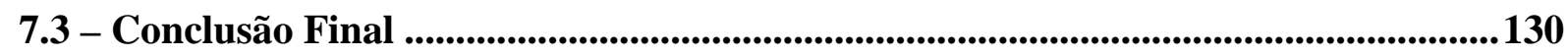

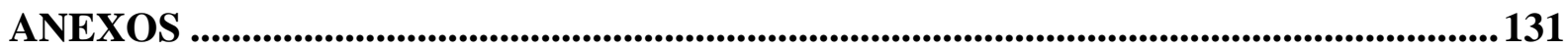

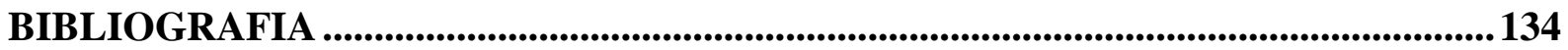




\section{CAPÍTULO 1}

\section{INTRODUÇÃO}

Para vários tipos de produtos, a embalagem é de considerável importância na determinação dos fatores custo e apresentação e, nas últimas décadas especificamente, no caso de produtos líquidos, a utilização de frascos plásticos vem sendo uma das alternativas mais utilizadas pois atende satisfatoriamente as condições de conservação do produto, dentro de um custo adequado e com a vantagem de poder assumir as mais diversas formas contribuindo para uma apresentação diferenciada.

Muitos métodos foram criados para a fabricação de frascos a partir de termoplásticos, contudo, o método mais comum de todos é baseado na extrusão de um tubo de polímero fundido posteriormente soprado com ar comprimido internamente a um molde. A máquina que desenvolve este processo é conhecida como sopradora e, devido à exigência de cada vez maior capacidade de produção, aplicam-se moldes com várias cavidades que têm como conseqüência a utilização de máquinas de curso longo.

Diante deste cenário são necessárias máquinas mais rápidas e assim, sistemas eletrohidráulicos tornaram-se uma boa alternativa devido a algumas características preponderantes como a possibilidade de posicionar grandes massas com boa velocidade sem a necessidade de grandes atuadores, respostas rápidas, simplicidade na transmissão e processamento de sinais.

O objetivo principal deste trabalho é a análise do sistema hidráulico de uma sopradora existente para a redução dos tempos de posicionamento. 
Com este intuito o presente trabalho está dividido em cinco capítulos que estão sumarizados da seguinte forma:

Este primeiro capítulo apresenta a introdução do trabalho.

No segundo capítulo é feita uma revisão da literatura existente, abrangendo técnicas de controle de movimento em equipamentos como termo de comparação com o sistema analisado neste trabalho.

No terceiro capítulo é caracterizada uma sopradora por extrusão para a fabricação de peças ocas em resinas plásticas com ênfase para o seu sistema hidráulico. São definidos os movimentos hidráulicos de maior relevância quanto ao tempo de posicionamento e como estes influenciam no tempo total de ciclo e produtividade do equipamento.

O quarto capítulo descreve a modelagem dos elementos que compõe os dois principais movimentos de posicionamento de molde da sopradora. São indicadas curvas que estimam a partir deste modelamento o desempenho atual da sopradora no que tange a vazões, coeficientes típicos de análise de desempenho hidráulico e velocidades dos movimentos. Neste capítulo são apresentadas duas possibilidades distintas de comando hidráulico: a primeira análise é realizada sobre um dos movimentos que possui um comando hidromecânico e a segunda um sistema de controle de malha aberta através de um controlador lógico programável, válvula proporcional e um atuador linear.

No quinto capítulo está indicada a metodologia para levantamento de dados. São definidas as grandezas a serem medidas bem como os pontos de aplicação dos transdutores. As características construtivas e de desempenho destes transdutores são descritas assim como os dados do equipamento para aquisição de dados são listados. A partir do registro do desempenho do equipamento ensaiado pode-se então, validar o modelo anteriormente estabelecido. 
O último capítulo aborda as principais conclusões sobre os dados obtidos em comparação aos resultados conseqüentes da modelagem. Algumas propostas para melhoria de desempenho do equipamento são sugeridas para implantação em equipamentos a serem fabricados futuramente. 


\section{CAPÍTULO 2}

\section{TÉCNICAS DE CONTROLE DE MOVIMENTO}

As definições de controle de movimento podem variar muito na industria atual. Dependendo da aplicação, controle de movimento pode significar um simples controle tipo "liga-desliga" ou uma seqüência de eventos para controlar a velocidade de um motor, mover objetos de um ponto para outro ou controlar precisamente a velocidade, aceleração e posição de um sistema ao longo de um movimento. A técnica de controle de movimento mais adequada e os componentes empregados para implementa-la depende de uma análise específica de cada aplicação. Inicialmente serão descritas as diversas possibilidades de acionamentos e atuadores utilizados e em seguida serão relacionadas as técnicas e tendências de controle de movimento.

Nas máquinas desenvolvidas no início da era da automação, o controle de posição e velocidade foi realizado através de soluções que contemplavam o uso de componentes mecânicos tais como engrenagens, polias, embreagens e cames. Alguns exemplos deste tipo de solução puderam ser vistos em máquinas têxteis e nos primeiros tornos mecânicos. As indústrias automobilística e de máquinas ferramentas, entre outras, enxergaram as técnicas de controle de movimento como um meio de realizar formas diversas relacionadas à operações complexas. Sendo capaz de movimentar materiais e realizar processos de modo repetitivo, valor e produtividade foram agregados nas diversas operações. Porém, soluções como estas funcionam bem em dispositivos que realizam operações dedicadas necessitando 
um grande esforço para modificar estes dispositivos para trabalharem com diferentes produtos e processos.

Com o surgimento da tecnologia da computação e de microprocessadores, outras opções tornaram-se possíveis. Em sistemas baseados em controle eletrônico, pode-se selecionar um grupo de diferentes parâmetros para uma aplicação meramente carregando um novo software no sistema. Por exemplo, para alterar um perfil de velocidade para uma operação, um sistema mecânico necessita trocar uma engrenagem ou um came enquanto que, para um sistema com controle de movimento programável, esta alteração é realizada simplesmente selecionando um novo perfil de velocidade a partir da memória do sistema.

Nos equipamentos atuais, o controle de movimento é realizado por um controlador programável constituído de hardware e software em conjunto com atuadores e dispositivos de realimentação de sinal. Assim, o sistema é composto dos seguintes elementos básicos: controlador, amplificador, atuador e dispositivo de realimentação. O diagrama de blocos simplificado da figura 2.1 ilustra este tipo de sistema.

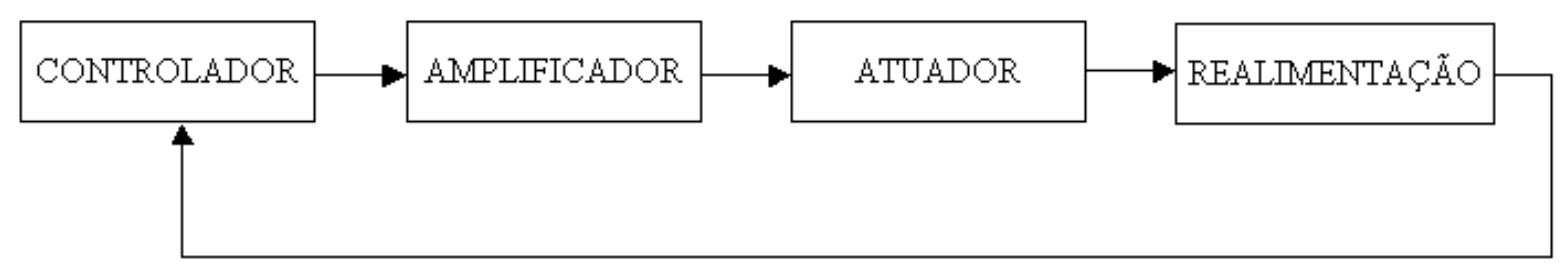

Figura 2.1 - Malha simplificada de controle de movimento (1).

A figura 2.2 fornece uma visão geral dos sistemas típicos de controle de movimento programável. Muitas vezes, o controlador é muito especializado e projetado para realizar tarefas em aplicações específicas. Exemplos deste tipo de controladores incluem Comando Numérico Computadorizado (CNC), robôs industriais, linhas de transferência, máquinas para plástico (sopradoras e injetoras) e máquinas de corte a plasma ou laser, entre outras. 

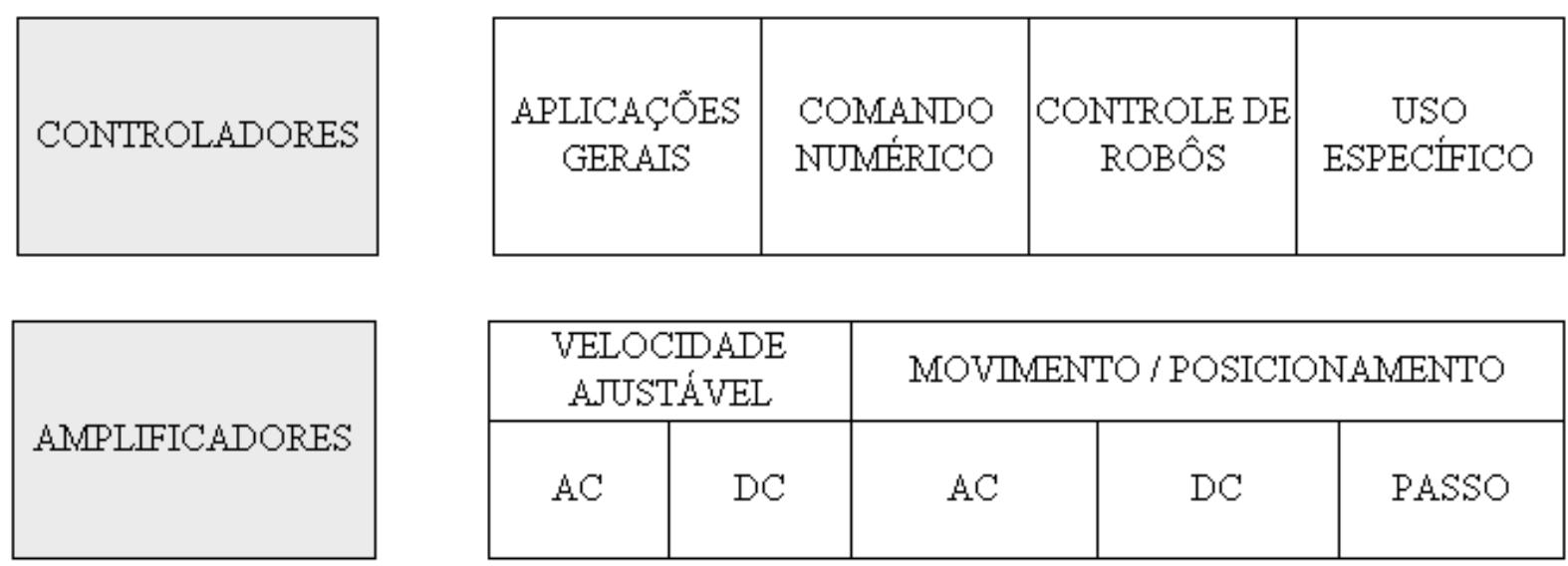

\begin{tabular}{|c|c|c|c|c|}
\hline \multicolumn{2}{|c|}{$\begin{array}{c}\text { VELOCDADE } \\
\text { AJUSTAVEL }\end{array}$} & \multicolumn{3}{|c|}{ MOVTMENTO/POSICIONAMENTO } \\
\hline AC & DC & AC & DC & PASSO \\
\hline
\end{tabular}
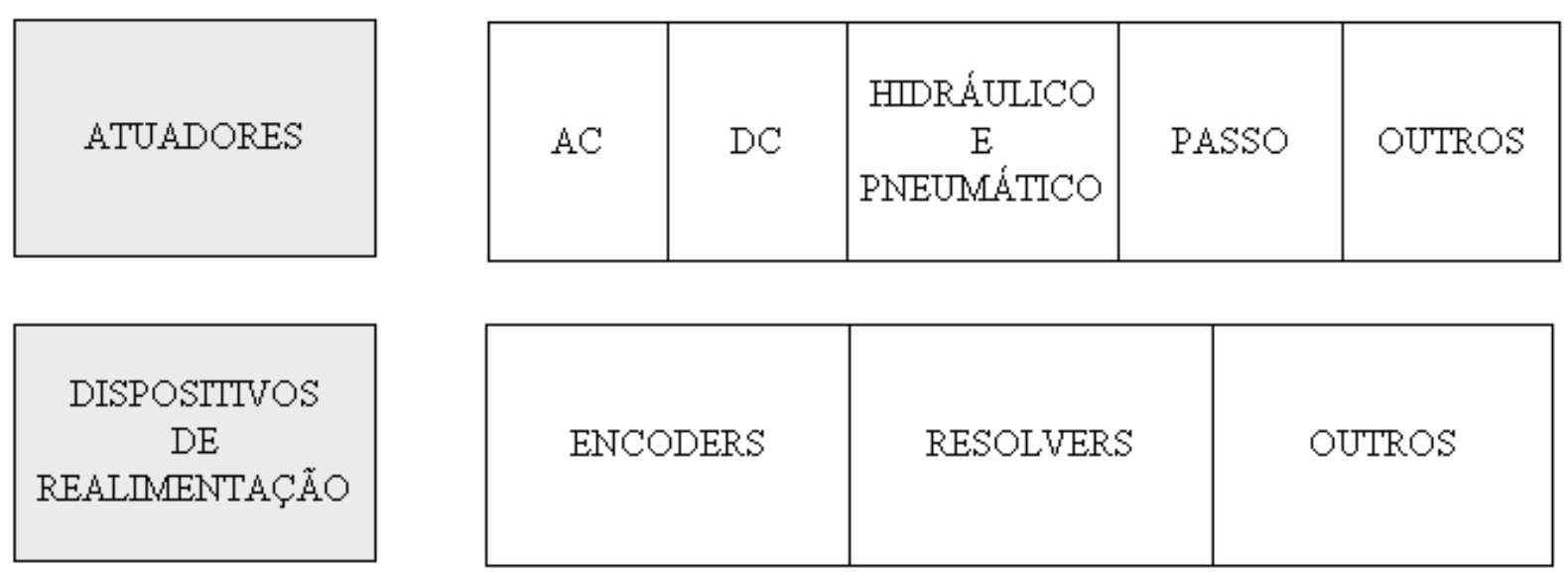

Figura 2.2 - Sistemas típicos de controle de movimento programável. (1)

Para aplicações onde se deseja controlar a velocidade de um movimento de rotação, é comum a utilização de motores de indução trifásicos acionados por inversores de freqüência. Neste caso, a velocidade de rotação varia diretamente com a frequiência de alimentação. Este tipo de acionamento é muito comum em equipamentos como pontes rolantes, extrusoras de plástico e bombas. Devido à resposta lenta causada pelas características de indutância no circuito do rotor, este tipo de motor não era muito usado em servo sistemas, porém devido ao desenvolvimento da tecnologia de controle vetorial, melhorias de desempenho foram realizadas e atualmente aplicações como acionamento de eixo árvore de máquinas 
ferramentas são comuns. São disponíveis no mercado inversores para acionarem motores numa gama ampla de potências que vai de 0,25 a 1500 CV (2).

Muitos sistemas de posicionamento utilizam um motor de passo. Motores de passo trabalham a partir de sinais que são pulsos. $O$ eixo do motor de passo gira de um determinado ângulo em resposta a cada pulso de entrada. Isto permite que ele gire em incrementos fixos, repetidos, diferentes de motores convencionais. Este tipo de motor é útil porque pode movimentar objetos a uma determinada distância simplesmente girando a partir de um número pré-ajustado de pulsos, ou seja, conforme indicado na figura 2.3 , este sistema opera em regime de controle de malha aberta. Assim, para obter um movimento a uma dada distância, o controlador envia um número exato de pulsos ao motor. A velocidade do motor é controlada variando a taxa de envio de pulsos pelo controlador. Sistemas de movimentação de peças leves em geral, tais como utilizado em máquinas de embalagem (rotuladeiras) e mesas de coordenadas são dois exemplos de aplicação deste tipo de acionamento. Porém, motores de passo são limitados quanto ao torque e são disponíveis normalmente em níveis de potência de até $3 \mathrm{CV}(3)$.

\section{Controlador Acionamento Motor}

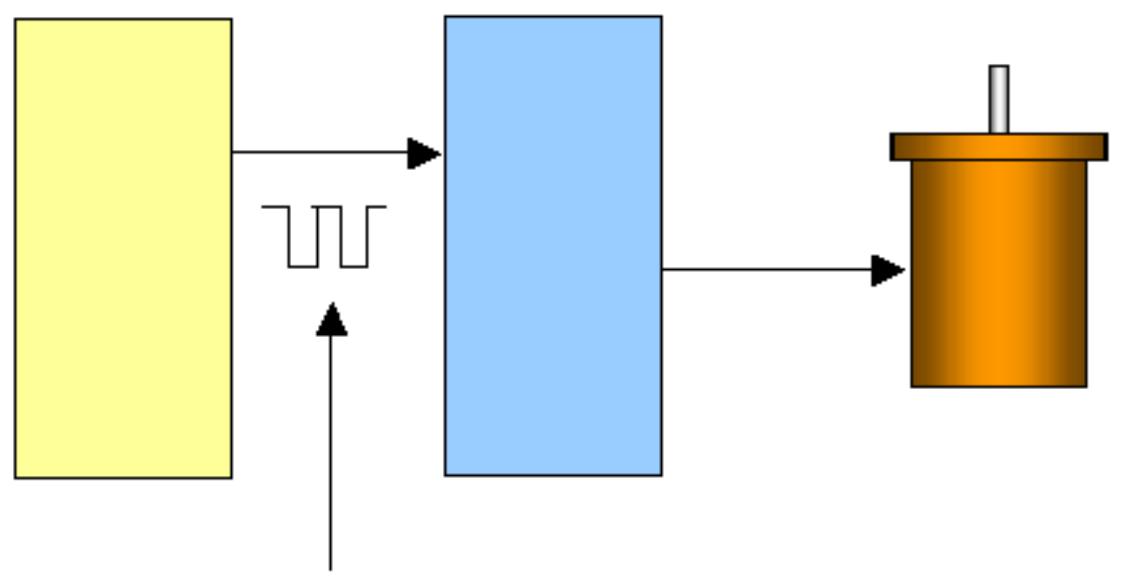

\section{Pulsos de Comando}

Figura 2.3 - Malha aberta de controle de um motor de passo. (4) 
Para aplicações com maior necessidade de torque onde são exigidos, entre outros, dinâmica, controle de rotação, torque constante e precisão de posicionamento, a utilização de servomotores é recomendada. Um servomotor é basicamente constituído de um estator dotado de uma bobinagem especial para proporcionar alta dinâmica, um rotor composto de imãs permanentes e um gerador de sinais instalado para fornecer sinais de velocidade e posição.

Inicialmente, servomotores de corrente contínua foram utilizados em larga escala porém, a partir do momento que os transistores foram capazes de controlar grandes correntes e comuta-las com alta frequiência, os servomotores de corrente alternada passaram a ser utilizados na maioria das aplicações. Os servomotores de corrente contínua tinham como inconveniente o alto nível de manutenção devido ás escovas de comutação entre estator e rotor. Porém, com o desenvolvimento de servomotores de corrente contínua sem escovas, este tipo de acionamento voltou a ser utilizado em muitas aplicações.

Num motor com escovas, o torque é facilmente controlado por ser proporcional à corrente contínua entre os dois terminais do motor, independente da rotação. Como os motores sem escova não comutam por si próprios, o torque gerado é mais difícil de ser controlado. Este tipo de motor possui três enrolamentos defasados mecanicamente de $120^{\circ}$ sendo a corrente aplicada em cada enrolamento controlada de forma independente como função da posição do rotor, de modo que a interação dos campos magnéticos dos enrolamentos e do imã do rotor gerem torque útil. A figura 2.4 mostra de um modo simplificado o controle por malha fechada de um servomotor. Para os servomotores sem escova o controle de torque pode ser realizado por um sinal trapezoidal, senoidal ou ainda diretamente pelo campo orientado gerado no estator (5). 


\section{Controlador Acionamento Motor}

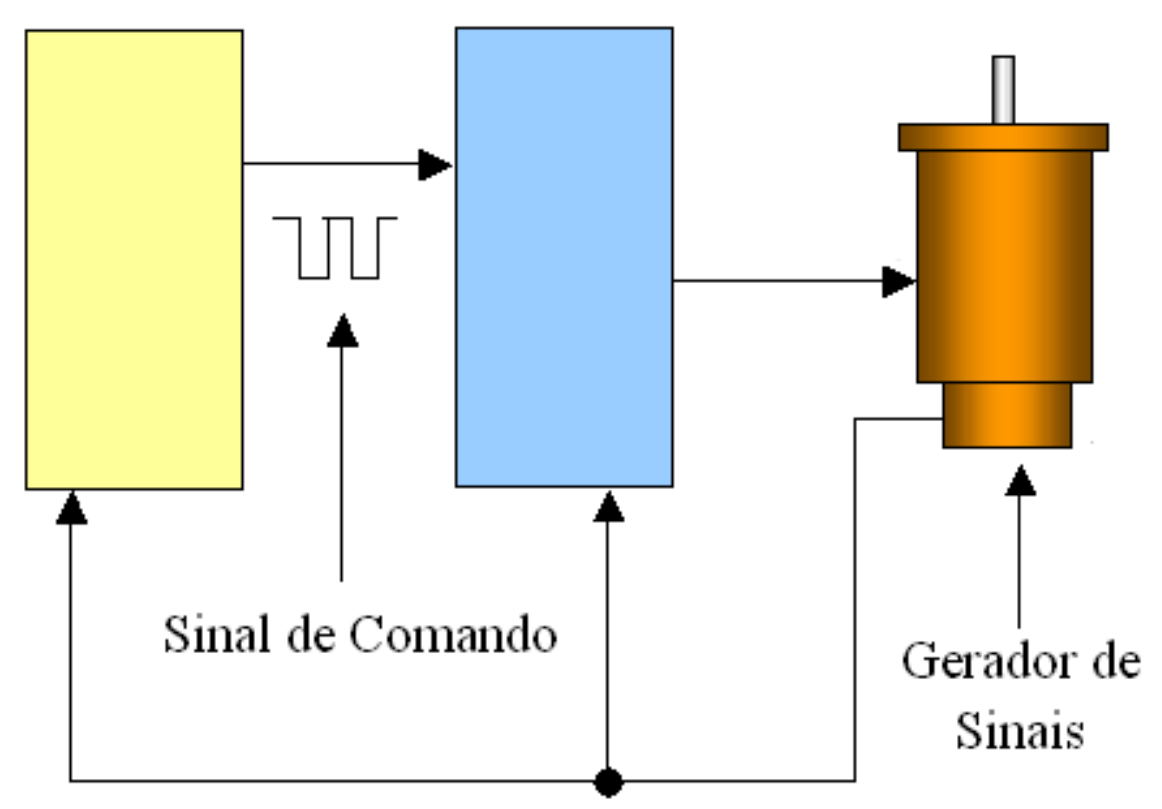

Figura 2.4 - Malha fechada de controle de um servomotor. (4)

Para aplicações onde se deseja transformar o movimento rotativo do servomotor em movimento linear para posicionamento, normalmente são utilizados componentes mecânicos de alta precisão tais como fusos e guias de esfera recirculantes. Em alguns casos, para adequar o torque e rotação do motor à aplicação, é também necessária a utilização de redutores planetários. Estes componentes mecânicos são caracterizados pela isenção de folga, o que permite trabalhar sem gerar instabilidade na malha de controle de posição. $\mathrm{Na}$ figura 2.5 está indicado um acionamento típico para posicionamento linear utilizando os componentes acima descritos. Este tipo de acionamento é comumente aplicado em máquinas operatrizes $\mathrm{CNC}$ tais como tornos, fresadoras e centros de usinagem.

Apesar de não ser uma idéia nova, a aplicação de motores lineares foi introduzida de uma forma mais efetiva em alguns setores da indústria na última década (6). Cada vez mais para algumas aplicações são exigidos posicionamentos com alta velocidade e precisão. A evolução dos sistemas de guias e encoders lineares com possibilidade de trabalhar com 
velocidades em torno de $5 \mathrm{~m} / \mathrm{s}$ também abriu caminho para aplicações deste tipo de componente.

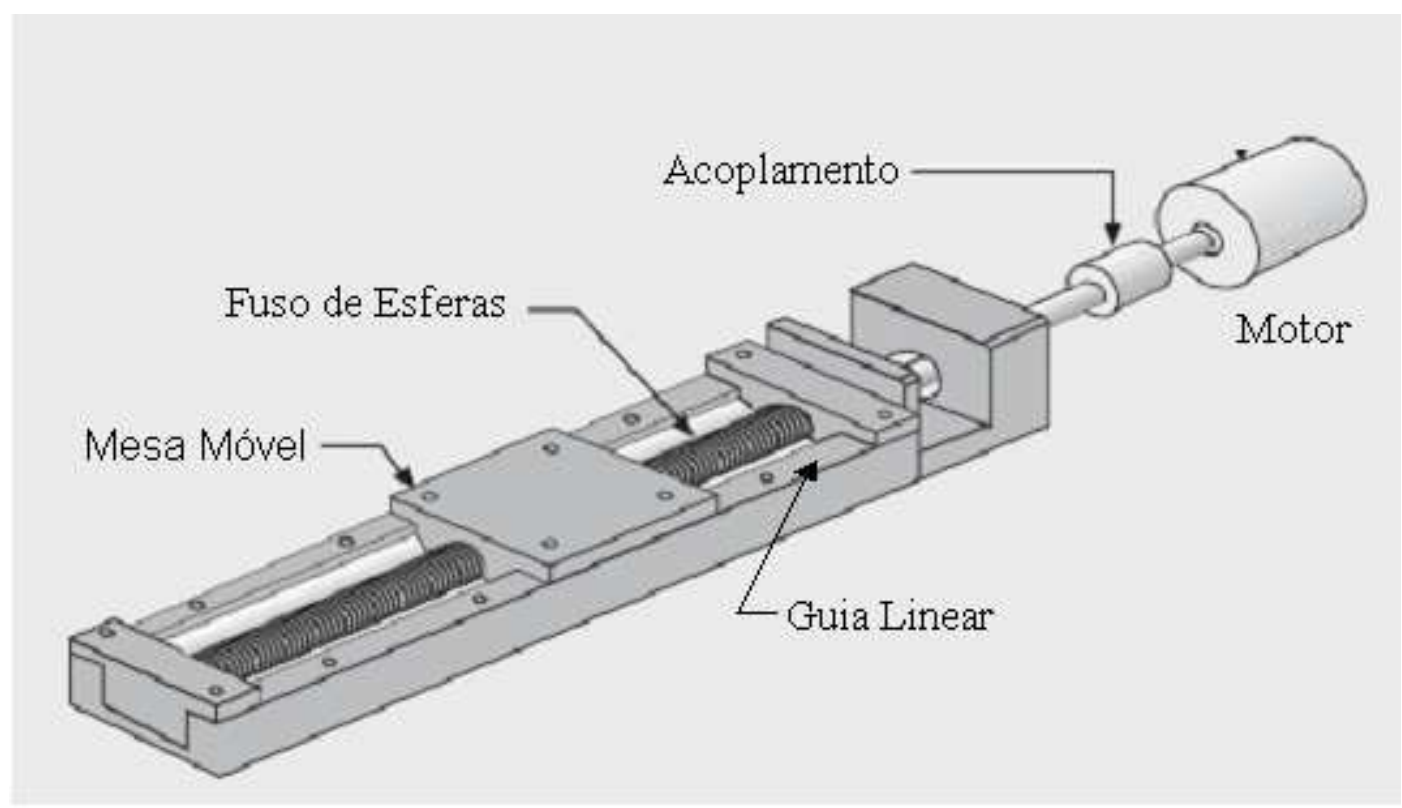

Figura 2.5 - Sistema de posicionamento linear acionado por servomotor. (7)

O conceito destes tipos de motores é similar ao dos motores rotativos adaptado ao movimento linear onde um elemento de força normalmente faz o papel do estator e um sistema de guias é a parte móvel equivalente ao rotor. Motores onde estes dois tipos de componentes exercem funções inversas também são encontrados. A carga a ser movimentada é montada diretamente no motor eliminando assim qualquer tipo de transmissão intermediária. São encontrados mais usualmente motores lineares de passo, motores de corrente contínua com escovas e sem escovas de comutação.

Motores lineares de passo possuem tanto enrolamentos como imãs permanentes no elemento de força. Este elemento movimenta-se ao longo de guias com uma estrutura em forma de dentes. Apesar de necessitar um sistema de controle simples em malha aberta, este tipo de motor possui limitações em termos de força e velocidade. 
O motor linear com escovas possui as bobinas na guia linear e os imãs permanentes estão no elemento de força. A comutação é realizada por uma barra ao longo do curso sempre em contato com as escovas que estão no elemento de força. Este é um sistema mais caro e que tem limitações de velocidade devido ao contato entre as escovas e a barra.

Com a tecnologia de servomotores lineares sem escovas e a eletrônica desenvolvida para aciona-los, algumas limitações de velocidade e força existente nos conceitos anteriores foram eliminadas. O elemento de força neste caso é formado por um conjunto de bobinas enquanto o estator é uma guia formada por imãs permanentes. A comutação é realizada eletronicamente onde sensores utilizando o princípio de efeito Hall localizados no elemento de força são ativados pelos imãs da guia. $\mathrm{O}$ amplificador traduz estes sinais em correntes com fases apropriadas. Comutação senoidal é realizada utilizando o sinal do encoder linear que realimenta o controlador. Na figura 2.6 é mostrado um desenho esquemático de um motor linear sem escovas com núcleo de aço.

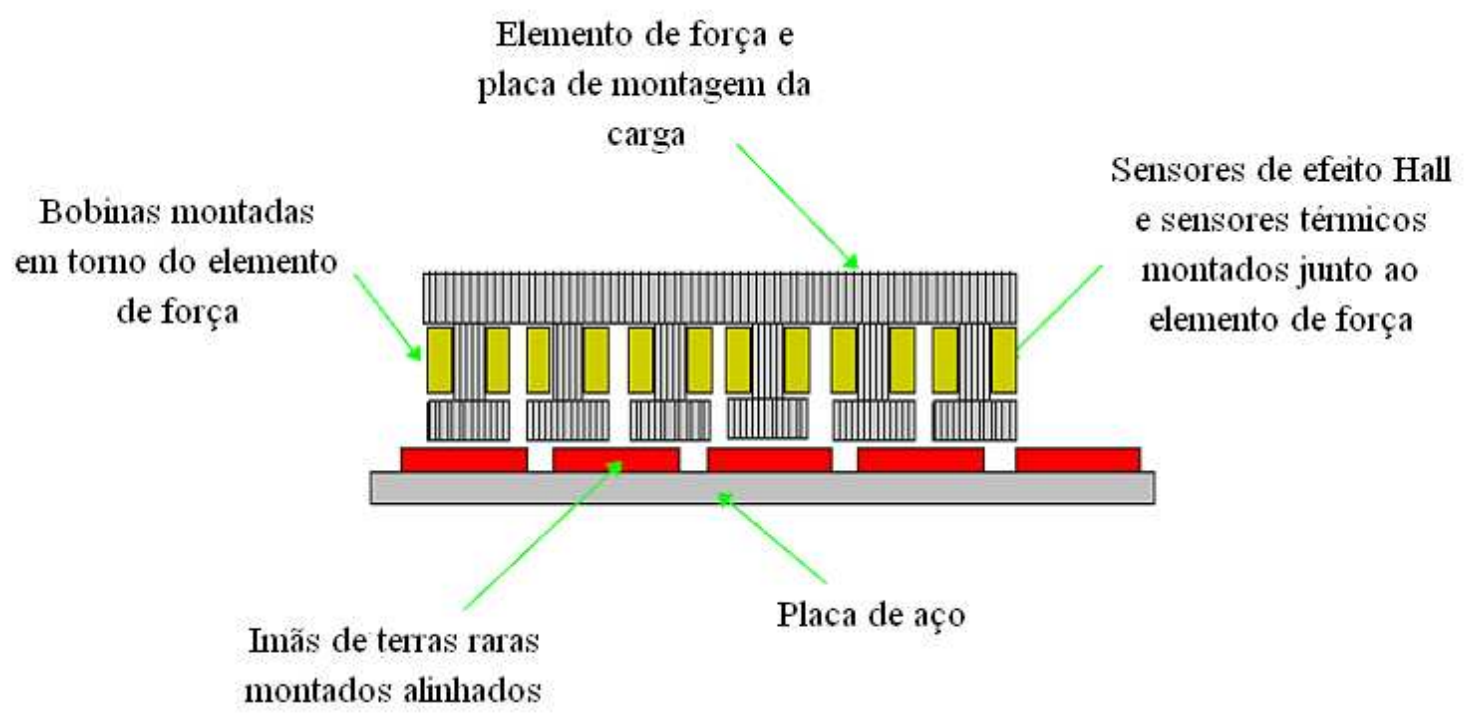

Figura 2.6 - Motor linear sem escovas com núcleo de aço.(6) 
A tabela 2.1 estabelece uma breve comparação entre os sistemas de posicionamento com servomotor e fuso (figura 2.5) e servomotor linear (figura 2.6) segundo componentes comercialmente disponíveis.

Tabela 2.1 - Característica de acionamento de servomotores rotativos e lineares. (7)

\begin{tabular}{|l|c|c|}
\hline & Servomotor + Fuso & Motor Linear \\
\hline Velocidade Máxima & $30(\mathrm{~m} / \mathrm{min})$ & $150(\mathrm{~m} / \mathrm{min})$ \\
\hline Resolução & microns & sub microns \\
\hline Aceleração & $2 \mathrm{~g}$ & $10 \mathrm{~g}$ \\
\hline Força Máxima & $100000(\mathrm{~N})$ & $21000(\mathrm{~N})$ \\
\hline
\end{tabular}

Para determinadas aplicações onde a precisão de posicionamento é fator determinante e esta precisão deve ser nano métrica, a utilização de motores piezoelétricos passa a ser viável. Alguns equipamentos nos setores de fabricação de semicondutores, metrologia, sistemas a laser e microscopia utilizam essa tecnologia. O princípio de funcionamento deste tipo de motores parte da utilização de material cerâmico piezoelétrico polarizado com campos elétricos na ordem de $2500(\mathrm{~V} / \mathrm{mm})$. Uma vez polarizado este tipo de material passa a apresentar uma propriedade bastante útil: quando submetido a uma tensão de 200 (V), por exemplo, um cristal com constante de deslocamento $d=500 \times 10^{-12}(\mathrm{~m} / \mathrm{V})$ apresenta um aumento de 0,1 mícron na sua espessura. Montando este cristal conforme arranjo indicado na figura 2.7, um movimento contínuo pode ser realizado ao alimenta-lo com uma tensão elétrica senoidal. Quando o sinal da tensão é positivo a espessura do cristal aumenta e a placa móvel é deslocada de um passo devido à força de atrito desta com o cabeçote do motor. Ao inverter o sinal da tensão, a espessura do cristal diminui fazendo com que ele retorne ao seu tamanho original sem deslocar a placa móvel. Se este processo é repetido com uma 
freqüência de $130.000(\mathrm{~Hz})$, conforme a freqüência da tensão de alimentação, uma velocidade de $13(\mathrm{~mm} / \mathrm{s})$ é atingida.

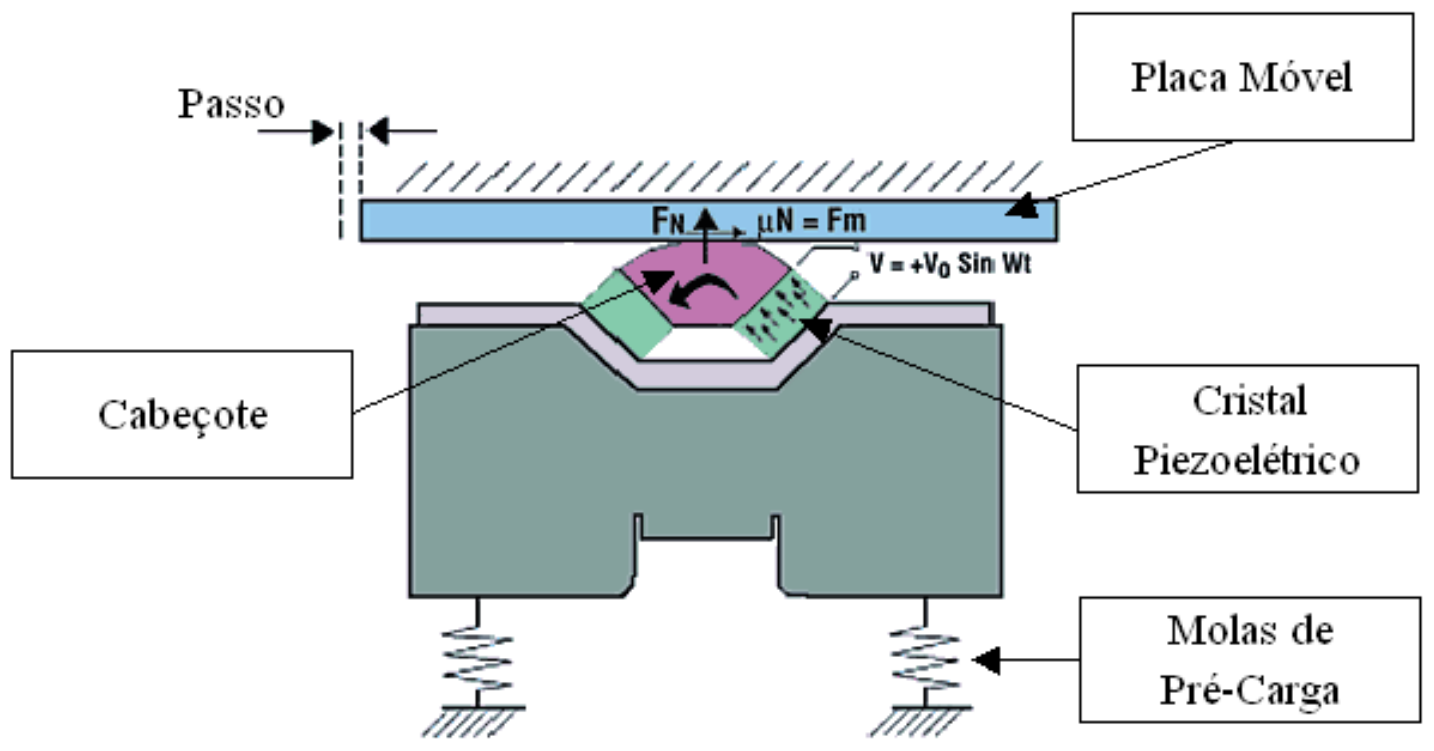

Figura 2.7 - Esquema construtivo de um motor piezoelétrico. (8)

Os motores piezoelétricos são encontrados comercialmente com as seguintes características (9):

- Curso Máximo: $400(\mathrm{~mm})$

- Força Máxima: $70(\mathrm{~N})$

- Resolução: entre $5(\mathrm{~nm})$ e $5(\mu \mathrm{m})$

- Velocidade Máxima: $250(\mathrm{~mm} / \mathrm{s})$

Apesar das possibilidades de acionamentos com motores elétricos descritos anteriormente, a utilização de atuadores hidráulicos torna-se inevitável em certos cenários devido ao uso de componentes confiáveis e de fácil manutenção e, principalmente, pela habilidade deste tipo de solução permitir gerar grandes forças por um período prolongado de tempo, inclusive em condições estáticas. Para os motores elétricos, o trabalho em condições 
onde há necessidade do sistema ficar submetido a uma alta carga em condição de baixa velocidade ou estática pode ser um fator limitante do uso deste tipo de componente devido às condições de refrigeração. Mesmo para motores refrigerados à água, o torque eficaz ao longo do ciclo não deve ultrapassar o torque nominal do motor. O torque de sobrecarga para os servomotores pode chegar a três vezes o torque nominal, porém limitado a uma duração de 200 (ms) (10).

A figura 2.8 mostra um sistema de controle de posição e velocidade com malha fechada. O sistema é constituído de um tanque a partir do qual o óleo é bombeado para o cilindro. Na linha de pressão, entre a bomba e a válvula, é montado um acumulador. A válvula está montada diretamente no cilindro junto a um bloco distribuidor para evitar atrasos de resposta. Este sistema possui realimentação tanto de posição, através de um transdutor acoplado ao cilindro com monitoramento direto da posição da haste, quanto da pressão diferencial, através de dois transdutores de pressão, montados um em cada pórtico. Os transdutores estão ligados a um controlador que compara os sinais destes com o sinal de comando gerando um erro que, uma vez amplificado, gera um novo sinal para a válvula mantendo assim o movimento da haste do cilindro dentro dos valores programados de velocidade e posição.

As bombas utilizadas para este tipo de sistema podem ser de vazão fixa ou variável. A forma construtiva mais utilizada no caso de vazão fixa inclui bombas de engrenagens, palhetas ou pistões axiais. Para as bombas de vazão variável, a forma construtiva com pistões axiais é a mais utilizada apesar de existirem também com o uso de palhetas. No caso de bombas de pistões axiais com a inclinação do disco ajustável, a vazão é proporcional à rotação de acionamento e ao volume deslocado. Mediante o ajuste da inclinação do disco, é possível uma variação progressiva da vazão. Esta característica construtiva abre a possibilidade de acoplar à bomba, reguladores de pressão e vazão. Estes reguladores que 
utilizam tanto válvulas mecânicas quanto válvulas proporcionais com regulagem eletrônica, garantem que a bomba recalque a quantidade de fluido hidráulico exigido pelos consumidores obtendo assim um menor consumo de energia em relação aos sistemas hidráulicos com bomba de vazão fixa (11).

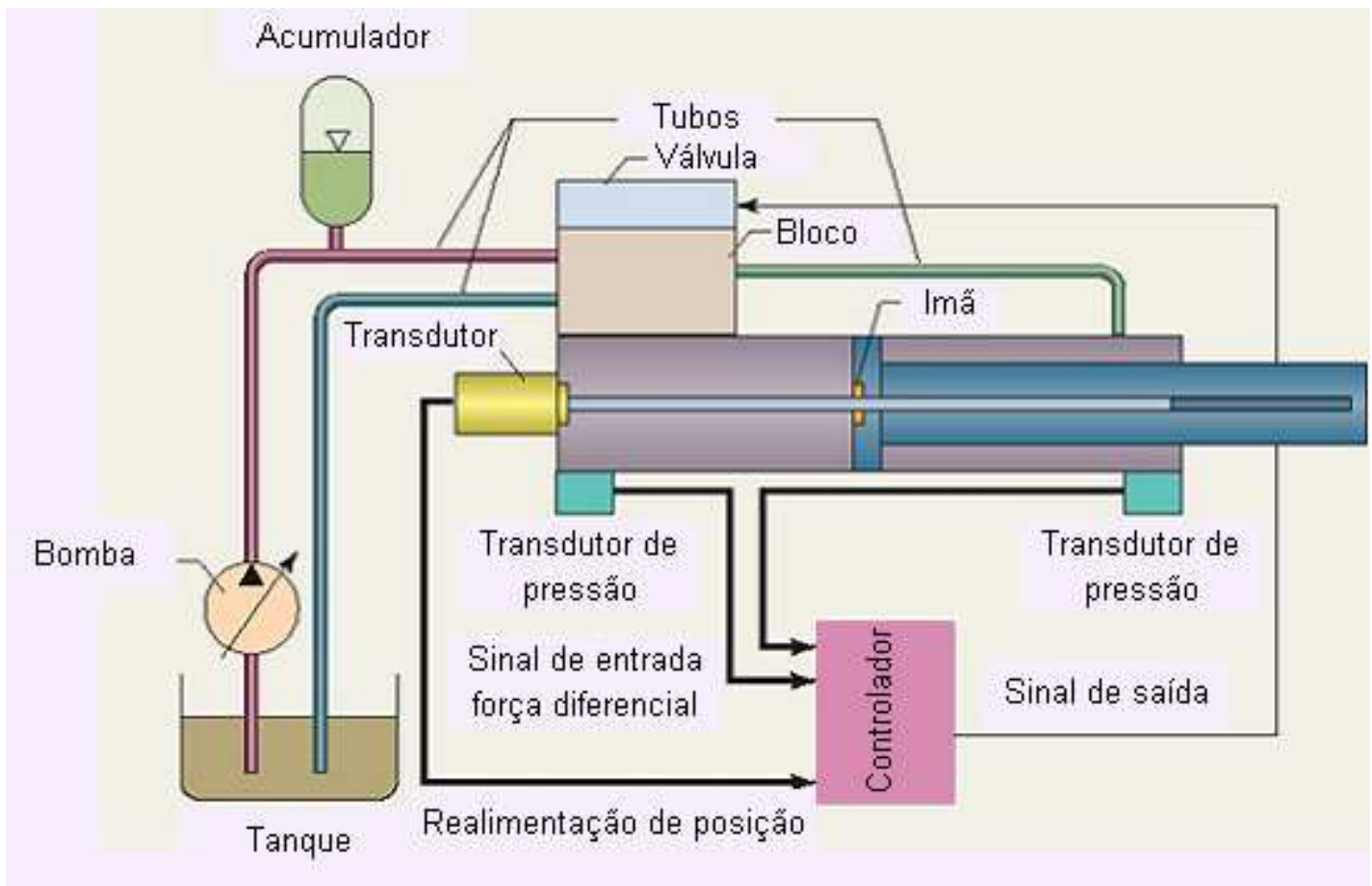

Figura 2.8 - Sistema hidráulico de controle de movimento (12).

O acumulador exerce dupla função num circuito hidráulico: economia de energia e absorção de golpes hidráulicos. Enquanto um acionamento com atuador elétrico deve ser dimensionado para a carga de pico, uma unidade de potência hidráulica num sistema eletrohidráulico pode ser dimensionada para a potência média exigida para todos os atuadores hidráulicos existentes neste sistema (12). Através do acumulador, energia pode ser acumulada quando a potência exigida for menor que a média e devolvida ao sistema nos momentos de pico. Isto resulta na utilização de menores moto-bombas e conseqüente economia de energia. Normalmente os acumuladores utilizados possuem uma bexiga de 
borracha internamente e são carregados com gás nitrogênio. Isto confere uma flexibilidade ao sistema hidráulico e a capacidade de absorver golpes.

As válvulas utilizadas nas aplicações de controle de movimento são normalmente proporcionais ou servoválvulas. Nas válvulas proporcionais um sinal enviado pelo controlador passa por uma cartela amplificadora que por sua vez envia o sinal amplificado para a bobina da válvula proporcional. A cartela amplificadora é necessária porque o sinal de entrada não tem potência suficiente para operar a bobina. A corrente enviada à bobina desenvolve força eletromotriz causando um movimento na armadura do solenóide. A armadura por sua vez exerce força no êmbolo da válvula fazendo com que este se mova proporcionalmente à corrente na bobina. As válvulas proporcionais podem ser de malha aberta ou fechada. Em válvulas de malha aberta não existe realimentação entre o sinal de entrada e a posição real do êmbolo da válvula. No caso de malha fechada, um transdutor de posição registra a posição real do êmbolo e realimenta o a cartela de controle da válvula. Esta cartela pode estar embarcada na válvula ou remota.

Dependendo da vazão necessária à aplicação as válvulas proporcionais podem ser de simples ou duplo estágio. Nas válvulas de simples estágio o solenóide proporcional atua diretamente no êmbolo da válvula. A partir de uma determinada vazão, as forças hidráulicas desenvolvidas no êmbolo são tais que o solenóide passa a não ter capacidade de força para controlar e manter a posição do êmbolo. Neste caso é necessária a utilização de uma outra válvula (primeiro estágio) que atua como piloto da válvula principal (segundo estágio). Os solenóides proporcionais atuam no êmbolo do primeiro estágio que por sua vez pilota hidraulicamente a válvula do segundo estágio. Na figura 2.9 está ilustrada uma válvula proporcional de dois estágios de malha aberta. 


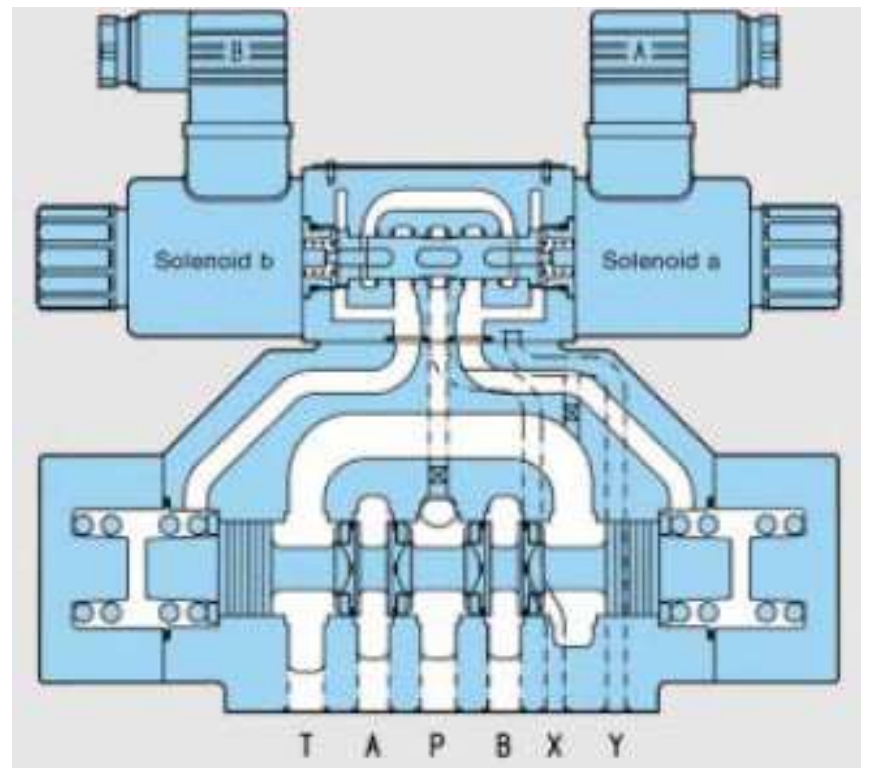

Figura 2.9 - Válvula proporcional de dois estágios com malha aberta (13).

Servoválvulas utilizam um pequeno motor de torque para controlar a pressão de pilotagem que movimenta o êmbolo. A forma construtiva mais comum utiliza um estágio com palheta para pilotagem do êmbolo e realimentação mecânica através de uma haste. A figura 2.10 ilustra o funcionamento deste tipo de válvula. Corrente elétrica na bobina do motor de torque cria forças magnéticas ocasionando uma rotação no conjunto armadura / palheta. A palheta fecha um dos bocais e direciona o fluxo para uma das extremidades do êmbolo que se movimenta e direciona a pressão de alimentação Ps para um dos pórticos de saída da válvula enquanto o outro pórtico é direcionado para a linha de tanque. O êmbolo puxa a haste de realimentação criando um torque restaurador no conjunto armadura / palheta. $\mathrm{O}$ torque restaurador torna-se igual ao torque gerado no motor e o conjunto armadura / palheta retorna à posição central. O êmbolo para na posição onde o torque de realimentação é igual ao torque devido à corrente de entrada. Com pressões constantes, a vazão direcionada para a carga é proporcional à posição do êmbolo. 

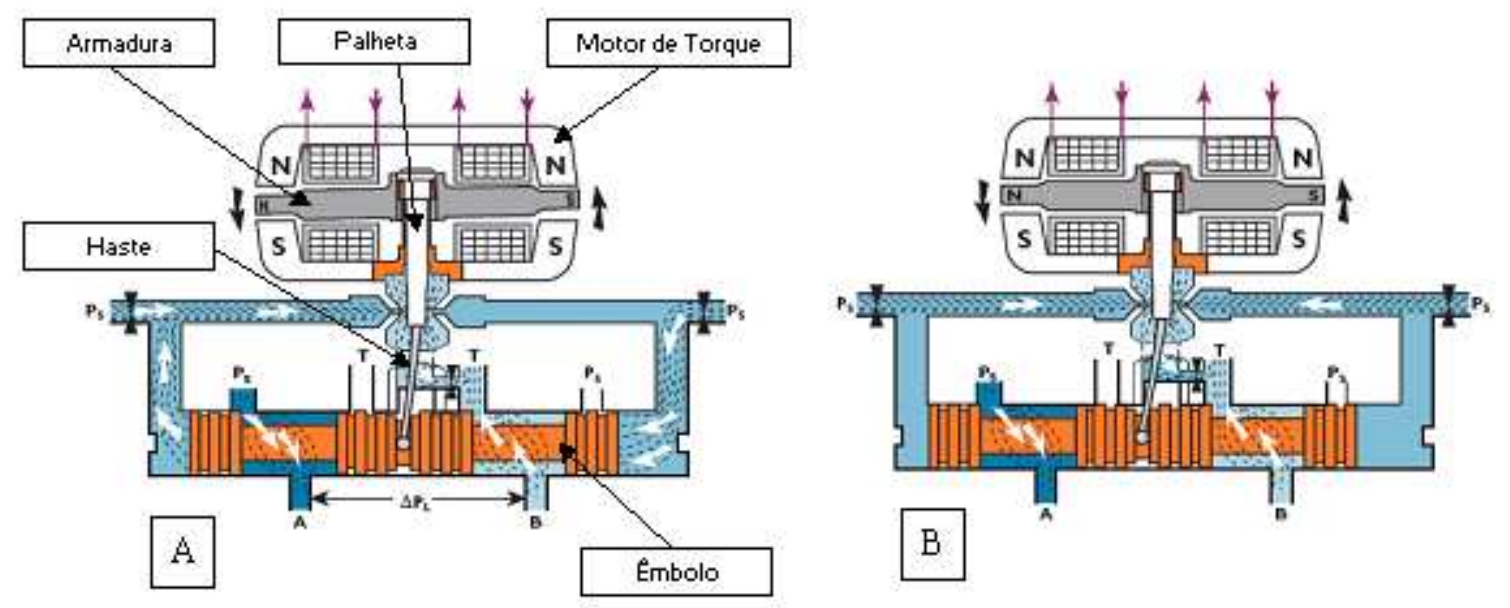

Figura 2.10 - Servoválvula de palheta com realimentação mecânica (14).

Um outro tipo de servoválvula utiliza um jato direcionado para executar a pilotagem do êmbolo conforme mostra a figura 2.11. Uma corrente enviada à bobina do motor de torque desloca o tubo de saída da sua posição neutra direcionando a vazão de pilotagem para uma das extremidades do êmbolo. O êmbolo se movimenta e conecta a linha de pressão (P) com um dos pórticos de saída (A ou B) da válvula e o outro pórtico com a linha de tanque (T). O transdutor de posição mede a posição real do êmbolo e envia este sinal ao controlador que o compara com o sinal de comando. O comando aciona a válvula piloto até que o erro entre o sinal de comando e o sinal do transdutor seja nulo.

As servoválvulas de jato direcionado são menos suscetíveis à contaminação do óleo hidráulico e por isso vem sendo mais utilizadas que as servoválvulas de palheta (14). Em termos de desempenho, as servoválvulas normalmente apresentam uma resposta mais rápida do que as válvulas proporcionais principalmente para capacidades de vazão acima de 150 1/min. Uma válvula proporcional com esta capacidade apresenta um atraso de resposta em torno de 30 ms para uma comutação de abertura do êmbolo de 0 a $100 \%$ do seu curso enquanto uma servoválvula nas mesmas condições tem um atraso de resposta de $10 \mathrm{~ms}$. Quanto à resposta em freqüência, considerando uma defasagem de $90^{\circ}$ em relação a um sinal 
de comando senoidal, a mesma servoválvula apresenta um valor de $60(\mathrm{~Hz})$ enquanto a válvula proporcional tem um valor de 40 (Hz) (15), (16).

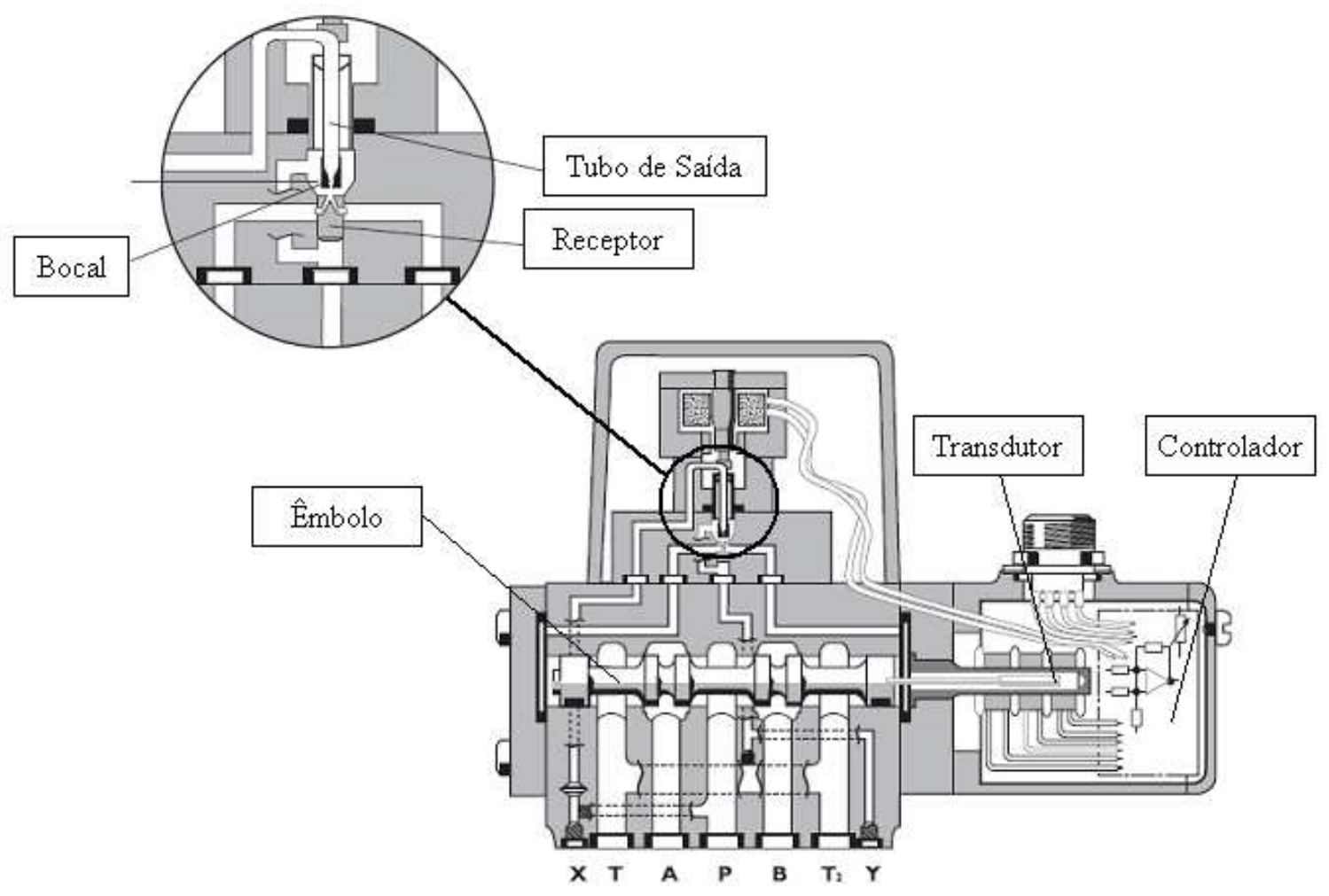

Figura 2.11 - Servoválvula com jato direcionado e realimentação eletrônica (14).

O sistema de controle de movimento hidráulico mostrado na figura 2.8 ainda é o mais utilizado na maioria das aplicações industriais. Para ter uma melhor idéia da aplicabilidade deste tipo de sistema vale ilustrar com o exemplo de uma prensa hidráulica destinada a realizar testes em protótipos de ferramentas de estampagem de grande porte (16). Esta máquina simula durante os testes, o perfil de deslocamento de uma prensa excêntrica mecânica, reproduzindo assim as condições normais de trabalho do ferramental. Vazões na ordem de 34.000 (1/min) são controladas e o ponto crítico de controle está entre $25-50 \%$ do curso da mesa móvel onde a prensa hidráulica deve reproduzir o mesmo movimento desta mesa numa prensa mecânica. A figura 2.12 mostra o resultado obtido. 


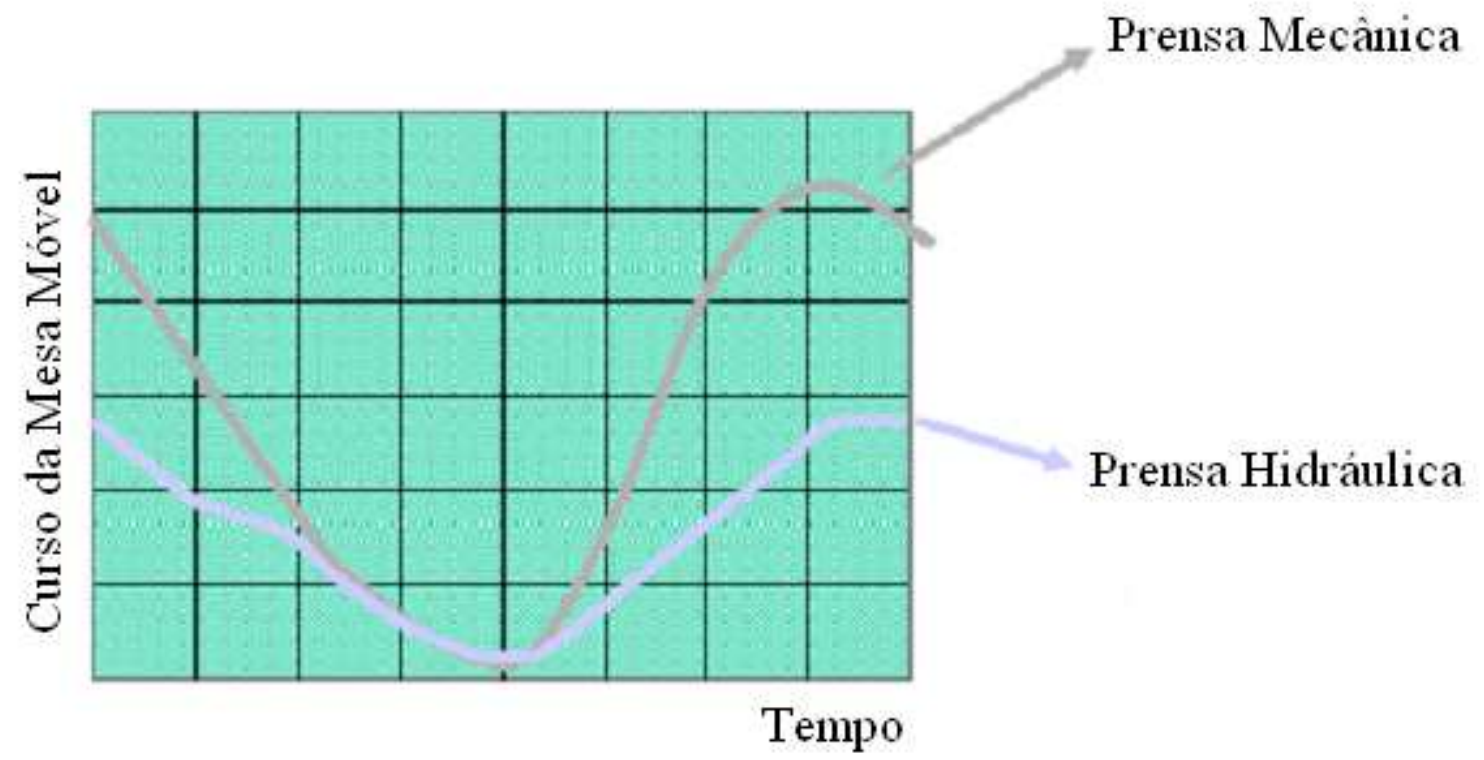

Figura 2.12 - Simulação do ciclo de produção de uma prensa mecânica (16).

Porém, novas tendências têm surgido principalmente com o intuito de obter um menor consumo energético e menor nível de ruído. Muitas inovações são aplicadas em máquinas injetoras de plástico. Numa máquina injetora de acionamento hidráulico, controle de velocidade, pressão e força são utilizados na unidade de fechamento do molde e na unidade de injeção do termoplástico para formação da peça. Estudos e aplicações já existem utilizando bombas de velocidade variável, acionadas por motor de indução trifásico controlado por inversor de freqüência ou mesmo por servomotor. A vazão e a pressão são adequadas à carga através da regulação da velocidade da bomba. Normalmente para esta aplicação são utilizadas bombas de deslocamento fixo. Comparado com um sistema de controle de movimento com válvula, este método elimina as perdas causadas por estrangulamento de um orifício além de possuir maior confiabilidade e ser menos sensível à contaminação de óleo. Por exemplo, na utilização em máquinas injetoras de plástico, o consumo de energia é reduzido cerca de $25 \%$ (17). A figura 2.13 ilustra o esquema de controle deste tipo de solução controlando o movimento de uma massa m através de um 
cilindro diferencial. Este sistema parte do princípio que durante o movimento a vazão assimétrica deve ser compensada automaticamente e que, para economizar energia, a vazão e a pressão devem ser adequadas apenas pela variação de velocidade nas bombas, sem estrangulamento do fluxo. Além disso, a influência de vazamentos e da compressibilidade do óleo deve ser eliminada através de pré-carga em ambos os lados do cilindro.

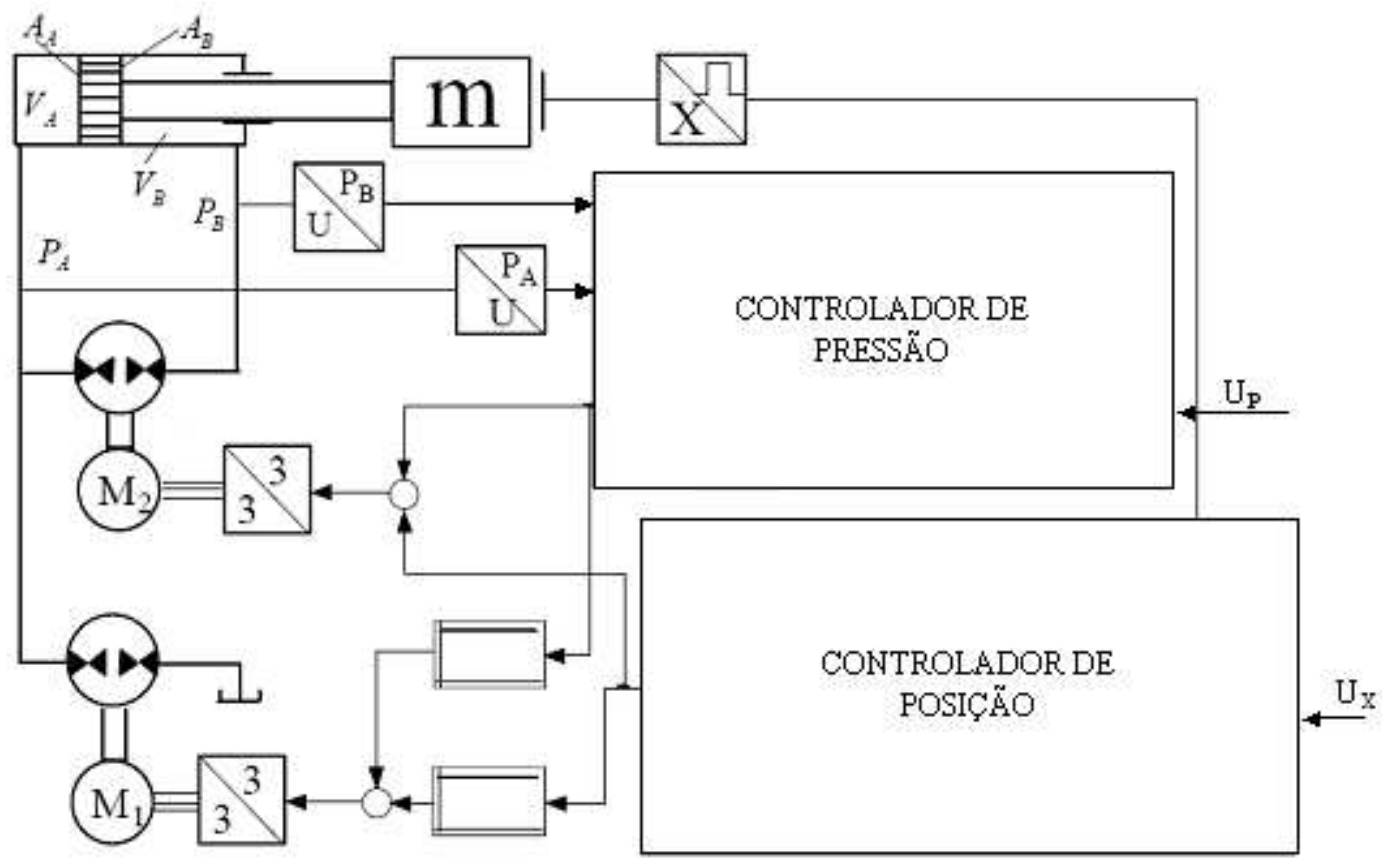

Figura 2.13 - Sistema de controle de movimento com duas bombas (17).

Neste sistema existem duas malhas de controle sendo uma de pressão e a outra de posição. Num sistema de controle utilizando válvula, ambos os lados do cilindro são mantidos pré-carregados e a soma das pressões deve ser constante, ou seja, enquanto a pressão de um lado cresce, a pressão do outro lado decresce na mesma proporção. Essa précarga do cilindro também aumenta a freqüência natural e a rigidez do sistema. No sistema com duas bombas este requisito é cumprido utilizando um controle da soma das pressões 
representado na figura 2.13 pelo bloco de controle de pressão que atua sobre ambas as bombas balanceando as pressões em ambos os lados do cilindro.

O controle de posição trabalha como se existissem dois cilindros: um como sendo um cilindro de haste passante de áreas iguais a $\mathrm{A}_{\mathrm{A}}$ e outro um cilindro de simples ação de área $A_{B}$. As funções da bomba 2 são controlar a velocidade do movimento e a direção do cilindro. Ela faz com que o cilindro tenha sempre a máxima velocidade tanto para avançar como para recuar. A função da bomba 1 é compensar a derivação de vazão causada pelo diferencial de área do cilindro. Quando a haste do cilindro avança, a bomba 1 fornece óleo para a câmara A e, quando a haste recua, ela bombeia óleo da câmara A para tanque.

Uma variação da aplicação acima descrita foi realizada comparando dois sistemas de bombeamento, um com bomba de deslocamento fixo com velocidade variável através de motor de indução trifásico e inversor de freqüência e outra de velocidade fixa e deslocamento variável com pistões axiais e inclinação do disco ajustável (18). Ambos os sistemas são comparados entre si em termos de capacidade de controle de velocidade e consumo energético e também com um sistema convencional mostrado na figura 2.8. São utilizadas duas malhas de controle distintas: malha de controle de velocidade e malha de controle de pressão diferencial na carga. O controlador de velocidade é o mesmo para ambos os casos e é baseado em lógica fuzzy. Para controle de pressão diferencial são utilizados dois métodos distintos. O primeiro método é baseado no controle da pressão de carga (load sense control) onde a pressão de alimentação é ajustada de acordo com a pressão de carga de modo a alcançar economia de energia mantendo um valor constante entre a diferença destas duas pressões. O segundo método é baseado na manutenção da pressão de alimentação constante. Nesta aplicação é controlado um cilindro com diâmetro do êmbolo de 100mm, diâmetro da haste de $65 \mathrm{~mm}$ e curso de translação de $500 \mathrm{~mm}$ atuando com velocidade de $50 \mathrm{~mm} / \mathrm{s}$. As bombas são acionadas por um motor trifásico de 4 pólos e potência de $45(\mathrm{~kW})$. É utilizado 
como controlador um computador com processador AMD K6-2 450 CPU 6 x 12 bits D/A, 16 x 12 bits A/D.

Os resultados indicam um controle de velocidade semelhante entre as soluções apresentadas, porém em termos de consumo energético, a solução utilizando bomba axial de pistões com deslocamento variável e controle de pressão de carga utiliza 6,5\% menos potência que a opção com bomba de deslocamento fixo e também controle de pressão de carga. Quando comparado com a solução com bomba de deslocamento fixo e controle com manutenção da pressão de alimentação constante, a necessidade de potência utilizando bomba de deslocamento variável e controle de pressão de carga é 35\% menor. Já o sistema mostrado na figura 2.8 consome cerca de $50 \%$ mais potência do que a solução com bomba de deslocamento variável e controle da pressão de carga.

Devido às não linearidades características de sistemas de controle de movimento hidráulicos, tais como: zonas mortas, condições de fluxo, atrito e histerese, alternativas a controladores PID foram desenvolvidas a partir do final dos anos 90 (19). Sistemas utilizando controle adaptativo são utilizados com o propósito de lidar com situações onde as técnicas de controle convencionais não conseguem resultados satisfatórios. Neste método, técnicas são utilizadas, geralmente utilizando um modelo de referência ou reguladores autoajustáveis, para variar os coeficientes de controle e obter desempenho satisfatório do sistema. A utilização de controle adaptativo de sistemas de movimento eletrohidráulicos utilizando redes neurais vem sendo utilizado em projetos com válvulas proporcionais de grande zona morta acionando cilindros diferenciais sujeitos a variação significativa de carga (20).

Outro método utilizado para aplicações de posicionamento em servo sistemas eletrohidráulicos com variação abrupta de carga trata-se do Controle de Estrutura Variável (VSC) (21). Sistemas de equações linearizadas utilizando realimentação executam o controle de sistemas não lineares, como por exemplo, no caso dos sistemas de controle hidráulico, 
com a desvantagem de que o controle de realimentação é válido somente na vizinhança do ponto de operação no qual o sistema de equações foi linearizado. Ao contrário, VSC trata um sistema linear globalmente através de um controle rápido que força o sistema não linear original comportar-se como um estável sistema linear equivalente.

O interesse por sistemas mais confiáveis e seguros tem crescido devido aos sistemas de controle tornarem-se mais complexos e ocorrerem várias falhas inesperadas de seus componentes. Controle Tolerante à Falha (FTC), conhecido também como controle confiável, leva em consideração como premissa de projeto, falhas inesperadas do sistema. Sistemas FTC podem ser classificados em dois tipos: passivo e ativo. Um sistema ativo reage à falha de componentes reconfigurando as ações de controle. Em contraste, num sistema passivo uma vez que uma falha ocorre, o sistema de controle pode tolera-la mantendo estabilidade e desempenho dentro de padrões aceitáveis. Este método também vem sendo utilizado em controle de sistemas de posicionamento eletrohidráulico (22). Outro exemplo de Controle Tolerante à Falha aplicado a sistemas de posicionamento eletrohidráulico utiliza este método para controlar o movimento de um atuador sujeito a uma falha no sistema de vedação (23).

Todos sistemas apresentados neste capítulo são utilizados de forma bastante ampla na indústria. Apenas a análise individual de cada projeto pode estabelecer qual a técnica mais viável em termos de desempenho e custo. No caso específico da máquina analisada neste trabalho, optou-se pela utilização de um sistema com atuadores hidráulicos. As características de um ciclo realizado por uma sopradora (ver figura 3.3) favorecem a utilização deste tipo de sistema. Primeiramente, todos os movimentos são realizados seqüencialmente e logo depois há a necessidade de um tempo de resfriamento do artigo soprado, tempo este em que os atuadores ficam pressurizados em condição estática mantendo força no fechamento do molde. Esta característica de ciclo indica a utilização de sistemas 
que possam trabalhar acumulando energia para posteriormente utiliza-la nos momentos de pico e também exige que o sistema possa trabalhar mantendo força em condição estática sem problemas de superaquecimento. Estas duas necessidades levam à utilização de um sistema hidráulico além da consideração deste tipo de sistema possuir, para este tipo de aplicação, menor custo em relação às demais opções apresentadas. 


\section{CAPÍTULO 3}

\section{CARACTERIZAÇÃO DA MÁQUINA DE SOPRO}

Este capítulo trata da caracterização do equipamento testado descrevendo os dispositivos que influenciam o desempenho de posicionamento dos dois principais movimentos ao longo de um ciclo típico, a saber: transporte do carro e abertura / fechamento do molde. Para estes dispositivos são abordados os mecanismos em geral e os sistemas eletrohidráulicos.

Para melhor entendimento, antes são descritos o processo de sopro e o respectivo ciclo típico de movimentos seqüenciais para a formação de um frasco plástico.

\subsection{O Processo de Sopro}

O processo de sopro é utilizado na fabricação de peças ocas em resinas plásticas como o polietileno e o polipropileno. Boa parte das aplicações está destinada a produção de embalagens na forma de frascos para vários segmentos da indústria. Existem algumas variações neste processo em função das características da peça a ser soprada (volume, formato, resina), capacidade de produção, tipo de produto a ser envasado entre outras exigências. No caso deste trabalho a análise é realizada sobre uma máquina que utiliza o processo de sopro por extrusão contínua. A figura 3.1 mostra esquematicamente uma máquina de sopro adequada a este processo. 


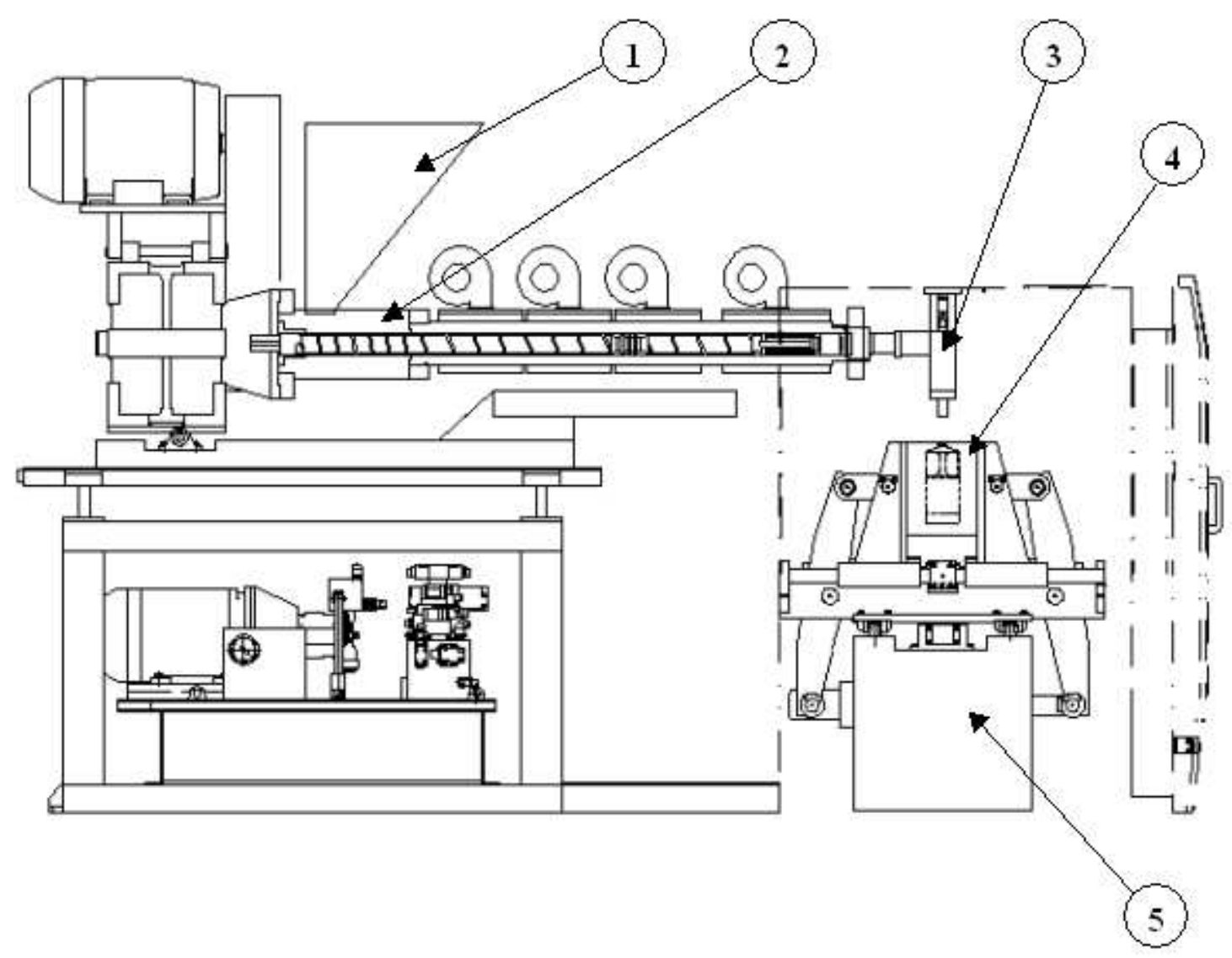

Figura 3.1 - Vista geral da sopradora

O processo inicia com a alimentação de uma extrusora (2), através de um funil (1), de resina granulada. A extrusora tem como função formar uma massa plástica homogênea com temperatura e vazão controlada. Essa massa plástica é transportada num fluxo contínuo até o cabeçote (3) que divide este fluxo numa quantidade de vias compatível com o número de cavidades existentes no molde (4). O cabeçote também tem como função manter vazões iguais em cada via. Este fluxo dividido é desviado no sentido vertical ocasionando a saída contínua de mangueiras plásticas com espessura controlada. O molde é então posicionado sob as mangueiras pelo dispositivo de transporte (5). Assim que as mangueiras atingem o comprimento ideal para a formação do frasco em processo, o molde é fechado unindo as duas metades e aprisionando as mangueiras. Um sistema de corte libera as mangueiras do 
fluxo contínuo proveniente da extrusora e o molde é transportado pela unidade de fechamento para a estação de calibração.

A figura 3.2 mostra a sequiência de sopro e a formação do frasco. Na estação de calibração, pinos refrigerados (1) descem e introduzem a ponta no molde (2) executando duas funções básicas: formar o gargalo dos frascos por compressão da ponta dos pinos contra o molde e insuflar ar comprimido nas cavidades do molde.

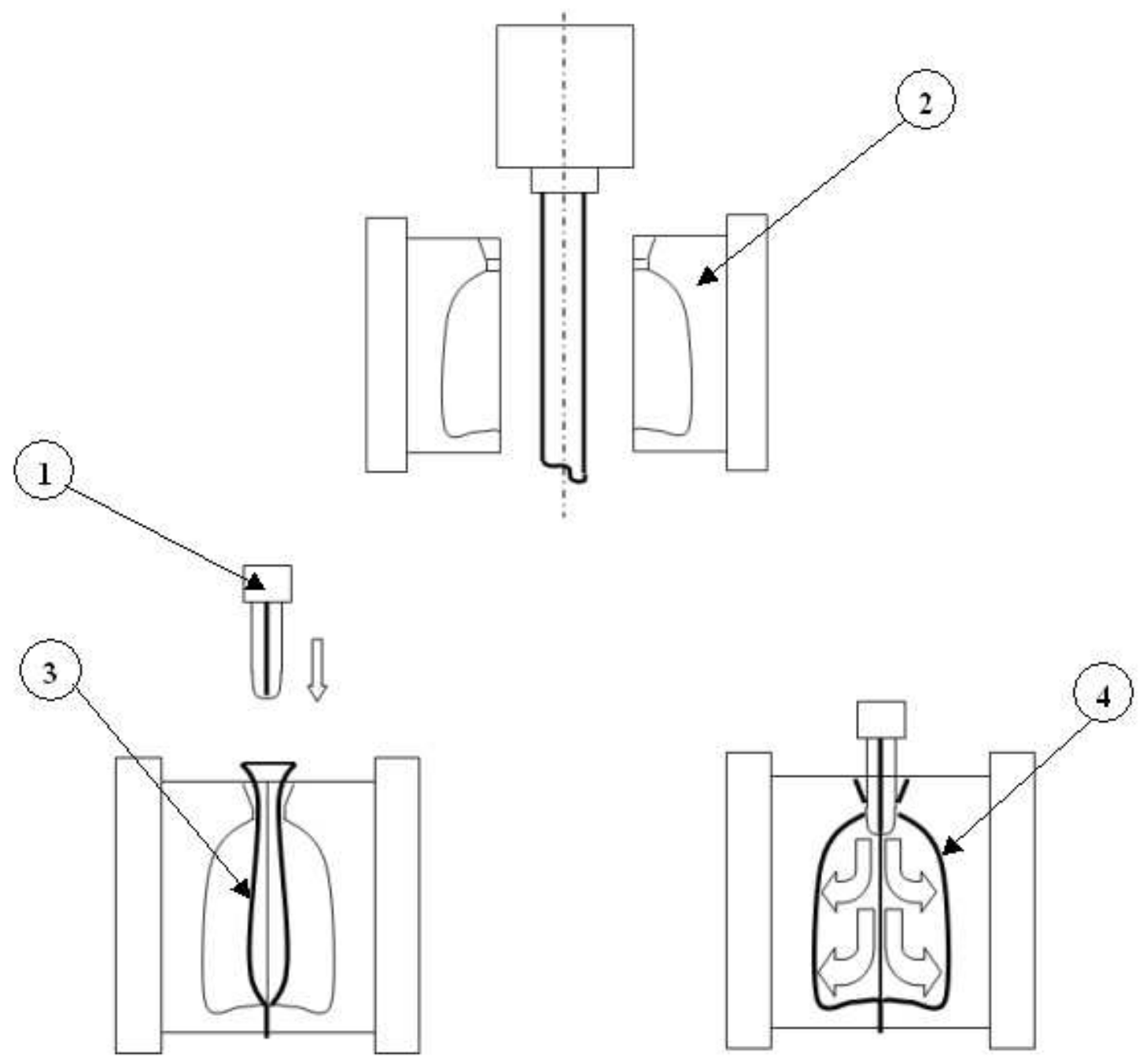

Figura 3.2 - Seqüência de sopro (24). 
Ao insuflar ar no molde, as mangueiras aprisionadas (3) são infladas até o limite estabelecido pelo desenho de cada cavidade do molde formando assim os frascos desejados (4). Após um tempo necessário para o resfriamento dos frascos o molde é aberto, isto é, as metades do molde são separadas e o molde é transportado novamente sob o cabeçote para aprisionar novas mangueiras e iniciar outro ciclo. Em tempo simultâneo os frascos já formados são transportados pela própria unidade de fechamento para uma estação de estampagem onde as rebarbas inerentes ao processo são retiradas e assim os frascos já limpos são conduzidos a uma esteira transportadora para a próxima etapa que pode ser, dependendo da configuração da fábrica, operações como armazenamento, rotulagem, envase, entre outras.

A máquina analisada possui duas unidades de fechamento em função da capacidade de produção necessária. Estas unidades realizam o ciclo acima descrito posicionando-se alternadamente sob o cabeçote para aprisionar as mangueiras. Existem na máquina duas estações de calibração e de estampagem para trabalho individual com cada molde.

\subsection{O Ciclo Hidráulico Seco}

A máquina de sopro trabalha continuamente conforme o ciclo descrito acima. Todos os movimentos que consomem tempo de produção e estabelecem o ciclo típico são realizados por atuadores hidráulicos. Existe um tempo dentro do ciclo total que é inerente às características do frasco e varia para cada caso. Este é o tempo necessário para que o frasco resfrie dentro do molde e garanta que, uma vez fora do molde, não perca suas características dimensionais. Porém neste trabalho o interesse é sobre o chamado ciclo seco que é definido como a soma dos movimentos hidráulicos que consomem tempo de produção. 
Na figura 3.3 são apresentados dois diagramas com o ciclo típico da sopradora incluindo o ciclo seco e o tempo de resfriamento. No diagrama da figura 3.3A os tempos considerados são:

- Abre / Fecha Molde: 0,6 [s]

- Avança / Recua Carro: 0,9 [s]

- Sobe / Desce Pino: 0,2 [s]

- Resfriamento: 2,6 [s]

Considerando estes tempos o ciclo total atinge 6 segundos e, devido à máquina possuir duas unidades, os movimentos de cada lado ocorrem defasados de meio ciclo, que neste caso equivale a um tempo de 3 segundos. Então, para um ciclo com a duração de 6 segundos temse um total de 600 ciclos realizados por hora de funcionamento do equipamento.

A figura 3.3B mostra o mesmo ciclo típico porém, simula uma situação onde os movimentos de abre / fecha molde e avança / recua carro são realizados em um tempo menor. Os demais tempos são mantidos conforme condição anterior. Neste diagrama os tempos considerados são:

- Abre / Fecha Molde: 0,5 [s]

- Avança / Recua Carro: 0,7 [s]

- $\quad$ Sobe / Desce Pino: 0,2 [s]

- Resfriamento: 2,6 [s]

Nesta condição, a duração do ciclo diminui para 5,4 segundos e pode-se realizar um total de aproximadamente 665 ciclos por hora. Nota-se assim um aumento de capacidade do equipamento obtido através do aumento de velocidade dos principais movimentos. 


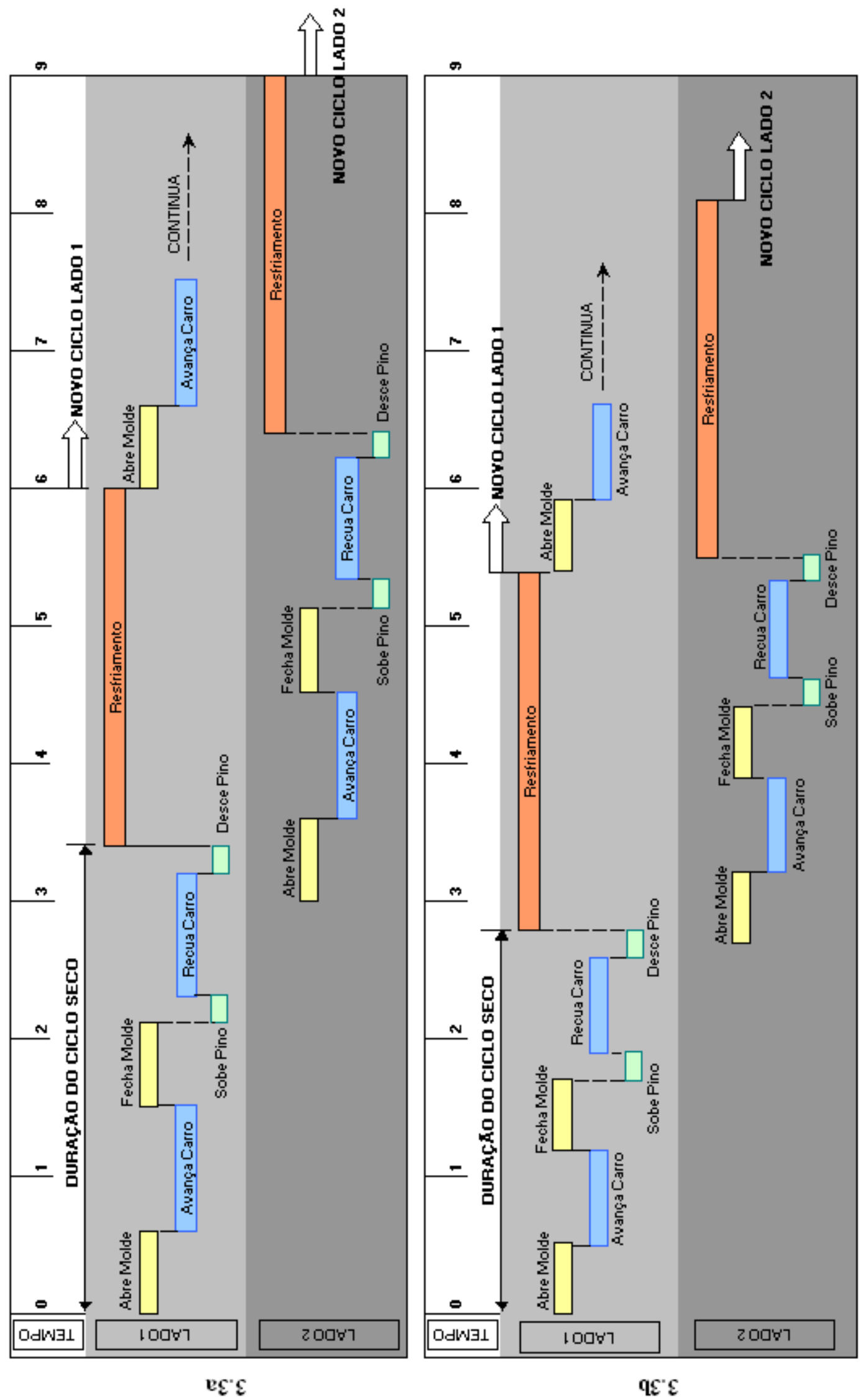

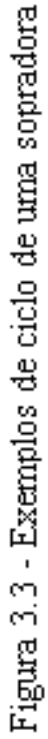


Na tabela 3.1 os valores de cada movimento estão descriminados. A soma dos tempos dos movimentos de abertura / fechamento e avanço / recuo de molde chega ao valor de 2,4 segundos representando pouco mais de $85 \%$ do tempo total do ciclo seco. Esta é a razão porque este trabalho coloca o foco das análises sobre estes dois movimentos com o objetivo de diminuir a duração do ciclo seco e aumentar a capacidade da sopradora.

Tabela 3.1 - Tempos estimados para os movimentos

\begin{tabular}{|c|l|c|c|}
\hline Dispositivo & Movimento & Tempo estimado (s) & Porcentagem(\%) \\
\hline \multirow{4}{*}{ Molde } & Abertura & 0,5 & 17,8 \\
\cline { 2 - 4 } & & & \\
\cline { 2 - 4 } & Fechamento & 0,5 & 17,8 \\
\cline { 2 - 4 } & & & 25 \\
\cline { 2 - 4 } & Avanço & 0,7 & 25 \\
\cline { 2 - 4 } & & & \\
\cline { 2 - 4 } & Recuo & 0,7 & 7,2 \\
\hline \multirow{3}{*}{ Calibraçẫo } & & & \\
\cline { 2 - 4 } & Subida & 0,2 & 7,2 \\
\cline { 2 - 4 } & & & \\
\hline
\end{tabular}

\subsection{Unidade de Fechamento}

O foco deste trabalho, conforme apontado anteriormente, acaba sendo o mecanismo da unidade de fechamento. Será descrito com mais detalhes este mecanismo com destaque para a figura 3.4 onde são identificados os componentes envolvidos nos movimentos de transporte e abertura / fechamento do molde.

A abertura e fechamento do molde saio realizados por um cilindro hidráulico (6) que transmite movimento às placas de fechamento (1) através de um mecanismo composto de braços (3), bielas (2), eixos centrais (9) e eixos secundários (11). Os braços rotacionam em torno dos eixos centrais que são suportados pelo carro (5) e fazem com que as bielas transmitam este movimento às placas de fechamento. As colunas de guia (10) garantem um 
movimento linear das placas de fechamento que se aproximam ou se afastam conforme a haste do cilindro hidráulico avança ou recua.

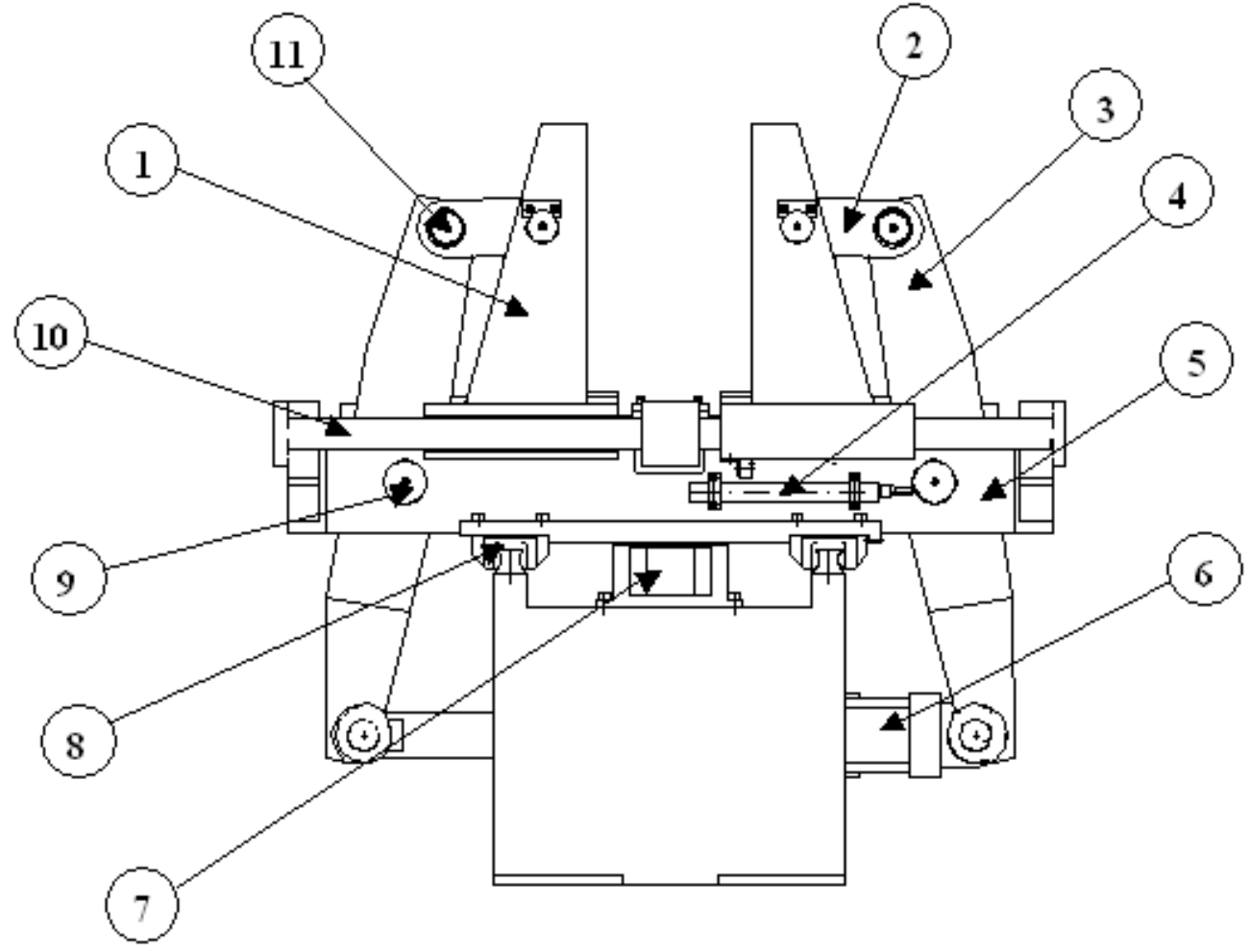

Figura 3.4 - Vista lateral da unidade de fechamento

Os itens destacados na figura 3.4 são identificados abaixo:

1- Placa porta molde.

2- Biela.

3- Braço.

4- Transdutor de posição.

5- Carro.

6- Cilindro hidráulico de abertura e fechamento do molde.

7- Cilindro hidráulico de transporte do molde.

8- Guias do movimento de transporte. 
9- Eixo central.

10- Coluna de guia de abertura e fechamento do molde.

11- Eixos secundários.

Existe ainda um dispositivo de sincronismo que tem como função garantir que o movimento das duas placas de fechamento seja sempre simétrico em relação à linha de centro da unidade. Na figura 3.5 este dispositivo é destacado: composto por duas cremalheiras e um pinhão, cada cremalheira é fixada em uma placa de fechamento e o pinhão está posicionado no carro. Quando as placas são movimentadas, qualquer diferença de atrito ou ajuste mecânico entre os dois lados do mecanismo é compensada por este dispositivo. $\mathrm{O}$ molde, composto de duas metades, é fixado nas placas de fechamento sendo uma metade fixada em cada placa. O movimento acima descrito faz com que, quando em operação, o molde seja aberto ou fechado.

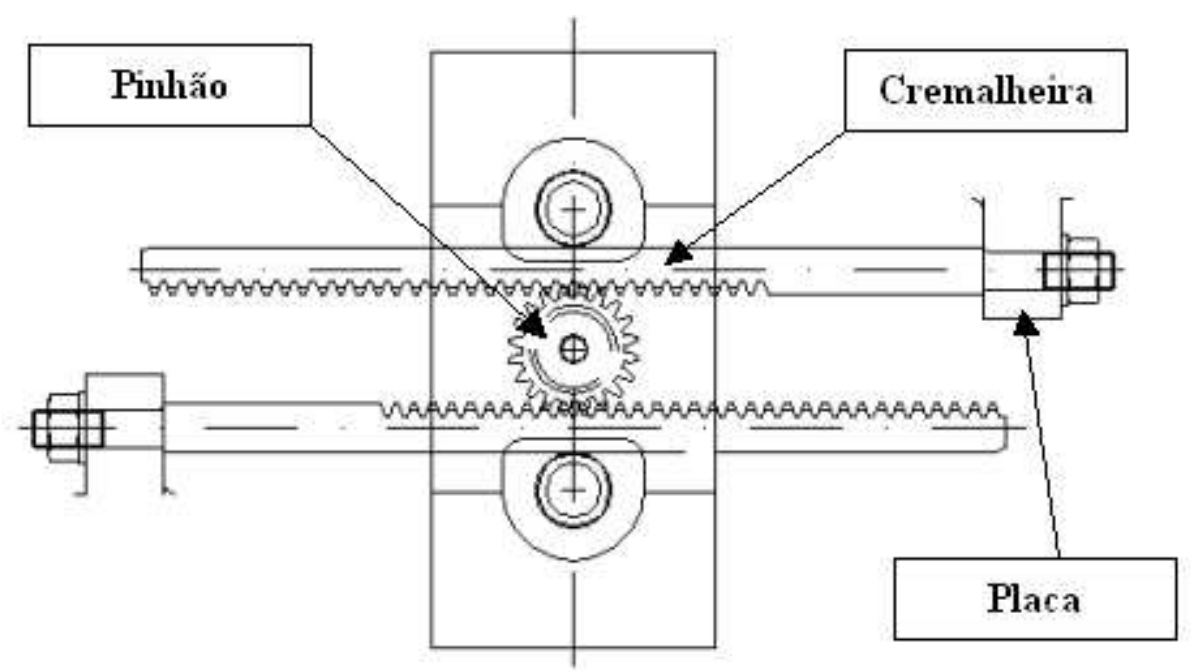

Figura 3.5 - Dispositivo de sincronismo

O movimento de transporte do carro é executado pelo cilindro hidráulico (7) que desloca todo o mecanismo composto de carro (5), placas de fechamento (1), bielas (2), 
braços (3), colunas (10), eixo central (9), eixos secundários (11) e cilindro de abertura e fechamento (6). Quando este cilindro (7) avança, todo o mecanismo é posicionado sob o cabeçote divisor onde as mangueiras são continuamente extrudadas. No recuo deste cilindro, o mecanismo é posicionado sob o dispositivo de calibração onde estão os pinos de sopro. Este movimento é guiado por guias lineares de esferas recirculantes (8).

Para melhor visualização, a figura 3.6 mostra uma vista frontal completa do equipamento em estudo que é composto de duas unidades de fechamento apoiadas sobre um mesmo sistema de guia. Estas unidades alternam-se nas posições sob o cabeçote divisor (posição avançada) e sob o dispositivo de calibração (posição recuada).

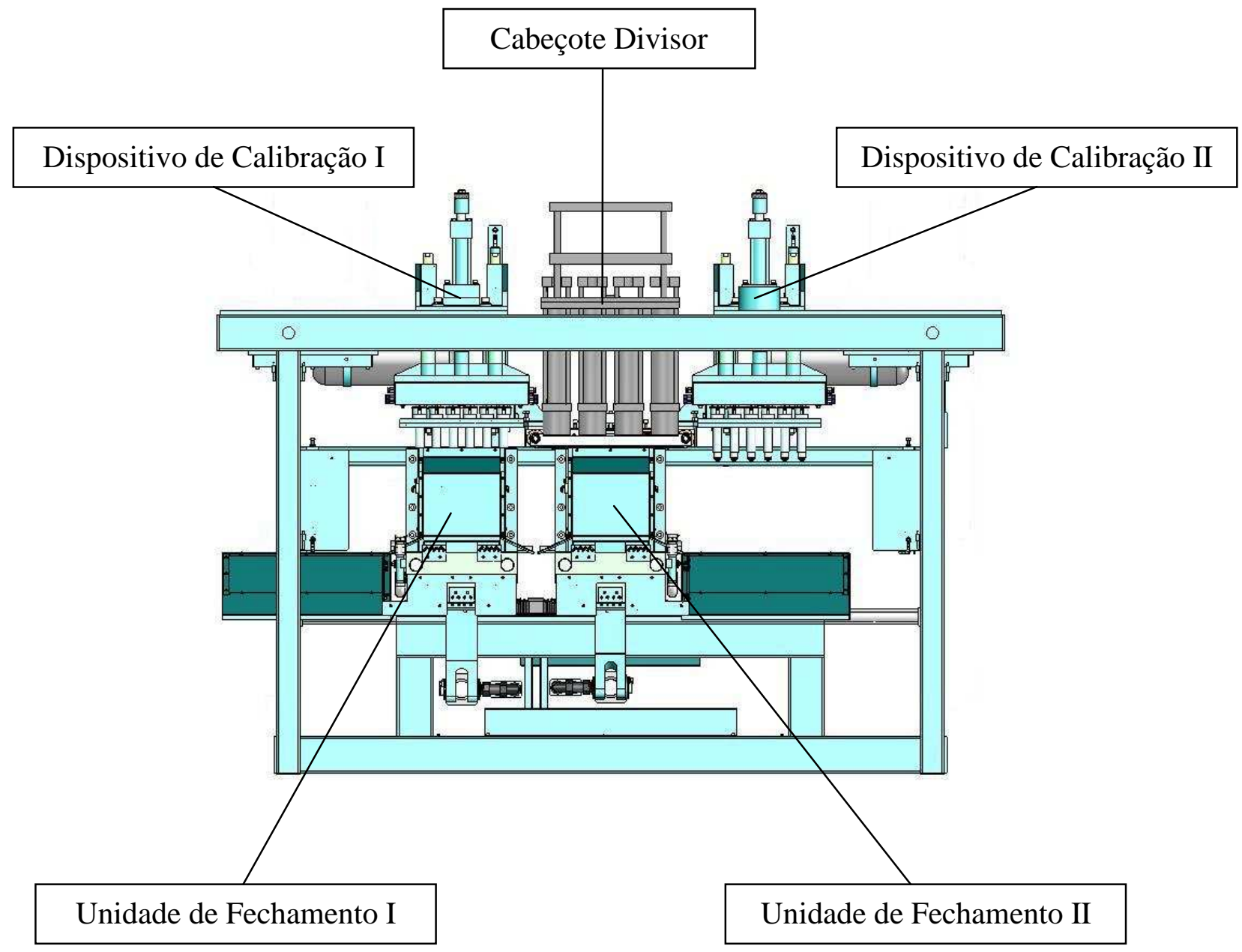

Figura 3.6 - Vista frontal da sopradora. 


\subsection{O Sistema Hidráulico}

Todos os movimentos descritos no item 3.3 são realizados por um sistema hidráulico. Os movimentos de transporte e abertura / fechamento de molde são controlados de formas bem distintas. Enquanto o movimento de transporte é comandado por um conjunto de válvula direcional, mecanismo de comando e válvula de freio, o outro movimento possui um controle mais sofisticado incluindo uma válvula direcional proporcional.

\subsubsection{Comando Hidráulico do Movimento de Transporte.}

$\mathrm{Na}$ figura 3.7 verifica-se o esquema hidráulico de comando do movimento de transporte. Ele é constituído de uma válvula direcional (1), uma válvula de freio (2) e o cilindro hidráulico (3). A válvula direcional comanda o sentido de movimento do cilindro e conseqüentemente da unidade de fechamento como um todo. Porém, entre a válvula direcional e o cilindro existe uma válvula de freio que controla a vazão de óleo que simultaneamente entra e sai do cilindro através da variação gradual da área do furo de passagem (5) conforme a posição do êmbolo (4).

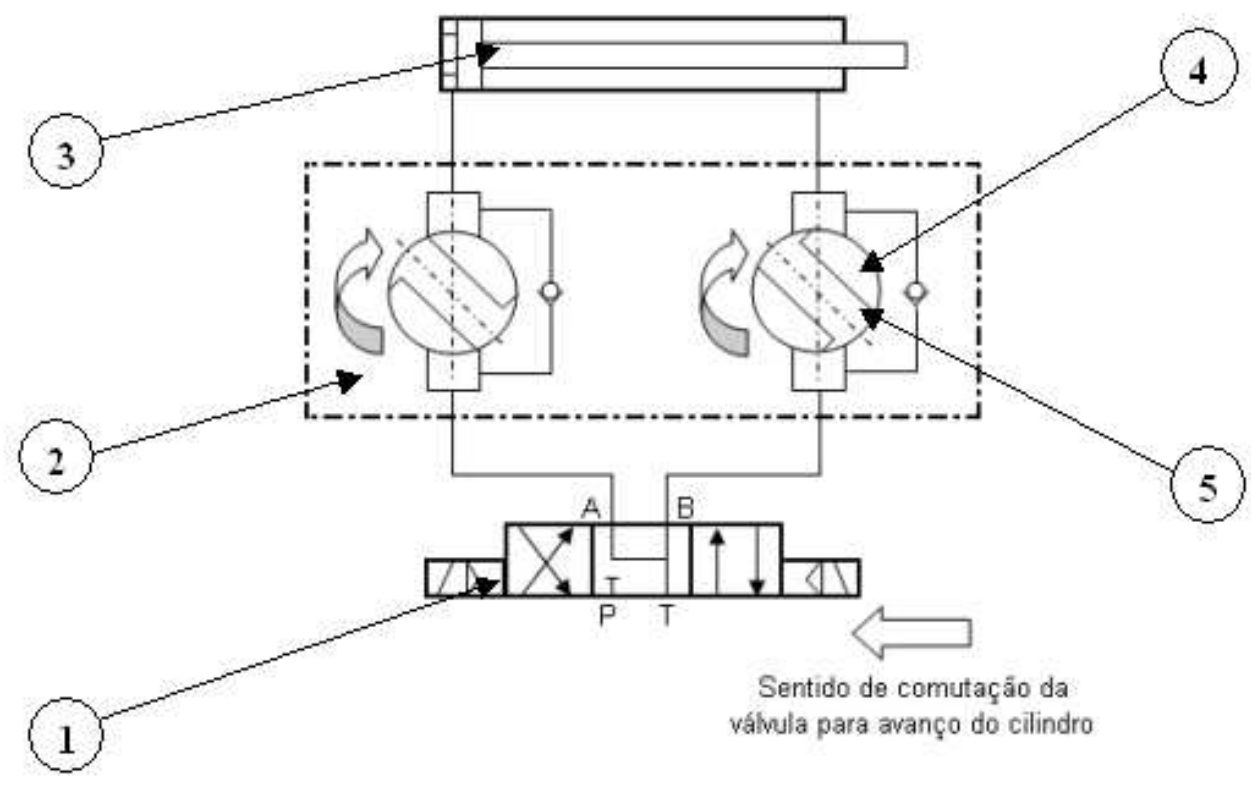

Figura 3.7 - Esquema hidráulico de comando do movimento de transporte 
Assim, a velocidade é controlada para obter um movimento rápido, porém com acelerações que não produzam choques que comprometam a integridade da unidade de fechamento ao longo do seu uso. Os detalhes construtivos desse sistema hidráulico serão melhor detalhados no Capítulo 4 - Modelamento dos Componentes Hidráulicos.

O êmbolo da válvula de freio opera com um movimento de rotação comandado por um conjunto de alavancas que são conectadas ao carro da unidade de fechamento. O próprio deslocamento do carro produz movimento no êmbolo da válvula e permite que se desenvolvam dinâmicas de aceleração ou frenagem da unidade de fechamento como um todo. A figura 3.8 mostra a válvula de freio (1) e o conjunto de alavancas nas posições da unidade de fechamento avançada e recuada. Nota-se que a alavanca superior (2) é conectada ao carro (3) através do braço de arraste (4) e, a alavanca inferior (5) transmite giro para o êmbolo da válvula de freio.

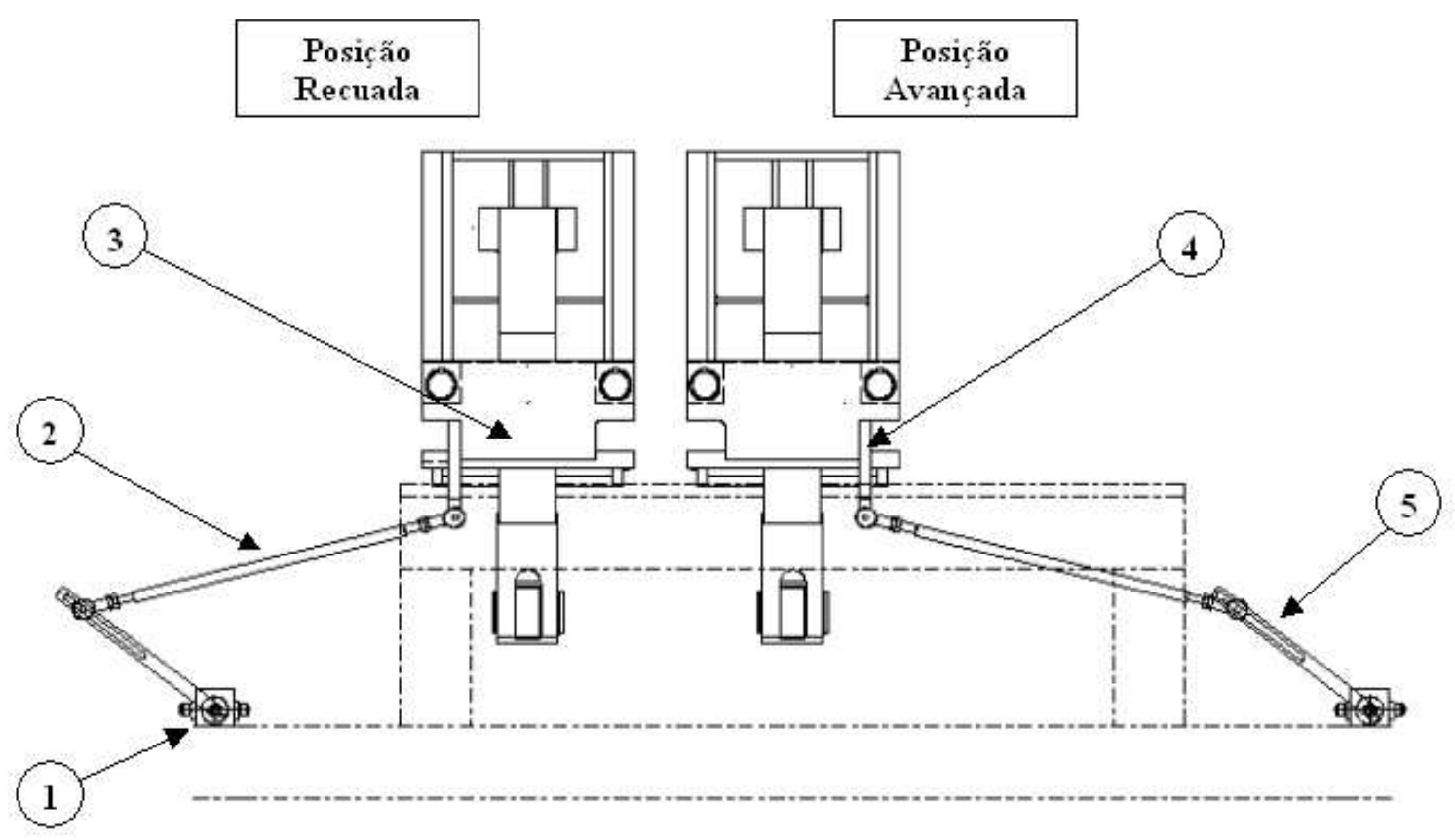

Figura 3.8 - Dispositivo de comando da válvula de freio. 


\subsubsection{Comando Hidráulico do Movimento de Abertura e Fechamento do Molde}

Ao contrário do comando do movimento de transporte do molde que é realizado por um sistema mecânico acionando uma válvula hidráulica, o movimento de abertura e fechamento do molde é obtido por um sistema eletrônico atuando sobre uma válvula proporcional. A figura 3.9 indica o esquema hidráulico de comando para o movimento de abertura e fechamento do molde.

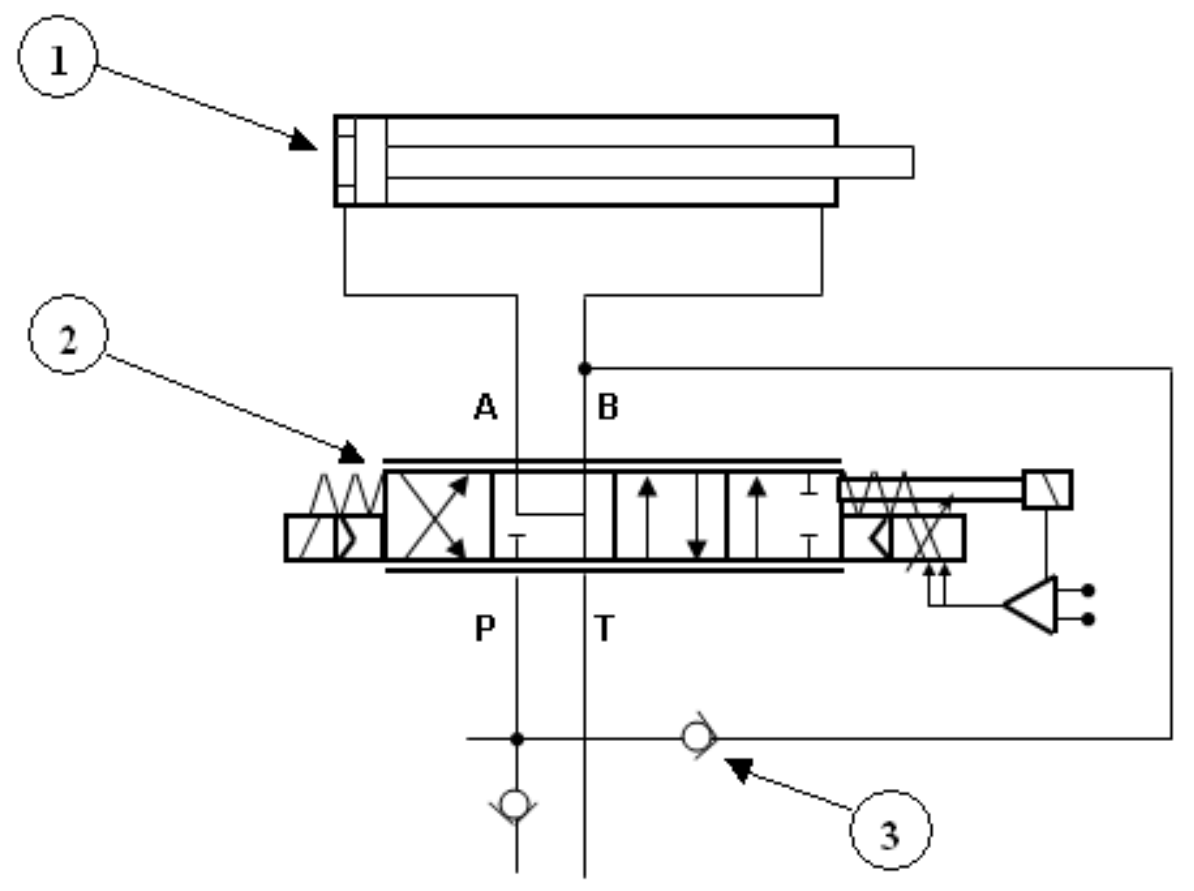

Figura 3.9 - Esquema hidráulico de abertura / fechamento de molde

A partir de um perfil de comando analógico entre 0 e 10 Volts, a válvula proporcional (2) é comandada para controlar a dinâmica de aceleração e frenagem dos movimentos de abertura e fechamento do molde. No Capítulo 4 - Modelagem dos Componentes Hidráulicos, a malha de controle deste movimento é detalhada.

Devido às dimensões do atuador (1), a válvula proporcional selecionada possui um êmbolo de 4 posições. Além das duas posições para direcionamento para avanço e recuo do atuador e da posição de repouso, existe uma quarta posição com função de regeneração. 
Nesta posição, o fluxo de óleo proveniente da câmara do lado da haste que normalmente seria direcionado para a linha de tanque (T) durante o avanço do atuador, é bloqueado e redirecionado para a linha de pressão $(\mathrm{P})$, através da abertura da válvula de retenção (3), retornando desta maneira para a câmara do lado do êmbolo. Com este sistema de regeneração, a necessidade de vazão de óleo suprida pela bomba durante o movimento de avanço do atuador é reduzida pela metade uma vez que a relação dos volumes de ambas as câmaras é 2:1. Como conseqüência, um conjunto moto-bomba menor pode ser utilizado. Esta posição de regeneração é selecionada durante o avanço do atuador a partir de um valor préajustado de tensão de comando. 


\section{CAPÍTULO 4}

\section{MODELAGEM DOS COMPONENTES HIDRÁULICOS}

Este capítulo trata da modelagem matemática dos componentes hidráulicos envolvidos no comando de posicionamento dos movimentos estudados, tais como válvulas de controle e atuadores hidráulicos (cilindros). Serão abordados separadamente os comandos hidráulicos dos movimentos transporte e abertura/fechamento do molde.

\subsection{Movimento de Transporte}

Conforme mostrado no capítulo anterior, figura 3.7, o movimento de transporte é realizado por uma válvula direcional acionando o cilindro de transporte. A dinâmica do movimento é controlada por uma válvula intermediária chamada válvula de freio. Neste item estes componentes são detalhados.

\subsubsection{Válvula Direcional}

Este tipo de válvula tem como função direcionar o fluxo de óleo controlando assim o sentido de movimento (avanço ou recuo) do atuador a ela acoplado.

O tipo de válvula direcional mais utilizado emprega um êmbolo deslizante como forma de controle da direção do fluxo de óleo. Este tipo construtivo normalmente é classificado por (a) número de vias pelas quais o fluxo de óleo pode circular através da válvula, (b) número de posições que o êmbolo pode assumir, (c) configuração do êmbolo na posição central. Devido ao fato de que uma válvula necessita uma via de alimentação de pressão, uma de retorno para tanque e uma ou duas vias para acionar a carga, as válvulas normalmente 
possuem de três a quatro vias. O número de posições varia também entre três e quatro, mas em válvulas especiais pode chegar até seis posições.

A figura 4.1 mostra a forma construtiva da válvula direcional utilizada no movimento de transporte. Esta é uma válvula direcional de êmbolo de acionamento por solenóide. Elas comandam partida, parada e direção de uma vazão com a possibilidade de ajustar o tempo de operação. As válvulas direcionais consistem basicamente da carcaça (1), de dois solenóides (2), do êmbolo de comutação (3), bem como das molas de retorno (4). As duas câmaras da mola são interligadas através de um furo de comunicação (5). Com isto, o fluido é deslocado de uma câmara para outra no processo de comutação. Se a seção deste furo for estrangulada altera-se o tempo de operação. No estado desenergizado, o êmbolo de comando (3) é mantido na posição central ou inicial através das molas de retorno (4). O acionamento do êmbolo de comando (3) é feito por solenóides em banho de óleo (2). A força do solenóide (2) atua sobre o êmbolo de comando (3) e desloca o mesmo de sua posição inicial para a posição desejada. Com isto libera-se a vazão de $\mathbf{P}$ para $\mathbf{A}$ e $\mathbf{B}$ para $\mathbf{T}$ ou $\mathbf{P}$ para $\mathbf{B}$ e $\mathbf{A}$ para $\mathbf{T}$. Após a desenergização do solenóide (2) o êmbolo de comando (3) retorna para a sua posição inicial através das molas (4).

No modelo estudado para o movimento de transporte, a válvula direcional tem como função determinar o sentido do movimento (avançar ou recuar). Uma vez comutada esta válvula, sem considerar a transição de posição do êmbolo, ela passa a representar para o nosso modelo um furo com área conhecida sujeita à equação de vazão através de um furo:

$$
\mathrm{Q}=C_{d} * A \sqrt{\frac{2(\Delta P)}{\rho}}
$$

Sendo:

$\mathrm{Q}=$ Vazão através da válvula $\left[\mathrm{m}^{3} / \mathrm{s}\right]$ 
$\mathrm{C}_{\mathrm{d}}=$ Coeficiente de descarga - adimensional

$\mathrm{A}=$ Área de passagem da válvula $\left[\mathrm{m}^{2}\right]$

$\Delta P=$ Diferencial de pressão entre os pórticos de entrada e saída da válvula [Pa] $\rho=$ Densidade do óleo hidráulico $\left[\mathrm{kg} / \mathrm{m}^{3}\right]$

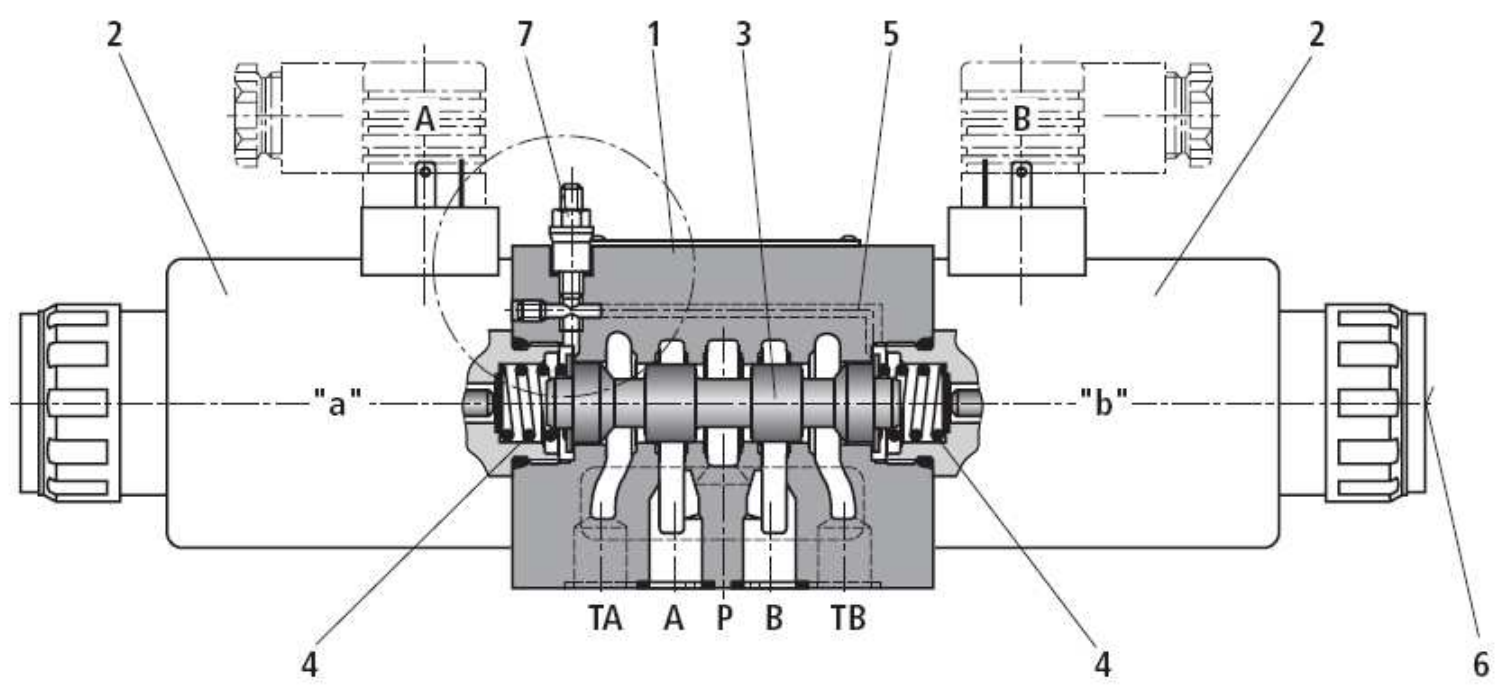

Figura 4.1 - Forma construtiva da válvula direcional. (11)

O fabricante da válvula nos fornece a curva característica de vazão x pressão para a válvula selecionada (5-4WE10J 33/CG24 - fabricante Bosch Rexroth) indicada na figura 4.2 abaixo. Esta curva apresentada pelo fabricante atende à equação 4.1 para uma válvula de tamanho nominal 10 (área de passagem equivalente a um furo com $10 \mathrm{~mm}$ de diâmetro), utilizando um óleo hidráulico com densidade aproximada de $881 \mathrm{~kg} / \mathrm{m}^{3}$ e um $\Delta P=5$ bar. Através da análise das curvas apresentadas pelo fabricante e dos dados acima, conclui-se que esta válvula possui um coeficiente de descarga de aproximadamente 0,65.

A válvula selecionada possui um desenho de êmbolo cuja posição central comunica os pórticos A e B para a linha de tanque (T), mantendo a linha de pressão (P) fechada. Este tipo de configuração é identificado pelo fabricante como sendo desenho tipo "J" e, neste caso deve ser considerada a curva 1 para o sentido de vazão de P-A e P-B e a curva 4 para o 
sentido de vazão de A-T e B-T. As curvas identificadas com outros números são válidas para válvulas com desenhos diferentes de êmbolo e não são aplicadas à este trabalho.

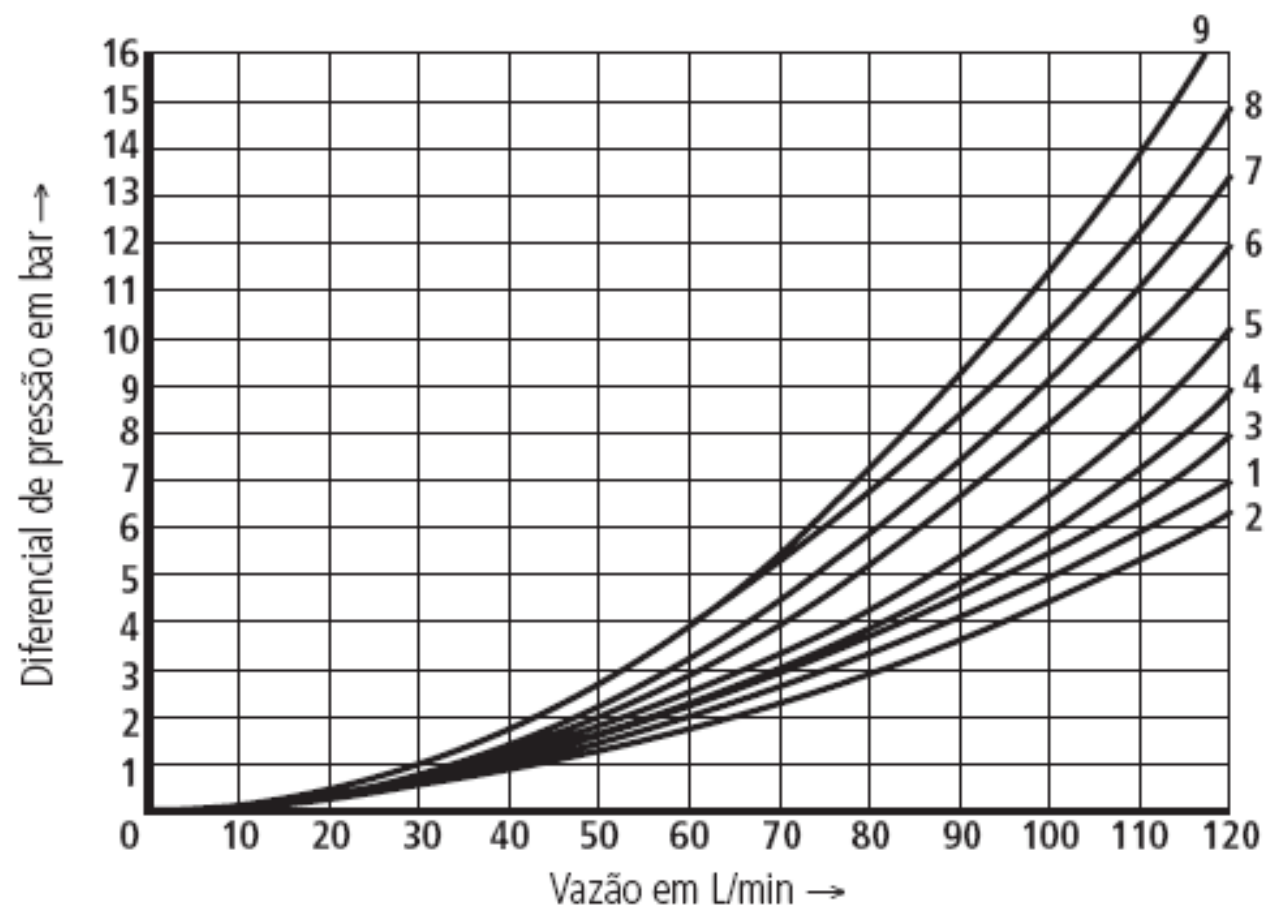

Figura 4.2 - Curvas de vazão x diferencial de pressão para a válvula direcional. (11)

É estabelecido pelo fabricante que a vazão máxima nominal desta válvula é de 120 litros/minuto. Conforme o esquema indicado na figura 3.8, a válvula direcional está disposta em linha com a válvula de freio. Isto indica que em algum momento ao longo do curso a válvula direcional pode limitar a vazão direcionada para o atuador devido à perda de carga por ela conferida e, conseqüentemente a velocidade de translação do movimento de transporte. Na prática, as curvas de vazão das duas válvulas, direcional e de freio, devem se sobrepor uma vez que estão montadas numa mesma linha. A seguir vamos detalhar as características da válvula de freio. 


\subsubsection{Válvula de Freio}

Esta válvula tem como função controlar a vazão de óleo que simultaneamente entra e sai do cilindro de transporte através da variação gradual da área de passagem.

A figura 4.3 mostra um corte esquemático da válvula de freio:

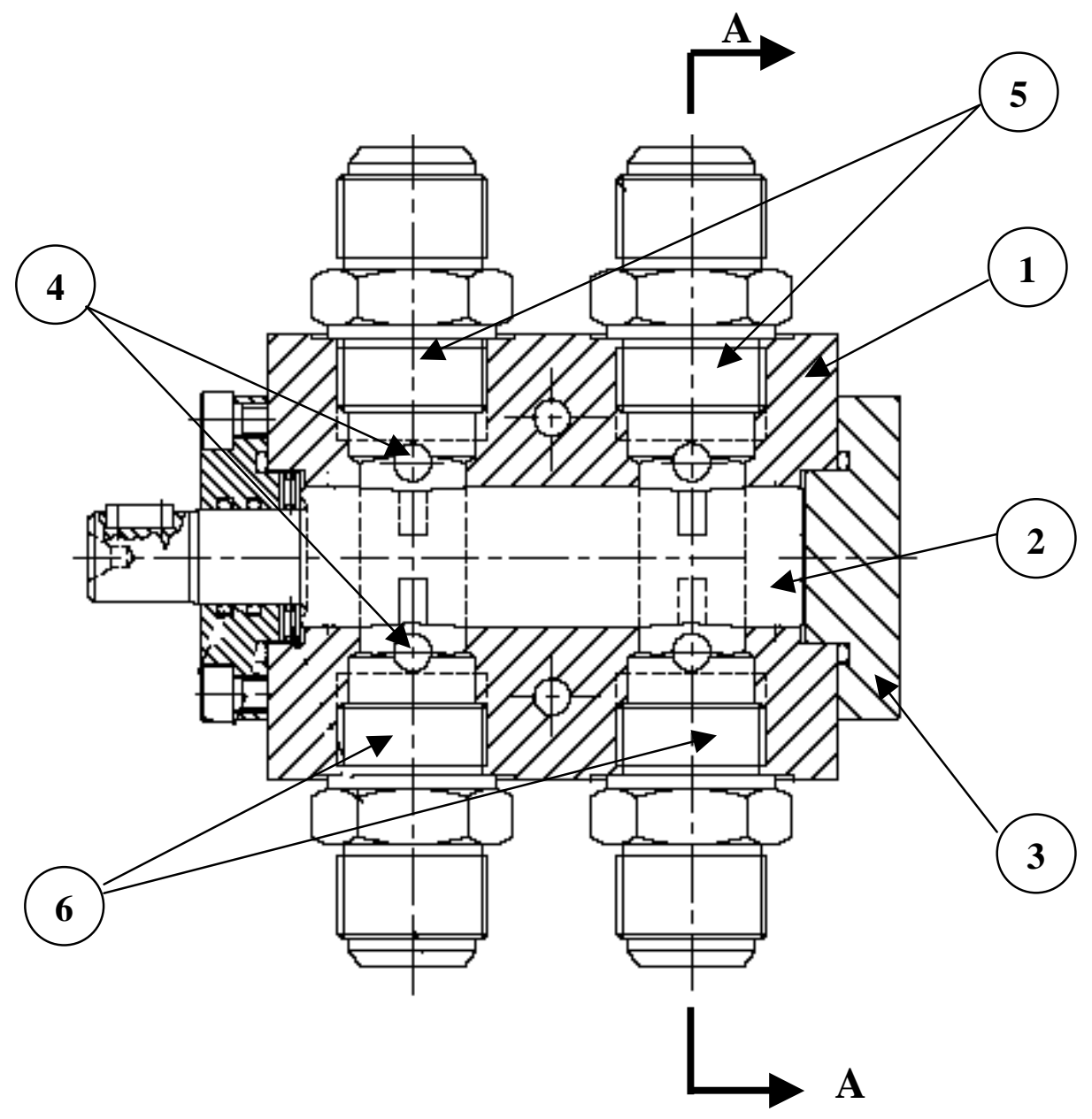

Figura 4.3 - Vista em corte da válvula de freio

O êmbolo (2) gira parcialmente em relação ao corpo (1) da válvula de freio, o que resulta em uma variação da área de passagem do óleo que flui entre os pórticos que estão conectados à válvula direcional (6) e os pórticos conectados ao cilindro de transporte (5). 
Desta maneira tanto a vazão de óleo que é enviada ao cilindro como a que sai do cilindro para a linha de tanque são controladas através desta variação gradativa de área. Como conseqüência, a velocidade do movimento de transporte é controlada.

Os furos de passagem (4) permitem que o óleo circule do pórtico de entrada para o de saída no início do movimento através da abertura da válvula de retenção (7), mostrada no corte A-A da figura 4.4.

A rotação do êmbolo é comandada por um sistema de alavancas fixado ao próprio carro de transporte conforme indicado na figura 3.8 .

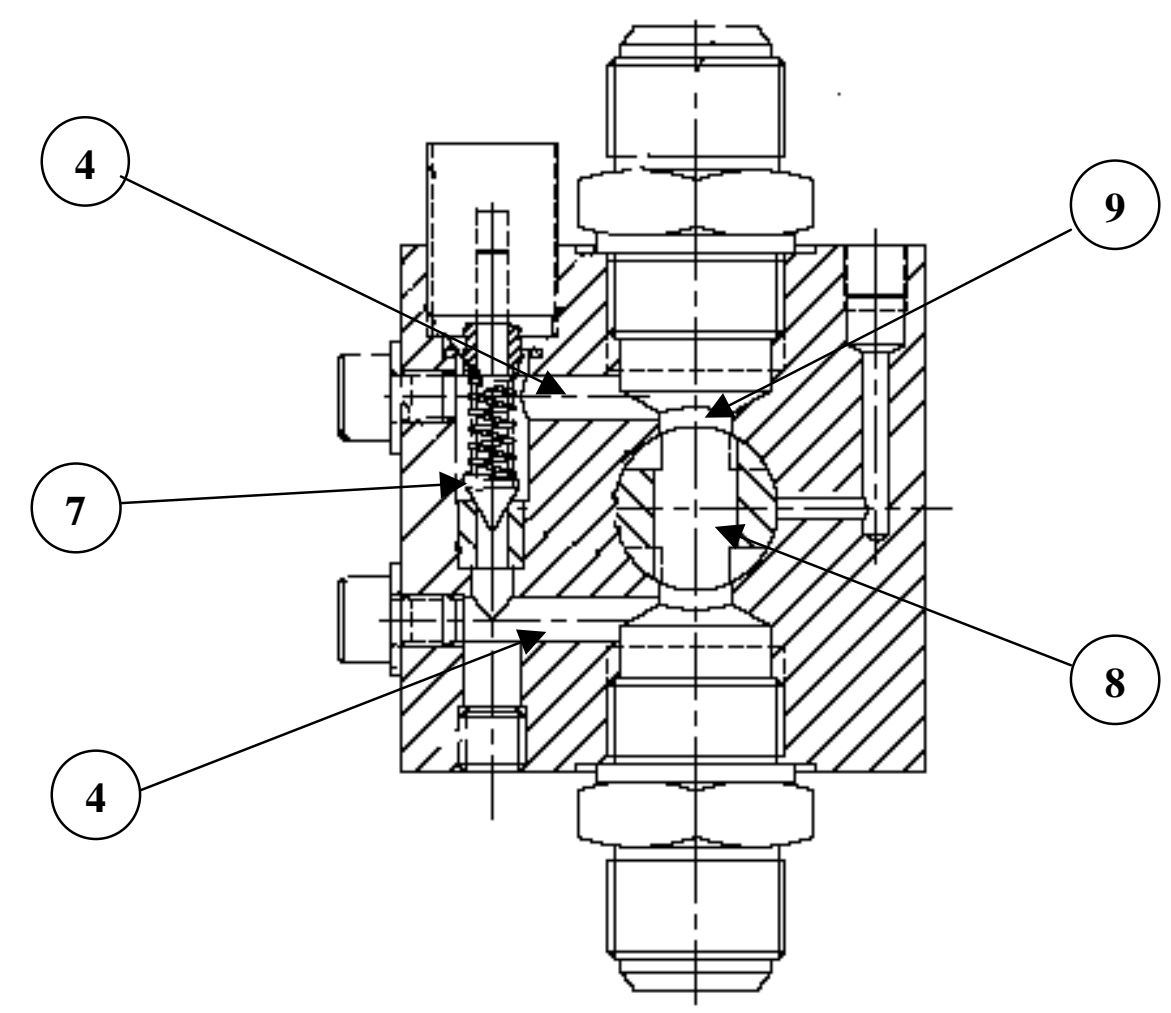

Figura 4.4 - Corte A-A da válvula de freio

Os furos de passagem tanto no êmbolo giratório (8) como no corpo da válvula (9) possuem as mesmas dimensões e são usinados na forma de um losango. Porém, no furo do êmbolo, em um dos vértices, é usinado adicionalmente um canal de alívio com dupla função: manter a câmara de avanço do cilindro de transporte pressurizada mesmo após o término do 
movimento e prover uma rápida despressurização desta mesma câmara no momento de inversão do movimento do cilindro.

A figura 4.5 ilustra o desenho do êmbolo com os dois furos de passagem.

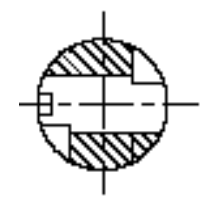

Corte A - A

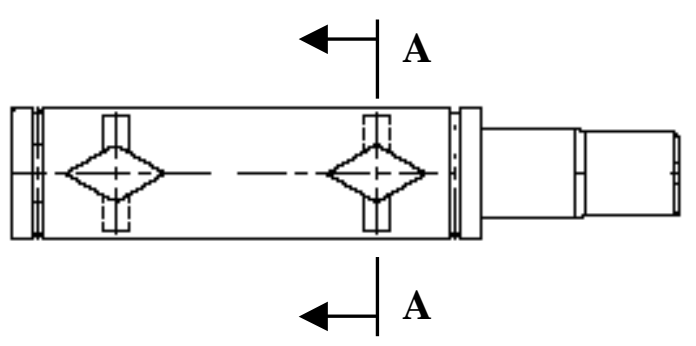

Figura 4.5 - Detalhe construtivo do êmbolo

A figura 4.6 mostra a seqüência para avanço do cilindro de transporte. Estão ilustradas a válvula direcional, válvula de freio e cilindro de transporte. Com esta sequiência pode-se visualizar melhor o funcionamento da válvula de freio.

No momento em que o solenóide Y2 da válvula direcional é energizado, o cilindro de transporte está recuado e o êmbolo da válvula de freio está posicionado de tal forma que a passagem da linha de pressão para a câmara "A" do cilindro está bloqueada (figura 4.6 / A). A câmara "B" é despressurizada para a linha de tanque através do canal de alívio existente no êmbolo. Inicia-se o movimento de avanço do cilindro pela abertura da válvula de retenção posicionada em paralelo ao furo de passagem do êmbolo.

Conforme o cilindro avança, a área de passagem de ambos os furos do êmbolo aumenta gradativamente e como conseqüência, a velocidade de avanço do cilindro também aumenta. Na figura 4.6 / B está indicada a situação em que o cilindro de transporte encontra-se próximo à metade do curso e a área de passagem dos furos do êmbolo é máxima.

Deste ponto para frente, o fenômeno inverte-se, isto é, a área de passagem é reduzida gradativamente com o avanço do cilindro até o limite em que o fluxo de óleo da câmara "B" para a linha de tanque é interrompido (figura 4.6 / C). Ao longo desta etapa a velocidade de 
avanço do cilindro de transporte é reduzida em função da diminuição da área de passagem dos furos do êmbolo.

FIGURA 4.6 / A

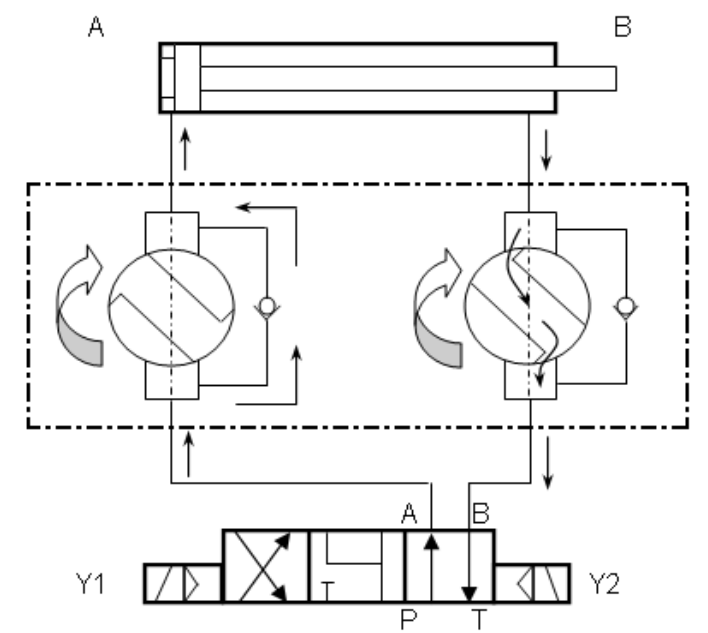

FIGURA 4.6 / B
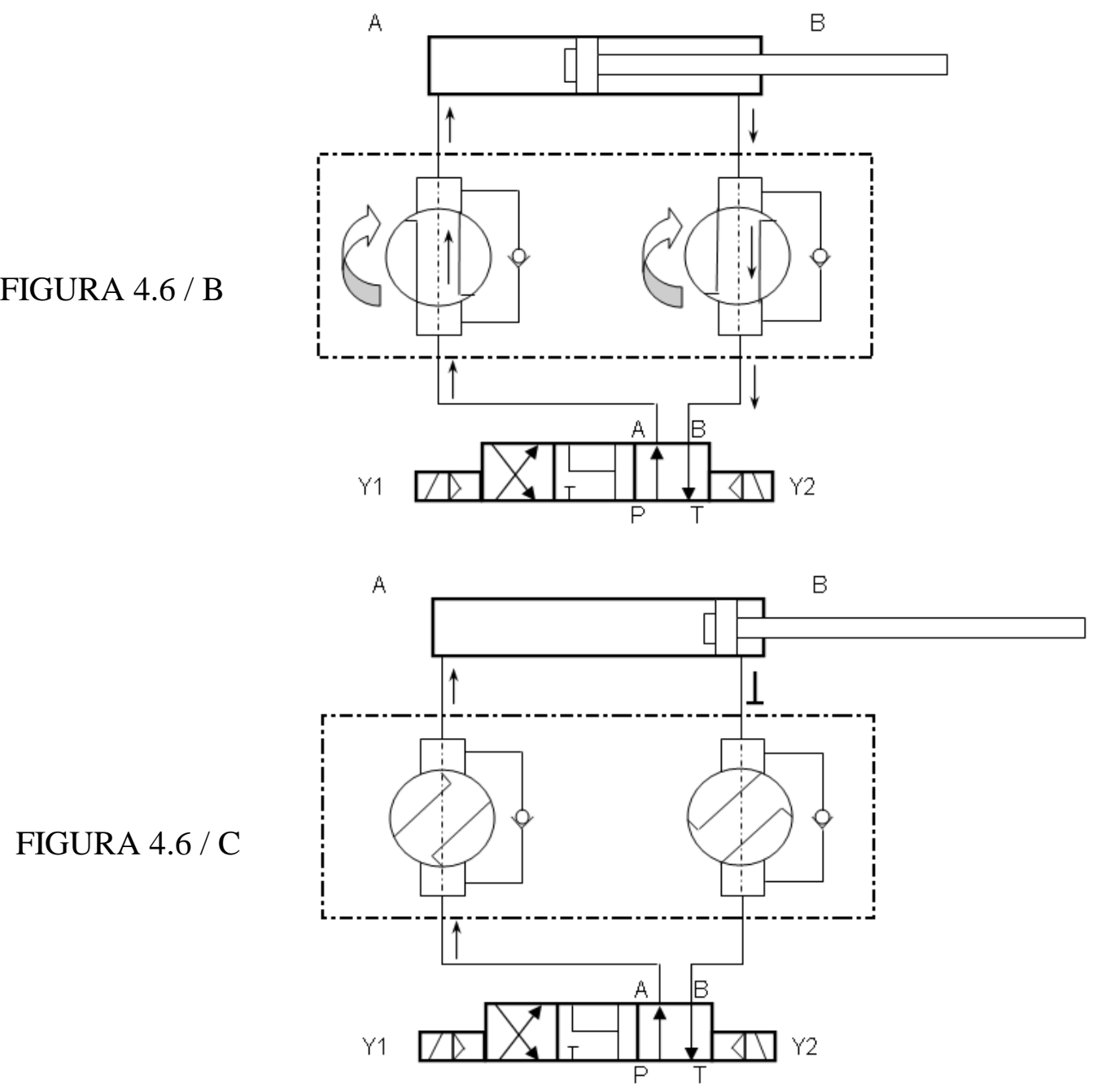

Figura 4.6 - Seqüência de avanço do cilindro de transporte 
Com o cilindro totalmente avançado, apesar de não haver mais movimento, a linha de pressão está conectada à câmara "A" através do canal de alívio do êmbolo. A câmara "A" fica pressurizada para garantir a posição avançada do cilindro de transporte.

Para inverter o movimento (recuo do cilindro), o solenóide Y2 é desenergizado ao mesmo tempo em que o solenóide Y1 é energizado. Com isso as câmaras "A" e "B" do cilindro passam a ser interligadas respectivamente com as linhas de tanque $(\mathrm{T})$ e pressão $(\mathrm{P})$ e todo o processo de controle da cinemática de movimento é repetido conforme descrito para o movimento de avanço.

Um modelo matemático pode ser feito para a válvula de freio com o objetivo de obterse a curva de vazão x pressão. Deste modelo podem-se definir também alguns coeficientes importantes para a caracterização da válvula como os coeficientes de vazão e vazão-pressão além da sensibilidade de pressão. No caso da válvula de freio torna-se importante também o estudo sobre a influência da geometria das alavancas que comandam o giro do êmbolo.

Esses pontos são analisados a seguir a partir da análise da variação da área de passagem na válvula de freio. A figura 4.7 mostra esquematicamente a sobreposição dos furos de passagem do corpo e do êmbolo da válvula que ocorre durante o movimento de transporte. Estabelece-se a coordenada X que define o deslocamento do furo do êmbolo em relação ao furo do corpo da válvula. O ponto de origem da coordenada X está na posição em que os furos estão totalmente sobrepostos e a área de passagem do fluxo de óleo é máxima. Este ponto está próximo à metade do curso de transporte e os deslocamentos deste ponto até o final do curso são considerados positivos enquanto que os deslocamentos do início até a metade do curso são tidos como negativos.

Resumindo os parâmetros envolvidos tem-se: 
$\mathrm{x}$ - Deslocamento linear do furo de passagem do êmbolo;

a - Comprimento da diagonal menor do furo do êmbolo e do corpo da válvula;

b - Comprimento da diagonal maior do furo do êmbolo e do corpo da válvula;

c - Comprimento da diagonal menor do furo de passagem;

d - Comprimento da diagonal maior do furo de passagem;

A - Área de passagem.

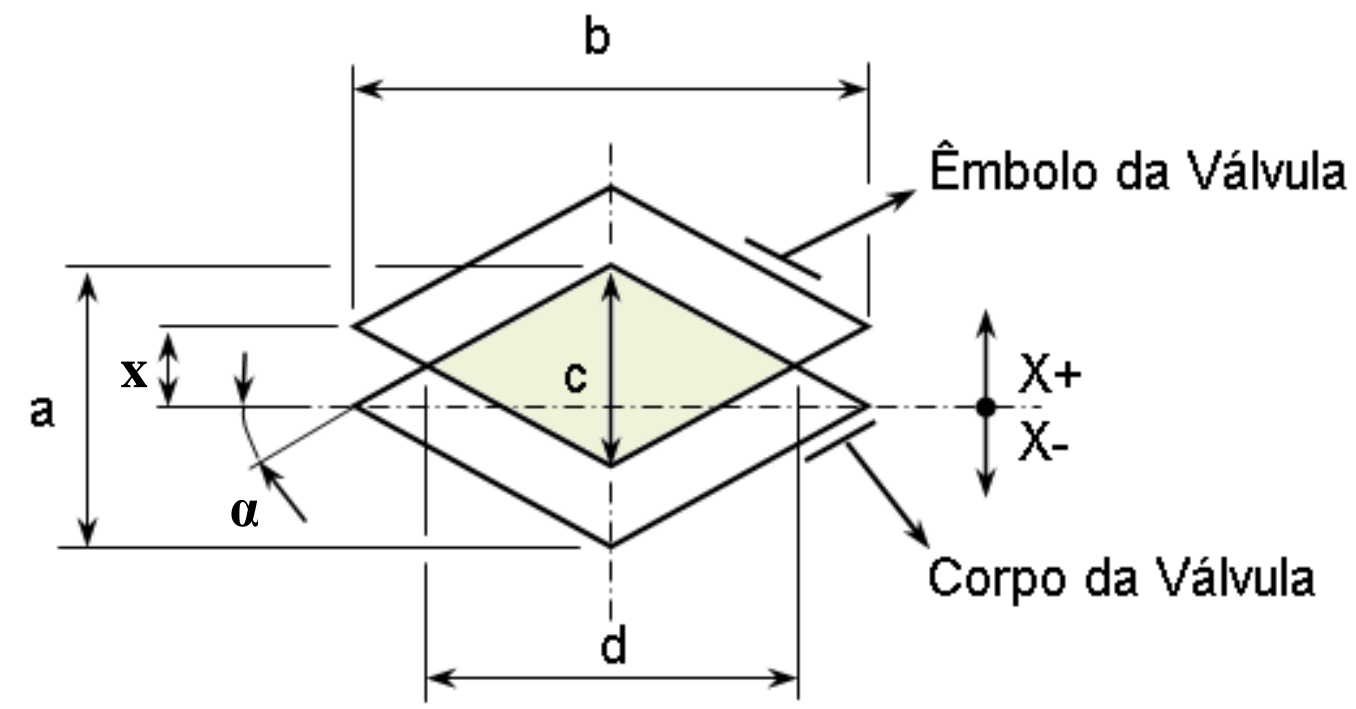

A - Área de passagem

Figura 4.7 - Área de passagem da válvula de freio

A área de passagem é definida como:

$$
A=\frac{c . d}{2}
$$

Mas é mais adequado definir a área de passagem A como função das grandezas fixas dos furos do êmbolo e corpo e do deslocamento do êmbolo. Com isso as seguintes relações são convenientes: 


$$
\begin{aligned}
& c=(a-x) \\
& \operatorname{tg} \alpha=\frac{(a-x)}{d} \\
& \operatorname{tg} \alpha=\frac{a}{b}
\end{aligned}
$$

Combinando (4.4) e (4.5) obtém-se:

$$
d=\frac{b(a-x)}{a}
$$

Substituindo (4.3) e (4.6) em (4.2) tem-se o resultado desejado:

$$
A=\frac{b(a-|x|)^{2}}{2 a}
$$

O módulo do deslocamento aparece na equação 4.7 pois, ao contrário do deslocamento, não são definidas áreas de passagem negativas.

É de interesse no modelo matemático da válvula de freio estabelecer a vazão como função não só da pressão de carga, mas também como função do deslocamento do carro. Por isso, a influência da geometria das alavancas de comando deve ser analisada.

A figura 4.8 indica a relação entre o deslocamento do carro e a geometria definida pelas alavancas de comando. Define-se: 
$\mathrm{L}_{0}$ - Comprimento entre o centro da válvula e a origem de coordenadas y;

$\mathrm{L}_{1}$ - Distância entre o centro da válvula e a articulação fixada no carro;

$\mathrm{L}_{\mathrm{A}}$ - Comprimento da alavanca superior;

$\mathrm{L}_{\mathrm{B}}-$ Comprimento da alavanca inferior;

$\alpha$ - Ângulo definido pela alavanca superior;

$\beta$ - Ângulo definido pela alavanca inferior $=$ Ângulo de giro do êmbolo;

y - Deslocamento do carro de transporte.

O deslocamento de transporte do carro y pode ser definido como:

$$
\begin{aligned}
& y=L_{0}-\left(\left|L_{A} \cos \alpha\right|+\left|L_{B} \operatorname{sen} \beta\right|\right) \quad \mathrm{p} /-52^{\circ} \leq \beta \leq 0 \\
& y=L_{0}-\left(\left|L_{A} \cos \alpha\right|-\left|L_{B} \operatorname{sen} \beta\right|\right) \quad \mathrm{p} / 0 \leq \beta \leq 52^{\circ}
\end{aligned}
$$

Ainda na figura 4.8 a seguinte relação pode ser deduzida:

$$
L_{1}=L_{A} \operatorname{sen} \alpha+L_{B} \cos \beta
$$




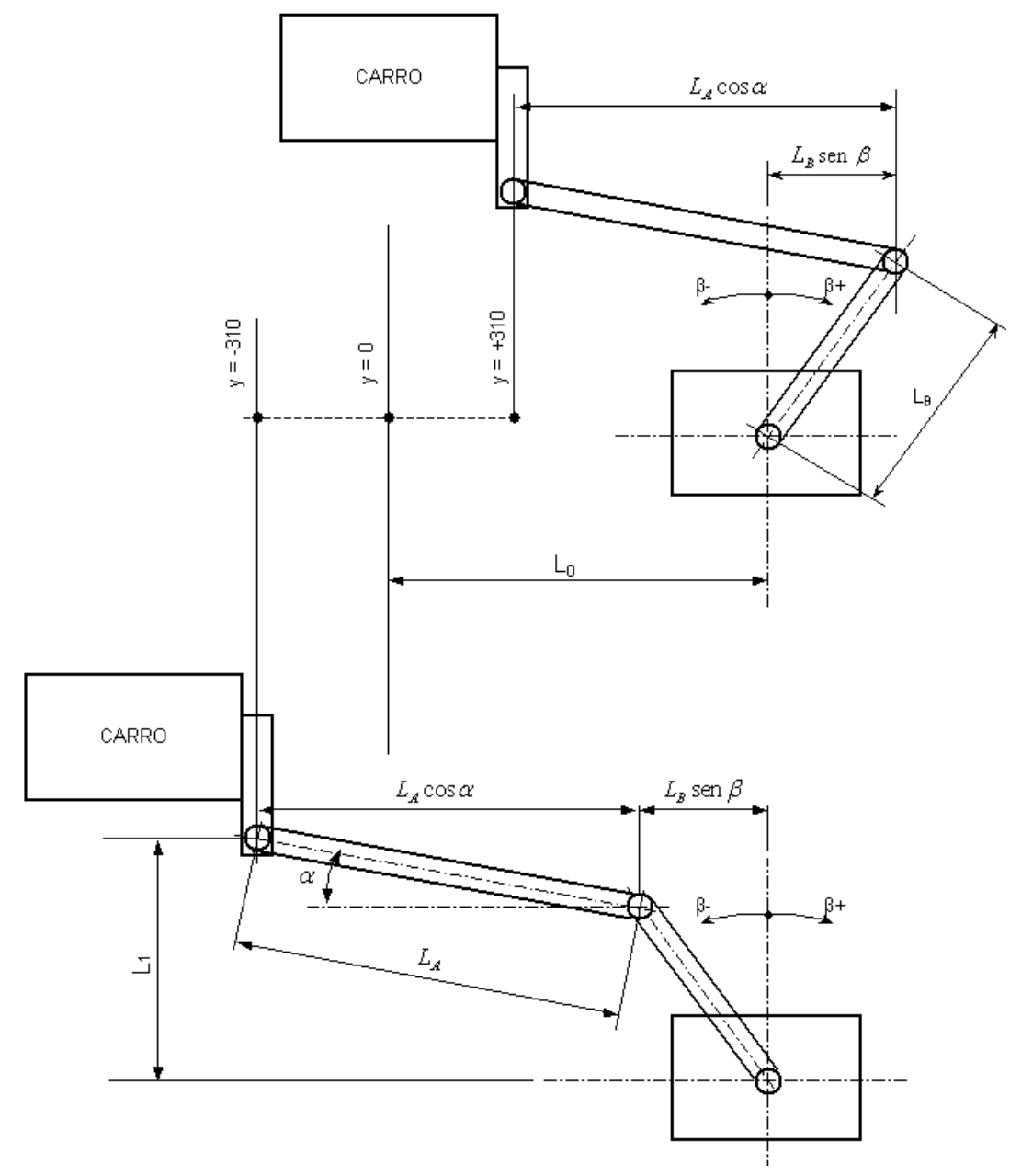

Figura 4.8 - Relação geométrica das alavancas de comando

Pode-se ainda relacionar o deslocamento linear " $\mathrm{x}$ " do êmbolo com o ângulo de giro " $\beta$ ” equivalente. A figura 4.9 ajuda a visualizar esta relação:

$$
\mathrm{x}=\mathrm{D}_{\mathrm{E}} \beta / 2
$$

Combinando as expressões 4.7 e 4.10 obtêm-se uma relação da área de passagem como função ângulo de giro. 


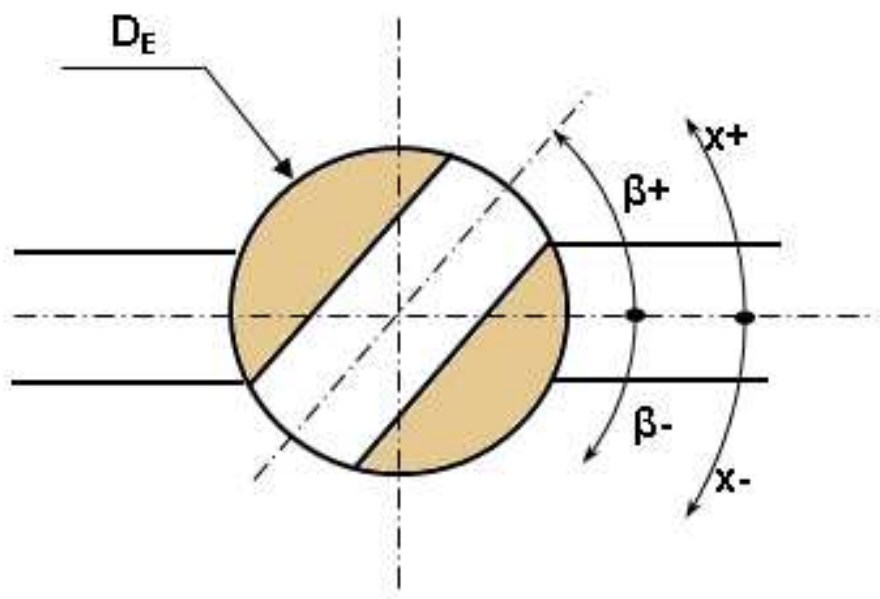

Figura 4.9 - Relação entre o ângulo de giro e o deslocamento do êmbolo

$$
A=\frac{b\left(a-\left|\frac{D_{E} \beta}{2}\right|\right)^{2}}{2 a}
$$

Sendo:

$\mathrm{D}_{\mathrm{E}}$ - Diâmetro externo do êmbolo.

$\beta$ - Ângulo de giro do êmbolo determinado pela geometria estabelecida nas equações 4.8 e 4.9 .

A partir das equações $4.8,4.9$ e 4.11 pode-se obter a curva indicada na figura 4.10 que relaciona o deslocamento do carro " $\mathrm{y}$ " com a área de passagem "A". 


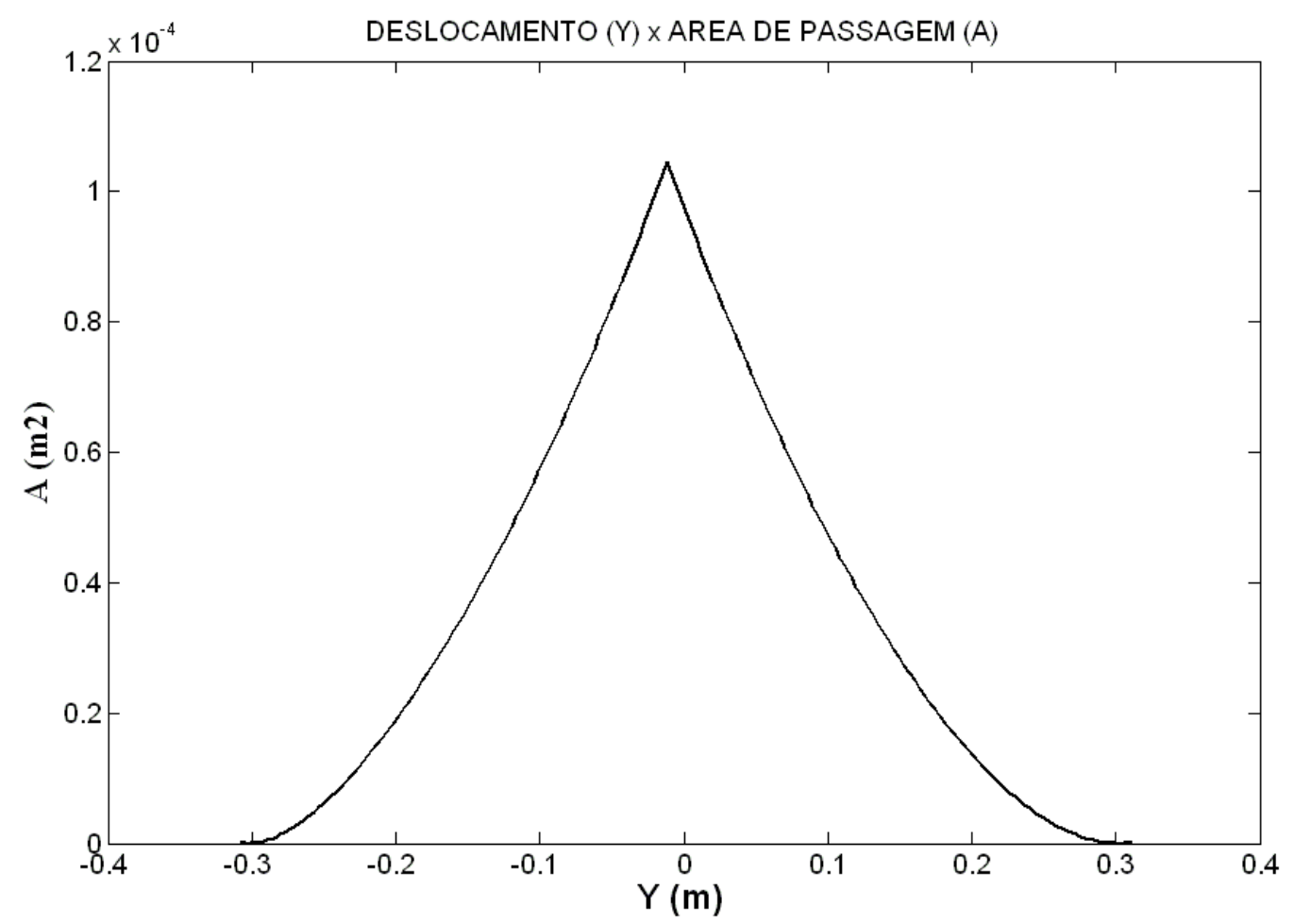

Figura 4.10 - Gráfico de Deslocamento x Área de Passagem

O gráfico acima foi obtido considerando-se os seguintes valores:

$-0,91 \leq \beta \leq 0,91$ [radianos]

$\mathrm{L}_{0}=0,875[\mathrm{~m}]$

$\mathrm{L}_{1}=0,395[\mathrm{~m}]$

$\mathrm{L}_{\mathrm{A}}=0,886[\mathrm{~m}]$

$\mathrm{L}_{\mathrm{B}}=0,393[\mathrm{~m}]$

$\mathrm{D}_{\mathrm{E}}=0,025[\mathrm{~m}]$

$\mathrm{a}=0,011[\mathrm{~m}]$

$\mathrm{b}=0,019[\mathrm{~m}]$

Vale ressaltar na figura 4.10 que existe uma leve assimetria da curva de área de passagem em relação ao ponto de origem (0) de coordenadas y. O ponto de área máxima de 
passagem está um pouco deslocado para a esquerda devido à geometria determinada pelas alavancas de comando.

Com a equação 4.11 pode-se determinar a vazão através dos pórticos da válvula de freio. No caso deste estudo, a válvula de freio está acoplada a um cilindro diferencial, isto é, a relação de áreas entre o lado do êmbolo e lado da haste é de 2:1. Assim, as seguintes equações de vazão podem ser escritas no caso do movimento de avanço do cilindro:

$$
\begin{aligned}
& Q_{L A}=C_{d} A \sqrt{\frac{2\left(P_{S}-P_{1}\right)}{\rho}} \\
& \frac{Q_{L A}}{2}=C_{d} A \sqrt{\frac{2\left(P_{2}-P_{0}\right)}{\rho}}
\end{aligned}
$$

Sendo as grandezas envolvidas identificadas na figura 4.11:

y - Deslocamento do carro de transporte;

QLA - Vazão de carga no lado da câmara 1 do cilindro, movimento de avanço;

$\mathrm{Q}_{\mathrm{S}}$ - Vazão de alimentação;

$P_{1}$ - Pressão na câmara 1 do cilindro, lado do êmbolo;

$\mathrm{P}_{2}$ - Pressão na câmara 2 do cilindro, lado da haste;

$\mathrm{P}_{\mathrm{L}}$ - Pressão de carga, diferencial de pressão no cilindro;

$P_{S}-$ Pressão de alimentação;

$\mathrm{P}_{0}$ - Pressão na linha de tanque;

F - Força de inércia resistente ao movimento; 


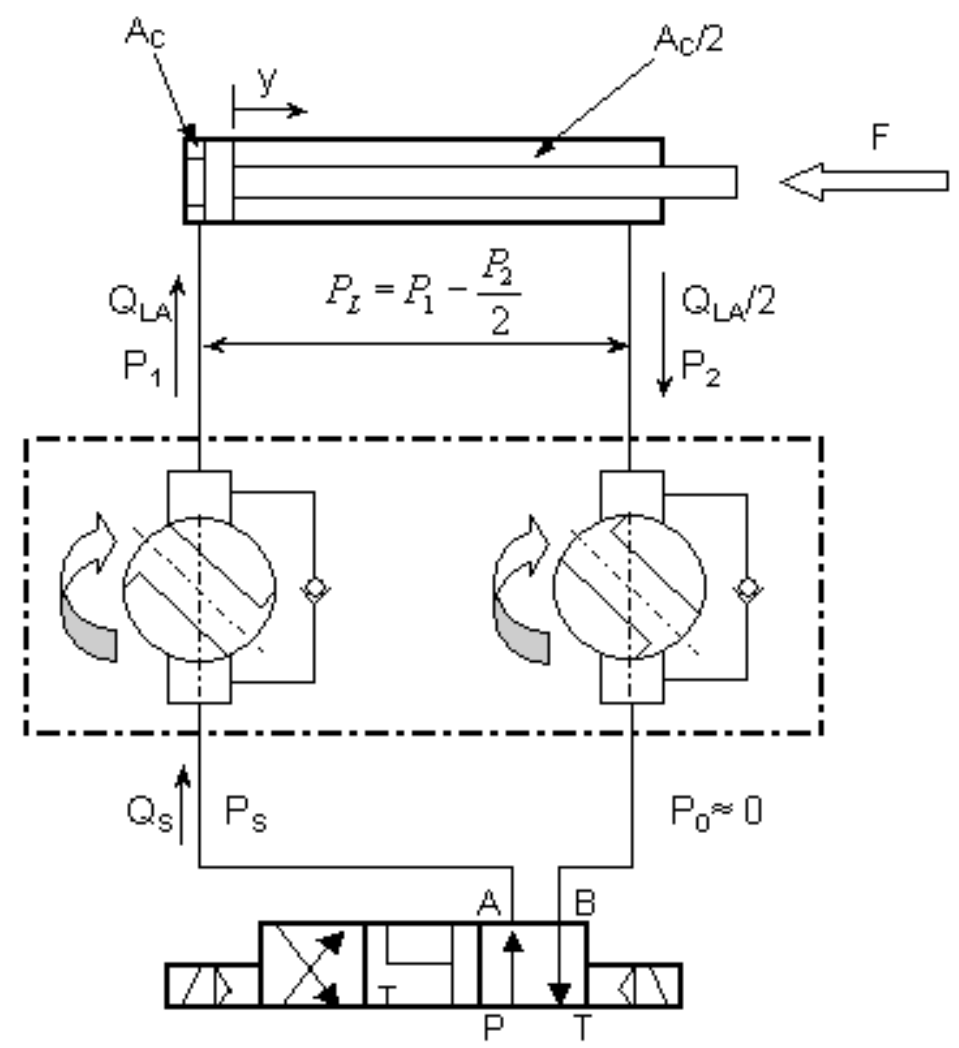

Figura 4.11 - Grandezas envolvidas no movimento de avanço

Considera-se que os vazamentos internos da válvula de freio são desprezíveis, logo, $\mathrm{Q}_{\mathrm{S}}=\mathrm{Q}_{\mathrm{L}}$. A força de atrito também é desprezada uma vez que o movimento ocorre sobre guias lineares de baixíssimo coeficiente de atrito.

Pode-se estabelecer o seguinte equilíbrio de forças durante o movimento de avanço no cilindro hidráulico sendo $\mathrm{A}_{\mathrm{C}}$ igual à área do êmbolo do cilindro:

$$
P_{1} A_{C}-P_{2} \frac{A_{C}}{2}=F
$$

Estabelecendo $P_{L}=\frac{F}{A_{C}}$ e combinando com 4.14 vem:

$$
P_{L}=P_{1}-\frac{P_{2}}{2}
$$


Combinado-se 4.12, 4.13 e 4.15 e considerando $\mathrm{P}_{0}=0$ obtém-se:

$$
Q_{L A}=\frac{4}{3} C_{d} A \sqrt{\frac{\left(P_{S}-P_{L}\right)}{\rho}}
$$

Para o movimento de recuo do cilindro pode-se definir a situação conforme figura 4.12. Considerando o vazamento interno da válvula desprezível tem-se que $\mathrm{Q}_{\mathrm{S}}=\mathrm{Q}_{\mathrm{LR}} / 2$.

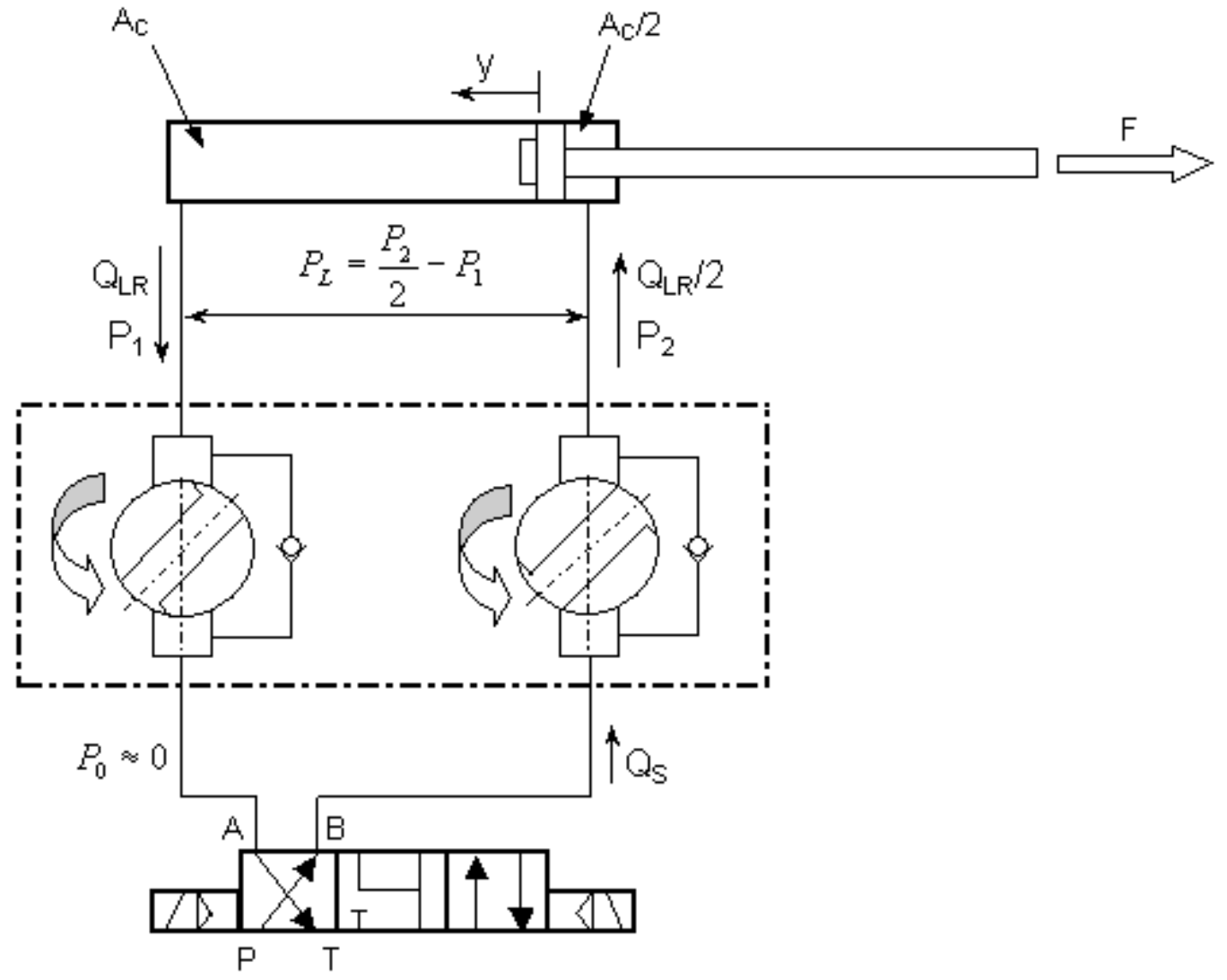

Figura 4.12 - Grandezas envolvidas no movimento de recuo

Seguindo o mesmo raciocínio empregado no movimento de avanço obtém-se as equações para o movimento de recuo:

$$
F=P_{2} \frac{A_{C}}{2}-P_{1} A_{C}
$$


Como por definição $P_{L}=\frac{F}{A_{C}}$ vem:

$$
P_{L}=\frac{P_{2}}{2}-P_{1}
$$

Da figura 4.12, utilizando-se a equação de vazão através de um furo tem-se:

$$
\begin{aligned}
& Q_{L R}=C_{d} A \sqrt{\frac{2\left(P_{1}-P_{0}\right)}{\rho}} \\
& \frac{Q_{L R}}{2}=C_{d} A \sqrt{\frac{2\left(P_{S}-P_{2}\right)}{\rho}}
\end{aligned}
$$

Combinando 4.18, 4.19 e 4.20 vem

$$
Q_{L R}=\frac{4}{3} C_{d} A \sqrt{\frac{\left(\frac{P_{S}}{2}-P_{L}\right)}{\rho}}
$$

Estabelecendo valores pode-se visualizar graficamente o resultado das equações 4.16 e 4.21. No gráfico da figura 4.13 estão representadas duas curvas de vazão ao longo do deslocamento sendo, $\mathrm{Q}_{\mathrm{LA}}$ a vazão para o movimento de avanço e $\mathrm{Q}_{\mathrm{LR}}$ para o movimento de recuo do cilindro. Os valores utilizados para o cálculo da vazão, QLA do movimento de avanço estão relacionados a seguir:

$$
\begin{aligned}
& \mathrm{P}_{\mathrm{S}}=8 \times 10^{6}\left[\mathrm{~N} / \mathrm{m}^{2}\right] \\
& \mathrm{P}_{1}=2,8 \times 10^{6}\left[\mathrm{~N} / \mathrm{m}^{2}\right] \\
& \mathrm{P}_{2}=1,4 \times 10^{6}\left[\mathrm{~N} / \mathrm{m}^{2}\right]
\end{aligned}
$$




$$
\begin{aligned}
\rho & =881\left[\mathrm{~kg} / \mathrm{m}^{3}\right] \\
\mathrm{C}_{\mathrm{d}} & =0,65
\end{aligned}
$$

Para o cálculo da vazão $\mathrm{Q}_{\mathrm{LR}}$ do movimento de recuo, as pressões $\mathrm{P}_{1}$ e $\mathrm{P}_{2}$ nas câmaras do cilindro são modificadas devido à inversão do movimento, isto é, P2 passa a ter o maior valor, pois o lado da haste do cilindro está ligado agora à linha de pressão do sistema. Para esta simulação, o valor de $\mathrm{P}_{2}$ é considerado o dobro do valor de $\mathrm{P}_{1}$. Assim, temos os seguintes valores no cálculo da vazão $Q_{\text {LR }}$ do movimento de recuo:

$$
\begin{aligned}
& \mathrm{P}_{\mathrm{S}}=8 \times 10^{6}\left[\mathrm{~N} / \mathrm{m}^{2}\right] \\
& \mathrm{P}_{1}=2,8 \times 10^{6}\left[\mathrm{~N} / \mathrm{m}^{2}\right] \\
& \mathrm{P}_{2}=5,6 \times 10^{6}\left[\mathrm{~N} / \mathrm{m}^{2}\right] \\
& \rho=881\left[\mathrm{~kg} / \mathrm{m}^{3}\right] \\
& \mathrm{C}_{\mathrm{d}}=0,65
\end{aligned}
$$

A área de passagem " $A$ " é obtida conforme equação 4.11 com os valores considerados na obtenção da figura 4.10 . 


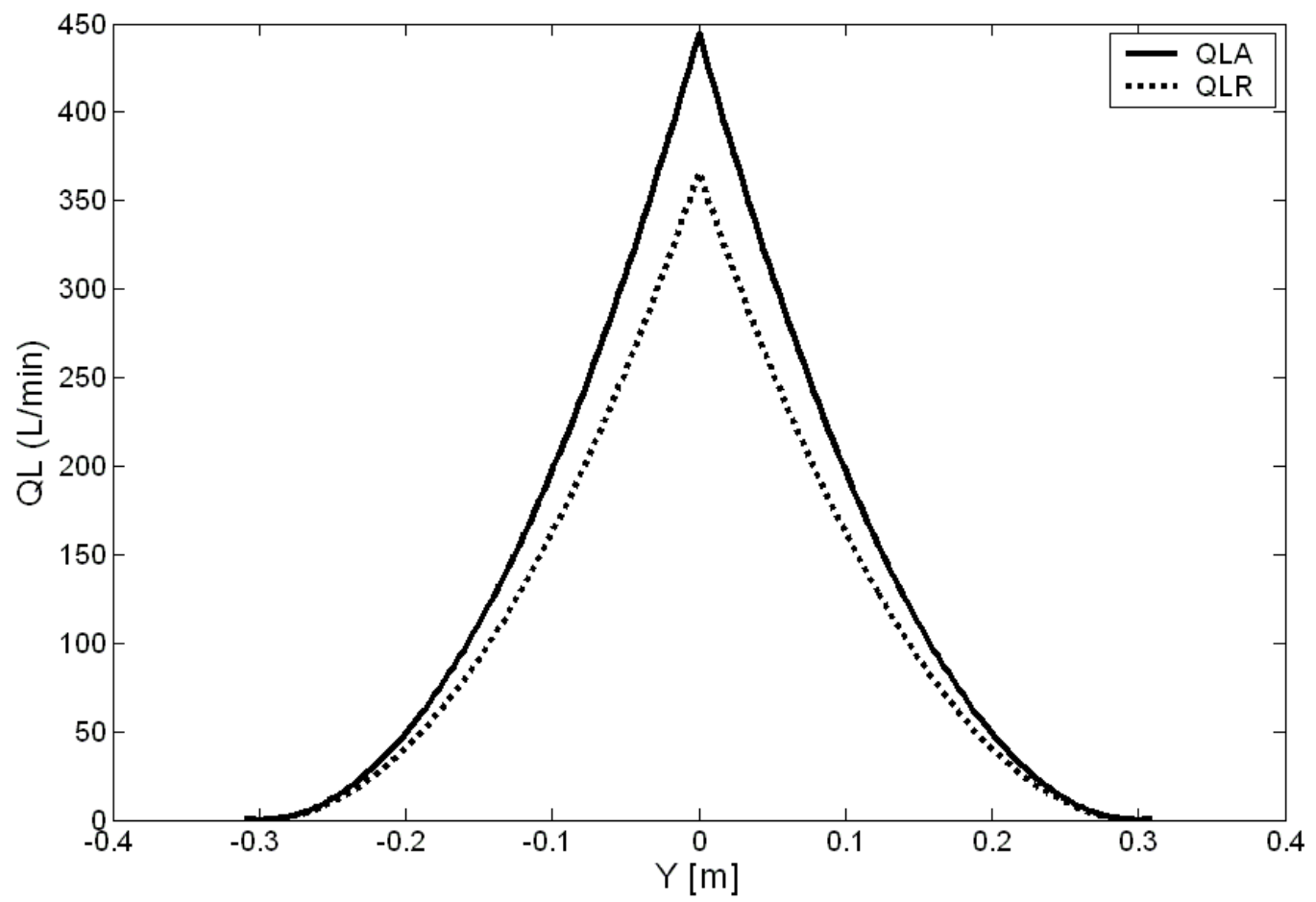

Figura 4.13 - Curvas de Vazão x Curso de Deslocamento para os movimentos de avanço e recuo.

QLA - Vazão para o movimento de avanço

$\mathrm{Q}_{\mathrm{LR}}$ - Vazão para o movimento de recuo

A velocidade de movimento é obtida pela relação entre a vazão e a área do êmbolo do cilindro $\left(\mathrm{A}_{\mathrm{C}}\right)$. Para um cilindro com diâmetro de êmbolo igual a 5,08 x $10^{-2}[\mathrm{~m}]$ as curvas da figura 4.14 são registradas. Vale ressaltar que a curva $\mathrm{V}_{\mathrm{A}}$ é para o movimento de avanço e a curva $\mathrm{V}_{\mathrm{R}}$ é para o movimento de recuo do carro. Logo:

$$
\begin{gathered}
V_{A}=\frac{Q_{L A}}{A_{C}} \\
V_{R}=\frac{Q_{L R}}{A_{C}}
\end{gathered}
$$




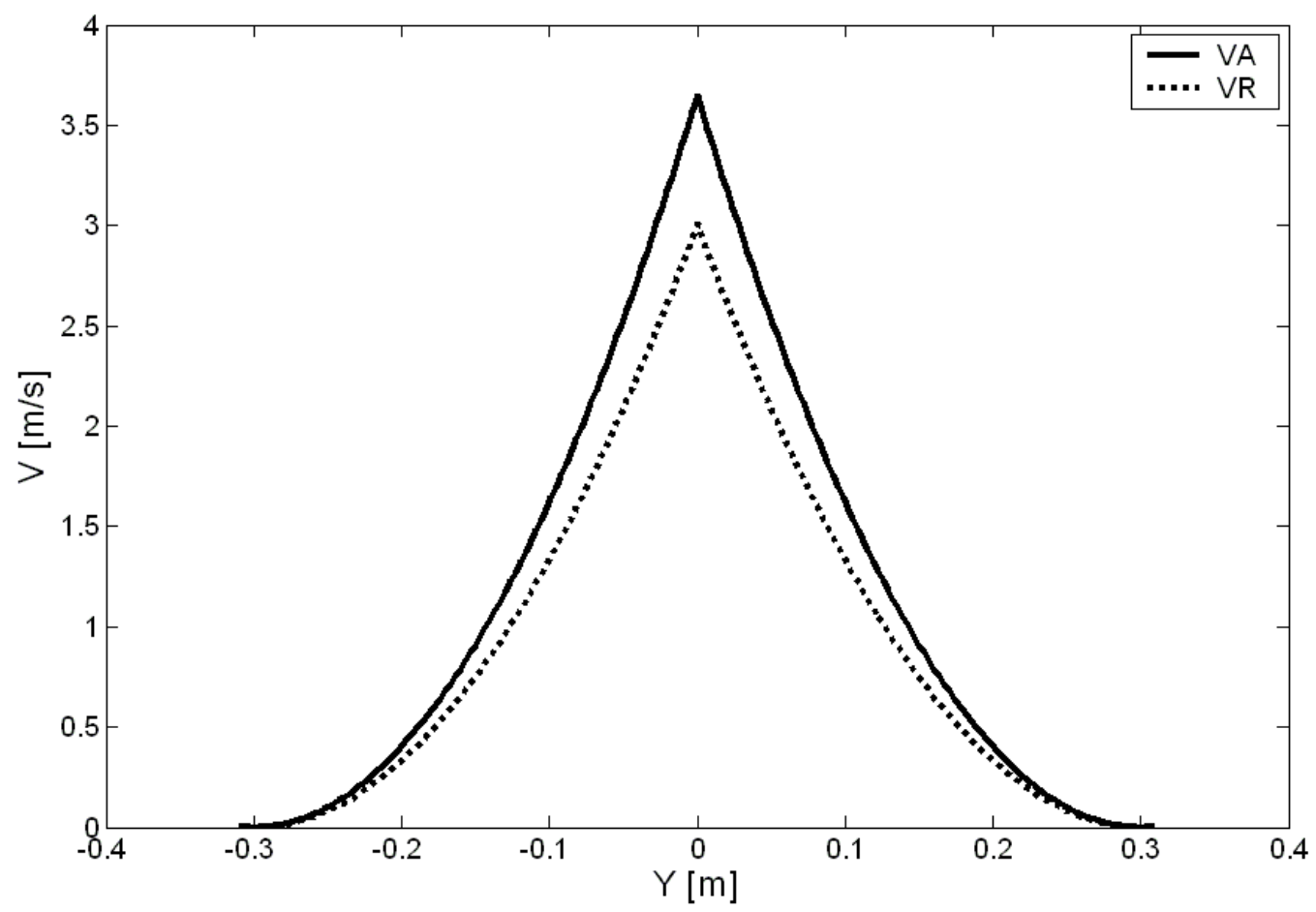

Figura 4.14 - Curvas de Velocidade x Curso de Deslocamento para os movimentos de avanço e recuo.

$\mathrm{V}_{\mathrm{A}}$ - Velocidade de Avanço

$\mathrm{V}_{\mathrm{R}}-$ Velocidade de Recuo

Nota-se a partir das curvas de velocidade que a dinâmica para os movimentos de avanço e recuo é diferente. Devido à relação de volumes entre as câmaras do cilindro diferencial considerado, o movimento de avanço está sujeito a uma maior aceleração/desaceleração que ocasiona uma maior velocidade máxima e conseqüentemente um movimento realizado em menor intervalo de tempo em relação ao movimento de recuo.

Outro ponto importante para a caracterização da válvula de freio é a definição dos coeficientes a ela relacionados.

Definem-se assim os seguintes coeficientes:

$$
\mathrm{C}_{\mathrm{X}}-\text { Coeficiente de Vazão }=\frac{\partial Q_{L}}{\partial x}
$$




$$
\begin{gathered}
\mathrm{C}_{\mathrm{P}}-\text { Coeficiente de Vazão-Pressão }=\frac{\partial Q_{L}}{\partial P_{L}} \\
\mathrm{~K}_{\mathrm{P}}-\text { Sensibilidade de Pressão }=\frac{\partial P_{L}}{\partial x}=\frac{C_{X}}{C_{P}}
\end{gathered}
$$

Pode-se definir estes coeficientes tanto para o movimento de avanço quanto de recuo do cilindro, do mesmo modo realizado anteriormente para as curvas de vazão e velocidade. Os coeficientes com índice "1" utilizam uma pressão de carga $\mathrm{P}_{\mathrm{L} 1}$ e os coeficientes com índice “2” uma pressão de carga $\mathrm{P}_{\mathrm{L} 2}$.

As equações dos coeficientes de vazão $\mathrm{C}_{\mathrm{XA}}$ e $\mathrm{C}_{\mathrm{XR}}$ são indicadas abaixo:

$$
\begin{gathered}
C_{X A}=\frac{4 C_{d} b(|x|-a)}{3 a} \sqrt{\frac{\left(P_{S}-P_{L}\right)}{\rho}}-\text { Coeficiente de vazão para o avanço } \\
C_{X R}=\frac{4 C_{d} b(|x|-a)}{3 a} \sqrt{\frac{\left(\frac{P_{S}}{2}-P_{L}\right)}{\rho}} \text { - Coeficiente de vazão para o recuo }
\end{gathered}
$$

Graficamente tem-se a figura 4.15 considerando os mesmos valores envolvidos para o cálculo das curvas de vazão. 


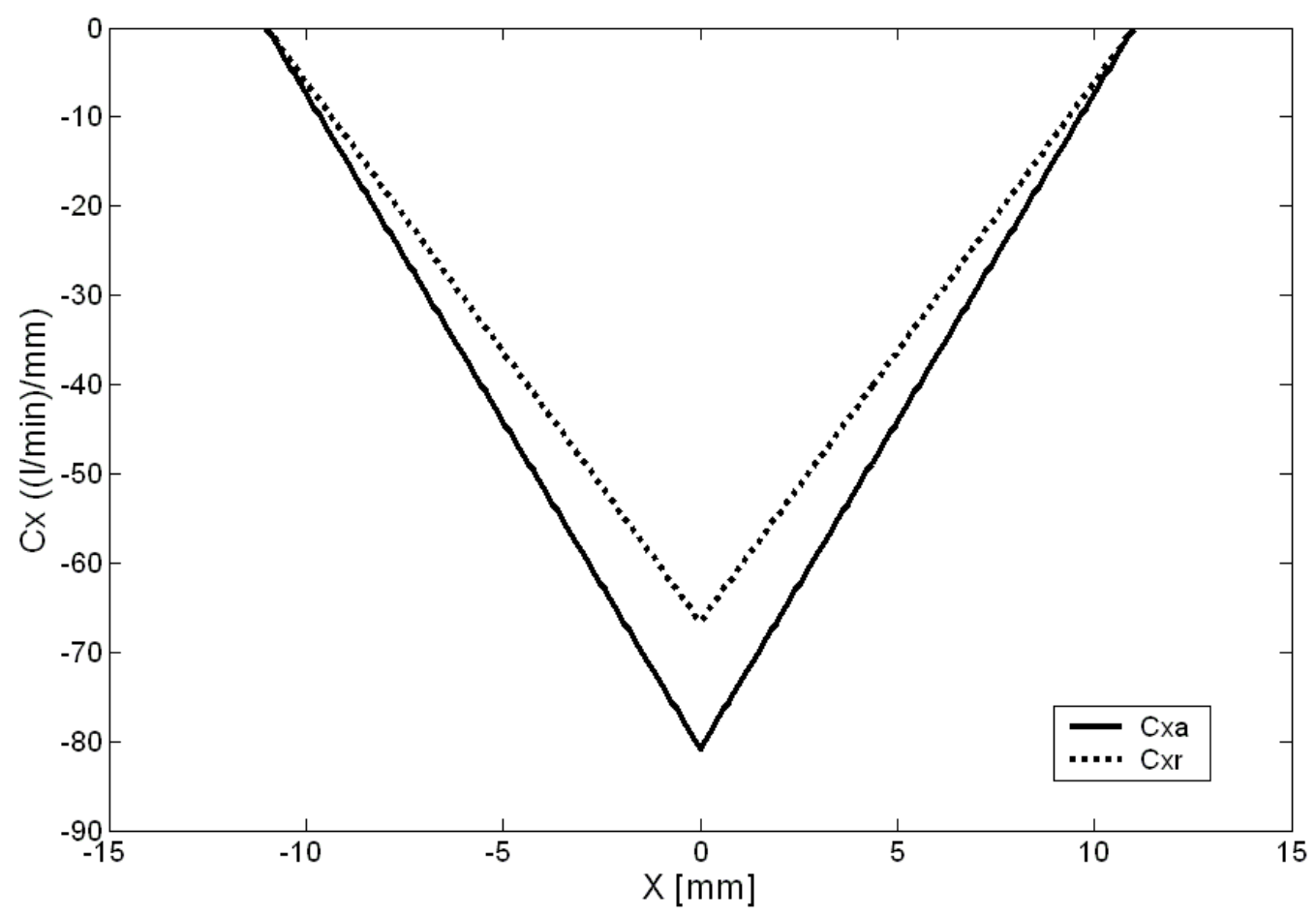

Figura 4.15 - Curvas do coeficiente de vazão para os movimentos de avanço e recuo.

Cxa - Coeficiente de vazão para o movimento de avanço $\mathrm{Cxr}$ - Coeficiente de vazão para o movimento de recuo

Do mesmo modo pode-se determinar as equações do coeficiente de vazão-pressão:

$$
\begin{gathered}
C_{P A}=-\frac{2}{3} C_{d} A \sqrt{\frac{1}{\rho\left(P_{S}-P_{L}\right)}} \quad \text { - Coeficiente vazão-pressão para o avanço } \\
C_{P R}=-\frac{2}{3} C_{d} A \sqrt{\frac{1}{\rho\left(\frac{P_{S}}{2}-P_{L}\right)}} \quad \text { - Coeficiente vazão-pressão para o recuo }
\end{gathered}
$$

Graficamente tem-se a representação da figura 4.16 considerando os mesmos valores envolvidos para o cálculo das curvas de vazão. 


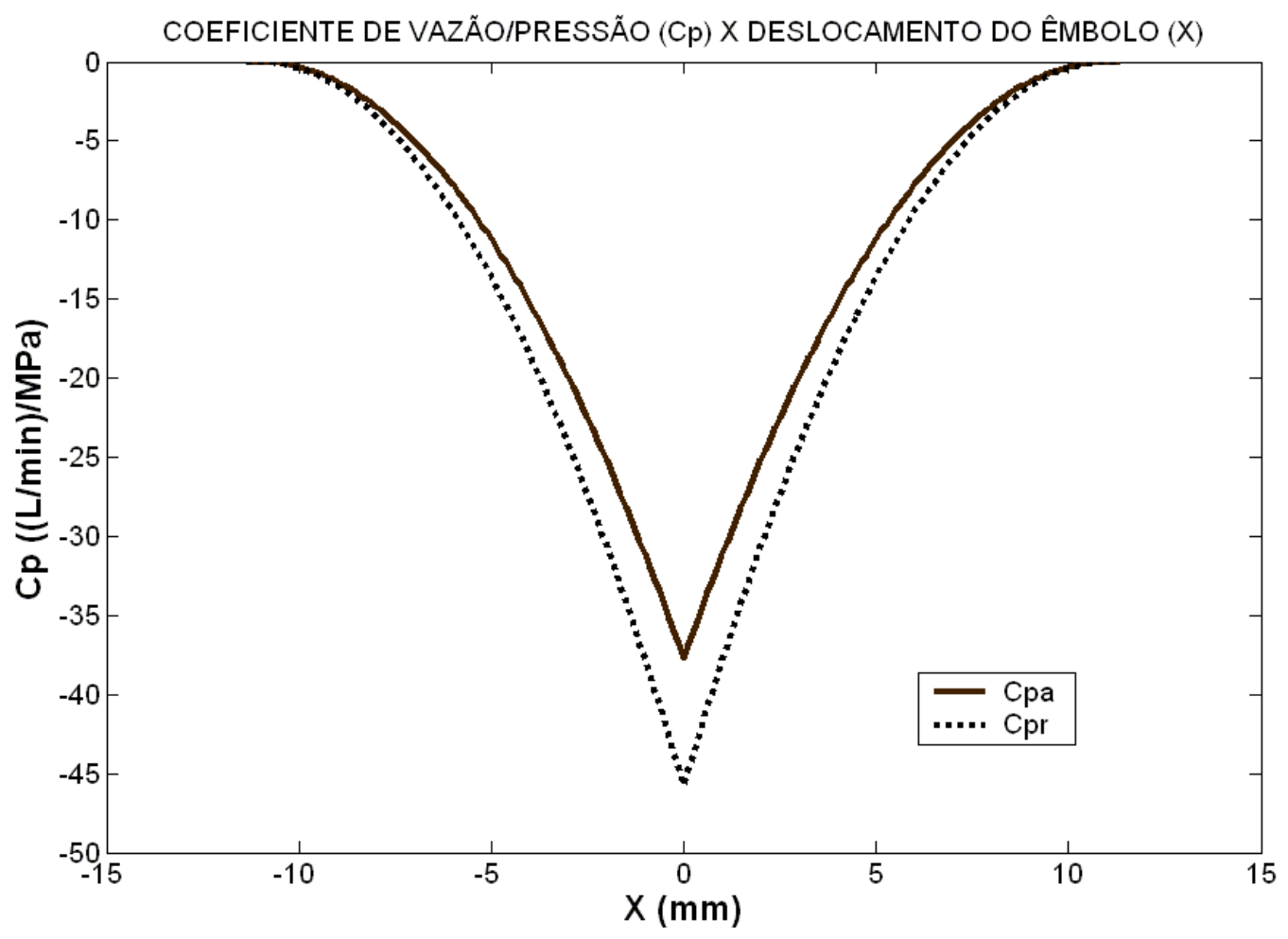

Figura 4.16 - Curvas do coeficiente de vazão-pressão para os movimentos de avanço e recuo. Cpa - Coeficiente de vazão-pressão para o movimento de avanço $\mathrm{Cpr}$ - Coeficiente de vazão pressão para o movimento de recuo

Por último, a sensibilidade de pressão pode ser estabelecida a partir dos coeficientes de vazão e vazão-pressão conforme segue:

$$
\begin{gathered}
K_{P A}=\frac{C_{X A}}{C_{P A}} \quad \text { - Sensibilidade de pressão para o avanço } \\
K_{P R}=\frac{C_{X R}}{C_{P R}} \quad \text { - Sensibilidade de pressão para o recuo }
\end{gathered}
$$

As figuras 4.17 e 4.18 mostram graficamente a variação da sensibilidade de pressão para ambos os sentidos de movimento respectivamente. 


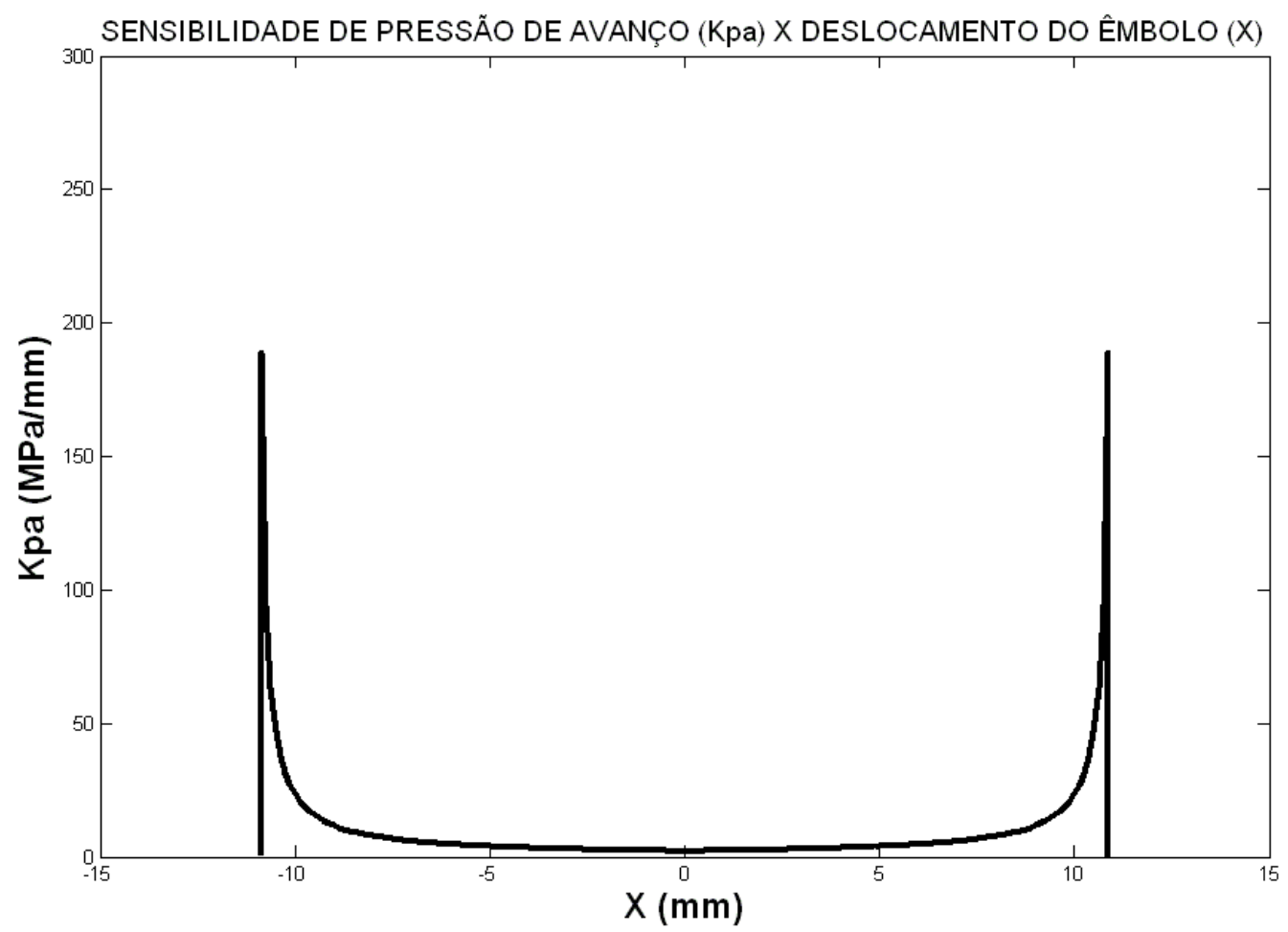

Figura 4.17 - Curva de sensibilidade de pressão para o movimento de avanço

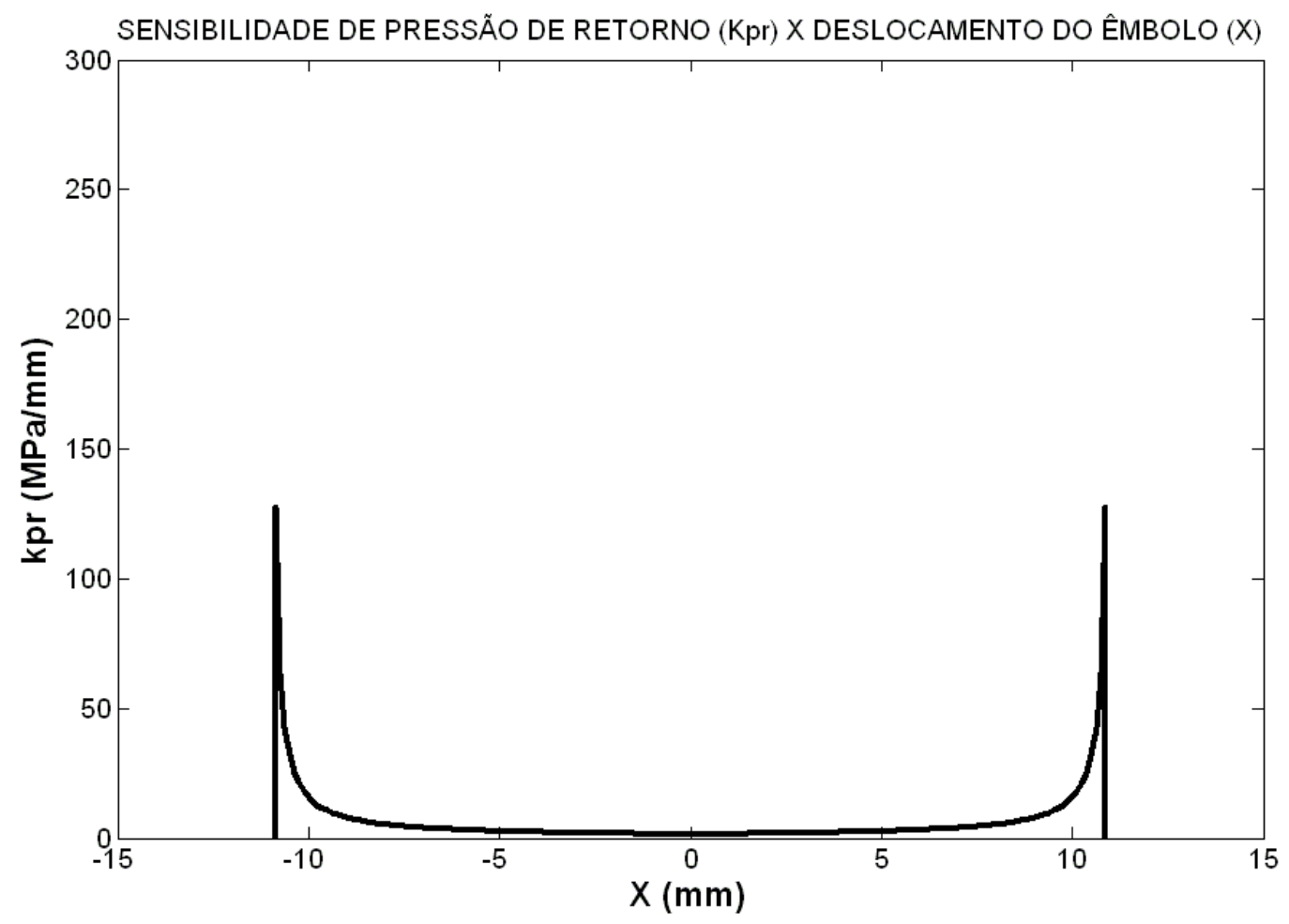

Figura 4.18 - Curva de sensibilidade de pressão para o movimento de recuo 
Comparando as curvas das figuras 4.17 e 4.18 confirma-se a conclusão extraída das curvas de velocidade (figura 4.14) de que o movimento de avanço está sujeito a maior aceleração e desaceleração e conseqüentemente, o tempo de duração deste movimento é menor que o tempo de duração do movimento de recuo. Os picos de pressão indicados nas curvas de sensibilidade ocorrem justamente no limite de abertura e fechamento da válvula de freio, posições estas equivalentes aos momentos iniciais e finais de movimento. Nota-se que na curva de movimento de avanço a amplitude destes picos é maior em relação à curva de recuo.

Uma possibilidade para melhorar a dinâmica do movimento de recuo, tornando-a similar à dinâmica do movimento de avanço, é aumentar a pressão de alimentação Ps. As curva da figura 4.13 foi obtida com o valor de $P s=8 \times 10^{6}\left[\mathrm{~N} / \mathrm{m}^{2}\right]$ e a figura 3.19 simula a vazão obtida para o movimento de recuo com pressão de alimentação Ps $=13 \times 10^{6}\left[\mathrm{~N} / \mathrm{m}^{2}\right]$. Verifica-se nesta figura o aumento da vazão máxima em relação à curva de vazão, QLR, do movimento de recuo obtida na figura 4.13.

Como conseqüência, a velocidade do movimento de recuo $\left(V_{R}\right)$ também aumenta indicando a realização do movimento de recuo em menor tempo. Os picos obtidos nos extremos da curva de sensibilidade de pressão $\left(\mathrm{K}_{\mathrm{PR}}\right)$ também tem a amplitude aumentada indicando maiores valores de aceleração e desaceleração ao longo do movimento. As figuras 4.20 e 4.21 mostram este aumento de desempenho quando comparadas respectivamente com as curvas 4.14 e 4.18 . 


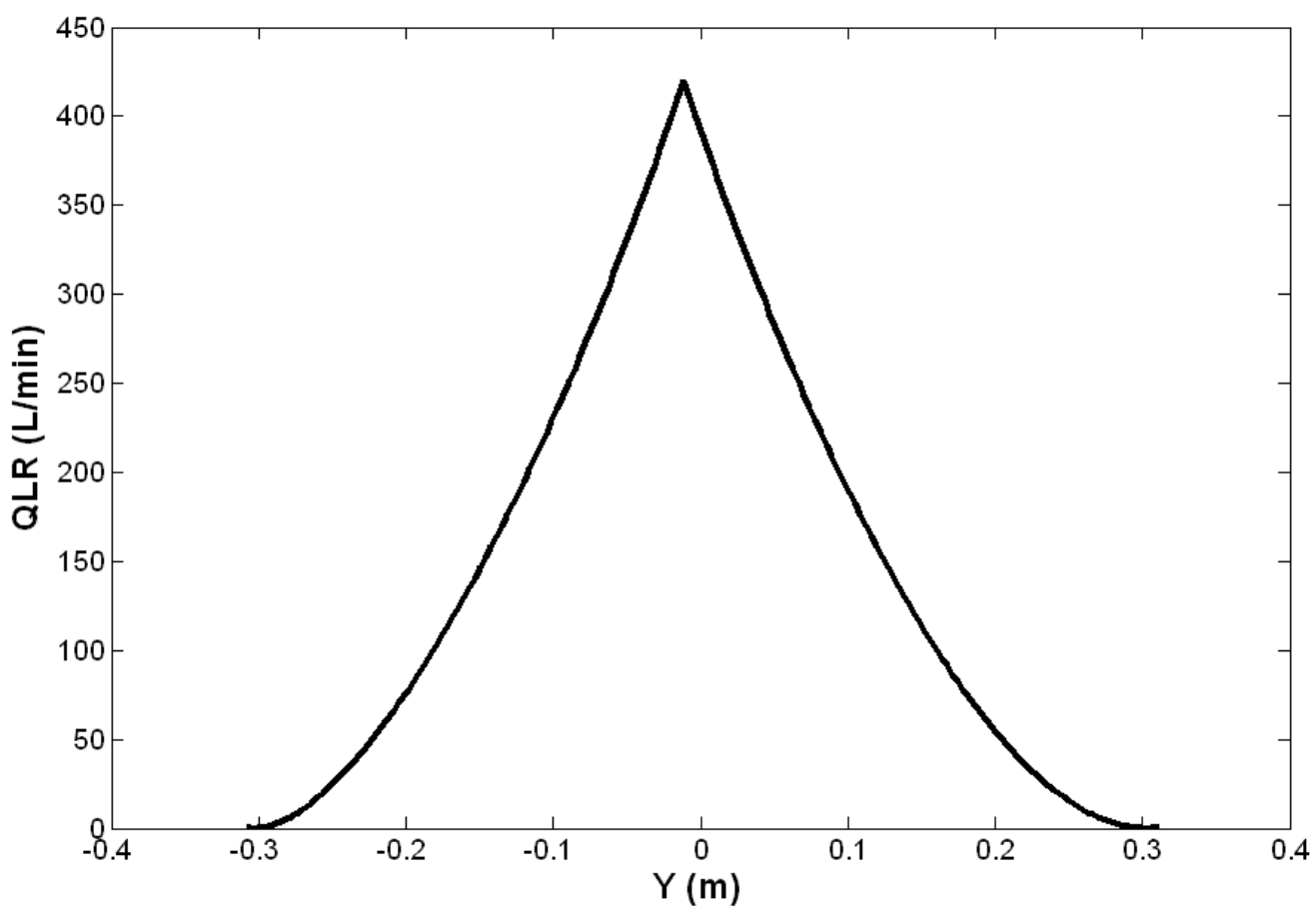

Figura 4.19 - Curva de vazão para o movimento de recuo $\left(\mathrm{Q}_{\mathrm{LR}}\right)$ com pressão de alimentação Ps $=13[\mathrm{MPa}]$.

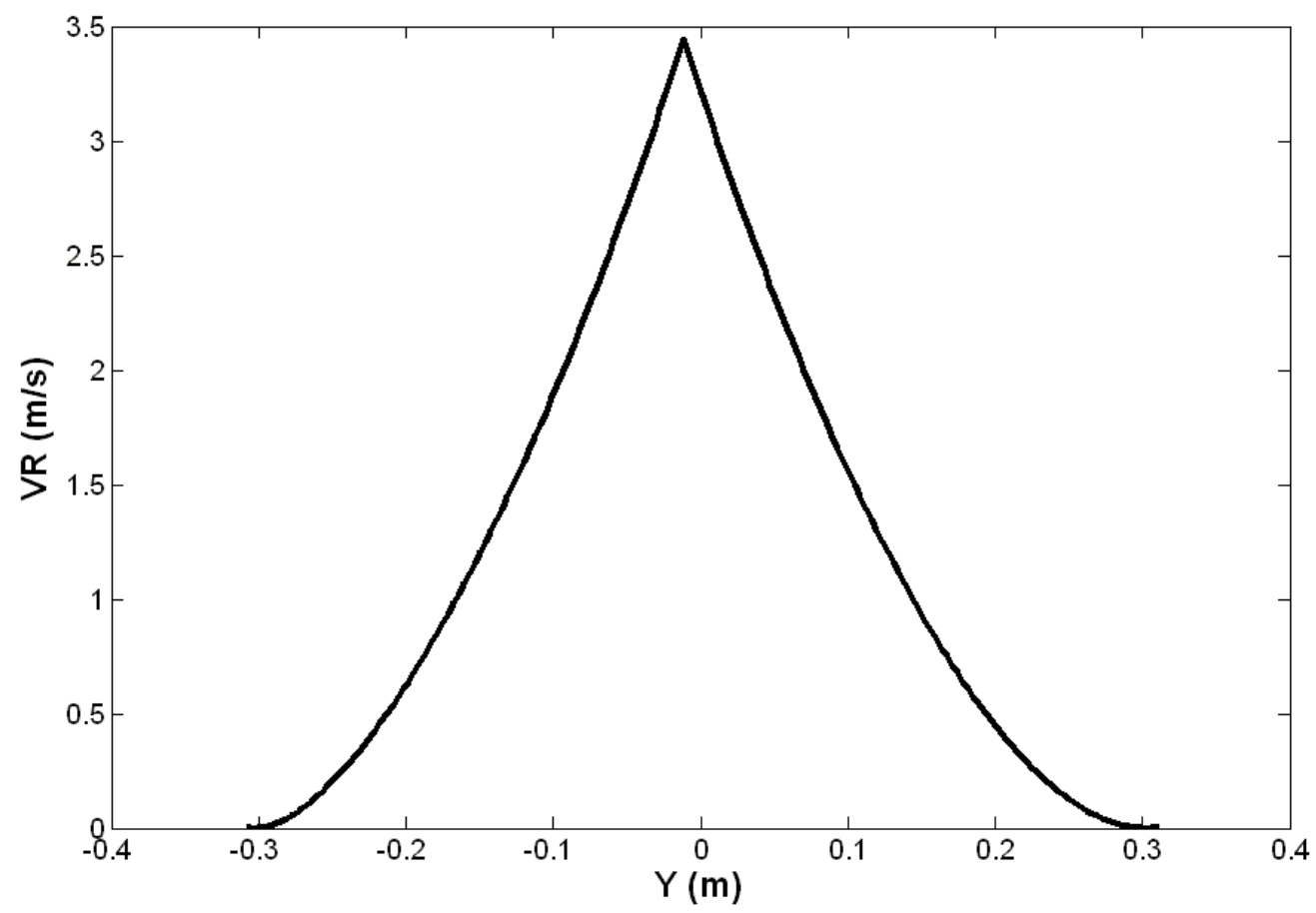

Figura 4.20 - Curva de velocidade para o movimento de recuo $\left(\mathrm{V}_{\mathrm{R}}\right)$ com pressão de alimentação Ps = $13[\mathrm{MPa}]$. 


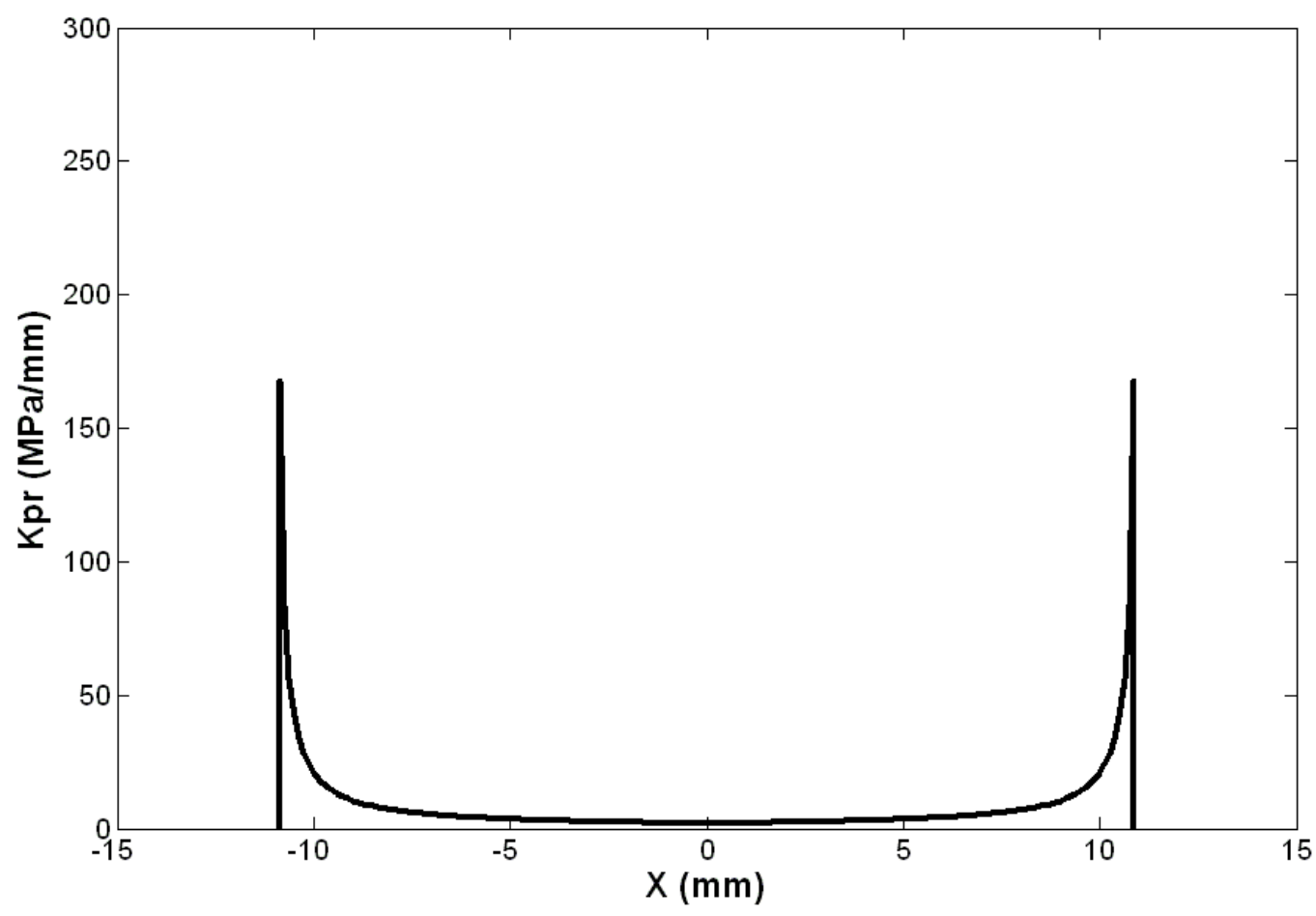

Figura 4.21 - Curva de sensibilidade de pressão para o recuo $\left(\mathrm{K}_{\mathrm{PR}}\right)$ com pressão de alimentação Ps = $13 \mathrm{MPa}$.

\subsection{Movimento de Abertura/Fechamento do Molde}

O movimento de abertura/fechamento do molde é controlado por uma válvula direcional proporcional que possui um desenho de êmbolo com característica de regeneração conforme demonstrado no item 3.4.2. Esta válvula controla a direção e vazão de óleo enviada a um cilindro hidráulico cuja função é realizar os movimentos de abertura e fechamento de molde através de dois braços simétricos e bielas. Este mecanismo está indicado na figura 3.5 .

Neste item, a malha de controle do movimento e os componentes envolvidos são detalhados. 


\subsection{1 - Malha de Controle}

A malha de controle do movimento de abertura/fechamento do molde realizado pelo mecanismo da figura 3.5 está indicada na figura 4.22.

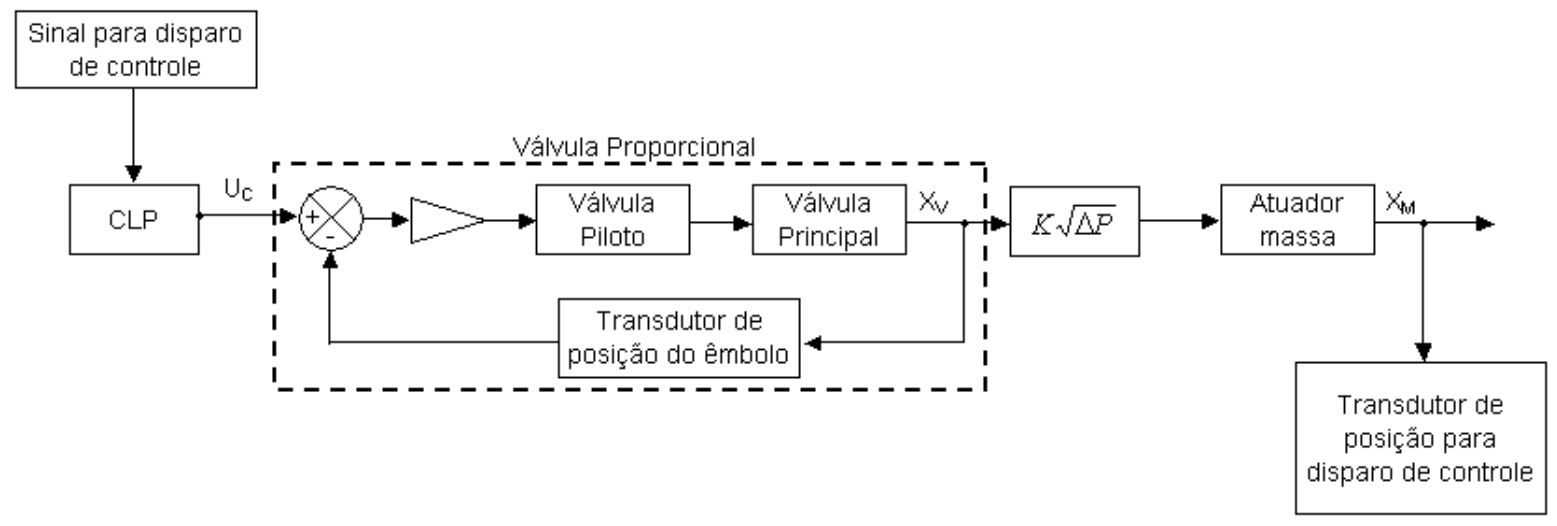

Figura 4.22 - Malha de controle do movimento de abertura/fechamento do molde

Um sinal de entrada é gerado por um controlador lógico programável (CLP). Este é um sinal analógico de tensão $\left(\mathrm{U}_{\mathrm{C}}\right)$ na faixa de $-10 \mathrm{~V} \leq \mathrm{U}_{\mathrm{C}} \leq+10 \mathrm{~V}$, programado conforme indicado na figura abaixo.

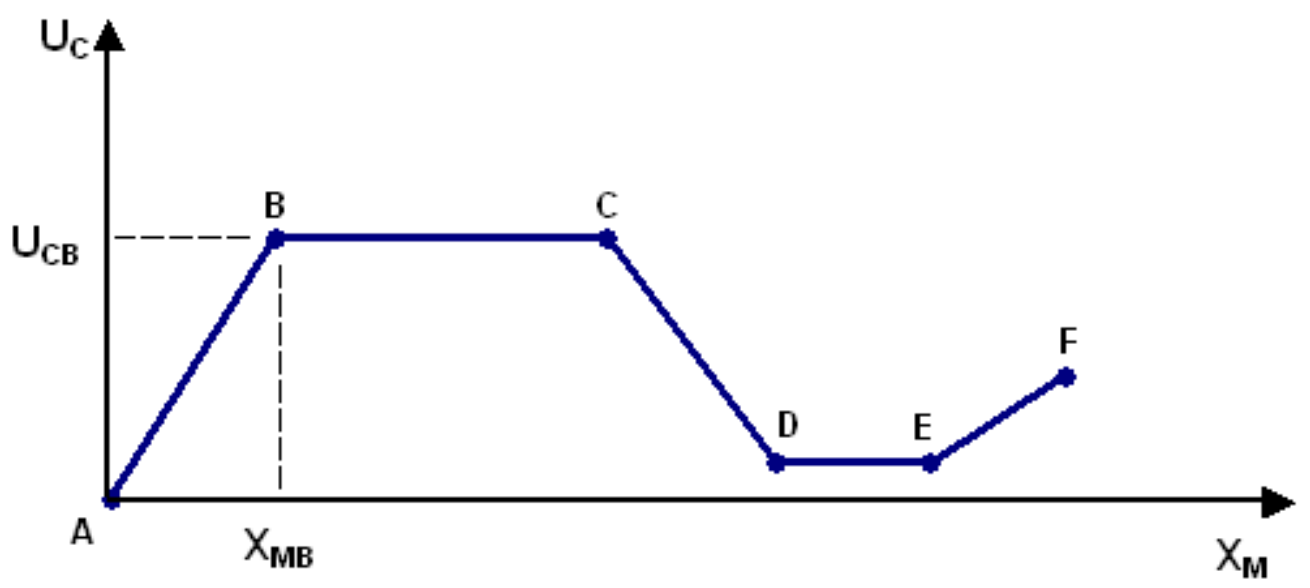

Figura 4.23 - Curva de programação do perfil do sinal de entrada 
O perfil do sinal de entrada é programado a partir da determinação de alguns pontos mestres. Estes pontos mestres estão indicados na figura 4.23 com as letras de "A" até "F". Determina-se para cada ponto as coordenadas $\left(\mathrm{X}_{\mathrm{M}} ; \mathrm{U}_{\mathrm{C}}\right)$ sendo, $\mathrm{X}_{\mathrm{M}}$ a coordenada de posição da massa e $\mathrm{U}_{\mathrm{C}}$ a tensão enviada como sinal de entrada na válvula proporcional na coordenada de posição $\mathrm{X}_{\mathrm{M}}$. Entre dois pontos mestres subseqüentes a lógica estabelecida no controlador interpola linearmente. Por exemplo, no início do movimento a massa está posicionada no ponto "A" e ao ser dado um comando de avanço da massa, ela será conduzida pelo atuador até o ponto " $F$ " passando pelos demais pontos intermediários. Entre os pontos "A" e "B" o movimento será acelerado com a manutenção de uma velocidade máxima constante até o ponto "C" e logo após ocorre uma frenagem com término no ponto "D". No final da curva entre os pontos "D" e "F" existe a possibilidade de programação de uma rampa residual com a função de facilitar a formação de alguns tipos de artigo soprados, ou seja, é um recurso relacionado ao processo de sopro.

A válvula proporcional determina a direção do movimento (avanço ou recuo) e também a vazão enviada ao atuador imprimindo assim velocidade a este e realizando conseqüentemente o posicionamento da massa. Esta vazão é modulada pelo sinal de entrada conforme indicado anteriormente determinando toda a dinâmica do movimento. Há ainda um transdutor que informa ao controlador a posição real da massa porém, vale ressaltar que este sinal não é comparado com o sinal de entrada, isto é, não existe uma malha de controle fechada entre a posição da massa e o perfil do sinal de entrada. O sinal do transdutor serve apenas para determinar a coordenada de posição para o perfil do sinal de entrada. Existe apenas uma malha de controle fechada internamente na válvula proporcional conforme está explicado no próximo tópico. 


\subsection{2 - Válvula Proporcional}

O tipo de válvula direcional proporcional mais utilizado emprega um êmbolo deslizante como forma de controle da direção do fluxo de óleo. Este tipo construtivo normalmente é classificado por (a) número de vias pelas quais o fluxo de óleo pode circular através da válvula, (b) número de posições que o êmbolo pode assumir, (c) configuração do êmbolo na posição central. Devido ao fato de que uma válvula necessita uma via de alimentação de pressão, uma de retorno para tanque e uma ou duas vias para acionar a carga, as válvulas normalmente possuem de três a quatro vias. O número de posições varia também entre três e quatro, mas em válvulas especiais pode chegar até seis posições.

A figura 4.24 mostra esquematicamente uma válvula de quatro vias e três posições.

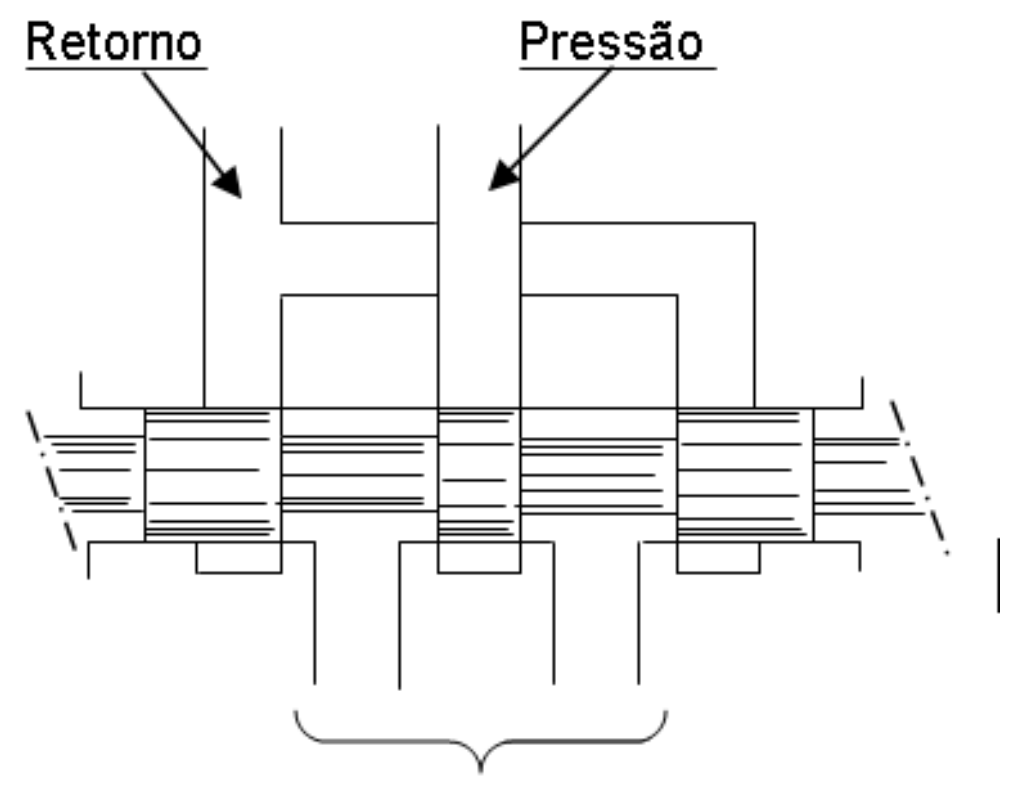

Para a carga

Figura 4.24 - Válvula direcional proporcional de 4 vias e 3 posições 
Se a largura da via de passagem é maior que a largura do ressalto equivalente no êmbolo, a válvula é denominada como centro aberto. Uma válvula com a mesma largura entre a via e o ressalto é dita como centro crítico e, por último, válvulas onde o ressalto tem largura maior que a via é classificada como centro fechado quando o êmbolo encontra-se na posição central. Certas características da válvula estão diretamente relacionadas com o seu tipo de centro. A característica mais importante é o coeficiente de vazão dado pela relação entre a vazão através da válvula e o curso de deslocamento do êmbolo.

A figura 4.25 mostra a influência do tipo de centro da válvula no coeficiente de vazão. Pode-se notar que para uma válvula com centro crítico existe uma relação linear entre vazão e curso do êmbolo em torno da posição neutra (central).

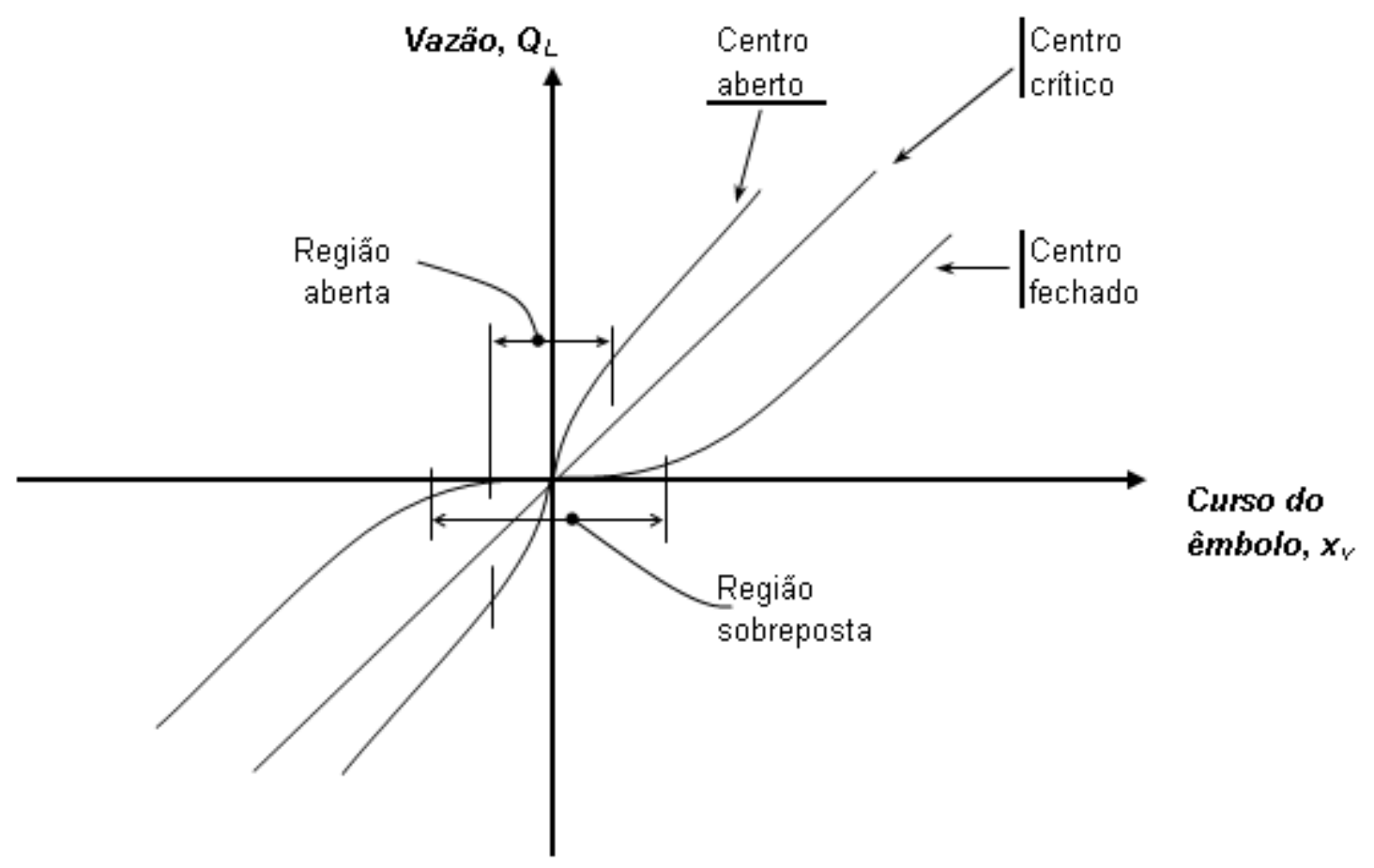

Figura 4.25 - Curvas de vazão para diferentes tipos de centro. (25) 
A figura 4.26 mostra um desenho em corte da válvula proporcional selecionada para este trabalho.

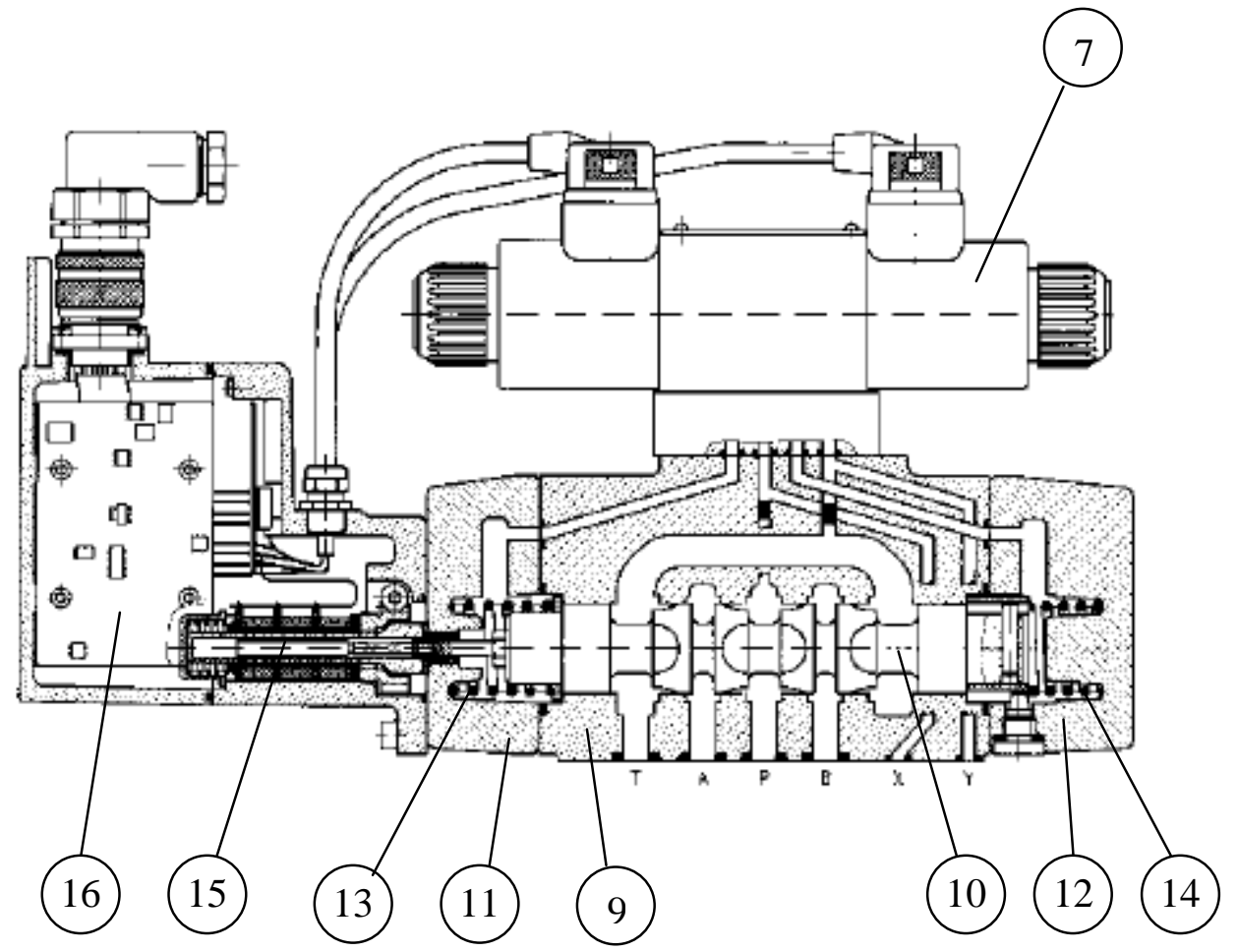

Figura 4.26 - Válvula proporcional do movimento de abertura/fechamento. (26)

Esta é uma válvula proporcional de dois estágios. Ela regula intensidade e direção de uma vazão. Nesta aplicação está considerada uma válvula proporcional de quatro vias e quatro posições de tamanho nominal 16 do fabricante Bosch Rexroth cujo código de referência é 4WRBKE-16 R5 180SJ 1X/6ZG24K31/A1.

Este tipo de válvula consiste basicamente da válvula piloto (7), carcaça (9), êmbolo principal (10), das tampas (11) e (12), molas (13) e (14) e sensor indutivo de curso (15).

O piloto (figura 4.27) é uma válvula proporcional de comando direto. Os solenóides proporcionais são para corrente contínua e atuam em banho de óleo. Eles convertem corrente elétrica proporcional em força mecânica. Um aumento na intensidade da corrente resulta numa maior força correspondente no solenóide. 
A válvula piloto é constituída da carcaça (1), solenóides proporcionais (2) e (3), do êmbolo (4) e molas (5) e (6).

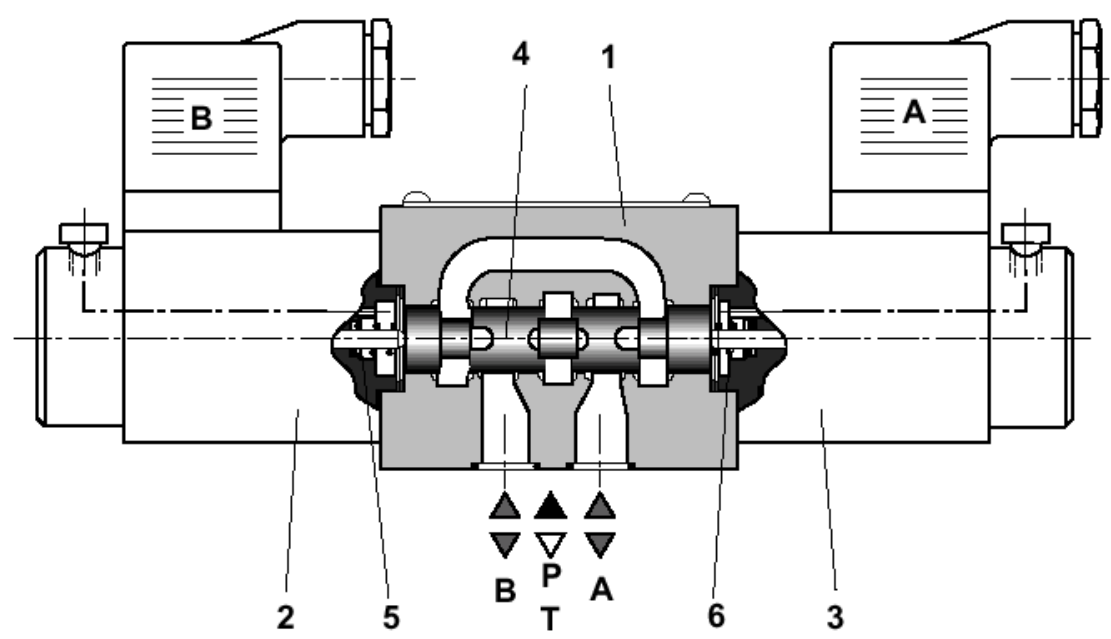

Figura 4.27 - Forma construtiva da válvula piloto. (26)

No estado desenergizado os dois consumidores estão interligados com a linha de tanque. Quando for energizado um dos solenóides, a força do mesmo desloca o êmbolo contra a mola. Após vencer a faixa de sobreposição fecha-se a passagem de um dos consumidores ao tanque e restabelece-se a interligação para a câmara de pressão. Assim passa uma vazão da linha de pressão para a câmara de comando do estágio principal.

Quando não houver nenhum sinal na entrada, o êmbolo principal (10) é mantido na posição central, através das molas (13) e (14). As duas câmaras de comando das tampas (11) e (12) são interligadas com a linha de tanque.

O êmbolo principal está ligado a uma eletrônica de comando apropriada (16), através do sensor indutivo de curso (15). Tanto a alteração do êmbolo principal, como também a alteração do valor programado no ponto de somatória do amplificador produzem uma tensão diferencial. 
Na comparação entre valor programado e valor real é constatado um desvio eventual de regulagem e passado isto ao solenóide proporcional da válvula piloto através de uma corrente elétrica.

A força proporcional a esta corrente desloca o êmbolo de comando, permitindo assim uma vazão correspondente em uma das câmaras de comando.

O êmbolo principal (10) com o núcleo do sensor indutivo afixado no mesmo (15) é deslocado, até que o valor real corresponda ao valor programado. No estado regulado há equilíbrio de forças no êmbolo principal (10) e o mesmo é mantido nesta posição regulada. O curso do êmbolo e a abertura de comando alteram-se proporcionalmente ao valor programado. Neste tipo de válvula a eletrônica de comando (16) é integrada à válvula e o seu esquema está detalhado na figura 4.28.

Conforme o código do fabricante pode-se determinar as principais características da válvula selecionada:

\section{WRBKE - 16 R5 180 S J-1X / 6Z G24 K31 / A1}

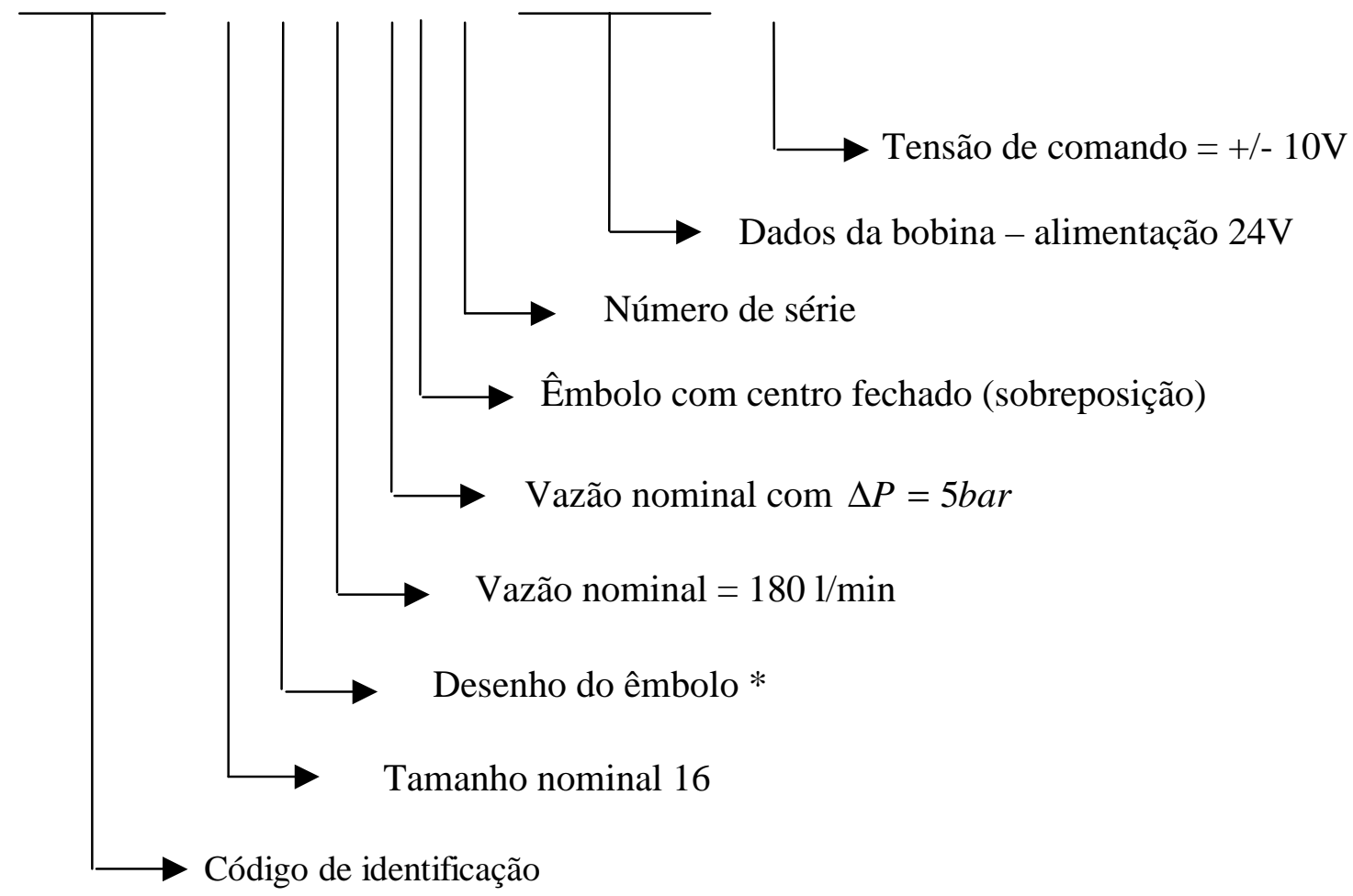


* Para o desenho de êmbolo tipo R5, a área dos pórticos de passagem não é simétrica. Este desenho de êmbolo foi desenvolvido para adequar a válvula ao trabalho com cilindro diferencial com relação de áreas 2:1. Neste caso, as áreas de passagem do êmbolo também possuem a relação 2:1 e as seguintes relações de vazão são válidas na válvula:

$$
\begin{aligned}
& P \text {---- } A=Q_{V} \\
& P \text {--- } B=Q_{V} / 2 \\
& A \text {--- } T=Q_{V} \\
& B \text {--- } T=Q_{v} / 2
\end{aligned}
$$

Sendo, $\quad \mathrm{Q}_{\mathrm{V}}=$ Vazão através da válvula proporcional.

O esquema da eletrônica de comando embarcada na válvula é visto na figura 4.28.

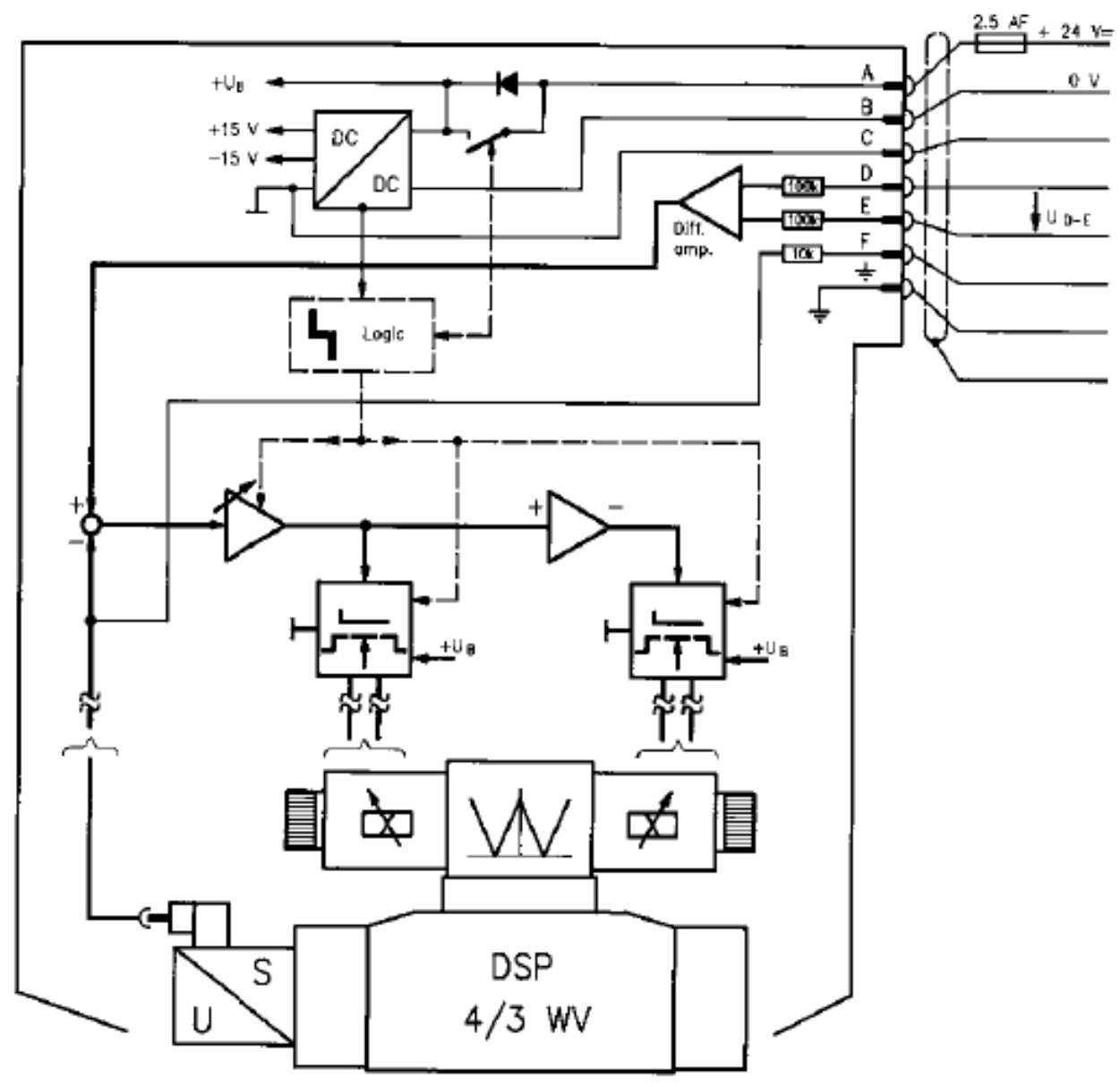

fonte zero referência sinal de entrada posição real terra

Figura 4.28 - Eletrônica de comando embarcada na válvula proporcional. (26) 
O mesmo modelamento realizado para o movimento do carro, envolvendo a válvula e o cilindro, pode ser feito para o movimento de abertura e fechamento de molde. A figura 4.29 indica as variáveis envolvidas para o avanço do cilindro, equivalente ao movimento de fechamento do molde.

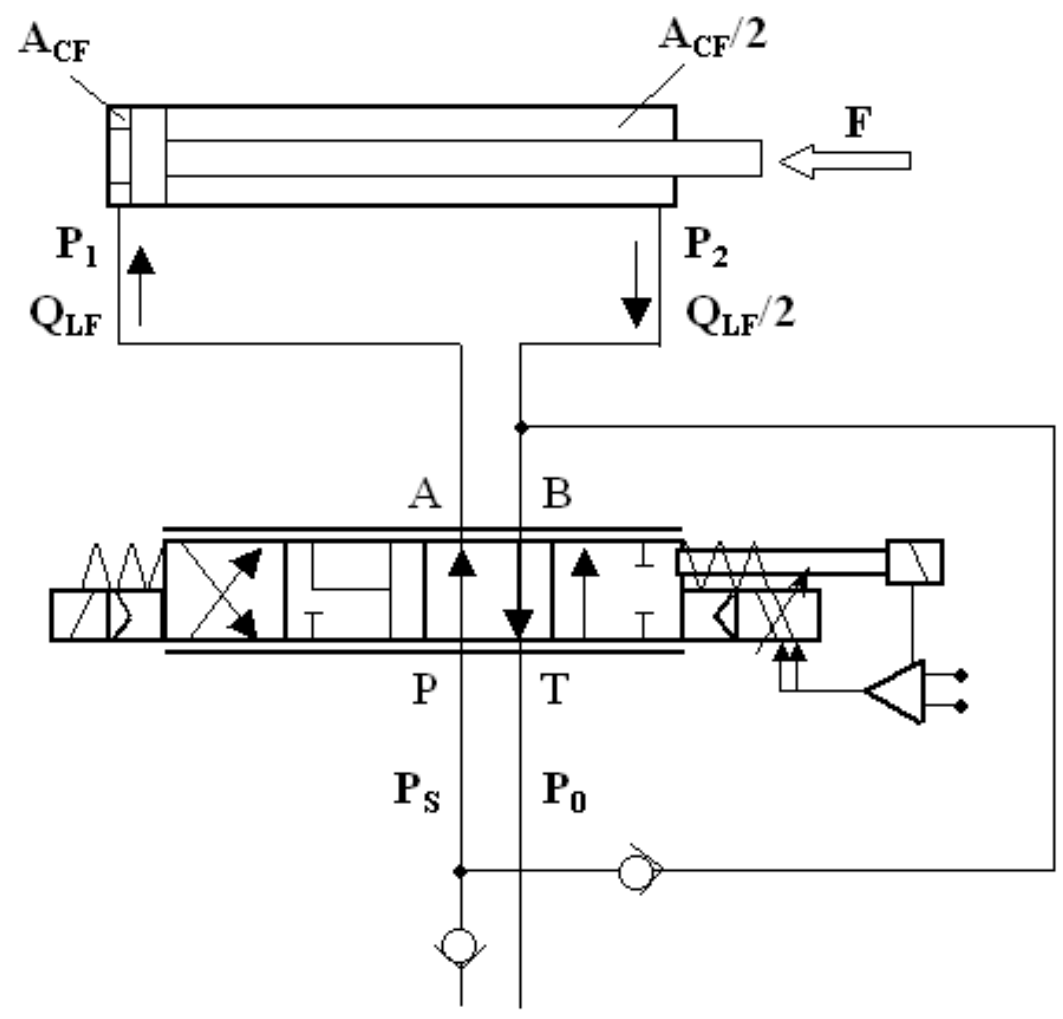

Figura 4.29 - Variáveis envolvidas no modelamento do movimento de fechamento.

A relação entre a área de passagem, diferencial de pressão e vazão controlada em uma válvula direcional proporcional está indicada nas equações abaixo. A equação 4.33 relaciona a vazão no lado do êmbolo e a equação 3.34 estabelece a vazão induzida no lado da haste do cilindro.

$$
Q_{L F}=C_{d} \cdot A_{A} \cdot \sqrt{\frac{2\left(P_{S}-P_{1}\right)}{\rho}}
$$




$$
\frac{Q_{L F}}{2}=C_{d} \cdot A_{B} \cdot \sqrt{\frac{2\left(P_{2}-P_{0}\right)}{\rho}}
$$

Sendo:

$\mathrm{Q}_{\mathrm{LF}}=$ Vazão de carga para o movimento de fechamento do molde

$\mathrm{C}_{\mathrm{d}}=$ Coeficiente de descarga

$\mathrm{A}_{\mathrm{A}}=$ Área de passagem do pórtico A da válvula

$\mathrm{A}_{\mathrm{B}}=$ Área de passagem do pórtico $\mathrm{B}$ da válvula

$P_{S}=$ Pressão de alimentação

$\mathrm{P}_{1}=$ Pressão da câmara do lado do êmbolo

$\mathrm{P}_{2}=$ Pressão da câmara do lado da haste

$\mathrm{P}_{0}=$ Pressão na linha de tanque

Porém, a válvula selecionada possui pórticos assimétricos e a seguinte relação construtiva é fornecida pelo fabricante:

$$
\mathrm{A}_{\mathrm{A}}=2 \mathrm{~A}_{\mathrm{B}}
$$

Combinando as equações $4.33,4.34$ e 4.35 temos:

$$
P_{2}=P_{S}-P_{1}
$$

Realizando a somatória de forças no cilindro temos a seguinte equação de equilíbrio: 
$P_{1} A_{C F}-P_{2} \frac{A_{C F}}{2}-F=0$

Sendo:

$\mathrm{A}_{\mathrm{CF}}=$ Área do êmbolo do cilindro de fechamento

$\mathrm{F}=$ Força externa a ser vencida pelo cilindro

Reordenando 4.37 vem:

$$
F=A_{C F}\left(P_{1}-\frac{P_{2}}{2}\right)
$$

Definindo $P_{L}=\frac{F}{A_{C F}}$, tem-se a seguinte relação

$$
P_{L}=\left(P_{1}-\frac{P_{2}}{2}\right)
$$

Onde:

$\mathrm{P}_{\mathrm{L}}=$ Pressão de carga

Combinando as equações 4.33, 4.36 e 4.39, tem-se a relação da vazão em função das pressões de alimentação e de carga para o movimento de fechamento do molde:

$$
Q_{L F}=C_{d} A_{A} \sqrt{\frac{4\left(P_{S}-P_{L}\right)}{3 \rho}}
$$


Para o recuo do cilindro, equivalente ao movimento de abertura do molde, pode-se visualizar através da figura 4.30 as variáveis envolvidas neste caso.

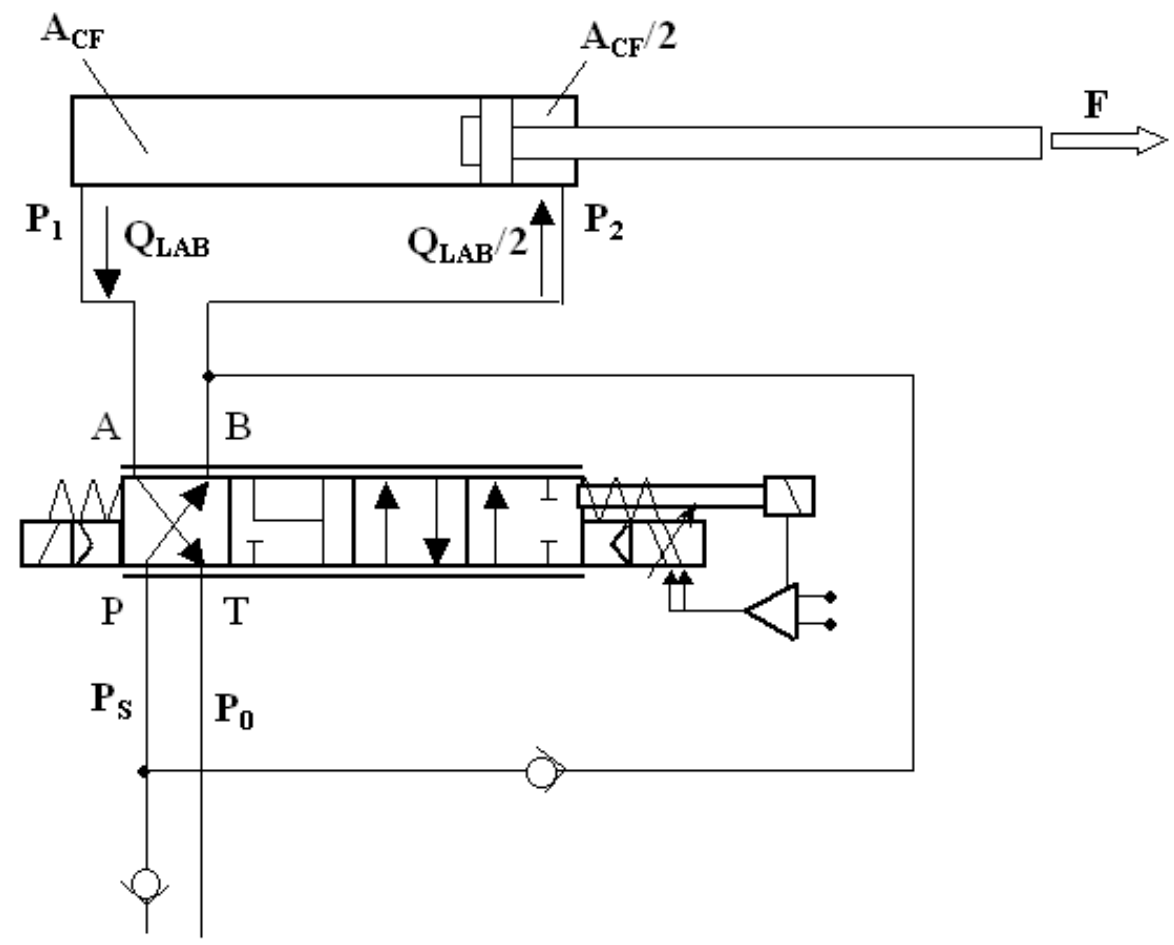

Figura 4.30 - Variáveis envolvidas no modelamento do movimento de abertura

A relação de vazão pode ser deduzida a partir da figura acima sendo, neste caso, a vazão induzida no lado do êmbolo do cilindro.

$$
\begin{gathered}
\frac{Q_{L A B}}{2}=C_{d} A_{B} \sqrt{\frac{2\left(P_{S}-P_{2}\right)}{\rho}} \\
Q_{L A B}=C_{d} A_{A} \sqrt{\frac{2\left(P_{1}-P_{0}\right)}{\rho}}
\end{gathered}
$$

Sendo: $\mathrm{Q}_{\mathrm{LAB}}=$ Vazão de carga para o movimento abertura do molde

Combinando as equações $4.35,4.41$ e 4.42 , chega-se à relação 4.36 obtida no caso do movimento de fechamento (avanço do cilindro): 


$$
P_{2}=P_{S}-P_{1}
$$

Nota-se assim que a relação entre as pressão de alimentação e as pressões nas câmaras 1 e 2 do cilindro permanece a mesma para os dois sentidos de movimento. Isto ocorre devido ao uso de uma válvula com uma relação de 2:1 entre as áreas de passagem dos pórticos A e B. Esta mesma relação aparece entre os volumes das câmaras 1 e 2 do cilindro diferencial utilizado.

A relação do equilíbrio de forças no cilindro ao longo do movimento de recuo pode ser estabelecida também a partir da figura 4.30:

$$
P_{1} A_{C F}-P_{2} \frac{A_{C F}}{2}+F=0
$$

Com a definição de $P_{L}=\frac{F}{A_{C F}}$ e reordenando a equação 4.43 obtém-se a relação entre a pressão de carga $P_{L}$ e as pressões nas câmaras do cilindro $P_{1}$ e $P_{2}$.

$$
P_{L}=\frac{P_{2}}{2}-P_{1}
$$

Combinando as equações 4.36, 4.41 e 4.44, chega-se à relação entre a vazão e as pressões de alimentação e de carga para o movimento de abertura de molde.

$$
Q_{L A B}=C_{d} A_{A} \sqrt{\frac{4\left(\frac{P_{S}}{2}-P_{L}\right)}{3 \rho}}
$$


A válvula selecionada possui curva característica de vazão conforme indicado na figura 4.31. Segundo dados do fabricante, esta curva foi obtida com um diferencial de pressão na válvula de $\Delta P=5$ bar e utilização de um óleo com viscosidade $v=32 \mathrm{~mm}^{2} / \mathrm{s}$. Esta curva pode ser corrigida para outros diferenciais de pressão utilizando-se a equação 4.46 fornecida pelo próprio fabricante.

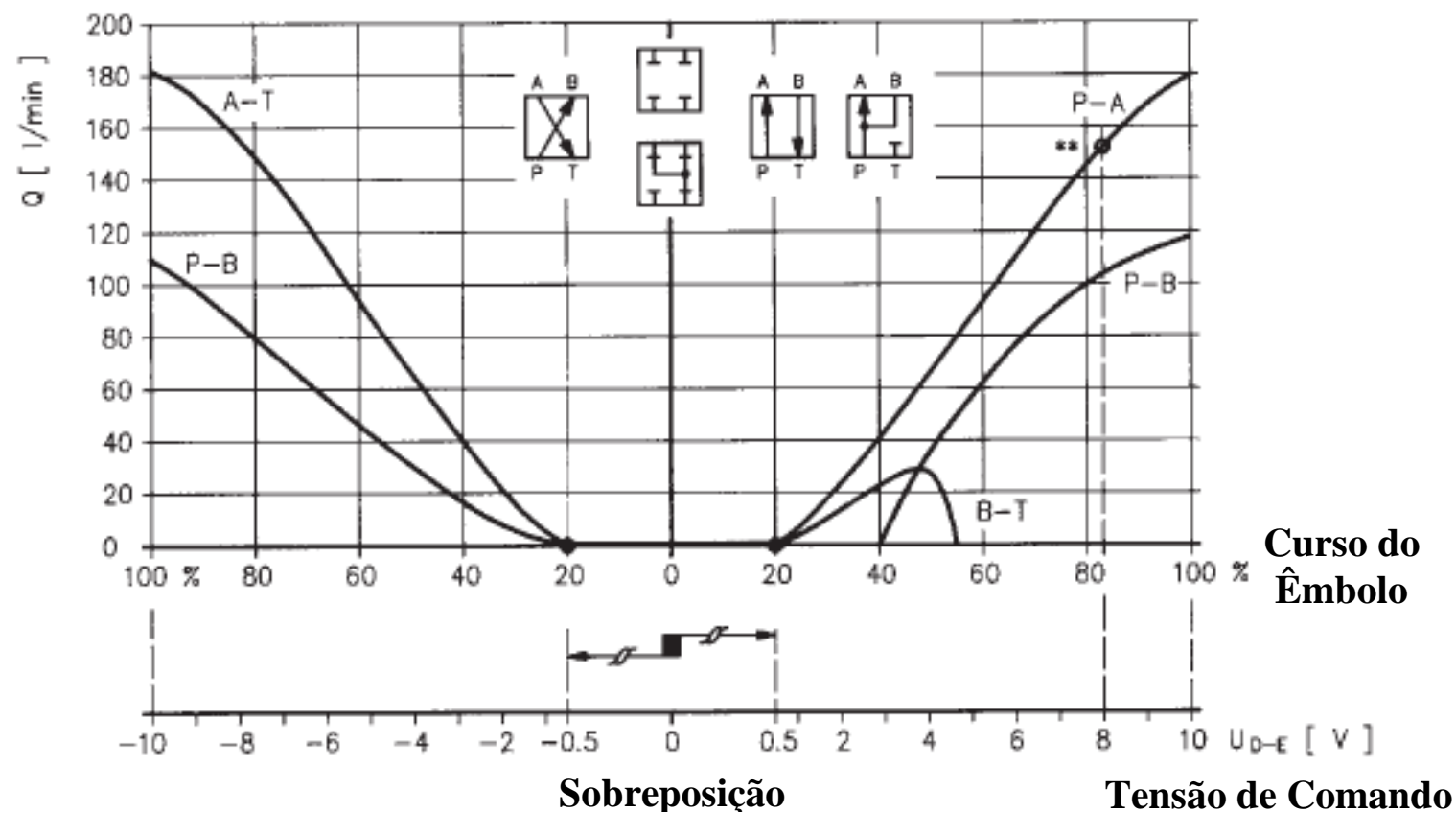

Figura 4.31 - Curva característica de vazão para válvula proporcional. (26)

$Q_{X}=Q_{\text {NOM }} \sqrt{\frac{\Delta P_{X}}{5}}$

Sendo:

$\mathrm{Q}_{\mathrm{X}}$ - Vazão corrigida para o diferencial de pressão $\Delta P_{X} \cdot[\mathrm{L} / \mathrm{min}]$

$\mathrm{Q}_{\mathrm{NOM}}$ - Vazão retirada da curva original de vazão. [L/min]

$\Delta \mathrm{P}_{\mathrm{X}}-$ Diferencial de pressão estabelecido. [bar] 
Pode-se notar na curva característica de vazão que a válvula selecionada apresenta $\pm 20 \%$ do curso de sobreposição. Esta sobreposição introduz uma zona morta desejável nas aplicações de controle de velocidade, uma vez que facilita controlar o movimento para pequenos sinais de entrada (27). As curvas da figura 4.31 indicam também a característica de regeneração da válvula. A partir do valor de sinal de comando de $+3 \mathrm{~V}$, equivalente a $40 \%$ do curso do êmbolo, a vazão induzida de B-T passa a ser gradativamente direcionada para a linha de pressão até o ponto com aproximadamente $+5 \mathrm{~V}$ de sinal onde toda a vazão no pórtico B retorna para o cilindro através da linha P-A. Assim, uma vazão menor é exigida do conjunto bomba - acumulador.

Deve-se ainda registrar o atraso de resposta característico da válvula proporcional selecionada a um sinal de entrada tipo degrau conforme figura 4.32. São indicadas curvas de abertura e fechamento do êmbolo do estágio principal para sinais de entrada com amplitude de 25, 50, 75 e $100 \%$ do sinal máximo da tensão de comando.

\section{Resposta ao Sinal de Abertura}

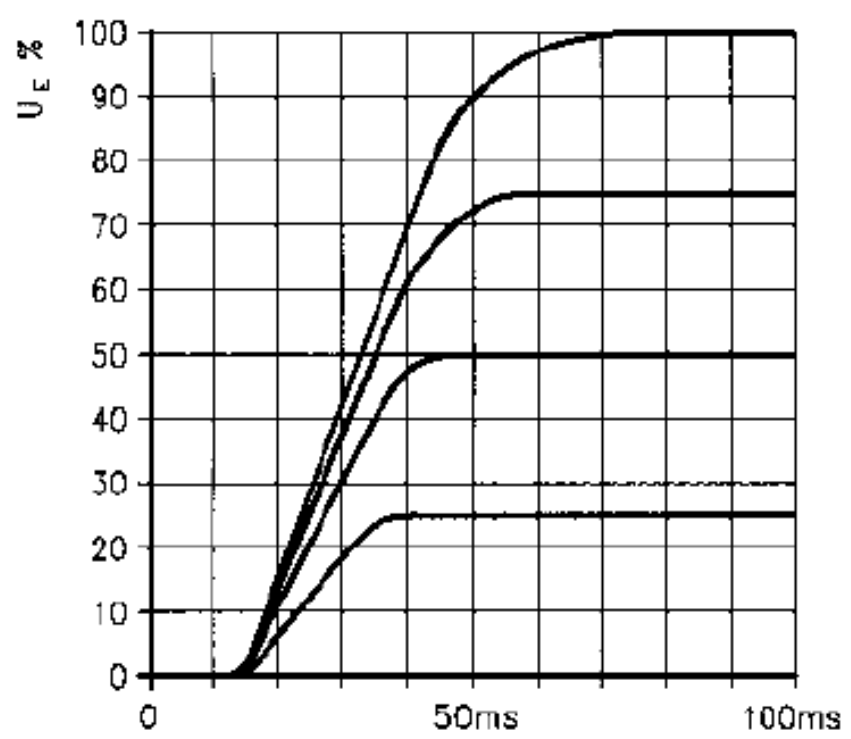




\section{Resposta ao Sinal de Fechamento}

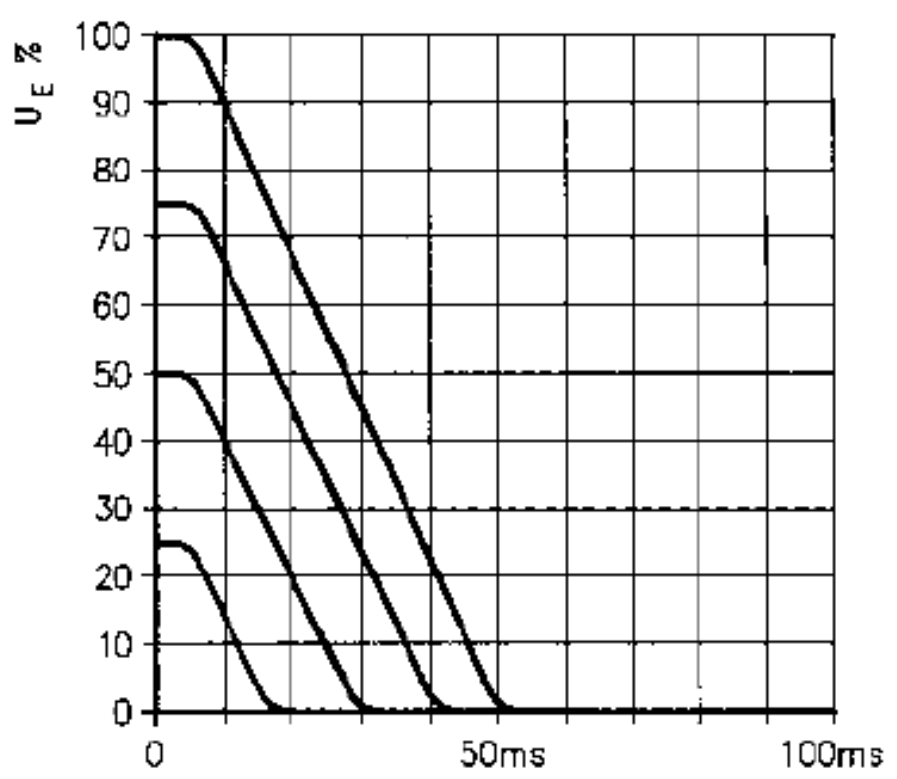

Figura 4.32 - Curvas de resposta da válvula proporcional. (26)

A partir da curva característica de vazão fornecida pelo fabricante (figura 3.31), podese determinar o produto entre o coeficiente de descarga e a área máxima de passagem para os pórticos da válvula proporcional. Nas curvas da figura 4.31 verifica-se que com o fluxo direcionado de P-A e A-T a vazão com $100 \%$ do sinal ( \pm 10 V ), ou seja, abertura máxima do êmbolo da válvula e um diferencial de pressão de 5 bar, a vazão atingida é de 180 [1/min]. Da mesma forma com o fluxo direcionado de P-B a vazão máxima é de 110 [1/min]. A vazão na válvula é dada pela equação 4.1 .

$$
\begin{aligned}
& C_{d} A_{A}=\frac{Q_{A}}{\sqrt{\frac{2 \Delta P}{\rho}}} \\
& C_{d} A_{B}=\frac{Q_{B}}{\sqrt{\frac{2 \Delta P}{\rho}}}
\end{aligned}
$$


Sendo:

$\mathrm{Q}_{\mathrm{A}}$ - Vazão no pórtico A da válvula proporcional.

$\mathrm{Q}_{\mathrm{B}}$ - Vazão no pórtico B da válvula proporcional.

$\mathrm{A}_{\mathrm{A}}$ - Área de passagem do pórtico A.

$A_{B}$ - Área de passagem do pórtico B.

\subsection{3 - Dinâmica do Movimento de Abertura/Fechamento do Molde}

Uma vez definidas as equações de vazão para os movimentos de abertura e fechamento de molde vamos realizar uma simulação do comportamento destes movimentos mediante um determinado sinal de comando.

Inicialmente vale analisar mais detalhadamente o mecanismo de abertura /fechamento do molde. A figura 4.33 mostra este mecanismo com alguns parâmetros importantes para esta análise.

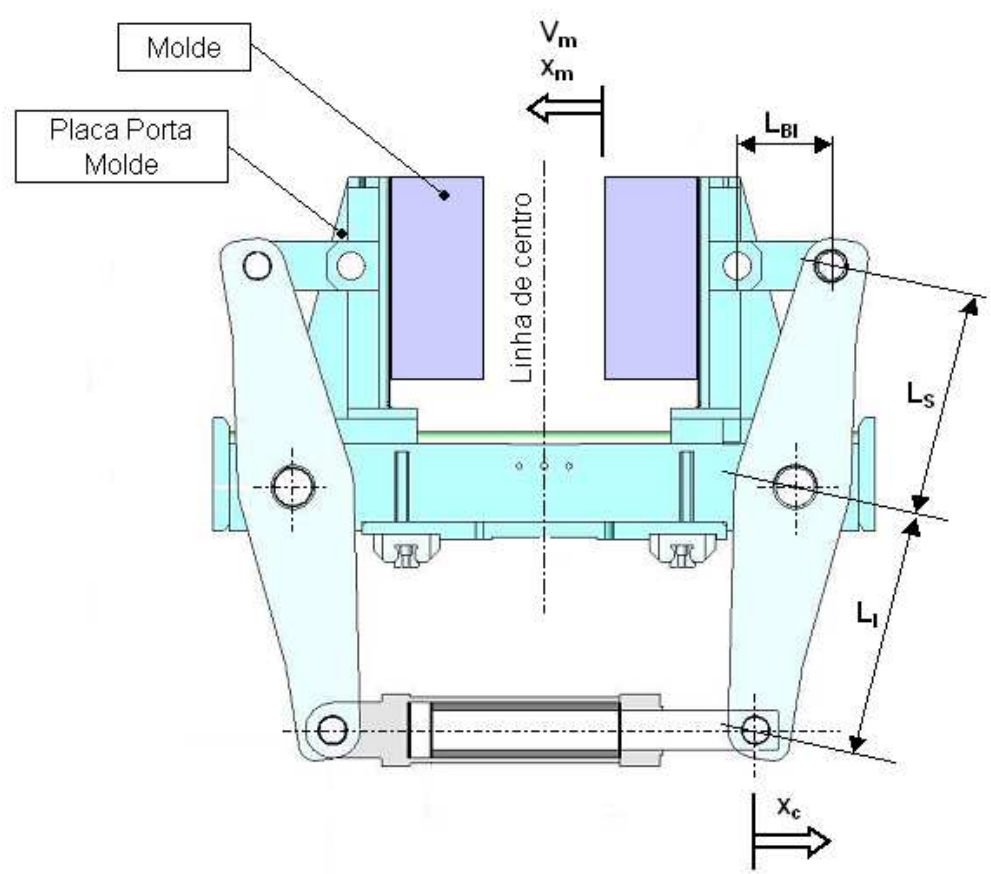

Figura 4.33 - Mecanismo para abertura/fechamento do molde 
$\mathrm{O}$ deslocamento da haste do cilindro, $\mathrm{X}_{\mathrm{C}}$, é transmitido para a placa porta molde $\mathrm{e}$ molde gerando o deslocamento $\mathrm{X}_{\mathrm{M}}$. A razão entre os dois deslocamentos depende da relação de alavanca existente no braço, $K_{B}=\frac{L_{S}}{L_{I}}$. A influência da projeção da biela de comprimento $\mathrm{L}_{\mathrm{BI}}$ na horizontal, onde $\mathrm{X}_{\mathrm{M}}$ é medido, pode também ser desprezada pois esta biela trabalha praticamente na horizontal durante todo o movimento. Assim, tem-se a seguinte relação de deslocamentos e velocidades:

$$
\begin{gathered}
X_{M}=K_{B} \cdot X_{C} \\
V_{M}=K_{B} \cdot V_{C}
\end{gathered}
$$

Vale ressaltar que $\mathrm{X}_{\mathrm{C}}$ equivale à metade do deslocamento total do cilindro uma vez que ele mede o deslocamento da haste. Como a camisa do cilindro é fixada no outro braço e considerando o mecanismo de sincronismo descrito na figura 3.6, que garante a simetria do movimento das duas metades do molde em relação à linha de centro, o deslocamento total do cilindro é igual a soma dos deslocamentos da haste e da camisa. Sendo assim, define-se o deslocamento e a velocidade total do cilindro, $\mathrm{X}_{\mathrm{TC}}$ e $\mathrm{V}_{\mathrm{TC}}$ respectivamente como sendo:

$$
\begin{aligned}
& X_{T C}=2 . X_{C} \\
& V_{T C}=2 . V_{C}
\end{aligned}
$$

A carga a ser movimentada pelo cilindro é relativa a inércia de giro do braço somada às inércias da placa porta molde e molde. $\mathrm{O}$ atrito nas guias pode ser desprezado devido à utilização de buchas de baixíssimo coeficiente de atrito. 
Pode-se estabelecer uma relação de velocidade da massa $\left(\mathrm{V}_{\mathrm{m}}\right)$ a ser movimentada em função da coordenada da própria massa $\left(\mathrm{X}_{\mathrm{m}}\right)$ a partir da curva característica de vazão da válvula proporcional e de um sinal de comando $\left(\mathrm{U}_{\mathrm{C}}\right)$ programado conforme o perfil descrito na figura 4.23. Para obter a velocidade da massa, deve-se inicialmente determinar a vazão a partir das equações 4.40 e 4.45 , respectivamente para os movimentos de fechamento e abertura do molde. Estas equações possuem um produto do coeficiente de descarga pela área de passagem do pórtico A da válvula. A este produto daremos o nome de coeficiente de passagem conforme segue:

$$
\begin{aligned}
K & =C_{d} * A_{A} \\
\mathrm{~K} & =\text { Coeficiente de Passagem }
\end{aligned}
$$

Este coeficiente pode ser determinado a partir da curva característica da válvula proporcional para cada valor de sinal de comando. Considerando a curva da figura 4.31 temse o valor de vazão para cada ponto de deslocamento do êmbolo da válvula. Com a equação 4.47 e os valores de $\Delta P=0,5[\mathrm{MPa}]$ e $\rho=881\left[\mathrm{~kg} / \mathrm{m}^{3}\right]$ obtém-se a curva indicada na figura 4.34 . 


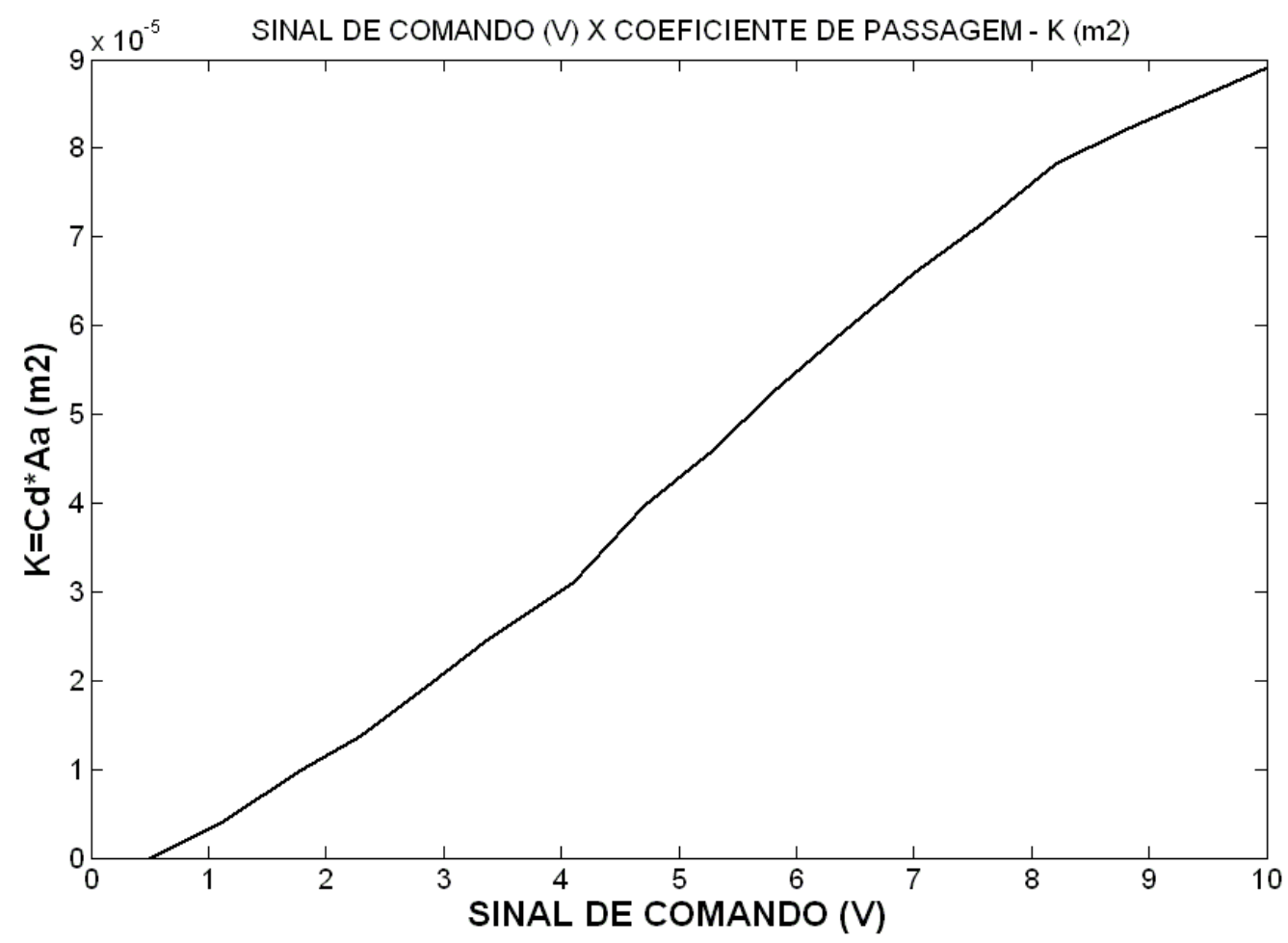

Figura 4.34 - Relação entre o sinal de comando e o coeficiente de passagem (K) da válvula proporcional.

Para simular a velocidade ao longo do movimento de fechamento define-se um sinal de comando conforme perfil apresentado na figura 4.35 .

Com este perfil de sinal de comando pode-se obter o coeficiente de passagem ao longo deste sinal e com a utilização da equação 4.40, obter a vazão e conseqüentemente, a velocidade estimada para este perfil. Vale ressaltar, conforme explicado anteriormente que o curso total do cilindro será o dobro do deslocamento da massa $\left(\mathrm{X}_{\mathrm{M}}\right)$ para um valor de relação de alavanca, $K_{B}=1$. 


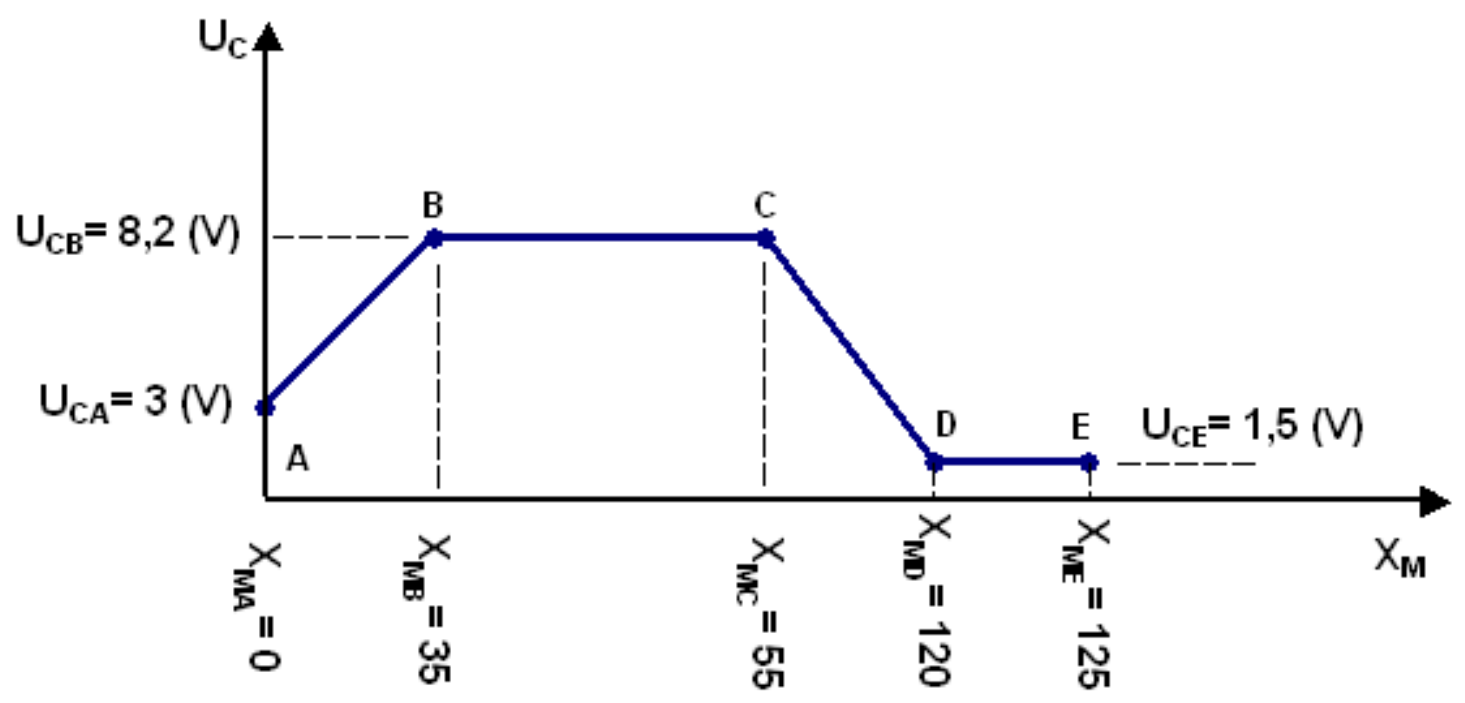

Figura 4.35 - Sinal de comando adotado para simulação da velocidade de fechamento.

A equação 4.40 pode ser reescrita conforme segue:

$$
Q_{L F}=K \sqrt{\frac{4\left(P_{S}-P_{L}\right)}{3 \rho}}
$$

A velocidade total do cilindro $\left(\mathrm{V}_{\mathrm{TC}}\right)$ para o movimento de fechamento é função da vazão e da área do cilindro de fechamento:

$$
V_{T C}=\frac{Q_{L F}}{A_{C F}}
$$

Devido ao sistema de sincronismo, o deslocamento de cada metade do molde é metade do deslocamento do cilindro. Logo:

$$
V_{M F}=\frac{V_{T C}}{2}
$$


$\mathrm{V}_{\mathrm{MF}}-$ Velocidade de fechamento do molde

Adotando os valores abaixo para as pressões de alimentação e de carga e para o diâmetro do cilindro de fechamento $\left(\mathrm{D}_{\mathrm{CF}}\right)$, consegue-se o resultado da simulação acima descrita. Este resultado é indicado graficamente na figura 4.36.

$$
\begin{aligned}
& \mathrm{P}_{\mathrm{S}}=150 \times 10^{5}[\mathrm{~Pa}] \\
& \mathrm{P}_{\mathrm{L}}=30 \times 10^{5}[\mathrm{~Pa}] \\
& \mathrm{D}_{\mathrm{CF}}=0,1[\mathrm{~m}] \\
& \rho=881\left[\mathrm{~kg} / \mathrm{m}^{3}\right]
\end{aligned}
$$

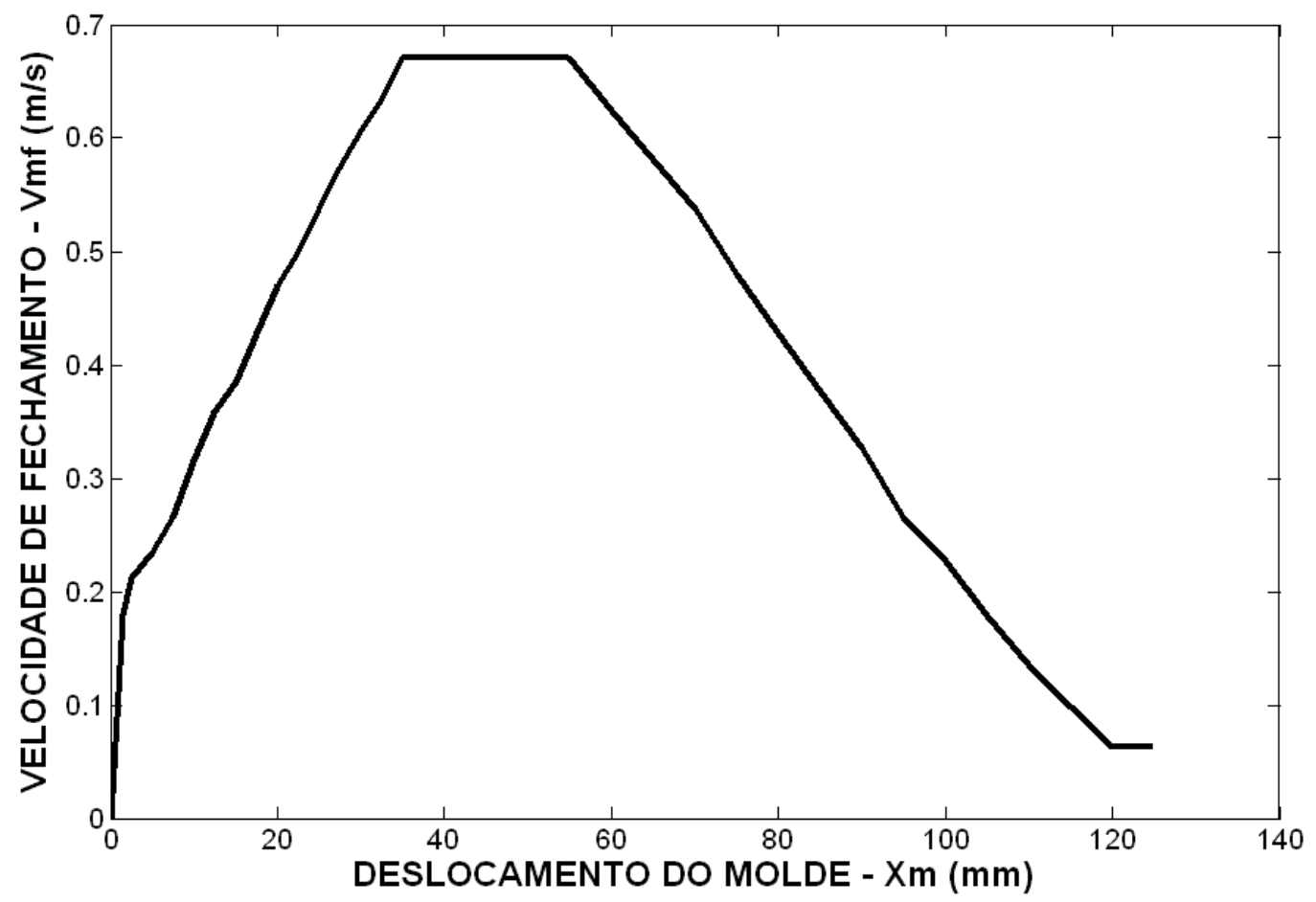

Figura 4.36 - Velocidade de fechamento do molde $\left(\mathrm{V}_{\mathrm{MF}}\right)$ em função do deslocamento do molde $\left(\mathrm{X}_{\mathrm{M}}\right)$ considerando o sinal de comando estabelecido na figura 4.35. 
Podemos repetir o mesmo procedimento para o movimento de abertura do molde. Porém, a equação 4.45 passa a ser válida para cálculo da vazão e, na figura 4.31, a curva a ser analisada para este movimento é relativa à vazão do pórtico A para T. Ao analisar esta curva percebemos que ela é praticamente igual à curva de vazão do pórtico $\mathrm{P}$ para $\mathrm{T}$ considerada no movimento de fechamento. Com isso, podemos considerar a mesma relação entre o sinal de comando e o coeficiente de passagem. Assim, a equação 4.45 pode ser reescrita da seguinte forma:

$$
\begin{aligned}
& Q_{L A B}=K \sqrt{\frac{4\left(\frac{P_{S}}{2}-P_{L}\right)}{3 \rho}} \\
& V_{T C}=\frac{Q_{L A B}}{A_{C F}} \\
& V_{M A}=\frac{V_{T C}}{2}
\end{aligned}
$$

$\mathrm{V}_{\mathrm{MA}}$ - Velocidade de abertura do molde

Se for considerado o sinal de comando segundo o perfil indicado na figura 4.37 , a curva de velocidade ao longo do deslocamento do cilindro pode ser obtida. 


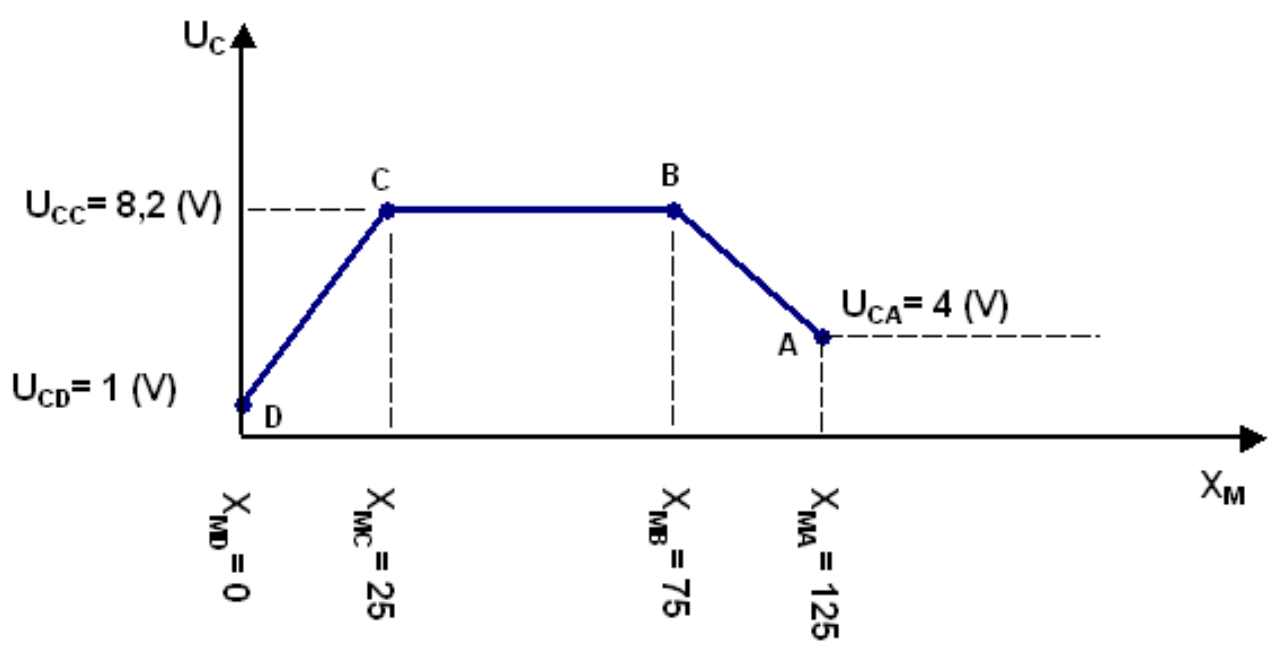

Figura 4.37 - Sinal de comando adotado para simulação da velocidade de abertura.

Considerando as mesmas condições de pressão de alimentação e de carga utilizada no movimento de fechamento do molde e considerando a curva de vazão característica da válvula proporcional, obtém-se a simulação de velocidade para o movimento de abertura baseado no sinal da figura 4.37 .

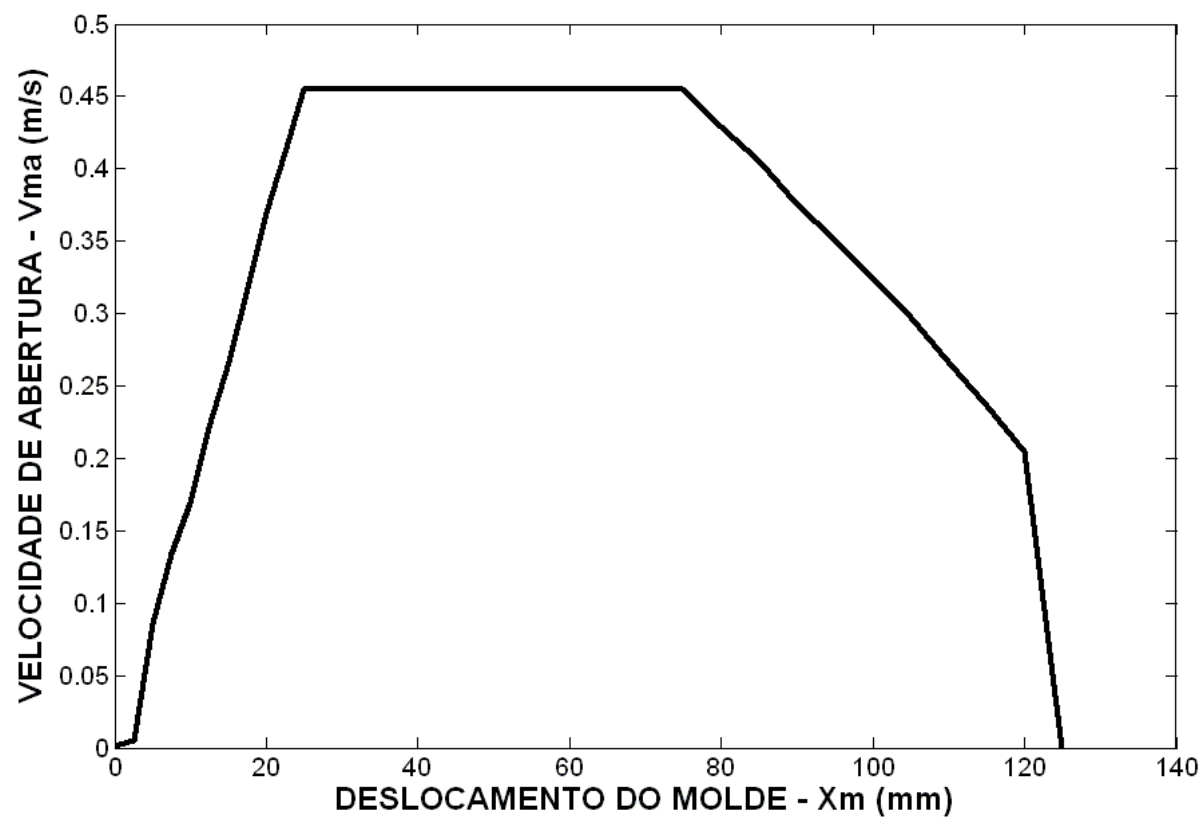

Figura 4.38 - Velocidade de abertura do molde $\left(\mathrm{V}_{\mathrm{MA}}\right)$ em função do deslocamento do molde $\left(\mathrm{X}_{\mathrm{M}}\right)$ considerando o sinal de comando estabelecido na figura 4.39. 
Observa-se a partir da comparação das figuras 4.36 e 4.38 que a velocidade de fechamento é maior que a velocidade de abertura. 


\section{CAPÍTULO 5}

\section{METODOLOGIA DE ENSAIO}

Este capítulo detalha a metodologia de ensaio para registro dos dados necessários para comparação com os resultados obtidos através da modelagem dos componentes hidráulicos realizada no Capítulo 4.

Serão descritos os sensores utilizados para a leitura das grandezas físicas de interesse assim como o equipamento para a aquisição de dados.

Inicialmente tem-se a apresentação da instalação adequada dos sensores para levantamento das variações de pressão e posição nos movimentos de transporte e abertura/fechamento de molde.

Com o registro destas grandezas e a utilização das equações de vazão pode-se obter as curvas de vazão para cada um dos movimentos para posterior comparação com as curvas obtidas no capítulo de modelagem.

\section{1 - Configuração de Instrumentação}

\subsection{1 - Movimento de Transporte}

A figura 5.1 indica a configuração de instalação dos sensores de pressão e posição para levantamento dos dados ao longo do movimento de transporte.

Com esta configuração é possível levantar as curvas de variação das pressões $\mathrm{P}_{1}$ e $\mathrm{P}_{2}$ registrando seus valores a cada posição ao longo de todo curso. Para o registro das pressões são utilizados dois sensores de pressão baseados no princípio de medição de extensômetros 
aplicados a uma fina membrana. Para a medição da posição é utilizado um sensor magnetoestrictivo. A pressão de alimentação $\mathrm{P}_{\mathrm{S}}$ é mantida constante com a utilização de uma válvula redutora de pressão no pórtico $\mathrm{P}$ da válvula direcional. Para a leitura da pressão de alimentação regulada na válvula redutora é utilizado um manômetro. No pórtico de entrada da válvula redutora é admitida a pressão proveniente do conjunto bomba/acumulador, $\mathrm{P}_{\mathrm{B}}$, pressão essa bem superior à pressão de alimentação $\mathrm{P}_{S}$.

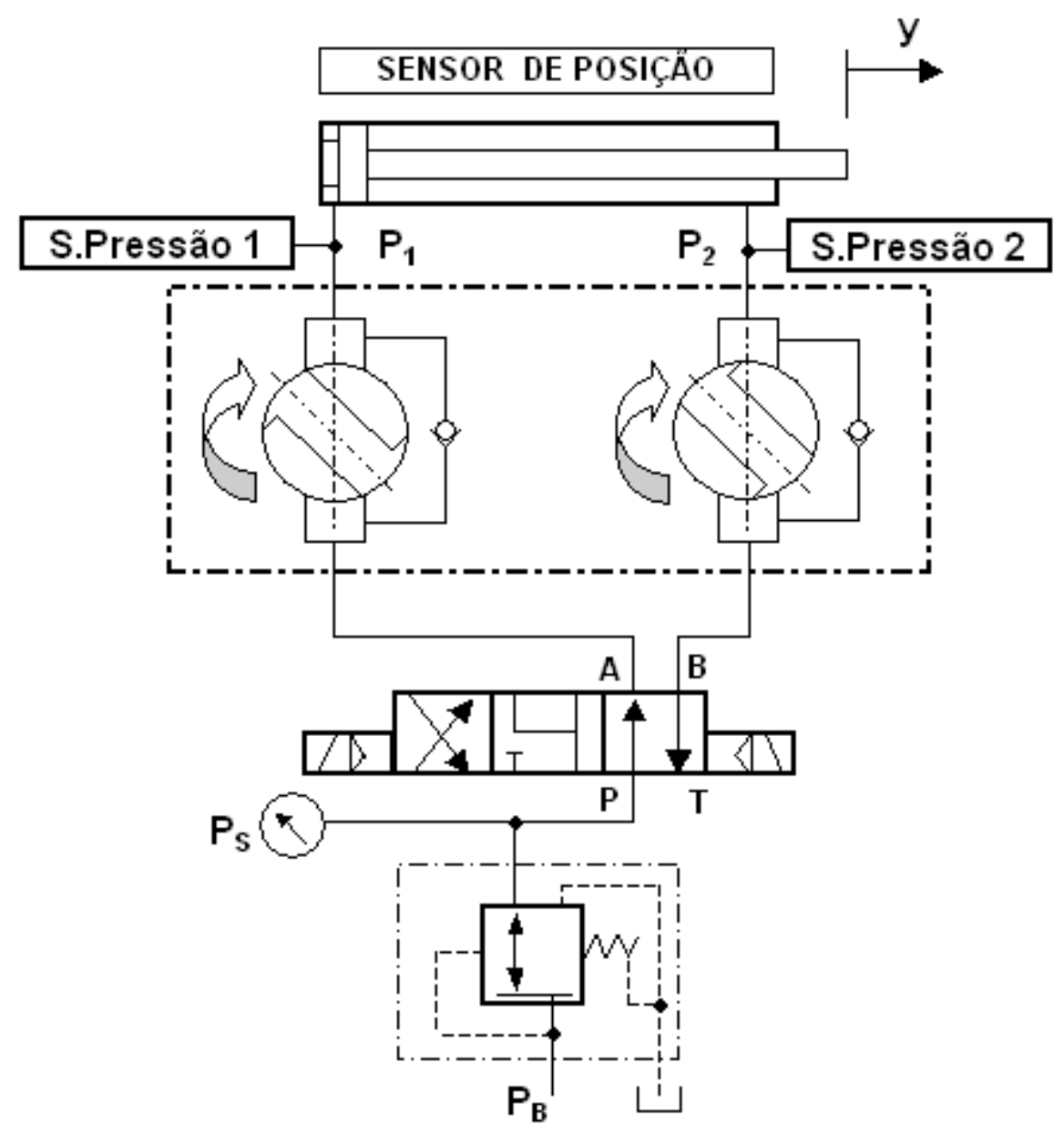

Figura 5.1 - Configuração de instrumentação do movimento de transporte

\subsection{2 - Movimento de Abertura/Fechamento do Molde}

Da mesma forma que no movimento de transporte, a instrumentação aplicada visa registrar as variações de pressão e posição ao longo do movimento para posterior obtenção das curvas de vazão e velocidade. 
A figura 5.2 indica a configuração desta instrumentação utilizando dois sensores de pressão e um de posição. Neste caso também está aplicada uma válvula redutora de pressão que regula uma pressão de alimentação $\mathrm{P}_{\mathrm{S}}$ estável no pórtico $\mathrm{P}$ da válvula proporcional. $\mathrm{A}$ pressão da bomba $\mathrm{P}_{\mathrm{B}}$ que alimenta todo o sistema é mantida bem acima de $\mathrm{P}_{\mathrm{S}}$.

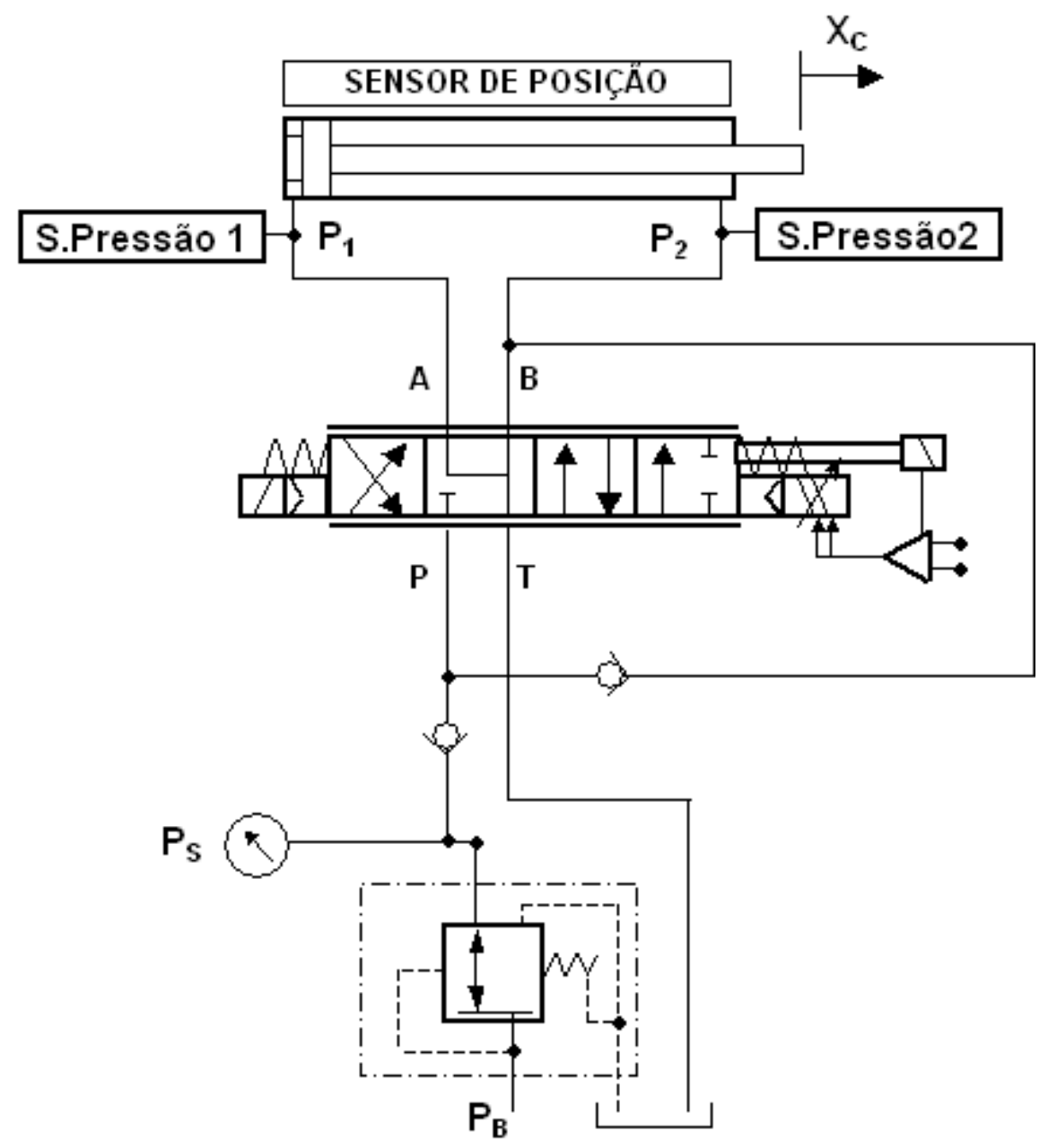

Figura 5.2 - Configuração de instrumentação do movimento do molde

\section{2 - Descrição da Instrumentação Utilizada}

Neste item são descritos os dois transdutores utilizados para leitura das grandezas envolvidas neste ensaio além do equipamento para aquisição e gravação dos dados. 


\subsection{1 - Sensor Linear de Posição}

Para a medição dos deslocamentos, $\mathbf{y}$ para o movimento de transporte e $\mathrm{X}_{\mathrm{C}}$ para $\mathrm{o}$ movimento do molde, foi escolhido um sensor isento de contato baseado no princípio físico da magnetoestricção. A figura 5.3 mostra esquematicamente este tipo de sensor.

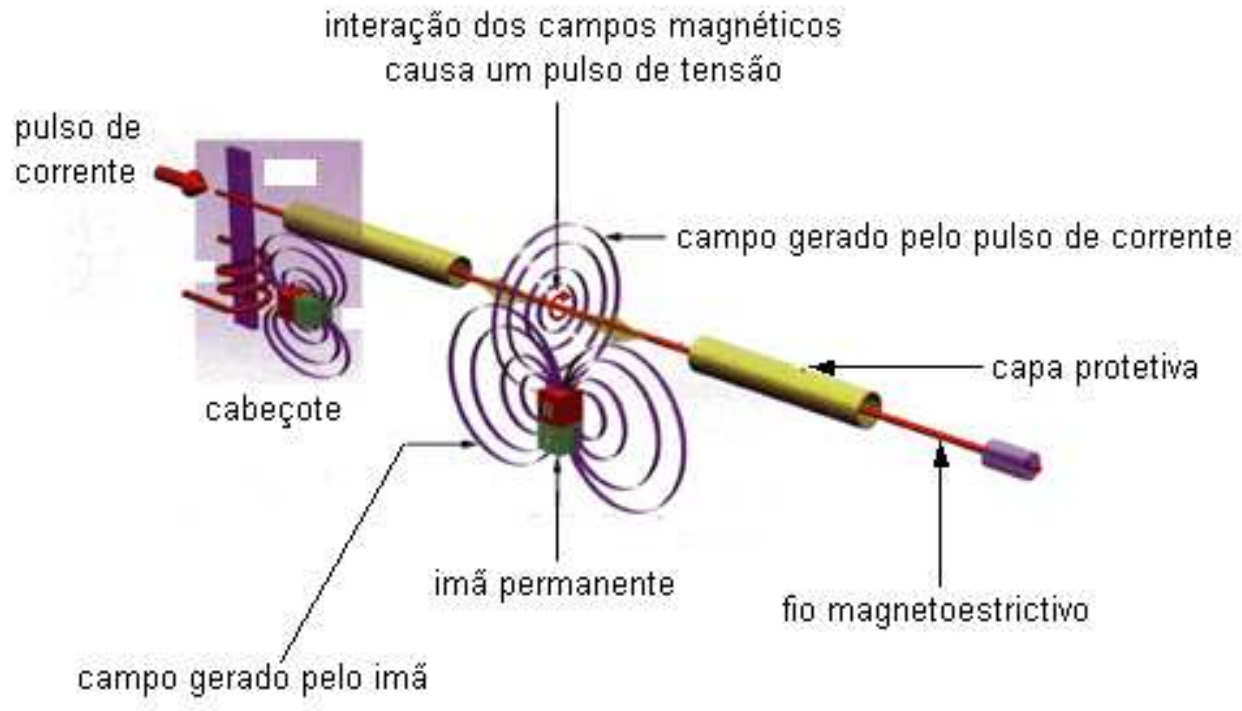

Figura 5.3 - Representação de um sensor magnetoestrictivo. (28)

Magnetoestricção é a propriedade de materiais ferromagnéticos como ferro, níquel e cobalto mudarem de tamanho e/ou forma quando submetidos a um campo magnético.

Dentro do transdutor, um pulso ultra-sônico é induzido em um fio de material ferromagnético pela momentânea interação de dois campos magnéticos. Um campo é gerado por um imã permanente que se movimenta ao longo do sensor. Este imã está acoplado ao elemento do qual deseja-se medir a posição.

O outro campo origina-se de um pulso de corrente aplicado no fio. A interação desses campos resulta numa torção no fio que gera um pulso mecânico que viaja ao longo deste e é detectado por um cabeçote na extremidade do sensor. A posição do imã permanente é determinada com alta precisão e velocidade através da medição do tempo entre a aplicação 
do pulso de corrente e a chegada no cabeçote da onda ultra-sônica. Uma capa protege o sensor e na extremidade oposta ao cabeçote há um amortecedor para absorver a onda mecânica que se propaga nesta direção.

Uma eletrônica embarcada no sensor gera o sinal de saída desejado que no caso do transdutor selecionado é um sinal de tensão entre $0 \mathrm{~V}$ e $10 \mathrm{~V}$. A figura 5.4 indica como o sinal de saída varia ao longo do curso útil do sensor.

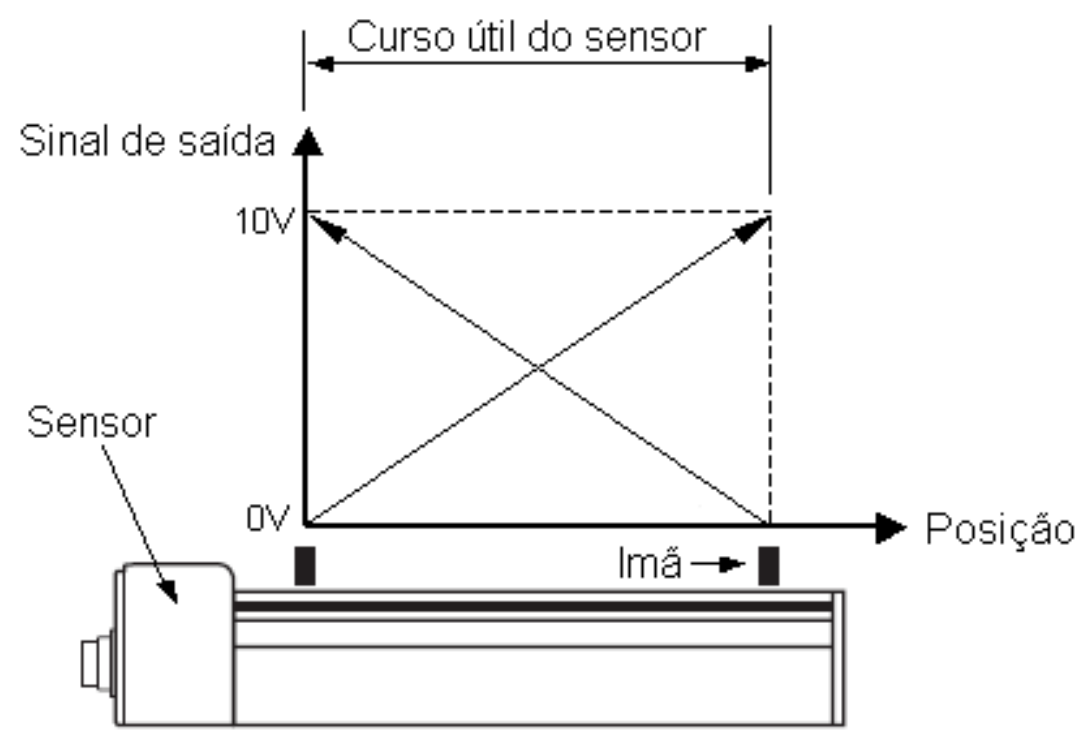

Figura 5.4 - Variação do sinal de saída do sensor de posição. (29)

As principais características técnicas do sensor selecionado estão listadas na tabela 5.1. 
Tabela 5.1 - Características do sensor de posição. (29)

\begin{tabular}{|c|c|}
\hline Tensão de saída & $0 \ldots 10 \mathrm{~V}$ e $10 \mathrm{~V} \ldots 0$ \\
\hline Corrente de Carga & $\max .5 \mathrm{~mA}$ \\
\hline Tensão máx. de ripple & $\leq 5 \mathrm{mV}$ \\
\hline Resoluçẫo do sistema & $\leq 10 \mu \mathrm{m}$ \\
\hline Repetibilidade & $\leq 10 \mu \mathrm{m}$ \\
\hline Precisâo de repetibilidade & $\leq 20 \mu \mathrm{m}$ \\
\hline Taxa de amostragem & $f_{\text {padrẫo }}=1 \mathrm{kHz}$ \\
\hline Nẫo linearidade & $\begin{array}{c}\leq \pm 200 \mu \mathrm{m} \text { para até } 500 \mathrm{~mm} \text { de curso } \\
\text { típico } \pm 0,02 \%, \text { max. } \pm 0,04 \% \\
500 \ldots 1500 \mathrm{~mm} \text { de curso nominal }\end{array}$ \\
\hline Tensâo de alimentaçâo & $24 \vee \mathrm{DC} \pm 20 \%$ \\
\hline Corrente de consumo & $\leq 70 \mathrm{~mA}$ \\
\hline Temperatura de operaçẫo & $0 \ldots+70^{\circ} \mathrm{C}$ \\
\hline
\end{tabular}

São utilizados nos ensaios dois sensores de posição distintos. Para o movimento de transporte cujo curso a ser medido é de $620 \mathrm{~mm}$ foi selecionado um sensor com $700 \mathrm{~mm}$ de curso útil e para o movimento do molde que possui um curso de $130 \mathrm{~mm}$ utiliza-se um sensor com curso útil de $150 \mathrm{~mm}$.

\subsection{2 - Sensor de Pressão}

O sensor de pressão selecionado tem seu funcionamento baseado no princípio de um extensômetro cuja resistência ôhmica varia quando submetido a uma deformação. Utiliza-se quatro extensômetros ligados em si segundo Ponte de Wheatstone e o desbalanceamento da mesma, em virtude da deformação dos extensômetros, é proporcional a pressão que a provoca. Os extensômetros são montados sobre uma membrana flexível muito fina. A figura 5.5 indica esquematicamente este tipo de sensor. 


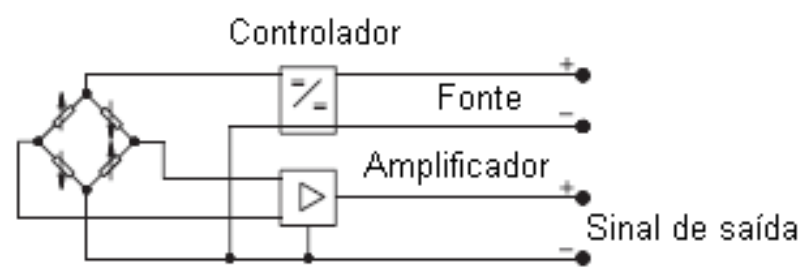

Figura 5.5 - Esquema do sensor de pressão. (30)

As características técnicas do sensor selecionado estão indicadas na tabela 5.2 a seguir.

Tabela 5.2 - Características do sensor de pressão. (30)

\begin{tabular}{|l|c|}
\hline Sinal de saída & $0 \ldots 10 \mathrm{~V}$ \\
\hline Faixa de medição & $0 \ldots 35 \mathrm{MPa}$ \\
\hline Precisão & $\pm 0,5 \%$ do fundo de escala \\
\hline Resolução & Infinita \\
\hline Tempo de resposta (10...90\% F.E.) & $<1 \mathrm{~ms}$ \\
\hline
\end{tabular}

\subsection{3 - Equipamento de Aquisição de Dados}

Para aquisição dos dados é utilizado um osciloscópio com quatro canais de leitura. Foi selecionado para os ensaios um osciloscópio da marca Tektronix, modelo TDS 2014. Com este equipamento é possível realizar a leitura simultânea das duas pressões $\mathrm{P}_{1}$ e $\mathrm{P}_{2}$ e do deslocamento de cada movimento. Este osciloscópio permite a gravação dos dados para posterior análise dos sinais registrados. As suas principais características técnicas estão listadas na tabela 5.3.

Tabela 5.3 - Características do osciloscópio

\begin{tabular}{|l|c|}
\hline$N^{\circ}$ de canais & 4 \\
\hline Banda máxima & $100 \mathrm{MHz}$ \\
\hline Taxa de amostragem/canal & $1 \mathrm{GHz}$ \\
\hline Escala de tempo & $5 \mathrm{~ns} \ldots 50$ s/divisẫo \\
\hline Comprimento de gravaçäo & 2500 pontos \\
\hline Resolução vertical & 8 bits \\
\hline Sensibilidade vertical & $2 \mathrm{~m} \vee$ a $5 \mathrm{~V} /$ div \\
\hline
\end{tabular}


Os tempos de duração dos sinais durante o ensaio são função da duração dos movimentos. Espera-se para o movimento de transporte um tempo entre 0,7 e 1 [s] e para o movimento do molde uma duração em torno de 0,6 [s].

\section{3 - Metodologia de Obtenção e Utilização dos Dados}

\subsection{1 - Movimento de Transporte}

Para registrar a grandeza posição, o transdutor utilizado para medição possui um curso útil de $700 \mathrm{~mm}$ variando o sinal de saída entre 0 e $10 \mathrm{~V}$. O curso do movimento de transporte é de $620 \mathrm{~mm}$. Deve-se considerar que o osciloscópio possui uma resolução vertical de 8 bits, ou seja, 256 níveis de tensão podem ser registrados ao longo da medição e existem 8 divisões no eixo vertical. Logo, para ajustar a resolução do osciloscópio ao curso a ser medido, é adequado que seja selecionada uma sensibilidade vertical de 1,25 V/divisão. Deste modo temse um fundo de escala no eixo vertical de $10 \mathrm{~V}$, equivalente a um curso de $700 \mathrm{~mm}$, e a resolução de medida de curso pode ser calculada:

Resolução de curso $=(10 \mathrm{~V} / 256$ níveis $) \times 70 \mathrm{~mm} / \mathrm{V}=2,73 \mathrm{~mm}$

Para a grandeza pressão o mesmo procedimento pode ser realizado considerando que o transdutor possui fundo de escala de 350 bar e sinal de saída variando de 0 a $10 \mathrm{~V}$. Porém, as pressões a serem medidas não devem ultrapassar 200 bar. Então, para obter uma melhor resolução, chega-se a uma sensibilidade vertical nos canais de medição de pressão de 0,75V/divisão. O fundo de escala de pressão é neste caso de $6 \mathrm{~V}$, equivalente a uma pressão de 210 bar, e a resolução de pressão pode ser calculada: 
Resolução de pressão $=(6 \mathrm{~V} / 256$ níveis $) \times 35$ bar $/ \mathrm{V}=0,82$ bar

No eixo referente ao tempo deve-se considerar que o osciloscópio tem como característica registrar sempre 2500 pontos. Baseado no perfil de velocidade estimado no capítulo 4 pode-se considerar uma velocidade média em torno de $1 \mathrm{~m} / \mathrm{s}$. Pode-se calcular o tempo total de amostragem:

Tempo de amostragem $=(0,00273 \mathrm{~m} / 1 \mathrm{~m} / \mathrm{s}) \times 2500$ pontos $=6,8$ segundos

Como o osciloscópio possui 10 divisões no eixo de tempo, a escala de tempo ideal deve ser de 680 ms/divisão.

Cada sinal (posição e dois sinais de pressão, um para cada lado do cilindro) será conectado a um canal de leitura do osciloscópio sendo o quarto canal de leitura ligado ao controlador da máquina registrando o sinal digital que comanda o avanço ou o recuo do carro. Esse sinal servirá como referência do início de comando de movimento.

Com o registro da posição do carro ao longo do tempo pode-se obter a curva de velocidade ao longo do movimento a partir da diferenciação destes valores de posição. Simultaneamente serão registradas as pressões em ambos os lados do cilindro possibilitando assim a obtenção da curva da pressão de carga a partir das equações 4.15 e 4.18. Com os valores de pressão de carga e o uso das equações 4.16 e 4.22 para avanço e 4.21 e 4.23 para recuo tem-se também os perfis de velocidade ao longo do movimento. Então, esses perfis de velocidade obtidos a partir da diferenciação da posição e dos perfis de pressão de carga, podem ser comparados para verificação do modelo estabelecido no capítulo 4 .

Para o transporte do carro, tanto para o movimento de avanço quanto de recuo, são reproduzidas as condições geométricas relacionadas para a obtenção da figura 4.10. 


\subsection{2 - Movimento de Abertura e Fechamento do Molde}

No caso do movimento de abertura e fechamento do molde o procedimento a ser seguido será o mesmo adotado no item 5.3.1. Porém, para registro da grandeza posição é considerado um curso de deslocamento do molde de $100 \mathrm{~mm}$ e o transdutor utilizado tem um campo útil de leitura de $150 \mathrm{~mm}$ com sinal de saída em tensão variando de 0 a 10V. Com isso, ajustando a sensibilidade vertical do osciloscópio para 1V/divisão obtém-se um fundo de escala de $8 \mathrm{~V}$, equivalente a $120 \mathrm{~mm}$. A resolução de posição é:

Resolução de posição = (8V / 256 níveis $) \times 15 \mathrm{~mm} / \mathrm{V}=0,47 \mathrm{~mm}$

Para a grandeza pressão são utilizados os mesmos transdutores do movimento de transporte. A pressão máxima deve chegar a aproximadamente 250 bar. Se for ajustada uma sensibilidade de $1 \mathrm{~V} /$ divisão no eixo vertical o fundo de escala será de $8 \mathrm{~V}$, equivalente em pressão a 280 bar. A resolução de pressão é:

Resolução de pressão $=(8 \mathrm{~V} / 256$ níveis $) \times 35 \mathrm{bar} / \mathrm{V}=1,09 \mathrm{bar}$

Para a escala de tempo, considerando os 2500 pontos sempre registrados pelo osciloscópio e uma velocidade média do movimento de $200 \mathrm{~mm} / \mathrm{s}$, pode-se obter a resolução de tempo de amostragem ideal:

Tempo de amostragem $=(0,47 \mathrm{~mm} / 200 \mathrm{~mm} / \mathrm{s}) \times 2500$ pontos $=5,8$ segundos .

Como no caso do movimento de transporte, a partir da diferenciação do sinal registrado de posição tem-se o perfil de velocidade ao longo do movimento. Com o registro das pressões em ambos os lados do cilindro e a utilização das equações 4.40, 4.57 e 4.58 para o 
fechamento do molde e $4.45,4.57$ e 4.58 para a abertura, obtém-se também o perfil de velocidade a partir do modelo estabelecido no capítulo 4. Estes dois perfis de velocidade podem ser comparados para verificação do modelo. 


\section{CAPÍTULO 6}

\section{ANÁLISE DOS DADOS}

Neste capítulo são apresentados os dados obtidos nos ensaios conforme metodologia descrita no capítulo anterior. A análise é realizada comparando os gráficos resultantes destes dados com os gráficos equivalentes obtidos a partir das equações modeladas no capítulo 4. A partir desta análise são apresentadas sugestões de melhorias.

\section{1- Movimento de Transporte do Carro}

Os dados são apresentados separadamente para o movimento de avanço e recuo. Para o movimento de recuo são apresentadas algumas opções visando melhoria de desempenho

\subsection{1- Movimento de Avanço}

Os dados do movimento de avanço são registrados utilizando pressão de alimentação $\mathrm{P}_{\mathrm{S}}$ $=8 \times 10^{6}[\mathrm{~Pa}]$. Na figura 6.1 a curva identificada como "Valor Registrado" equivale aos dados registrados no teste e a curva "Valor Aproximado" é obtida por interpolação polinomial de sexto grau devido ao ruído apresentado ao longo da medição (ver ANEXO 1). Foi utilizada a metodologia padrão deste tipo de interpolação existente no software Excel existente no Office 2000. O ponto de $\mathrm{t}=0$ é determinado pelo envio do sinal de comando de avanço do carro. O ponto A indica o início efetivo do movimento sendo que o tempo de $76 \mathrm{~ms}$ entre $\mathrm{t}=0$ e o ponto A representa o atraso de resposta. Os pontos $\mathrm{B}$ e $\mathrm{C}$ indicam que o momento em que o carro atingiu respectivamente a metade e o final de curso, com o movimento sendo realizado num tempo total de 0,67 [s]. 


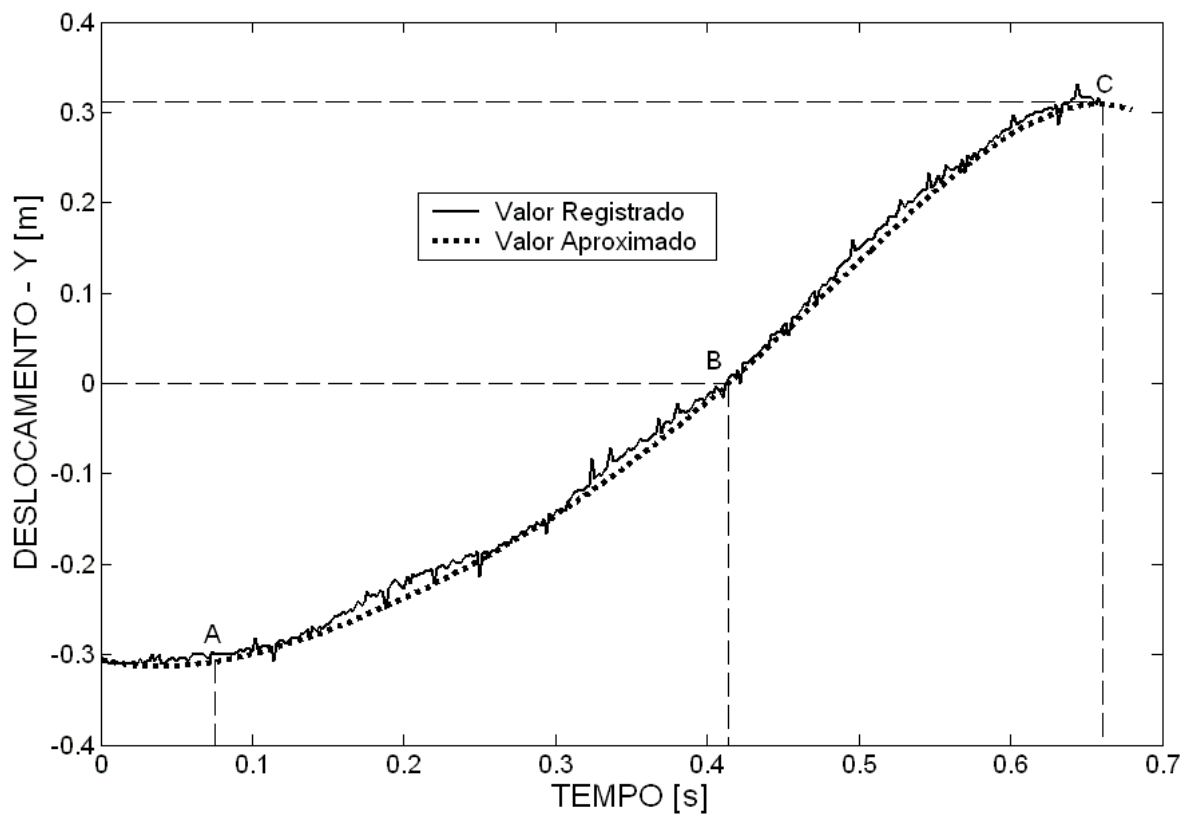

Figura 6.1 - Gráfico de deslocamento do movimento de avanço

A partir da diferenciação da curva de "Valor Aproximado" da figura 6.1 tem-se a curva de velocidade. A velocidade atingida ao longo deste movimento está mostrada na figura 6.2.

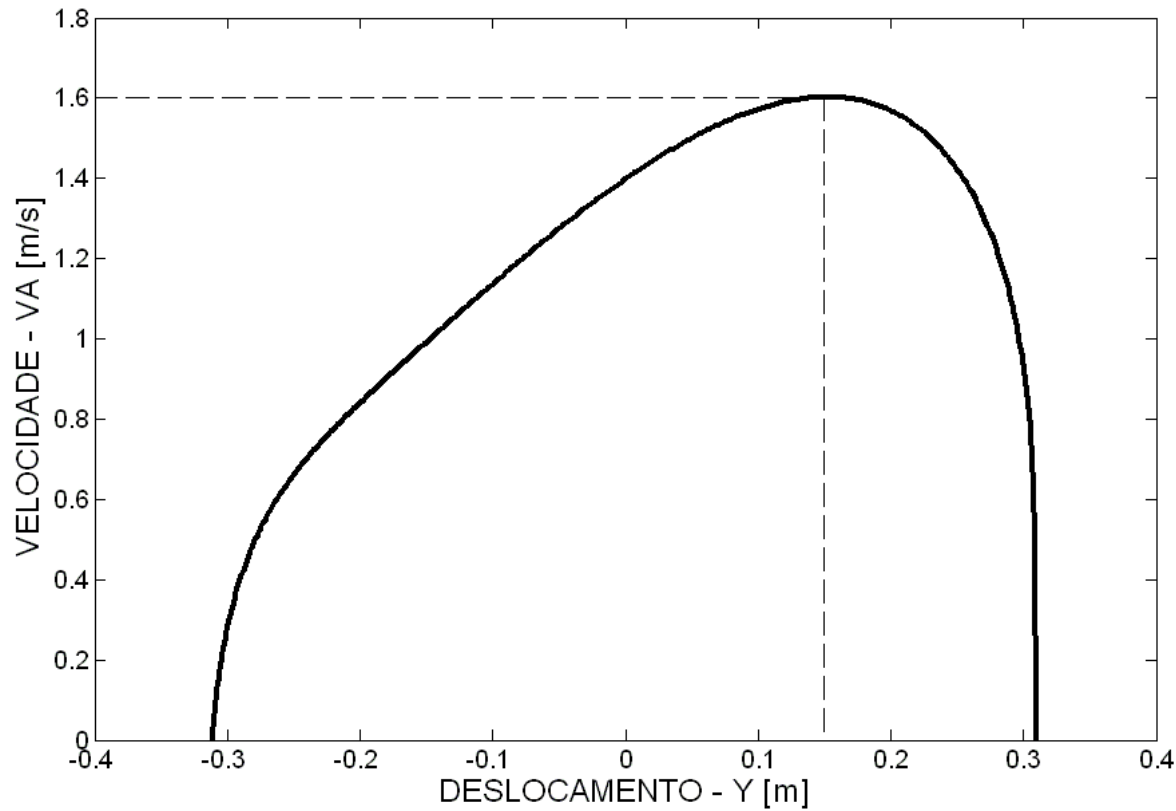

Figura 6.2 - Velocidade de avanço do transporte do carro. 
Da mesma forma pode-se obter a velocidade ao longo do movimento a partir das equações 4.16 e 4.22. Na equação 4.16 a área de passagem da válvula de freio A e a pressão de carga $\mathrm{P}_{\mathrm{L}}$ são variáveis ao longo do curso. A área de passagem é determinada em função do deslocamento Y medido e calculada conforme as equações 4.8, 4.9 e 4.11. A pressão de carga é calculada a partir da equação 4.15 utilizando os valores de $\mathrm{P}_{1}$ e $\mathrm{P}_{2}$ medidos. $\mathrm{O}$ resultado está indicado no gráfico da figura 6.3.

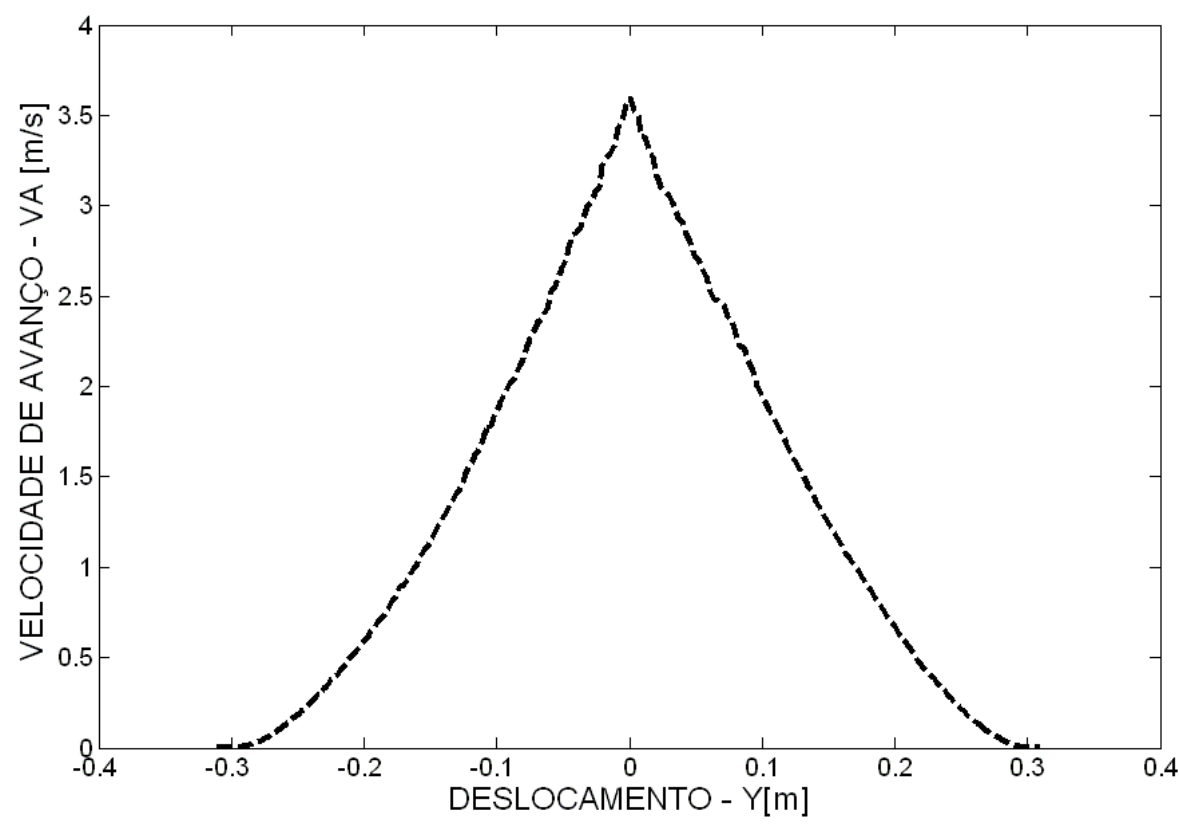

Figura 6.3 - Velocidade ao longo do movimento de avanço.

Pode-se notar a partir da comparação das curvas apresentadas nas figuras 6.2 e 6.3 , a existência de desvios de amplitude e de forma. O desvio de amplitude é justificado pela desconsideração das perdas de carga na obtenção da curva da figura 6.3 , isto é, na equação 4.16 foi considerado o valor de pressão $\mathrm{P}_{\mathrm{S}}$ como sendo igual ao valor regulado na bomba que alimenta o sistema (8 $[\mathrm{MPa}])$ e o valor de pressão $\mathrm{P}_{0}$ como sendo igual a zero. Dessa forma não foram consideradas as perdas de carga existentes entre a bomba, o reservatório de óleo e a válvula de freio. $\mathrm{O}$ desvio de forma pode ser explicado pelo fato do modelo de variação de área na válvula de freio considerar uma relação puramente geométrica. A influência da 
flexibilidade e possíveis graus de liberdade relacionados às alavancas superior e inferior e pelo braço de arraste (vide figura 3.9) não foi considerado no modelo aplicado.

Para realizar uma melhor análise da curva acima algumas outras curvas podem ser mostradas. A figura 6.4 indica a variação das pressões $\mathrm{P}_{1}$ e $\mathrm{P}_{2}$ em ambas as câmaras do cilindro. Nota-se que inicialmente a pressão $P_{1}$ atinge o mesmo valor da pressão de alimentação $\mathrm{P}_{\mathrm{S}}=8[\mathrm{MPa}]$, valor este necessário para acelerar o carro e vencer os atritos estáticos. Logo após, o valor de $\mathrm{P}_{1}$ cai pela metade ao longo do movimento enquanto a pressão $\mathrm{P}_{2}$ mantém-se num valor baixo em torno de 1,5 [MPa]. Na coordenada de $\mathrm{Y}=0[\mathrm{~m}]$, devido ao estrangulamento gradativo do fluxo proporcionado pela válvula de freio, a pressão $\mathrm{P}_{1}$ começa a cair levemente caracterizando o início do processo de frenagem. No final do curso de avanço ocorre um grande pico da pressão $\mathrm{P}_{2}$, pois a válvula de freio praticamente fecha toda a passagem de fluxo de óleo ocasionando uma frenagem brusca. Percebe-se que este processo de frenagem brusca ocorre nos últimos $0,2[\mathrm{~m}]$ do curso de avanço com ênfase no último $0,1[\mathrm{~m}]$.

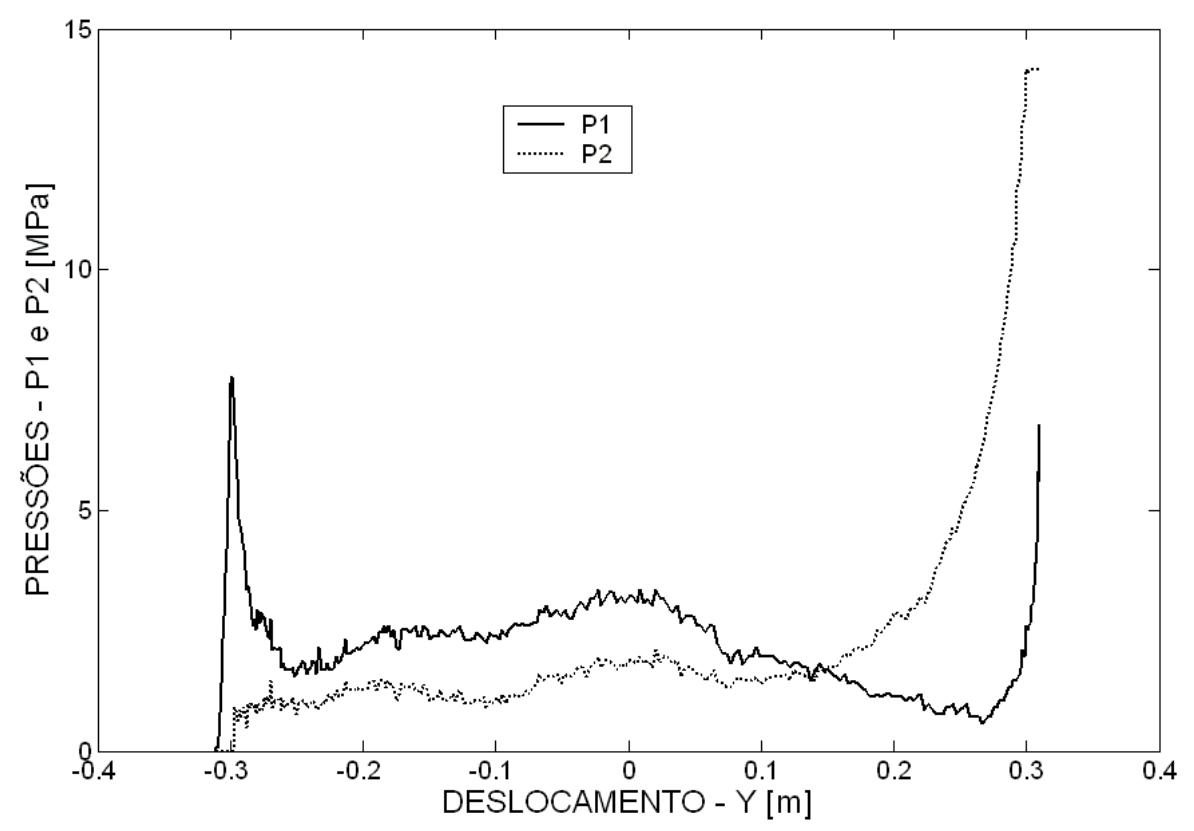

Figura 6.4 - Pressões ao longo do movimento de avanço 
Utilizando as pressões registradas ao longo do movimento e a equação 4.14 pode-se estabelecer a força resultante no cilindro conforme indicado na figura 6.5. Os picos de força resultante para aceleração e freio do carro atingem 15.000 [N] e $10.000[\mathrm{~N}]$ respectivamente e ocorre uma inversão de sentido da força resultante pouco depois da coordenada de deslocamento de $0,1[\mathrm{~m}]$.

Para o movimento de avanço conclui-se que a dinâmica do movimento é bastante satisfatória com o atraso de resposta menor que 0,1 [s], tempo de duração do movimento em 0,67 [s], aceleração e frenagem bastante curtas, velocidade máxima próxima a 1,6 [m/s] e velocidade média de aproximadamente $1[\mathrm{~m} / \mathrm{s}]$.

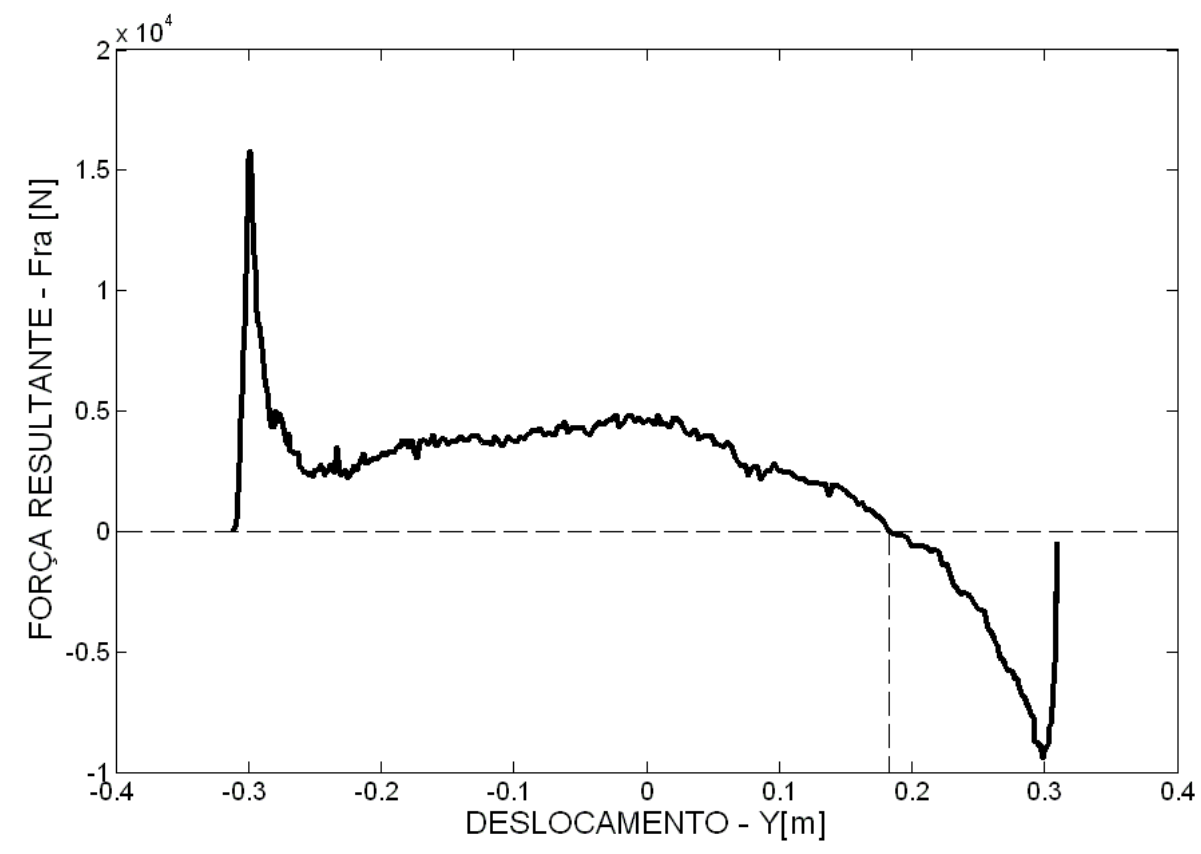

Figura 6.5 - Força resultante ao longo do movimento de avanço

\subsection{2 - Movimento de Recuo (Configuração Inicial).}

Da mesma forma que para o movimento de avanço, os dados de deslocamento e pressões podem ser tratados para obtenção das curvas de deslocamento, velocidade, pressão de carga e força resultante. Para o registro dos dados do movimento de recuo foi utilizada 
também uma pressão de alimentação $\mathrm{P}_{\mathrm{S}}=8 \times 10^{6}[\mathrm{~Pa}]$. O gráfico de deslocamento x tempo é mostrado na figura 6.6.

Da mesma forma que no caso do movimento de avanço, são registradas duas curvas sendo a curva "Valor Registrado" obtida com os valores lidos em teste e a curva "Valor Aproximado" obtida a partir de uma interpolação polinomial de sexto grau conforme indicado no ANEXO 1.

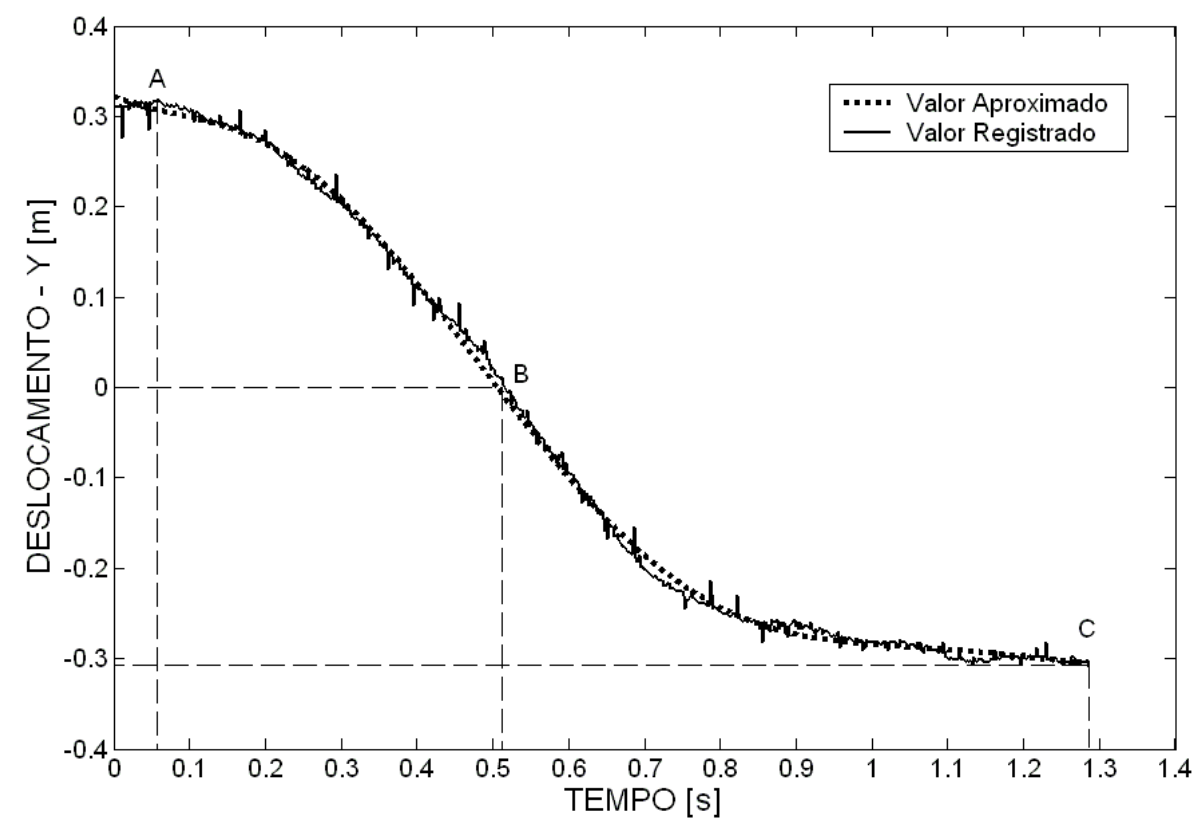

Figura 6.6 - Gráfico de deslocamento do movimento de recuo

A partir dos dados registrados acima, obtém-se a velocidade ao longo do movimento derivando o deslocamento obtido pela aproximação polinomial em relação ao tempo. $\mathrm{O}$ resultado está indicado na figura 6.7 abaixo. 


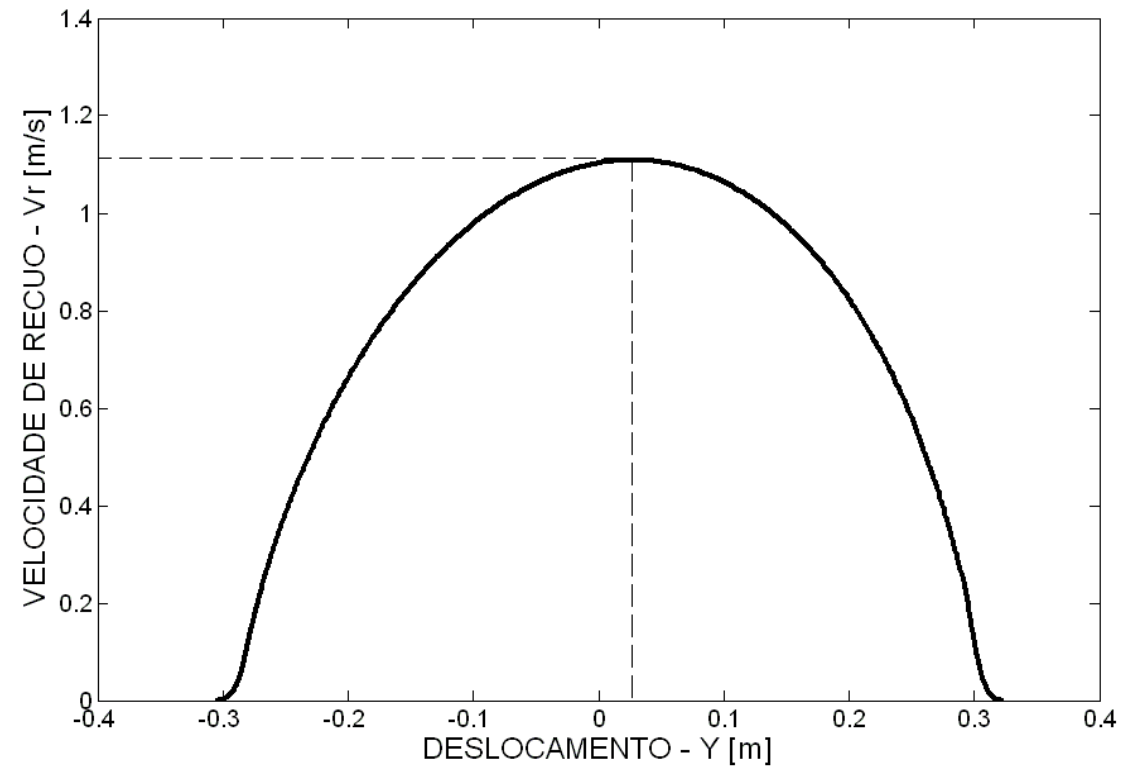

Figura 6.7 - Velocidade de recuo ao longo do movimento

Esta curva de velocidade pode ser obtida também a partir das equações 4.21 e 4.23 . Na equação 4.21 a área de passagem do êmbolo A e a pressão de carga $\mathrm{P}_{\mathrm{L}}$ são variáveis ao longo do tempo. A área de passagem é determinada pelas equações 4.8, 4.9 e 4.11 utilizando o valor de deslocamento $\mathrm{Y}$ registrado ao longo do movimento. Com a equação 4.18 e as pressões $\mathrm{P}_{1} \mathrm{e}$ $\mathrm{P}_{2}$ medidas tem-se a pressão de carga. $\mathrm{O}$ resultado é mostrado na figura 6.8.

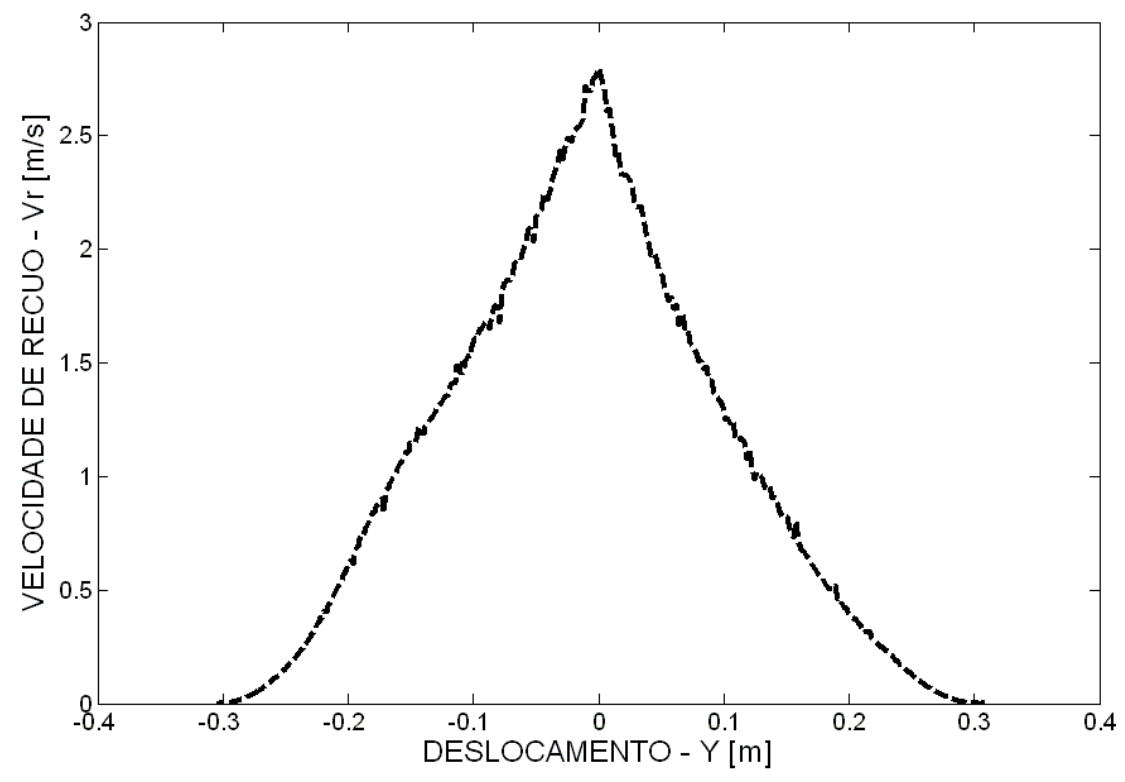

Figura 6.8 - Velocidade ao longo do movimento de recuo 
Como no movimento de avanço, alguns gráficos adicionais podem ser apresentados para melhor analisar a dinâmica do movimento. As pressões nas câmaras dos cilindros são registradas e indicadas na figura 6.9. Nota-se que, diferente do movimento de avanço, o valor da pressão $\mathrm{P}_{2}$ não cai de modo significativo logo após o pico necessário para vencer a inércia inicial e os atritos estáticos. O valor mantém-se em torno de 6 [Mpa] ao longo de todo o movimento. Também a pressão $\mathrm{P}_{1}$, que neste caso é medida na câmara cujo fluxo é direcionado para a linha de tanque, mantém um valor de aproximadamente 2,5 [Mpa].

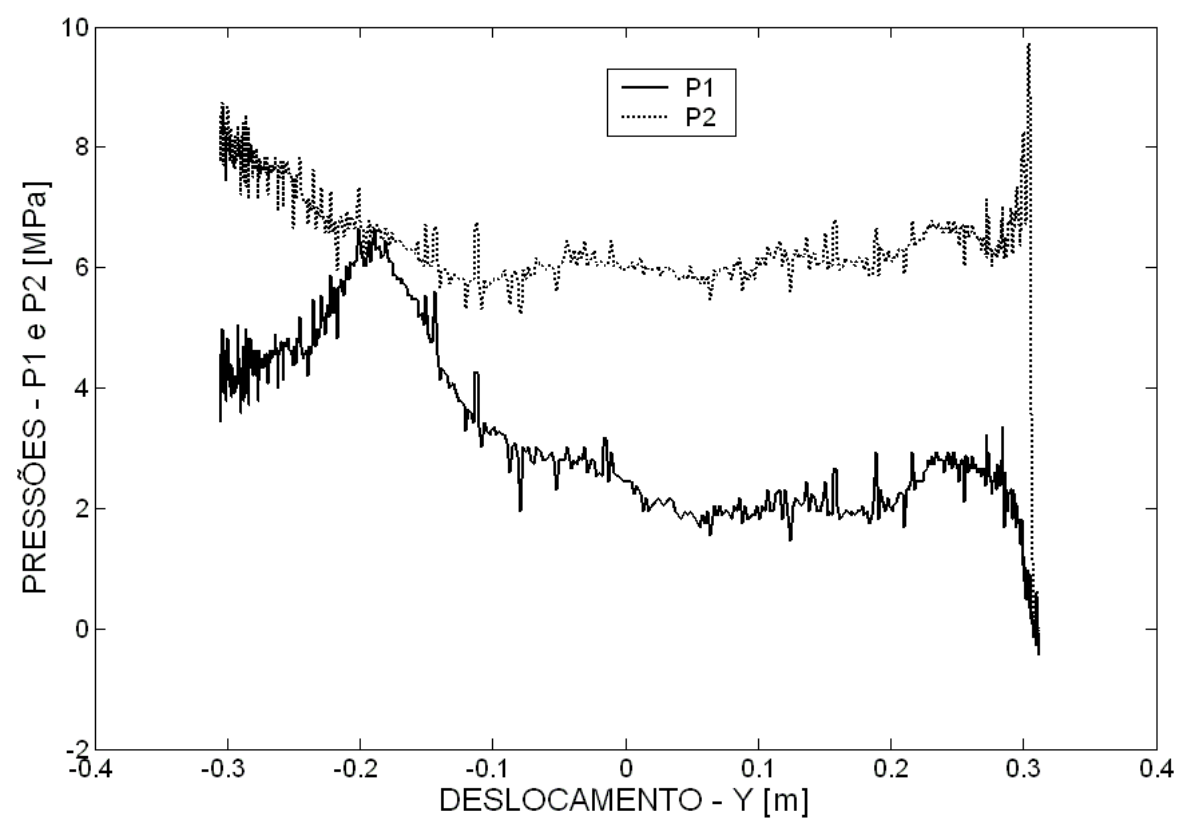

Figura 6.9 - Pressões ao longo do movimento de recuo

A força resultante ao longo do movimento é obtida com a equação 4.17 e a variação das pressões registradas na figura 6.9. O resultado está indicado na figura 6.10. 


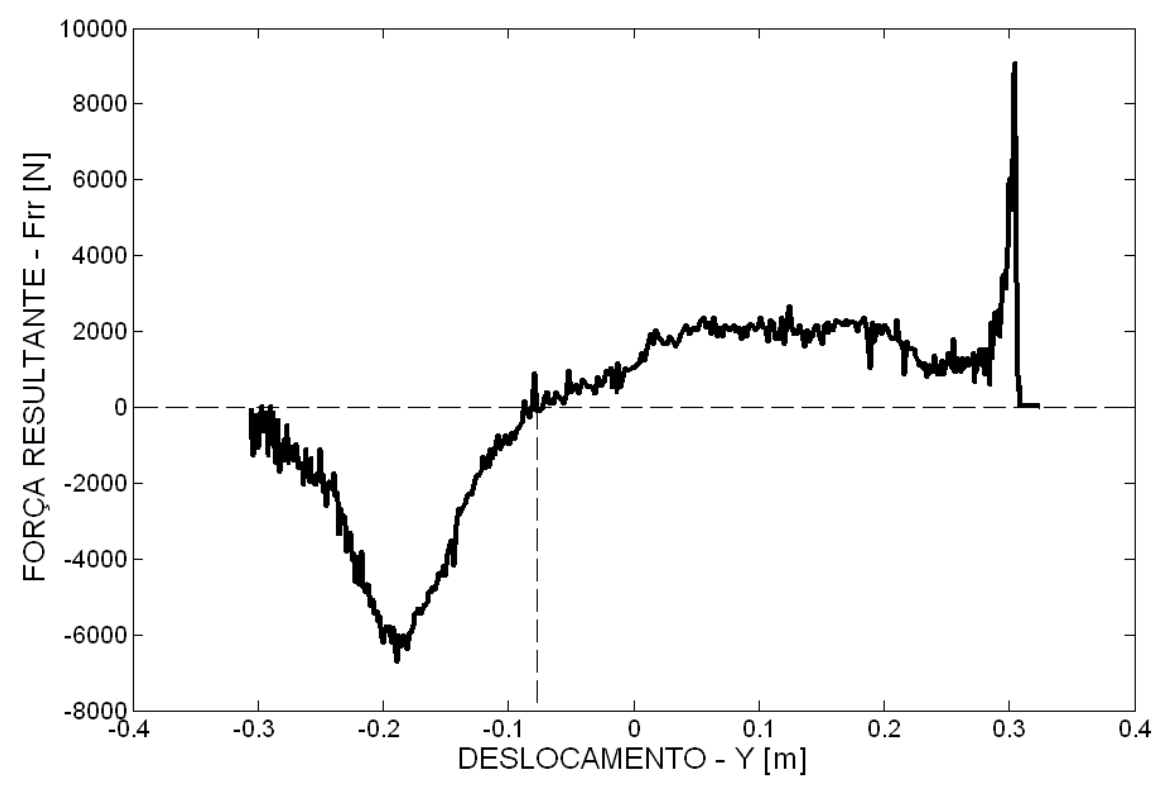

Figura 6.10 - Força resultante ao longo do movimento de recuo.

Percebe-se a partir da análise da figura 6.10 e, comparando com a figura 6.5 do movimento de avanço, que a dinâmica do movimento de recuo não equivale à do movimento de avanço e atinge valores menores de velocidade e aceleração. O pico inicial de força resultante atinge $7.500[\mathrm{~N}]$ o que ocasiona uma menor aceleração. Também no processo de desaceleração a inversão da força resultante ocorre logo após a metade do curso resultando numa frenagem mais longa.

Para o movimento de recuo conclui-se que, com a configuração inicial utilizada, o resultado não é tão satisfatório quando comparado com o movimento de avanço. O tempo de duração do movimento é de 1,28 [s], aceleração e frenagem mais longas, velocidade máxima de $1,1[\mathrm{~m} / \mathrm{s}]$ e velocidade média de $0,5[\mathrm{~m} / \mathrm{s}]$.

Este desempenho dinâmico pior no movimento de recuo é causado pela diferença de área no cilindro. Utilizando a mesma pressão de alimentação para os dois sentidos de movimento, a incidência desta pressão numa área menor no caso do movimento de recuo torna este movimento com uma dinâmica pior. Também deve-se considerar que no movimento de recuo a vazão induzida na linha de tanque é maior e com isso uma 
contrapressão maior ocorre devido à perda de carga dos componentes que estão entre o cilindro e o tanque (válvula de freio, válvula direcional, mangueiras e conexões). Essa contrapressão maior conforme indicada na figura 6.9 incide sobre uma área também maior no cilindro ocasionando uma menor força resultante conforme indicado na figura 6.10.

\subsection{3 - Movimento de Recuo (Pressão de Alimentação = 13 [MPa] ).}

Devido às conclusões anteriores foram também realizados testes com uma maior pressão de alimentação para o movimento de recuo com o objetivo de aferir uma dinâmica satisfatória a este movimento. Os dados a seguir são relativos aos testes realizados com uma pressão de alimentação de 13 [MPa]. A figura 6.11 indica o gráfico de deslocamento x tempo.

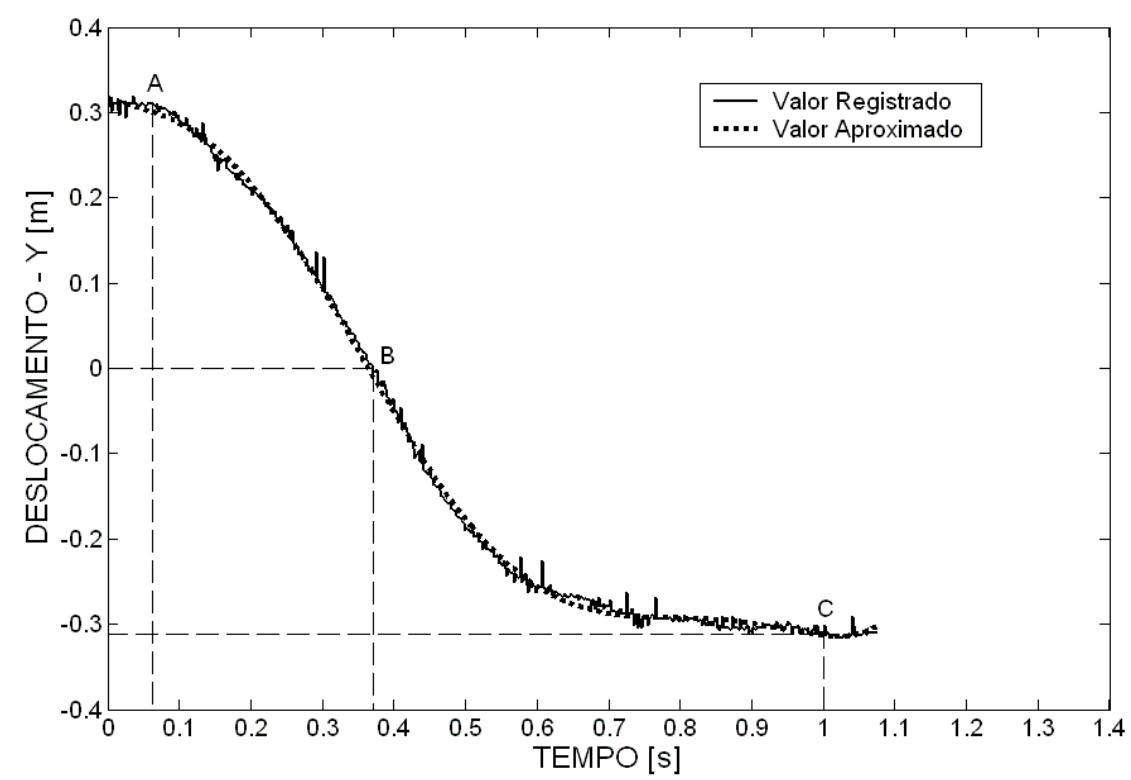

Figura 6.11 - Gráfico de deslocamento do movimento de recuo com pressão de alimentação de 13 [MPa].

Comparando a curva acima com a curva apresentada na figura 6.7, nota-se que houve uma pequena melhora na dinâmica do movimento de recuo com o aumento da pressão de alimentação de 8 para 13 [MPa]. O atraso de resposta inicial (ponto A) permanece dentro da 
mesma ordem de grandeza porém a coordenada que representa a metade do curso (ponto B) foi atingida 0,15 [s] antes e o movimento (ponto C) foi realizado com um tempo total próximo de 1,0 [s]. Porém, nota-se que a frenagem ainda continua longa quando comparada com o movimento de avanço. Ainda há uma perda de tempo no final deste movimento.

A partir dos dados de deslocamento indicados na figura 6.11, obtém-se a velocidade do movimento derivando o deslocamento do "Valor Aproximado" em relação ao tempo. O resultado está indicado na figura 6.12.

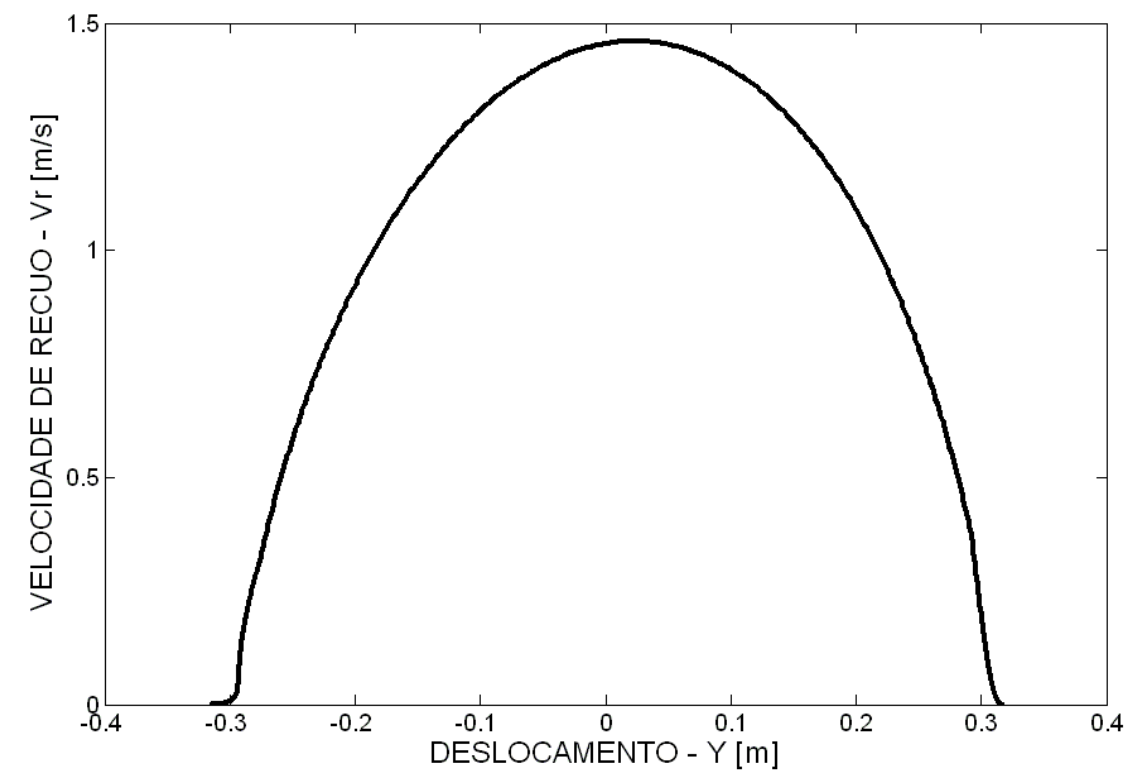

Figura 6.12 - Velocidade de deslocamento do movimento de recuo com pressão de alimentação de 13 [MPa].

Da mesma maneira anterior a curva de velocidade pode ser obtida a partir das equações de modelamento 4.21 e 4.23 considerando os dados registrados para as pressões $\mathrm{P}_{1}, \mathrm{P}_{2}$ e o cálculo da área de passagem a partir das coordenadas de deslocamento. O resultado está apresentado na figura 6.13 .

Como no gráfico de deslocamento, os gráficos de velocidade também indicam uma melhora no movimento de recuo utilizando pressão de alimentação de 13 [MPa]. A velocidade máxima atingida no gráfico da figura 6.12 é de $1,45[\mathrm{~m} / \mathrm{s}]$ contra $1,1[\mathrm{~m} / \mathrm{s}]$ com pressão de alimentação de 8 [Mpa] (figura 6.7) e a velocidade média aumenta de 0,5 [m/s] para 0,6 [m/s]. 
Para as curvas de velocidade modelada (figuras 6.8 e 6.13), a velocidade máxima é de 3,5 [m/s] com pressão de $13[\mathrm{MPa}]$ contra 2,9 [m/s] com pressão de 8 [MPa].

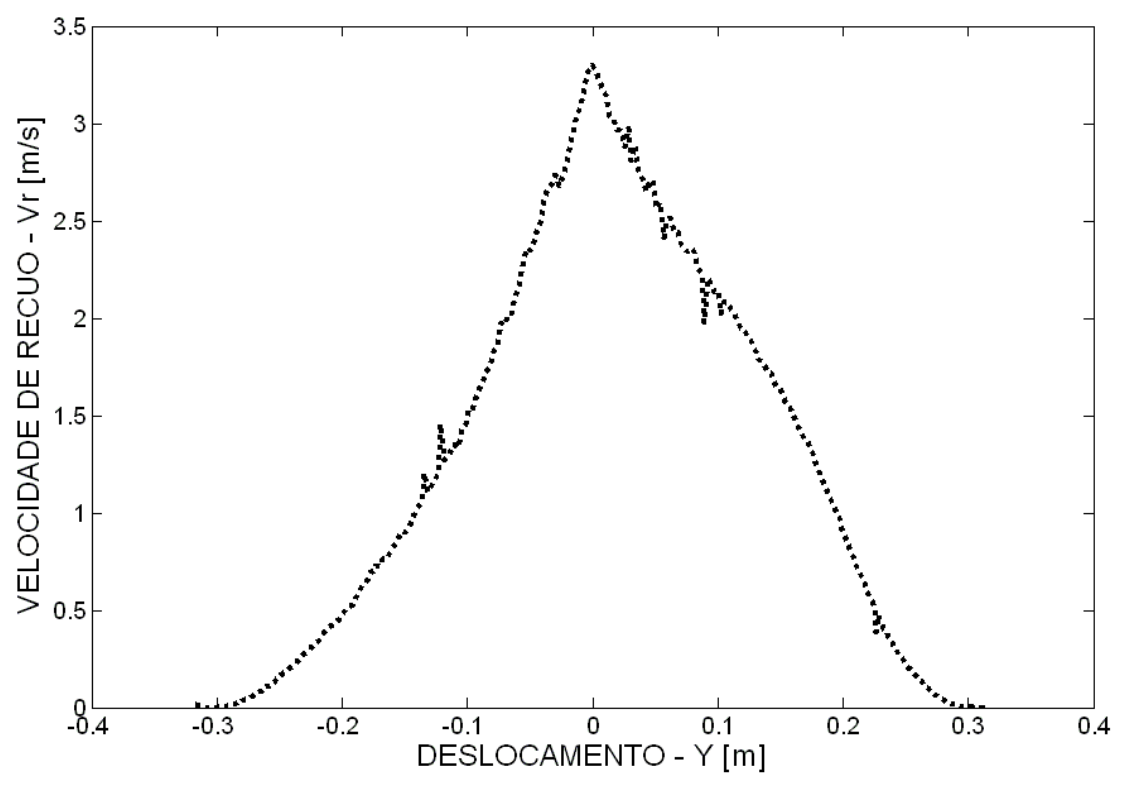

Figura 6.13 - Velocidade de recuo com pressão de alimentação de 13 [MPa].

Os gráficos das pressões $\mathrm{P}_{1}$ e $\mathrm{P}_{2}$ ao longo dos movimentos (figura 6.14) e da força resultante (figura 6.15) confirmam a ocorrência de aceleração e desaceleração com maior intensidade, porém ainda persiste o problema de uma frenagem longa.

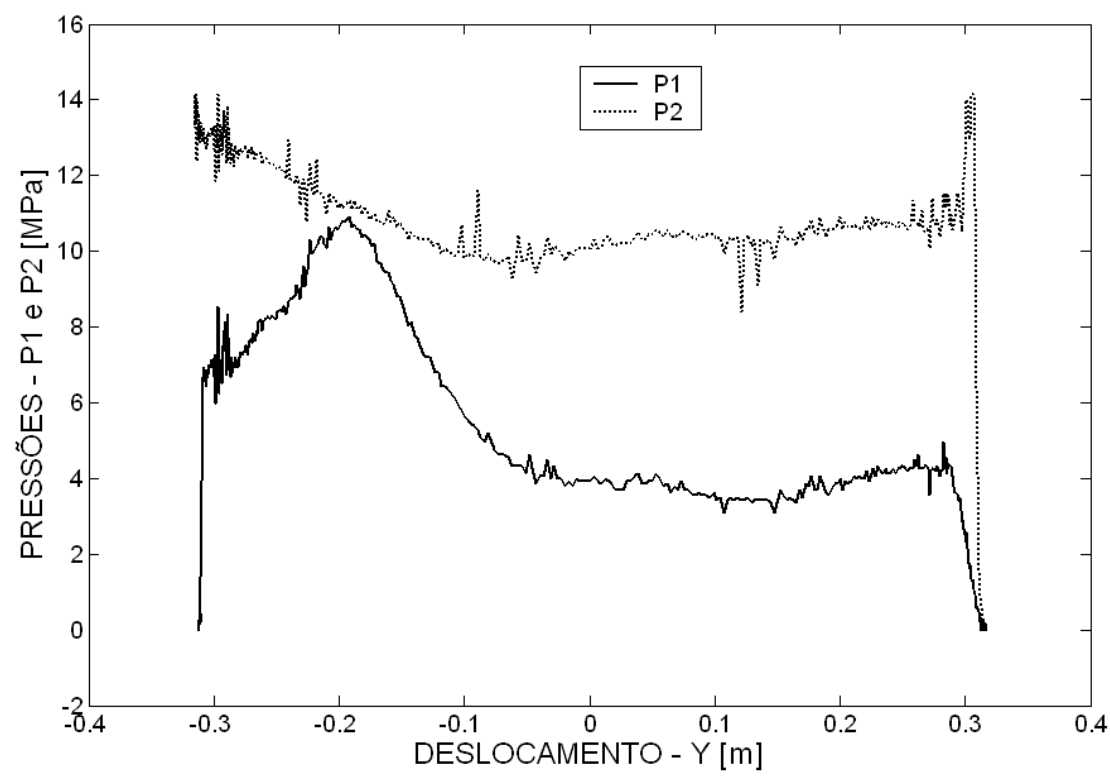

Figura 6.14 - Pressões ao longo do movimento de recuo com pressão de alimentação de $13[\mathrm{MPa}]$. 
A presença de uma frenagem longa apesar do aumento de pressão de alimentação pode ser visto melhor no gráfico da força resultante abaixo. O ponto de inversão do sentido da força continua o mesmo daquele apresentado na figura 6.10 , ou seja, coordenada de posição de $-0,1$ $[\mathrm{m}]$.

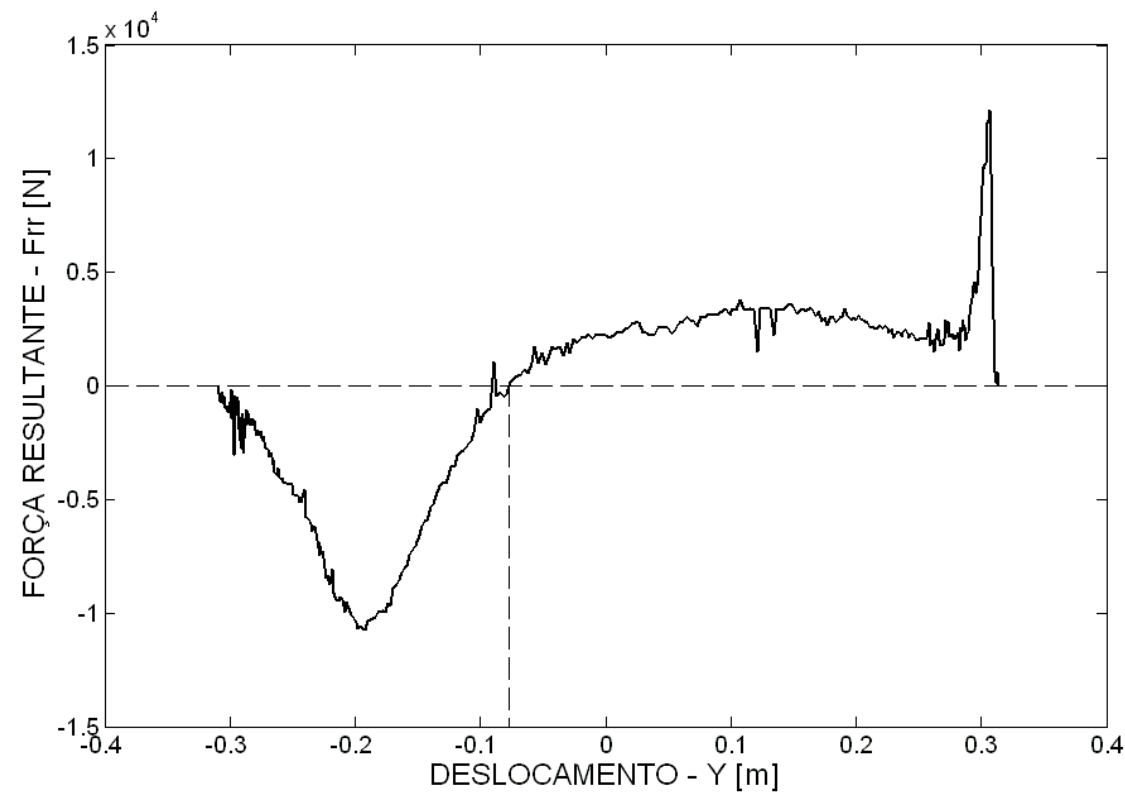

Figura 6.15 - Força resultante ao longo do movimento de recuo com pressão de alimentação de 13 [MPa].

\subsection{4 - Movimento de Recuo (Bloco de Passagem Residual e Válvula Pilotada).}

Conforme visto no item anterior o aumento da pressão ocasionou um aumento da velocidade, porém ainda persiste uma frenagem final que consome um tempo significativo. A idéia deste item é criar através da introdução de um bloco, uma área de passagem residual constante que minimize o efeito da válvula de freio para o final do movimento de recuo. A figura 6.16 mostra esquematicamente como o bloco de passagem residual é aplicado no esquema hidráulico. Com esta passagem residual espera-se reduzir o valor de $\mathrm{P}_{1}$ na fase final do movimento. Considerando a equação 4.17, a força resultante será conseqüentemente aumentada imprimindo assim uma maior velocidade nesta fase final de movimento. 


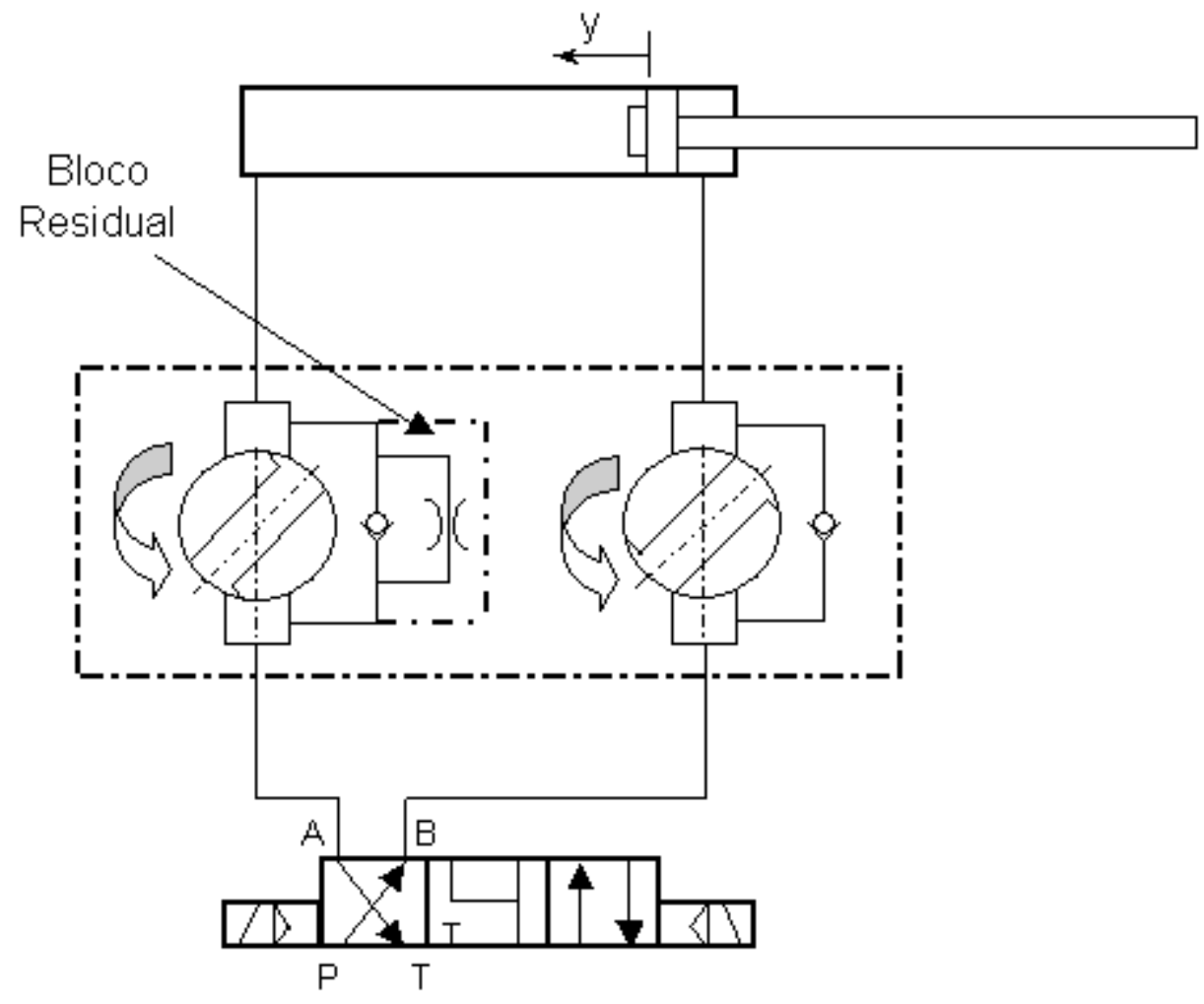

Figura 6.16 - Esquema de movimento de recuo com bloco de passagem residual

Além da introdução do bloco de passagem residual, neste levantamento de dados foi utilizado um outro modelo de válvula direcional. Ao invés de utilizar uma válvula diretamente operada como no item 6.1.1.2 conforme modelo 5-4WE10J/CG24 descrito no item 4.1.1, foi selecionada uma válvula pilotada modelo 4WEH10J33/CG24 (fabricante Bosch Rexroth). Esta nova válvula possui vazão nominal de 160 [1/min] contra 120 [1/min] da válvula anteriormente utilizada. Com esta válvula haverá uma menor perda de carga e uma maior velocidade ao longo do movimento.

Utilizando uma pressão de alimentação de 8 [MPa] e um furo calibrado de diâmetro 1,5 [mm] no bloco de passagem residual, obteve-se a curva de deslocamento indicada na figura 6.17. Nesta figura nota-se que um tempo menor de posicionamento foi obtido quando comparado com a curva da figura 6.6 relativa ao movimento de recuo com a configuração inicial. O tempo foi reduzido de 1,28 [s] para 1,05 [s]. Pode-se perceber através da análise da figura 6.17 que um dos motivos desta redução de tempo é causado por uma rampa de 
frenagem menos suave devido à utilização do bloco de passagem residual. $\mathrm{O}$ furo residual permite uma vazão adicional àquela proporcionada pela válvula de freio, vazão esta significativa no trecho final do curso qual a área de passagem da válvula encontra-se bem estrangulada.

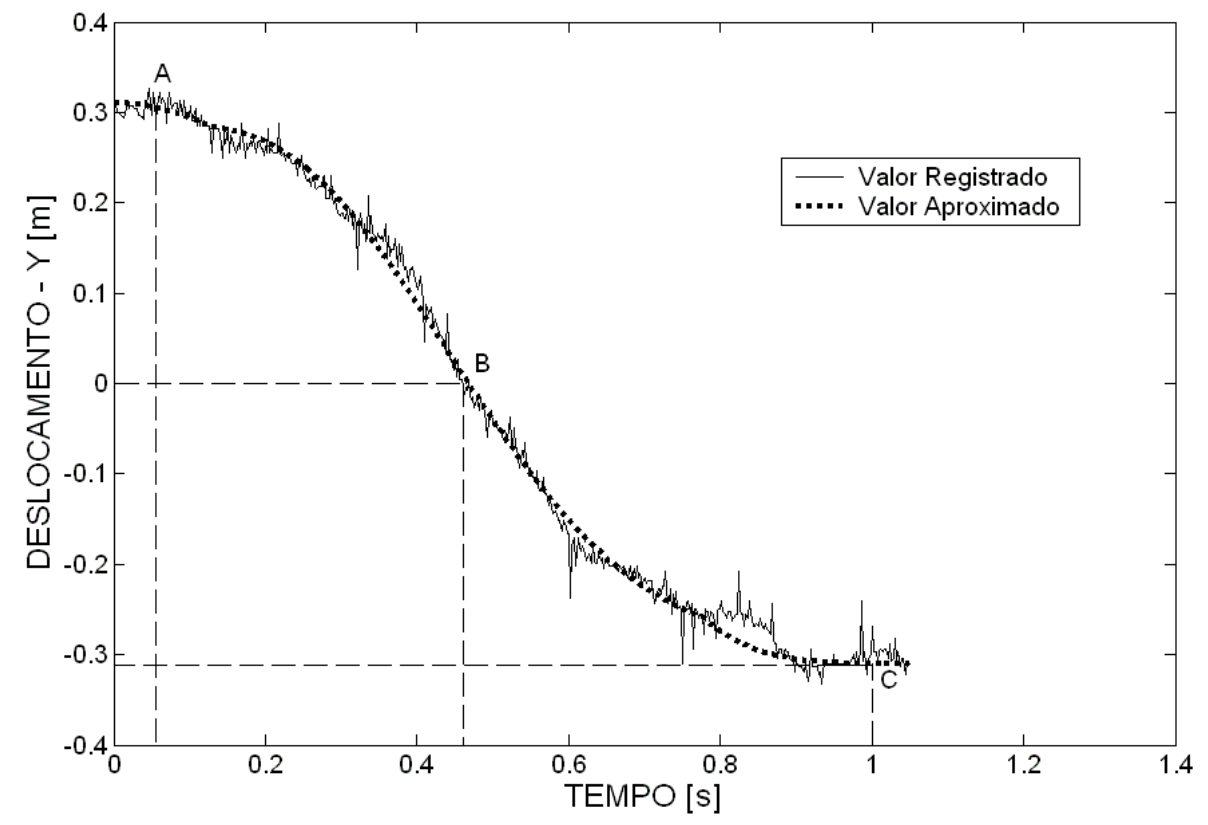

Figura 6.17 - Deslocamento do movimento de recuo com bloco residual e válvula direcional pilotada.

O outro fator que contribui com a diminuição do tempo de posicionamento é a utilização da válvula de maior capacidade de vazão. Ela tem efeito no aumento da velocidade máxima atingida. Este efeito pode ser visto na curva de velocidade da figura 6.18. A velocidade máxima atingiu aproximadamente $1,3[\mathrm{~m} / \mathrm{s}]$ contra $1,1[\mathrm{~m} / \mathrm{s}]$ registrada na figura 6.7 para o movimento de recuo com configuração inicial. 


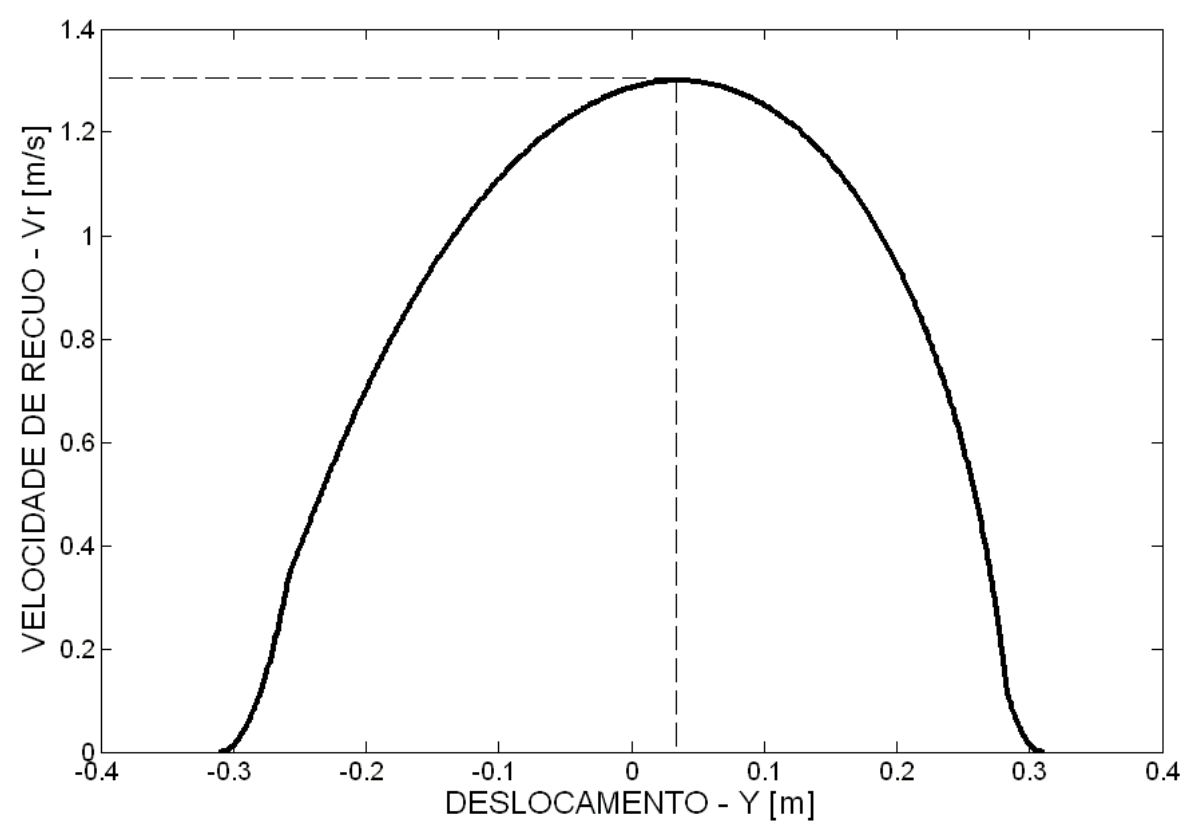

Figura 6.18 - Velocidade do movimento de recuo com bloco residual e válvula pilotada

\subsection{5 - Comparativo dos Movimentos de Recuo}

Para melhor visualização dos resultados obtidos com as configurações apresentadas nos itens de 6.1.1.2 a 6.1.1.4 vamos apresentar estes resultados sobrepostos em um só gráfico. Inicialmente na figura 6.19 estão expressos os resultados de posição ao longo do tempo. As curvas apresentadas são aquelas obtidas por aproximação polinomial conforme descrito em cada item específico. Nota-se que a melhora de desempenho anteriormente comentada pode ser notada tanto na condição com pressão de alimentação de 13 [MPa] quanto com a utilização do bloco residual e a válvula direcional pilotada. Porém, estas duas condições se equivalem em tempo total de posicionamento quando utilizadas isoladamente. A condição de maior pressão de alimentação ganha em velocidade ao longo de quase todo o movimento, porém perde no final do curso por possuir uma frenagem mais longa. 


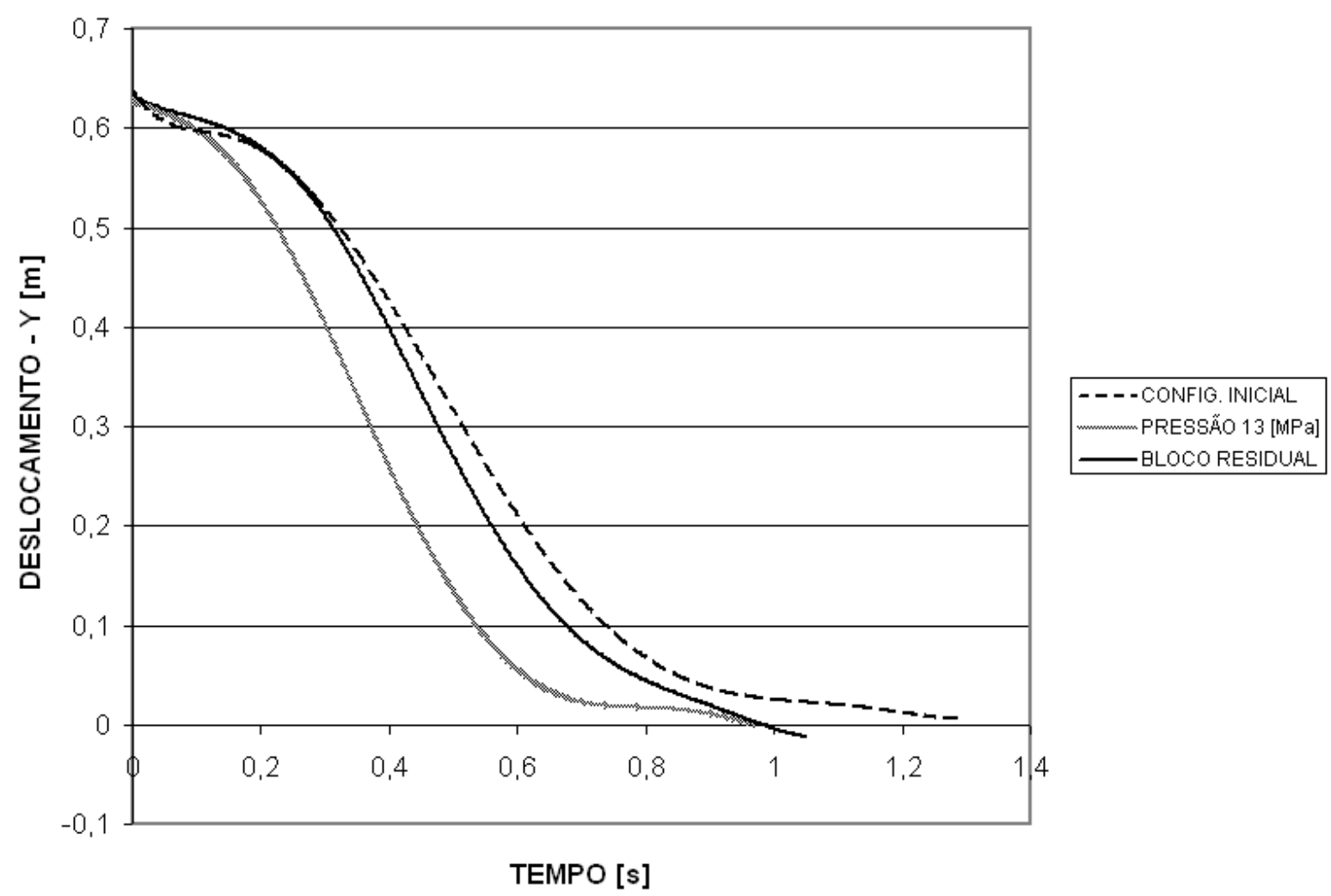

Figura 6.19 - Comparativo de curvas de deslocamento

\section{2 - Movimento de Abertura / Fechamento do Molde}

Os dados são apresentados separadamente para os movimentos de fechamento e abertura do molde.

\subsection{1 - Movimento de Fechamento do Molde}

Os dados do movimento de avanço são registrados com pressão de alimentação $\mathrm{P}_{\mathrm{S}}=10$ [MPa]. O gráfico de deslocamento x tempo obtido nos testes está indicado na figura 6.20. Como no caso do movimento de transporte, é utilizada uma interpolação polinomial para aproximar o sinal medido devido a presença de ruído durante a medição (ver ANEXO 1). 


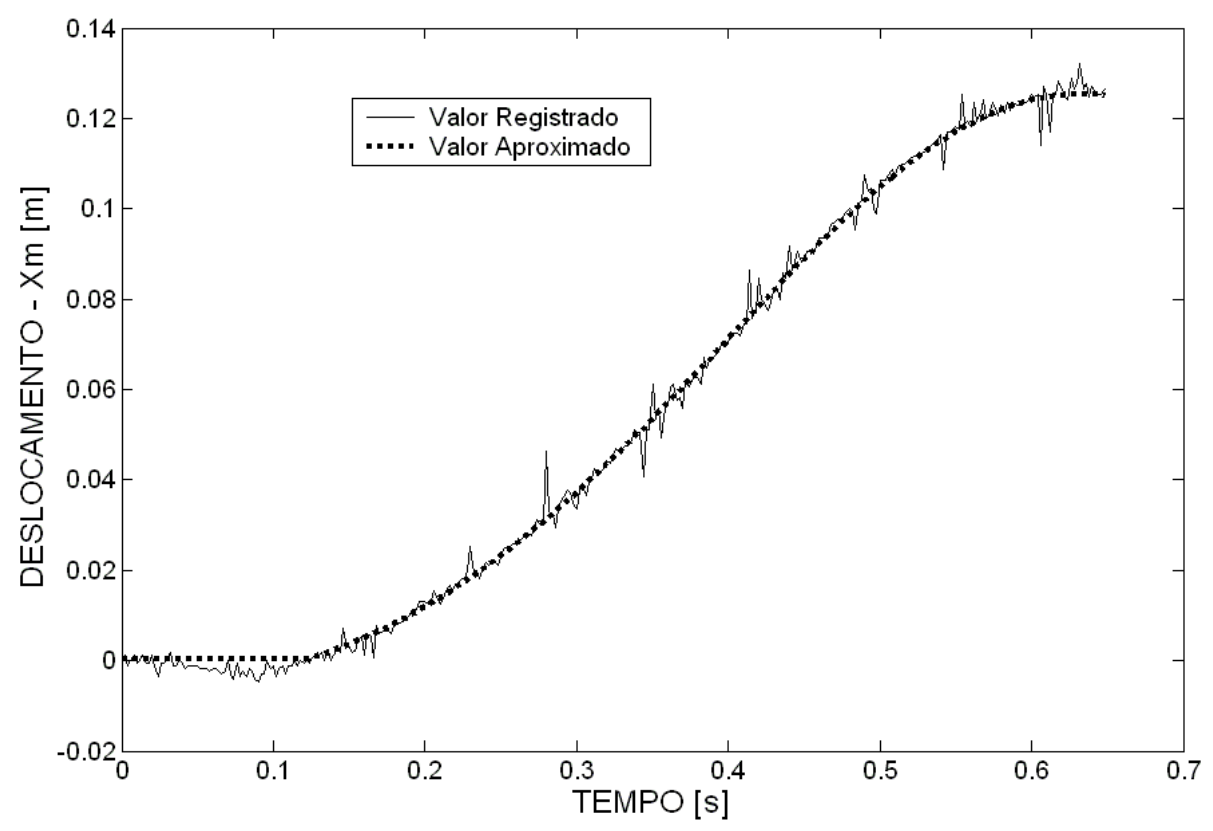

Figura 6.20 - Deslocamento do molde para movimento de fechamento

O valor aproximado de posição pode ser derivado em relação ao tempo para obtenção da velocidade ao longo do movimento. Da mesma forma, a velocidade de fechamento do molde também pode ser obtida a partir das equações 4.56 e 4.58 com o uso do sinal de comando estabelecido na figura 4.35 e considerando a curva de coeficiente de passagem estabelecida na figura 4.34. A figura 6.21 mostra estas curvas de velocidade para efeito de comparação entre o valor derivado e o valor modelado a partir das equações acima relacionadas. Como pode-se notar, o valor modelado é influenciado fortemente pelo sinal de comando e pelo coeficiente de passagem da válvula proporcional enquanto o valor derivado diretamente do valor de posição mostra uma variação mais suave de velocidade.

Em função das pressões registradas e considerando que o cilindro de fechamento possui diâmetro do êmbolo de 100 [mm] e diâmetro da haste de 70 [mm] pode-se determinar a força resultante ao longo do movimento conforme indicado na figura 6.22. 


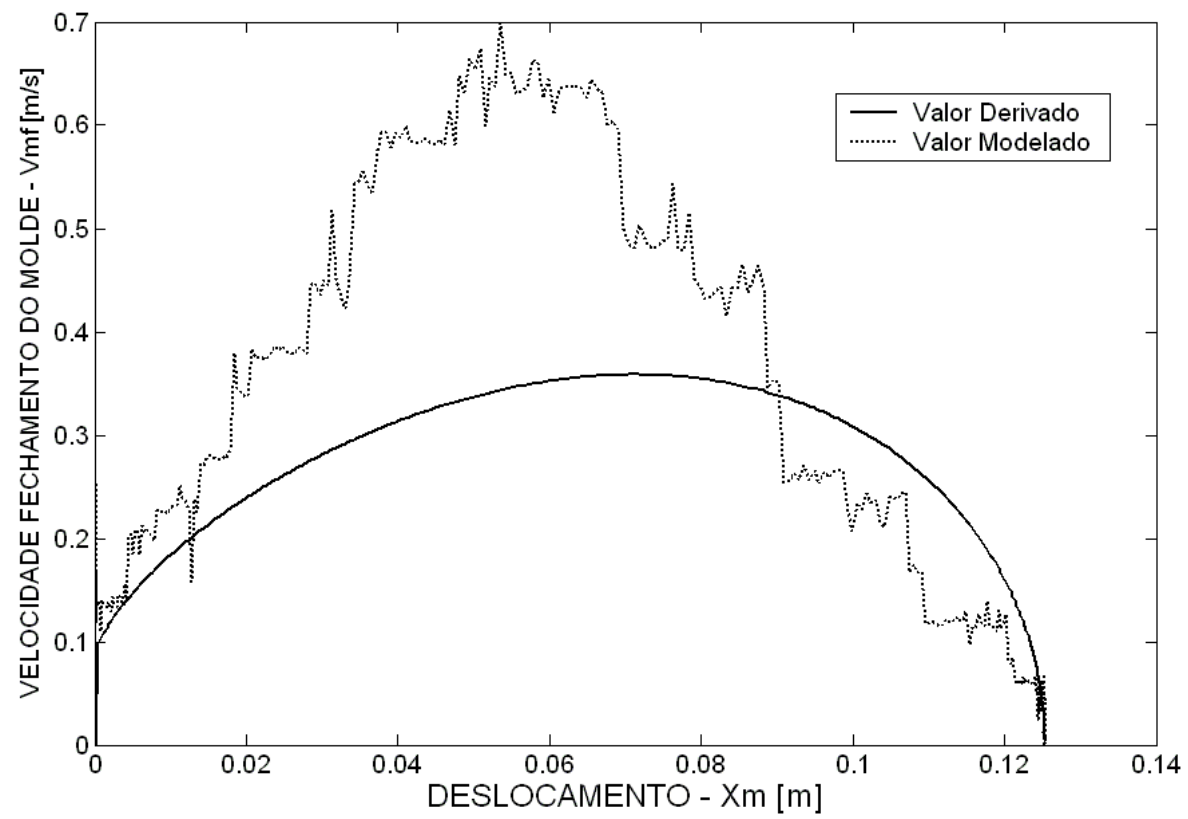

Figura 6.21 - Comparativo entre velocidades derivada e modelada para o fechamento.

Desconsiderando os picos originados por influência do ruído registrado, a força resultante permanece quase constante ao longo do movimento. Isto é devido ao fato do cilindro de fechamento é dimensionado não para mover o molde e sim para manter uma força estática durante o processo de resfriamento do frasco. Com isso, a massa do molde passa a ser uma carga pequena considerando o diâmetro do cilindro e a pressão utilizada.

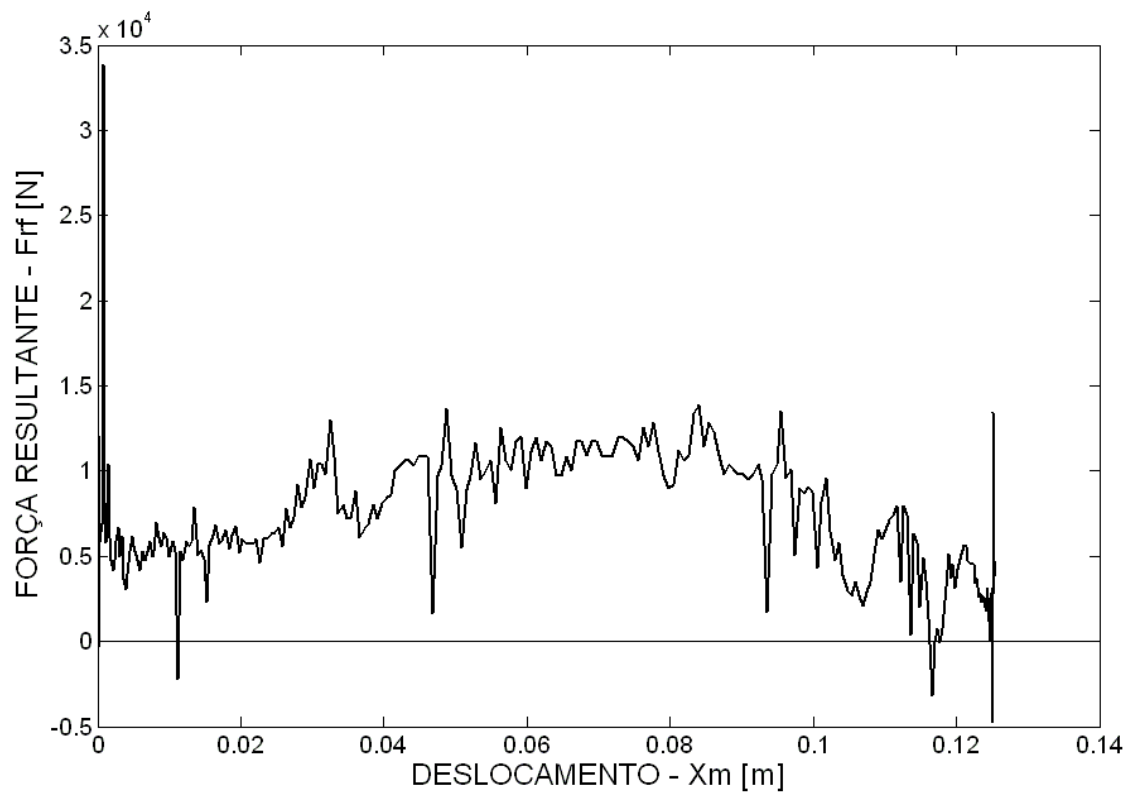

Figura 6.22 - Força resultante ao longo do movimento de fechamento do molde 
$\mathrm{O}$ movimento de fechamento do molde mostra um desempenho adequado com um tempo de posicionamento de $0,64[\mathrm{~s}]$.

\subsection{2 - Movimento de Abertura do Molde.}

Da mesma forma que para o movimento de fechamento, podemos estabelecer o perfil de velocidade de duas formas distintas para o movimento de abertura. Para isso devemos determinar primeiro a curva de deslocamento em função do tempo medido no teste realizado. A figura 6.23 estabelece esta relação.

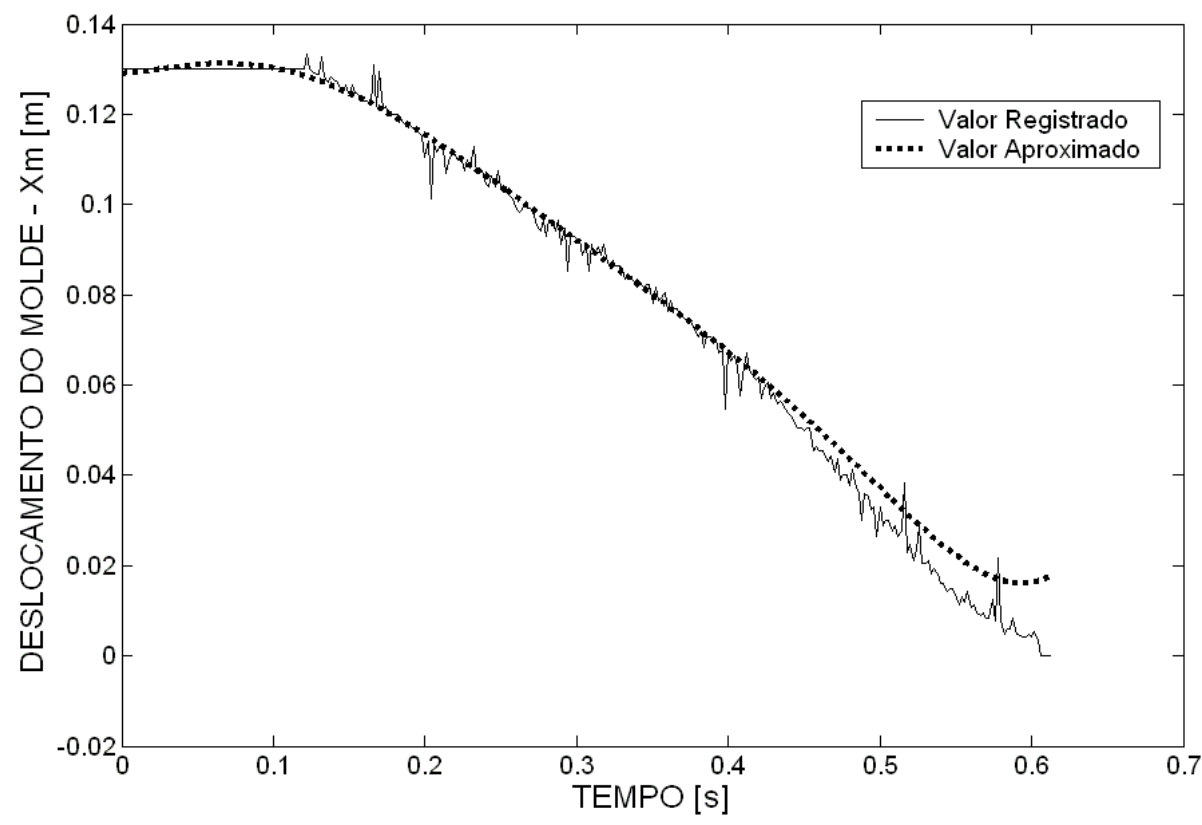

Figura 6.23 - Deslocamento do molde para o movimento de abertura

Derivando o valor aproximado de deslocamento apresentado acima se obtém a velocidade de abertura ao longo do fechamento. Esta velocidade pode ser alcançada também através da utilização das equações 4.59 e 4.61 utilizando o sinal de comando estabelecido na figura 4.37 e da curva do coeficiente de passagem em função deste sinal de comando 


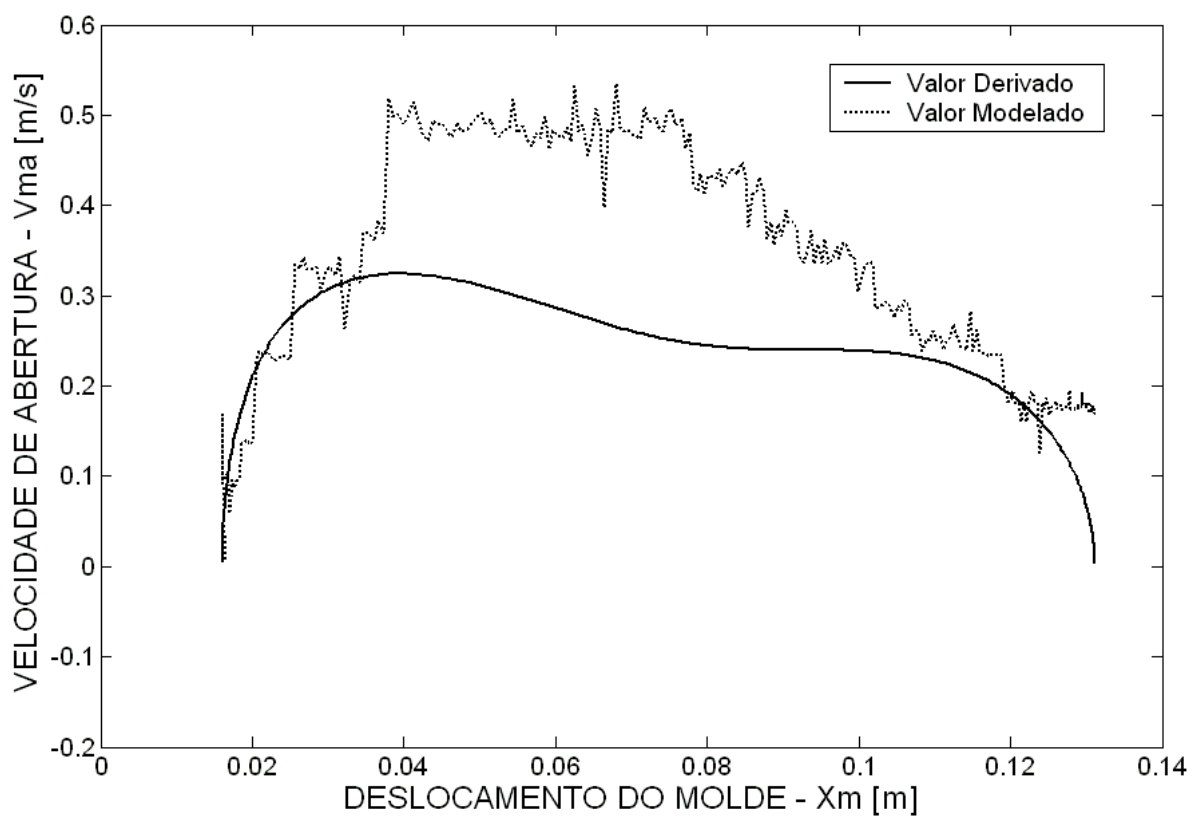

Figura 6.24 - Comparativo de velocidade modelada e derivada para abertura do molde

O sinal de comando de abertura possui um patamar de velocidade máxima constante. Isto gera um achatamento na curva de da velocidade de abertura obtida a partir das curvas de modelamento. A velocidade de abertura tem aproximadamente o mesmo módulo da velocidade de fechamento. Isto é devido ao fato de que o diâmetro do cilindro e a pressão de alimentação ajustada são grandes quando comparados com a carga a ser movimentada.

Pode-se ainda para ilustrar um pouco mais este movimento apresentar a curva de força resultante conforme indicado na figura 6.25. Desconsiderando os picos ocasionados pelo ruído presente durante a medição, verifica-se que a força resultante permanece praticamente constante e aproximadamente no mesmo nível de intensidade que a força resultante do movimento de fechamento. Isto justifica porque os tempos de movimentos para abertura e fechamento são próximos. 


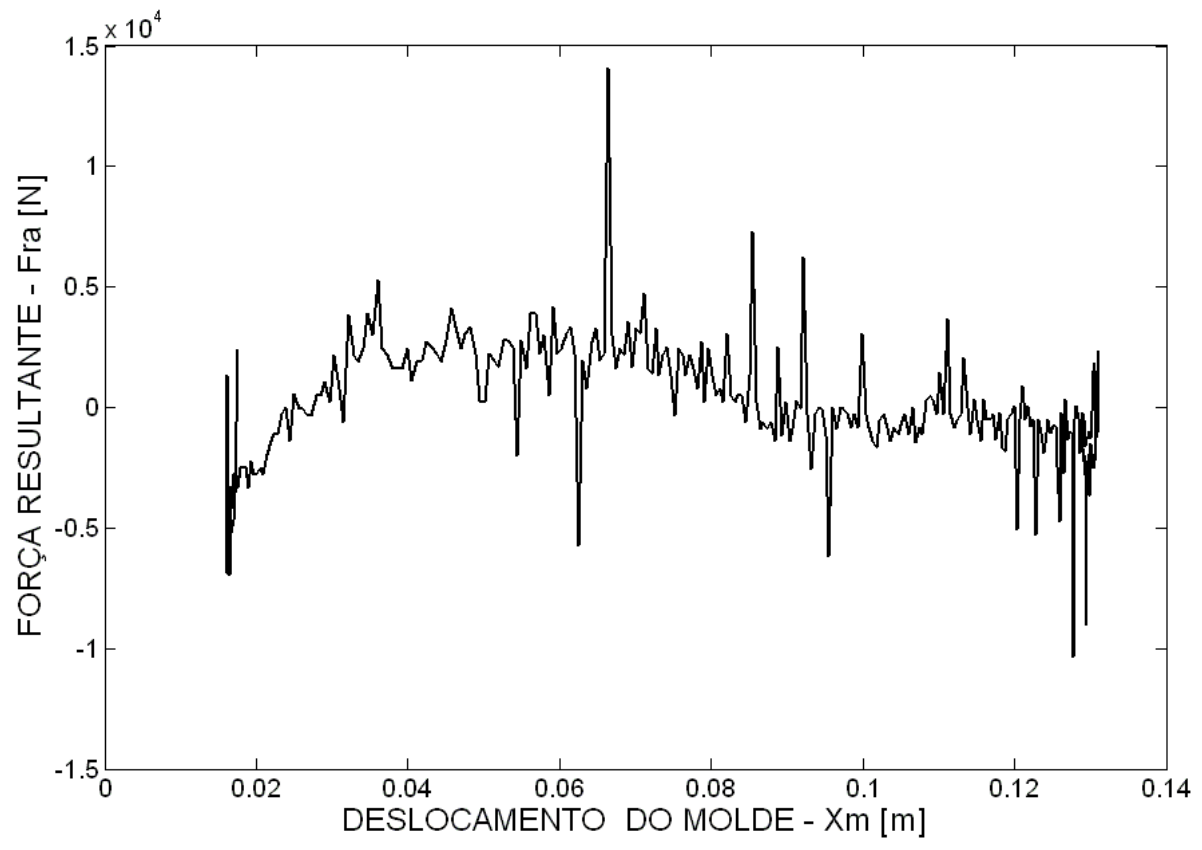

Figura 6.25 - Força resultante ao longo do movimento de abertura. 


\section{CAPÍTULO 7}

\section{CONCLUSÕES}

As conclusões são apresentadas inicialmente de forma separada para os movimentos de transporte e abertura / fechamento do molde.

\section{1 - Movimento de Transporte}

O desempenho do movimento de transporte mostrou-se inicialmente adequado para o sentido de avanço, no que diz respeito ao tempo consumido para a realização do movimento. Já para o sentido de recuo este tempo é demasiadamente longo. Para este caso a velocidade máxima está abaixo do desejado para uma máquina sopradora do porte desta ensaiada. Podem ocorrer limitações de tempo de ciclo para moldes de múltiplas cavidades. Além disso, a fase final de frenagem também é demasiadamente longa, atrasando o ciclo da máquina.

As propostas apresentadas para melhoria deste desempenho apresentaram um resultado satisfatório. O ajuste de uma pressão de alimentação maior aumenta significativamente a velocidade porém, deve ser considerado caso seja implementada esta opção de forma definitiva no projeto da máquina, a possibilidade de trabalhar com pressões diferentes para ambas as câmaras do cilindro. O pico de pressão apresentado no movimento de avanço passa a ser um problema caso se alimente a câmara do lado do êmbolo com pressões maiores que a pressão inicialmente ajustada de $8[\mathrm{MPa}]$. Além disso, o aumento da pressão de alimentação ocasiona um aumento direto da potência consumida e conseqüentemente do custo operacional.

A utilização de uma válvula direcional de mesmo tamanho nominal porém pilotada e a utilização do bloco de passagem residual melhoraram também o desempenho e do ponto de 
vista de custo / benefício é uma opção mais vantajosa que o simples aumento da pressão de alimentação uma vez que não necessita do aumento da pressão de alimentação e o custo da implementação desta solução é irrisório.

Outra possibilidade seria o redimensionamento do cilindro de transporte. Deve-se entender porém que cilindros maiores exigem válvulas maiores e mais caras além de exigir maior capacidade da unidade de bombeamento. Uma possibilidade para este caso é a alteração, não do diâmetro nominal do cilindro mas, apenas a redução do diâmetro da haste. Além disso, esta medida permite aumentar um pouco a pressão de alimentação, pois esta nova relação de área fica sujeita a picos de pressão menores no movimento de avanço.

As diferenças da intensidade dos valores de velocidades derivadas e modeladas indicam a influência da perda de carga existente. Uma boa possibilidade para verificação do modelo estabelecido seria a colocação de transdutores de pressão diretamente nos pórticos de entrada da válvula de freio. Dessa forma seriam suprimidas as influências das perdas de carga nas leituras de pressão realizadas.

O desvio de forma destas curvas mostram uma possível influência da rigidez das alavancas de comando de giro do êmbolo da válvula. Isso significa que as relações geométricas estabelecidas para relacionar o deslocamento do carro Y com a área de passagem A podem ser fortemente alteradas por esta característica. Um complemento da instrumentação utilizada seria útil para uma melhor verificação deste fato e introduzir uma melhoria no modelo estabelecido ao longo deste trabalho. Neste caso poderia ser introduzido um transdutor rotativo diretamente no êmbolo da válvula para registro da variação do ângulo $\beta$ simultaneamente com a variação de posição Y do carro. Essa medição acusaria a influência da rigidez das alavancas de comando na relação geométrica estabelecida para a variação da área de passagem na válvula de freio. 


\section{2 - Movimento de Abertura / Fechamento do Molde}

O movimento de abertura / fechamento do molde apresentou um desempenho satisfatório. O tempo de posicionamento, tanto para o movimento de abertura quanto de fechamento do molde, está dentro do valor desejado para o porte de máquina ensaiada.

Uma vez que o cilindro de fechamento é dimensionado para segurar o molde fechado durante o processo de sopro, ele fica super dimensionado para a realização dos movimentos. Isto pode ser caracterizado pela manutenção de baixas pressões nas câmaras do cilindro, resultando uma pequena pressão de carga ao longo da execução dos movimentos. A partir desta análise visualiza-se uma possibilidade de melhoria de projeto no que diz respeito à unidade de bombeamento, pois neste movimento quando há necessidade de velocidade não é exigida força e quando o molde é efetivamente fechado o contrário ocorre. Dessa maneira pode-se utilizar duas bombas geminadas sendo uma de alta vazão e baixa pressão e outra de baixa vazão e alta pressão com o intuito de economia de energia ao longo do ciclo.

Quanto às curvas modeladas ocorre o mesmo fenômeno relativo ao movimento de transporte: as curvas de velocidades modeladas tem intensidade diferente quando comparadas àquelas obtidas a partir da diferenciação dos dados de posição registrados. Neste caso também não foram consideradas as perdas de carga na linha de fechamento do molde. Existe também um desvio de forma entre estas curvas. Isto pode ser consequiência de um atraso de resposta no sistema de controle indicado na figura 4.22 e das curvas características da válvula indicadas na figura 4.32. A leitura da posição real do êmbolo da válvula proporcional simultaneamente com o sinal de comando e a coordenada de deslocamento do molde $\mathrm{X}_{\mathrm{M}}$ pode caracterizar este atraso de resposta. Esta análise pode ser um desdobramento do trabalho atual.

Conclui-se que de uma forma geral, o dimensionamento do sistema de abertura e fechamento do molde está adequado. 


\section{3 - Conclusão Final}

A redução total de tempo de posicionamento foi de 0,28 segundos, alcançada especificamente no movimento de transporte, sentido de recuo. Os demais movimentos apresentaram um tempo de posicionamento adequado considerando o porte de máquina ensaiada.

Deve-se notar portanto, que a diminuição de tempo de posicionamento obtido com a utilização de uma válvula direcional de maior vazão somada à implementação do bloco residual é significativa. Isso é relevante quando se considera que o investimento para adicionar esta solução é praticamente nulo. Para melhor visualização deste ganho, vale quantifica-lo através de um exemplo real. Considerando a máquina ensaiada trabalhando com moldes de 12 cavidades no caso de uma produção de frascos de $200 \mathrm{ml}$ de volume, tem-se um ciclo original de 9 segundos. Isto equivale a uma produção de 9600 frascos/hora. Com a redução apresentada de 0,28 segundos no tempo de posicionamento a partir da solução implementada (válvula pilotada e bloco residual), o novo ciclo passa a ser de 8,72 segundos e a produção horária cresce para 9908 frascos/hora. Projetando esta nova capacidade para uma máquina que trabalha 600 horas/mês e 12 meses/ano, tem-se um ganho de produção total de 2.200.000 frascos/ano.

Conclui-se a partir do modelamento e dos testes realizados que o dimensionamento do cilindro exerce uma importante influência no desempenho do movimento. Assim, para trabalhos futuros pode-se indicar uma análise da influência da relação de área do cilindro sobre a velocidade de posicionamento. 


\section{ANEXOS}

\section{ANEXO 1 - Sinal de Ruído}

Os ensaios apresentados neste teste foram realizados em máquinas operando em uma fábrica. Ficou caracterizado ao longo das medições a existência de um ruído provavelmente por deficiência no sistema de aterramento desta fábrica. O ruído incide, conforme a figura abaixo indica, inclusive sobre o sinal de alimentação, ou seja, os transdutores são alimentados por uma tensão de 24 [V] que sofre oscilações periódicas conforme indica o sinal registrado no canal 4 da figura abaixo. Os canais de 1 a 3 são respectivamente os sinais de saída dos dois transdutores de pressão e do transdutor de posição utilizados. A figura abaixo foi registrada com a máquina parada e desligada sendo os transdutores alimentados por uma fonte chaveada externa. Nota-se a mesma amplitude e frequiência para todos os canais. A escala para todos os canais foi ajustada em 1 [V] / divisão.

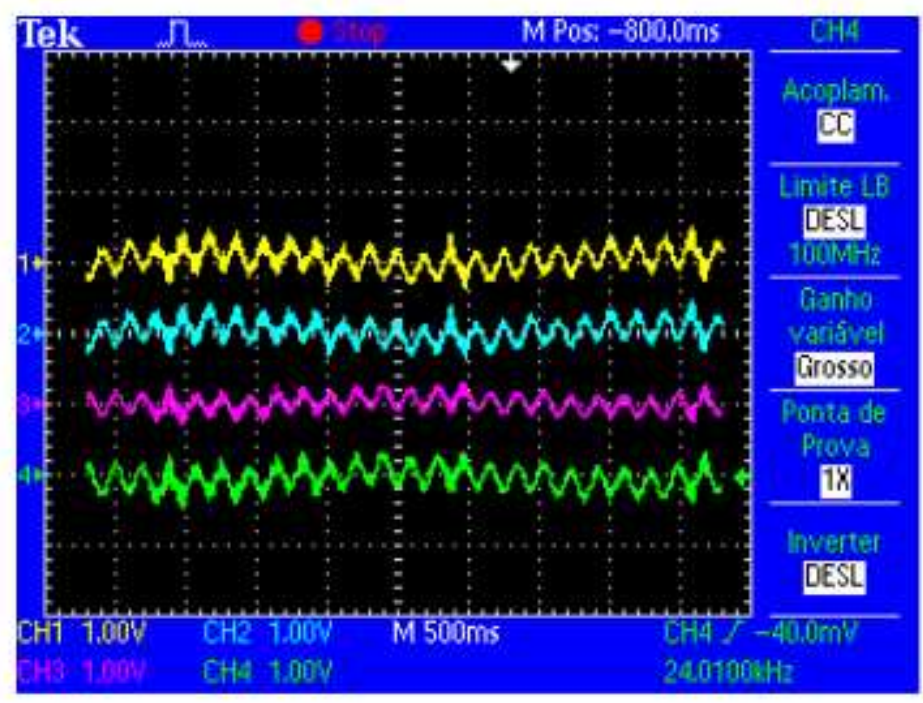

Ruído registrado durante os ensaios 
Um sinal originalmente apresentado pode ser visto na figura abaixo. Nota-se a interferência deste ruído nos valores registrados, inclusive no sinal de comando (canal 4).

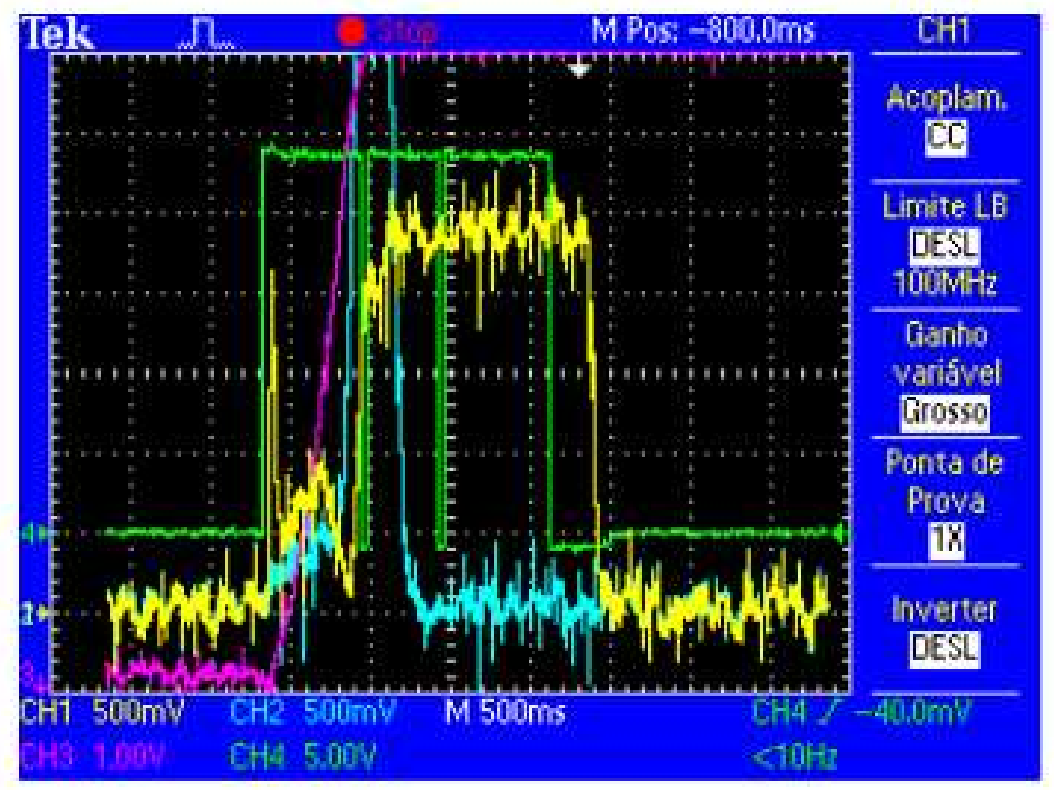

Sinal original registrado 


\section{BIBLIOGRAFIA}

(1) O’NEIL, S.J. (1998). Motion Control Handbook. USA, artigo disponível em <www.micromo.com>. Acesso em: 12 jan 2007.

(2) WEG EQUIPAMENTOS ELÉTRICOS S.A. (2006), Inversores de Freqüiência Modelo CFW. Jaraguá do Sul, catálogo, disponível em 〈www.weg.com.br $>$. Acesso em: 19 dez 2006.

(3) BASICS OF MOTION CONTROL. (2006). USA. Machine Design Magazine, artigo disponível em <www.machinedesign.com > Acesso em: 19 dez 2006.

(4) NIPPON PULSE MOTOR CO. (2006). Basics of Servomotor Control. Japão, artigo disponível em <www.nipponpulse.com>. Acesso em: 10 jan 2007.

(5) PROCTER, G. (2006). What is Field Oriented Control. USA, artigo disponível em <www.copleycontrols.com>. Acesso em: 10 jan 2007.

(6) BARRET, J.; HARNED, T.; MONNICH, J. (2005). Linear Motor Basics. USA, artigo disponível em <www.parkermotion.com>. Acesso em 15 jan 2007.

(7) PROCTER, G. (2006). Linear Motor Advantages in Machine Vision Systems. USA, artigo disponível em <www.copleycontrols.com>. Acesso em: 10 jan 2007.

(8) COOK, G. (2001). An Introduction to Piezoelectric Motors. Sensors Magazine, artigo disponível em <www.sensorsmag.com>. Acesso em: 18 jan 2007.

(9) ALIO INDUSTRIES (2006), Ceramic Servomotors. USA, catálogo, disponível em <www.alioindustries.com>. Acesso em: 15 dez 2006.

(10) SEW-EURODRIVE. (2006), Servomotores Assíncronos. Brasil, catálogo, disponível em <www.sew.com.br〉. Acesso em: 16 jan 2007.

(11) BOSCH REXROTH LTDA. (2000), Catálogo de Hidráulica, São Paulo, catálogo, (RS/P 00 130/09.00). 
(12) NACHTWEY, P. (2006). Accumulators: The unsung heroes of hydraulic motion control. Hydraulics \& Pneumatics Magazine, artigo, edição dezembro 2006. Disponível em <www.hydraulicspneumatics.com>. Acesso em: 19 jan 2007.

(13) DE ROSE, D. (2003). Proportional and Servo Valve Technology. Fluid Power Journal, edição mar/abr 2003.

(14) MOOG INC. (2005). Electrohydraulic Valves: A Technical Look. East Aurora, artigo, (CDL6566 Rev D), disponível em <www.moog.com>. Acesso em 23 jan 2007.

(15) MOOG INC. (2003). Servovalves: Product Line Overview. East Aurora, catálogo disponível em <www.moog.com>. Acesso em 23 jan 2007.

(16) BODENSTEIN, B.; HOFFMANN, W. (2003). Fluidtechnische Antriebe und Steurung in Hydraulishen High Speed Tryout Pressen, Kolloquium Über Energieübertragung und Signalverarbeitung Durch Fluide. IFAS RWTH, Aachen, nov 2003.

(17) NEUBERT, T.; HELDUSE, S.; LONG, Q. (2001). Differential Cylinder Servo System Based on Speed Variable Pump and Sum Pressure Control Principle. China, Fifth International Conference on Fluid Power Transmission and Control (ICFP 2001). Disponível em <www.fluid.power.net>. Acesso em 19 dez 2006.

(18) CHIANG, M.H. ; LEE, L.W. ; TSAI, J.J. (2004). The Concurrent Implementation of High Velocity Control Performance and High Energy Efficiency for Hydraulic Injection Moulding Machines. International Journal of Advanced Manufacturing Technologies. 23: p.256-262, Springer-Verlag London Limited.

(19) JEROUANE, M.; LAMNABHI, F. (2001). A New Robust Sliding Mode Controller For a Hydraulic Actuator. USA, Proceedings of the $40^{\text {th }}$ IEEE Conference on Decision and Control.

(20) KNOHL, T.; UNBEHAUEN, H. (1999). Adaptative Position Control of Electrohydraulic Servo Systems Using ANN. Mechatronics 10 (2000) 127-143. Elsevier Science Ltd.

(21) GHAZY, M.A. (2001). Variable Structure Control for Electrohydraulic Position Servo System. The $27^{\text {th }}$ Annual Conference of the IEEE Industrial Electronics Society, IECON'01. 
(22) NIKSEFAT, N.; SEPEHRI, N. (2002). A QFT Fault-Tolerant Control for Electrohydraulic Positioning Systems. IEEE Transactions of Control Systems Technology, vol. 10, $\mathrm{n}^{\circ}$ 4, jul 2002.

(23) KARPENKO, M.; SEPEHRI, N. (2003). Robust Position Control of an Electrohydraulic Actuator With a Faulty Actuator Piston Seal. Journal of Dynamic Systems, Measurement and Control. Vol.125, set 2003, ASME.

(24) WHELAN, T. (1999). Manual de Moldagem por Sopro, São Paulo, Politeno.

(25) MERRITT, E. H. (1967). Hydraulic Control Systems, USA, John Wiley \& Sons.

(26) BOSCH REXROTH AG (2005). Proportional Directional Control Valve, Piloted Operated With On-Board Electronics and Inductive Position Transducer. Alemanha, catálogo RE 29076 / 12.05.

(27) WALTERS, R.B. (1991). Hydraulic and Electro-Hydraulic Control Systems, New York, Elsevier Applied Science.

(28) MTS SYSTEMS CORPORATION. (2005). How Magnetostriction Works, USA, artigo disponível em 〈www.mtssensors.com>. Acesso em 29 jul 2005.

(29) BALLUFF CONTROLES ELÉTRICOS LTDA. (2004), Micropulse AT - Sistema de Posicionamento sem Contato Direto. São Paulo, catálogo $n^{\circ} 823664$, disponível em: <www.balluff.com.br>. Acesso em: 25 mai. 2006.

(30) GEFRAN SPA. (2006), TK Pressure Transmitter, Itália, catálogo cod. TK-01/06, disponível em <www.gefran.com>. Acesso em 06 jul 2006.

(31) TEKTRONIX INC. (2006), Digital Storage Osciloscope. USA, catálogo, disponível em < www.tektronix.com>. Acesso em: 25 mai. 2006.

(32) ANDERSON, W. (1988). Controlling Electro-Hydraulic Systems, New York, Marcel Dekker Inc.

(33) CAPORALI, A. S. (1999). Modelagem, Simulação e Análise de Servomecanismo Eletro-hidráulico. Tese (Mestrado), Departamento de Engenharia Mecânica, Universidade de São Paulo, São Carlos, São Paulo. 
(34) FRADEN, Y. (1996). Handbook of Modern Sensors: Physics, Design and Applications, New York, Springer-Verlag.

(35) KLEMAN, A. (1989). Interfacing Microprocessors in Hydraulic Systems, New York, Marcel Dekker.

(36) MATSUMOTO, E. Y. (2001). Matlab6 - Fundamentos de Programação, São Paulo, Érica.

(37) OGATTA, K. (1985). Engenharia de Controle Moderno, Rio de Janeiro, Prentice Hall do Brasil. 